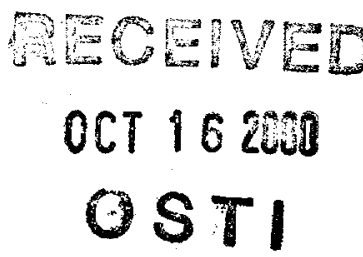

\title{
Residential Commissioning: A Review of Related Literature
}

\author{
C.P. Wray, M.A. Piette, M.H. Sherman, R.M. Levinson, N.E. Matson, \\ D.A. Driscoll, J.A. McWilliams, T.T. Xu, and W.W. Delp \\ Environmental Energy Technologies Division \\ Ernest Orlando Lawrence Berkeley National Laboratory \\ University of California \\ Berkeley, California 94720
}

March 2000

This work was supported by the Assistant Secretary for Energy Efficiency and Renewable Energy, Office of Building Technology, State and Community Programs, of the U.S. Department of Energy under Contract No. DE-AC03-76SF00098. 
The Lawrence Berkeley National Laboratory, 1 Cyclotron Road, Berkeley, CA 94720 is a national laboratory of the U.S. Department of Energy managed by the Regents of the University of California for the U.S. Department of Energy under Contract Number DE-AC03-76SF00098. This report was prepared as a result of work sponsored by the California Energy Commission (Commission). It does not necessarily represent the views of the Commission, its employees, or the State of California. The Commission, the State of California, its employees, contractors, and subcontractors make no warranty, express or implied, and assume no legal liability for the information in this report, nor does any party represent that the use of this information will not infringe upon privately owned rights. This report has not been approved or disapproved by the Commission nor has the Commission passed upon the accuracy or adequacy of the information in this report.

THE GOVERNMENT AND THE CONTRACTOR MAKE NO EXPRESS OR IMPLIED WARRANTY AS TO THE CONDITIONS OF THE RESEARCH OR ANY INTELLECTUAL PROPERTY, GENERATED INFORMATION, OR PRODUCT MADE OR DEVELOPED UNDER THIS AGREEMENT, OR THE OWNERSHIP, MERCHANTABILITY, OR FITNESS FOR A PARTICULAR PURPOSE OF THE RESEARCH OR RESULTING PRODUCT; THAT THE GOODS, SERVICES, MATERIALS, PRODUCTS, PROCESSES, INFORMATION, OR DATA TO BE FURNISHED HEREUNDER WILL ACCOMPLISH INTENDED RESULTS OR ARE SAFE FOR ANY PURPOSE INCLUDING THE INTENDED PURPOSE; OR THAT ANY OF THE ABOVE WILL NOT INTERFERE WITH PRIVATELY OWNED RIGHTS OF OTHERS. NEITHER THE GOVERNMENT NOR THE CONTRACTOR SHALL BE LIABLE FOR SPECIAL, CONSEQUENTIAL, OR INCIDENTAL DAMAGES ATTRIBUTED TO SUCH RESEARCH OR RESULTING PRODUCT, INTELLECTUAL PROPERTY, GENERATED INFORMATION, OR PRODUCT MADE OR DELIVERED UNDER THIS AGREEMENT. 


\section{DISCLAIMER}

This report was prepared as an account of work sponsored by an agency of the United States Government. Neither the United States Government nor any agency thereof, nor any of their employees, make any warranty, express or implied, or assumes any legal liability or responsibility for the accuracy, completeness, or usefulness of any information, apparatus, product, or process disclosed, or represents that its use would not infringe privately owned rights. Reference herein to any specific commercial product, process, or service by trade name, trademark, manufacturer, or otherwise does not necessarily constitute or imply its endorsement, recommendation, or favoring by the United States Government or any agency thereof. The views and opinions of authors expressed herein do not necessarily state or reflect those of the United States Government or any agency thereof. 


\section{DISCLAIMER}

Portions of this document may be illegible in electronic image products. Images are produced from the best available original document. 


\section{TABLE OF CONTENTS}

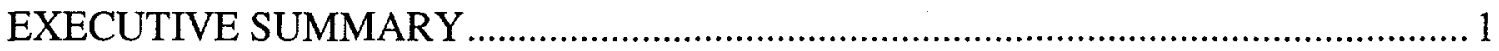

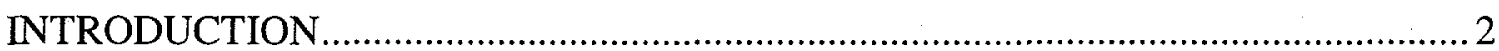

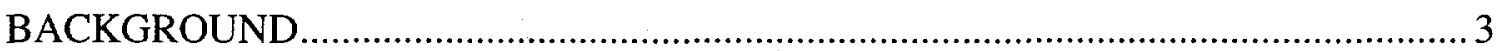

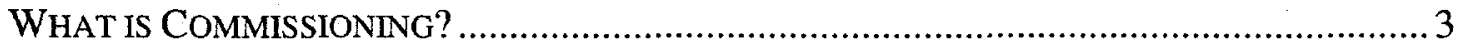

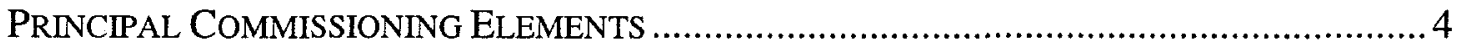

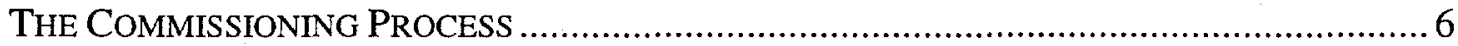

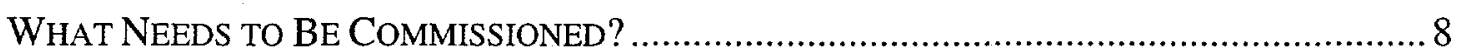

COSTS AND BENEFITS OF COMMISSIONING .......................................................

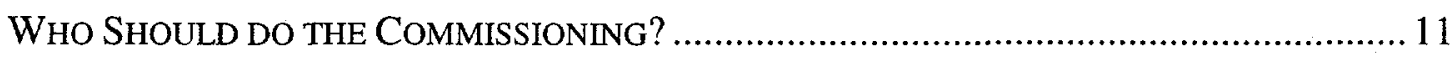

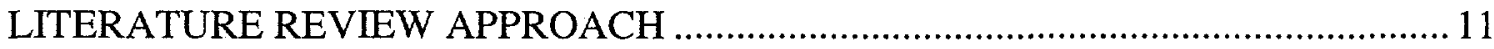

SUMMARY OF RELEVANT METRICS, DIAGNOSTICS, AND NORMS ................ 12

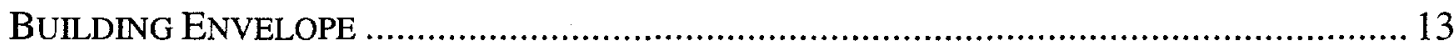

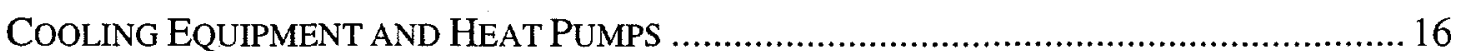

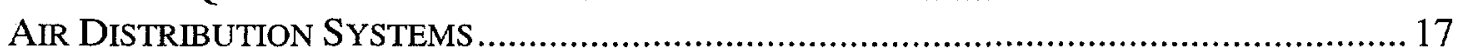

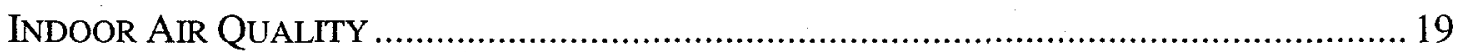

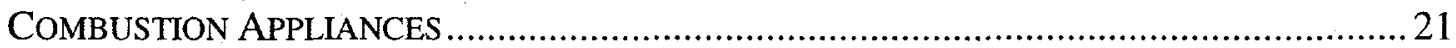

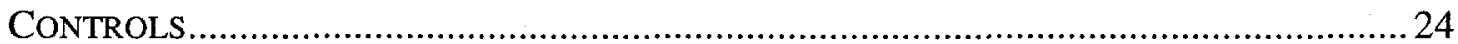

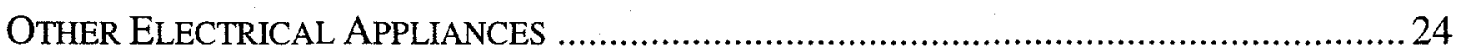

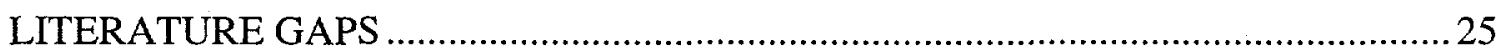

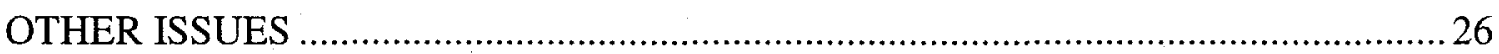

APPENDIX A: ANNOTATED BIBLIOGRAPHY ......................................... A-1

APPENDIX B: ALPHABETICAL LIST OF REFERENCES ............................... B-1

APPENDIX C: LITERATURE CATEGORIZATION GUIDELINE .......................... C-1 


\section{EXECUTIVE SUMMARY}

Currently, houses do not perform optimally or even as many codes and forecasts predict, largely because they are field assembled and there is no consistent process to identify problems or to correct them. The emerging process of residential commissioning can rectify this situation by providing performance assurances.

Residential commissioning is defined within this report as a performance assurance process in the form of agreed upon metrics, diagnostics, and norms that might be carried out between the time installation and construction are complete and when the buyer occupies the new house. It also includes many activities such as rating, auditing, supercommissioning, or recommissioning. As such, it represents an expansion of processes currently carried out by people such as home energy raters, home inspectors, auditors, and weatherization contractors. This expansion includes the energy performance of the large number of existing California houses, as well as the indoor environmental performance of all houses in the State.

The literature review reported here is the first step in a larger 30 month-long project that will lay the groundwork for a residential commissioning industry in California focused on end-use energy and non-energy issues. The intent of the review is to facilitate access to existing literature related to residential commissioning. Emphasis is placed on reviewing documents published over the past 20 years, which represents the period of time over which building commissioning and closely related issues have been actively reported.

This report discusses the status of commercial building commissioning and compares it with residential commissioning. Based on an extensive review of 469 readily available documents, it summarizes existing metrics, diagnostics, and norms for all building types that are relevant for evaluating, tuning, and retrofitting various aspects of new and existing houses. The relevant areas of concern for California houses are: Building Envelope, Cooling Equipment and Heat Pumps, Air Distribution Systems, Indoor Air Quality, Combustion Appliances, Controls, and Other Electrical Appliances.

There is a substantial amount of useful information in the literature about metrics, diagnostics, and norms that are relevant to residential commissioning. However, there are also some significant gaps. This report concludes by highlighting gaps in existing knowledge that require further research and development.

Areas in particular need of work include: metrics, diagnostics, and norms for thermal mass and moisture-damage susceptibility; diagnostics for steady-state capacity and efficiency, as well as refrigerant charge level, for cooling equipment and heat pumps; diagnostics and norms for ventilation effectiveness and efficiency; diagnostics to evaluate the potential for backdrafting and combustion gas spillage; and metrics, diagnostics, and norms for controls and other electrical appliances.

Only 33 of the 469 papers specifically addressed a house as a system of interacting components, although many mentioned that this is an important issue. It appears that more research is necessary to assess and describe the performance of a house as a system. 


\section{INTRODUCTION}

Currently, houses do not perform optimally or even as many codes and forecasts predict. For example, Jump et al. (1996 [223] ${ }^{\text {*) }}$ found variations of a factor of two in distribution system efficiency. Walker et al. (1998 [448]) found similar magnitudes of variation for distribution systems. The latter study also found changes of $50 \%$ in envelope leakage for houses with the same design, builder, and subcontractors within the same subdivision. A substantive reason for these problems is that most buildings are field assembled from a large number of components and there is no consistent process to identify problems or to correct them.

To ensure components and systems interact together as intended and to yield the energy and non-energy performance that building designers, trades, owners, and occupants find acceptable, performance must be judged using appropriate and agreed upon metrics, diagnostics, and norms. Many of these elements already exist in a fragmented environment. Some are already used to commission commercial buildings. Most can be integrated into residential commissioning to provide performance assurances.

The work reported here is the first step in a larger 30 month-long project that will lay the groundwork for a residential commissioning industry in California focused on end-use energy and non-energy issues. The overall goal of this project is twofold: it will demonstrate the value that performing building commissioning services would have in both new and existing residences; it will also develop and document residential building commissioning procedures. The project will address the house as a system of interacting components and will attempt to redress the problem that treating them separately has led to sub-optimization of performance. Developing metrics, diagnostics, and norms to quantify energy and indoor environmental performance within this framework will contribute to the improvement of the energy cost/value of electricity for the State. It will also contribute to the quality, comfort, and safety of homes for the citizens of California.

One technical objective of this project is to collect and analyze data on the methods and techniques of residential commissioning, as well as on its costs and benefits. The results of this work will provide new insights on how to address the problems of energy and indoor environmental performance in new and existing houses. These results will also foster the discussion of how to integrate aspects of commissioning with other building industry processes so that more value can be obtained from a single site visit. Another objective is to provide standardized, robust, cost-effective, and accurate tools and techniques for verifying house performance, by adapting existing ones or developing new ones. The ultimate objective of this project is to increase the number of houses that undergo building commissioning, which will optimize their energy and indoor environmental performance.

As the first step toward meeting these goals and objectives, this report discusses the status of commercial building commissioning and compares it with residential commissioning. Based on an extensive review of readily available literature, it summarizes existing metrics, diagnostics, and norms for all building types that are relevant for evaluating and tuning various aspects of new and existing houses. Gaps in

\footnotetext{
* The bracketed value refers to the reference number in Appendix B (Alphabetized List of References).
} 
existing knowledge that require further research and development are highlighted. Each of the 469 documents that were collected and reviewed is listed in the annotated bibliography attached as Appendix A. All these documents are also listed in alphabetic order in Appendix B.

In the next step of the project, a set of metrics, diagnostics, and norms for residential commissioning will be developed based on data from the literature review and on analyses performed using simulation tools. This selected set of commissioning elements will subsequently be tested in the field to demonstrate the accuracy, usability, relative importance, and value of each element for both new and existing California houses. Finally, guidelines for the building industry will be developed to document the commissioning procedures. Research findings will also be transferred through workshops with and presentations to the building industry.

\section{BACKGROUND}

This section provides an overview of the emerging process of commissioning in commercial and residential buildings. It describes what commissioning is, why it is done, its principal elements, how its process is structured, what needs to be commissioned, some of its costs and benefits, and who does it today. It should be noted that the elements of this discussion pertaining to residential commissioning are largely preliminary, because such a practice does not yet exist. It is one of the goals of this project to formulate and clarify these residential commissioning issues.

\section{What is Commissioning?}

Commissioning has its roots in shipbuilding where the term was first used to describe the process that ensures a ship is sea worthy and ready for service. While there are many definitions for commissioning, one simple one is "a set of procedures, responsibilities, and methods to advance a system from static installation to full working order in accordance with design intent" (Yoder and Kaplan 1992 [465]). The variations in definitions relate to the scope of commissioning, and the activities related to commissioning. Some commissioning projects begin early in the design stage and continue through ongoing operations and maintenance. Others include activities to optimize performance beyond design intents (super-commissioning) or to adjust performance of existing facilities (recommissioning).

Commissioning is common practice today in industrial plant operations, where control systems are regularly "commissioned". The principles behind commissioning are also similar to those of "total quality management" (TQM). In TQM, one attempts to establish metrics that can be tracked and evaluated to determine whether the quality of the desired activity or system meets expectations.

While many in the building industry may think of commercial buildings when the subject of commissioning is raised, it is still uncommon to commission these buildings at any stage of their life cycle. Based on the definition above, only a few percent of commercial buildings are commissioned. Some of the primary issues that are now driving the building industry to pursue commissioning of commercial buildings are: 
- Demand-side management evaluations of energy-efficiency measures in commercial buildings have shown that many of these measures do not perform optimally or even as well as intended, typically because commissioning was never done or it was done haphazardly (Piette et al. 1995 [329]). Commissioning that follows formalized methods can establish and track operations and provide intended energy performance from startup throughout the life cycle of the building.

- Architects and engineers pay little attention beyond initial start up to ensuring that building systems meet intended energy efficiency, comfort, indoor air quality, and operations and maintenance $(O \& M)$ targets. The lack of involvement results in a knowledge gap: designers often do not understand how the systems they design actually function. This can lead to persistent design errors and deficiencies in subsequent designs. Commissioning can help alleviate this problem by educating building designers, so their designs and building technologies can be improved.

- Commercial buildings are becoming more complex and dynamic. Energy Management Control Systems, dynamic daylighting, direct-digital controls, variable frequency drives, and thermal-energy storage systems are just a few of the technologies contributing to this issue. Most of these technologies interact, which confuses building operators and demands that commissioning be used to optimize their mutual performance.

Residential buildings have many of the same problems and motivators, although their systems tend to be less complex. However, houses are becoming more complex. This is especially problematic, because few houses are now built or retrofitted using formal design procedures. As a result, residential commissioning is an even more nascent practice that means little to most people at this time.

In its narrowest sense, residential commissioning could be defined as the performance assurance process that might be carried out between the time installation and construction are complete and when the buyer occupies the new house. This process would assure the buyer that all required equipment is installed correctly, the final product is assembled correctly, and the house performs as intended. To this end, the California Title 24 energy code already provides elements of commissioning in the form of metrics, some diagnostic methods, and norms for evaluating the energy performance of new houses. The extensive literature associated with building commissioning also describes many such elements.

For the purposes of this project, we use a broader definition of residential commissioning, which includes many activities such as rating, auditing, super-commissioning, or recommissioning. As such, it represents an expansion of processes currently carried out by people such as home energy raters, home inspectors, auditors, and weatherization contractors. This expansion includes the energy performance of the large number of existing California houses, as well as the indoor environmental performance of all houses in the State.

\section{Principal Commissioning Elements}

Every commissioning process includes three principal elements: metrics, diagnostics, and norms. The following defines these elements and offers examples to aid understanding: 
- Metrics: For whole buildings, there are two broad performance objectives of interest: Energy Performance and Indoor Environmental Performance (e.g. IAQ and comfort). Each objective can be represented by various performance metrics, which are simply defined as a quantification of the performance of the relevant components or systems.

To understand what a metric is, consider a manufacturer that produces a pen. One relevant metric in this case might be how long a line the pen can produce until it runs out of ink. Three other examples, but in terms of building performance, are duct leakage, which is a metric that represents the airtightness of a duct system; specific leakage area, which is a metric that represents the airtightness of the building envelope; and house depressurization, which is a metric that represents the backdrafting potential for combustion appliances. These latter three metrics each has implications in terms of energy and indoor environmental performance. However, the importance of a particular metric to each performance objective may be weighted differently, and therefore each must be able to stand on its own.

To assure whole-building performance, it is also necessary to consider the relationships between metrics for components and systems, due to interactions between systems and components (Koles et al. 1996 [241]). For example, it is necessary to quantify duct leakage, specific leakage area, and house depressurization to understand the impact that duct leakage flows can have on combustion safety in tight houses.

- Norms: A metric itself does not indicate good or bad performance. However, when quantified, each metric forms the basis for developing the norms against which component or system performance is compared. As with the metrics, the norms will vary depending on the objective of the commissioning. They will also depend on the stage of the house in its life-cycle.

To understand what a norm is, again consider the pen. A norm in this case might be the length of a line of ink produced by a reference pen, it might be an average of the length of lines drawn by several pens, or it simply might be the general length of line that the user wants it to produce. For the metrics related to building performance, consider that various building standards specify requirements for maximum duct leakage, for minimum or maximum specific leakage area, and for maximum house depressurization levels. An example is the Title 24 norm that duct leakage be $6 \%$ or less of the nominal total airflow through the air handler.

- Diagnostics: Diagnostics are usually defined as relatively quick short-term field procedures involving measurements and perhaps analyses to evaluate performance metrics for a system or component under functional test or actual building site conditions. While it is also possible and sometimes preferable to evaluate metrics using data taken over an entire season, time limitations make it impractical to collect and analyze such long-term information during residential commissioning. Such limitations will be largely dependent on the value of the commissioning process to the involved parties. However, for an existing house, commissioning can often use readily-available historical data either as part of diagnostics or to set norms. 
To understand what a diagnostic is, consider once again the pen. The diagnostic to quantify the line length metric might be using a tape measure to determine how long a line the pen was able to produce. Once the line length metric is quantified with this diagnostic measurement, its value can be compared with the norm to determine whether the pen's performance is acceptable or not. From the building performance examples above, consider duct leakage. A possible diagnostic is to use airflow measuring equipment that creates and measures pressure differences, which can then be used in subsequent computerized analyses to calculate the duct leakage.

The same metrics and diagnostics can be used in new and existing houses, although some diagnostics may not be appropriate early in the construction process. However, the norms for existing houses will have to be adjusted to account for the economic viability of meeting stricter standards than those in place at the time of construction. For example, a house built in 1930 does not come close to meeting Title 24 specifications for energy consumption. The retrofitting required to meet Title 24 insulation levels in this example would be prohibitively expensive.

\section{The Commissioning Process}

Even for commercial buildings, there is no universal or even dominant approach for commissioning. ASHRAE (1996 [30]) offers HVAC commissioning guidelines that are probably the most widely utilized in the United States. However, the focus of these guidelines is too narrow for the many projects that involve activities such as whole building commissioning.

Three other commonly referenced documents relevant to commercial building commissioning include:

- "Building Commissioning Guidelines" (PECI 1992 [316]),

- "Procedural Standards for Buildings Systems Commissioning" (NEBB 1999 [300]), and

- "HVAC Systems - Testing, Adjusting, and Balancing" (SMACNA 1993 [407]).

While the details of the commissioning procedures vary among various guidelines and procedures, most descriptions of commissioning for commercial buildings include the following three general steps:

1. Develop Commissioning Plan: The Commissioning Authority develops a plan that includes items such as the project schedule, construction contractor responsibilities, outstanding information requirements, component and system test procedures, monitoring requirements (if any), and building operator training.

2. Execute Commissioning Tests: The testing activities typically begin with precommissioning or inspection tests to verify that the equipment and controls are installed as specified. More sophisticated functional performance tests follow these inspections. These acceptance tests are intended to assess whether the installed system is adequate, the controls are properly calibrated and have correct control sequences, and that proper actions occur in response to predefined stimuli. 
3. Operations and Maintenance Summary and Training: The Commissioning Authority reviews the training procedures and O\&M manuals to ensure that proper attention is given to key issues. This step may also include periodic inspections and tests of the type described above.

Most of this discussion about commissioning commercial buildings is concerned with new construction. Many of the same principles and methods are equally relevant to commissioning of a retrofit or tuning up an existing building. In the case of an existing commercial building, the procedures can be modified to focus on identifying major O\&M problems, or there may be an extensive "recommissioning", which generally refers to a systematic review of building systems to ensure they perform as desired. A good resource guide for commissioning existing commercial buildings is provided by DOE (1998 [119]). For these buildings, the basic process is again to outline how you think the building systems should be performing, conduct a series of tests and measurements to examine actual performance, and reconcile differences between expectations and reality.

Houses tend to be less unique from one another than is the case for commercial buildings. Also, few houses have operations and maintenance staff. As a result, developing a unique commissioning plan and O\&M manual for each house may be unwarranted. In addition, it is anticipated that commissioning can sometimes provide better performance than is called for in the design. Therefore, the residential commissioning process as envisioned in this project is slightly different. It has three main phases that can probably be encompassed by generic guidelines geared to specific commissioning issues or system and component types:

1. Audit and Diagnostic: In the first phase of commissioning, the metrics for the house are surveyed using instrumented and non-instrumented techniques. The results of this survey are then compared with the norms for the house. For new construction, the norms will be those of the Title 24 compliance material or of the equivalent local building codes. For an existing house, the norms may be based on design intent (if any was ever documented) or on what a particular component should be able to do compared to other similar houses.

2. Tuning and Tweaking: The performance of many components and systems may not meet the norms, but it will be possible to improve their performance by making minor adjustments, repairs, or retrofits on the spot. An example is sealing leaky ducts. Such tuning and tweaking can often provide significant improvements in performance for very little marginal cost. The purpose of this step is to improve the performance of the house to at least the design intent. Sometimes, that intent will be unknown. In those cases, the optimization will be to other norms, such as the best performance achievable without repair or retrofit.

3. Opportunity Identification: After the tuning and tweaking, there still may be components that are not performing up to their potential. This commissioning step provides the client with information about what potential repair or retrofit opportunities should be further investigated. Even when components are performing to their norms, newer technology may make replacement worth considering. 


\section{What Needs to Be Commissioned?}

The most critical items to commission in commercial buildings are the dynamic systems, especially the Energy Management Control Systems (EMCS), and other HVAC equipment. Lighting controls are equally as important to commission. Some Commissioning Authorities and building owners include many additional systems in commissioning. These can include static systems such as the building envelope, as well as non-energy systems such as life safety and plumbing equipment.

There are also many components and subsystems of a house that need to be examined in the course of residential commissioning. For houses, the seven key performance areas of current concern in California are as follows: Building Envelope, Cooling Equipment and Heat Pumps, Air Distribution Systems, Indoor Air Quality, Combustion Appliances, Controls, and Other Electrical Appliances.

- Building Envelope: The building envelope is more important to the performance of a house than it is to that of a commercial building, because unlike commercial buildings, the envelope loads instead of internal loads dominate the house heat transfer mechanisms. Assumed thermal loads, equipment sizing, structural durability, and occupant comfort for houses are based on having the building envelope perform as intended, including windows, air tightness, and insulation levels. In new houses, installation failures, especially in insulation and air sealing, can cause problems. In existing houses, subsequent loss of durability can also decrease performance. Poor material selection and installation (e.g. insulation settling, air barrier damage from UV exposure) can result in performance reductions over time.

- Cooling Equipment and Heat Pumps: Even in new houses, cooling systems rarely perform as intended (Sherman et al. 1987 [401]). Refrigerant charge levels, airflow across coils, and other operating conditions often do not meet manufacturers specifications used in the system design. As a result, the capacity and efficiency of the equipment is degraded. Heat pumps share many of the same problems associated with cooling systems, but have some unique features. Use of electric resistance ("strip") heaters can significantly increase energy consumption. Heat pump (and desuperheater based) water heaters require careful integration into the whole-building to be successful.

- Air Distribution Systems: Ducts that are part of the thermal distribution system may be the single worst performer in the energy performance of a house (Jump et al. 1996 [223]). Duct leakage, duct insulation compression, and other poor installation practices can reduce duct efficiency by $30 \%$ from even a moderate level of design performance. Compared to the space conditioning system, the ventilation system in most houses is simple. It consists of operable windows, infiltration, and a few (if any) intermittently-operated local exhaust fans. However, some houses use wholehouse ventilation as well, which is sometimes directly linked to the space conditioning system. The delivery effectiveness and room by room distribution efficiency of both the thermal and ventilation distribution systems thus depends on the proper flow of air through the air moving equipment. Poor operation of the air distribution systems can cause comfort problems, structural moisture problems, and poor indoor environmental quality, as well as wasted energy. 
- Indoor Air Quality: Related to the performance of thermal and ventilation distribution systems is a host of indoor air quality issues that apart from the airflows themselves include the generation, transport, and removal of pollutants. Examples of pollutants in houses include gaseous ones such as carbon monoxide and nitrogen oxides; biological ones such as molds, fungi, and mites; and particulates such as dust.

- Combustion Appliances: In addition to fuel-related issues for these kinds of appliances, poor operation of vented and non-vented appliances can reduce their efficiency and indirectly affect electricity usage. Fueled appliances must vent as intended. Poor installation of either the combustion equipment or air moving equipment can also reduce efficiency and lead to backdrafting and combustion gas spillage or other hazards. Such events, along with insufficient ventilation for unvented combustion appliances, can directly affect the indoor environment by causing health, comfort, or indoor air quality problems.

- Controls: In commercial commissioning, control problems are the key item of concern. While not as important in residential houses, controls can still play an important role, especially when the systems become complex (e.g. multistage systems, integrated heat-pump/ventilation systems) Even common heating setback / cooling setup thermostats need to be properly commissioned. Making sure that these controls are doing what was intended or is appropriate is often crucial to achieving good energy performance.

- Other Electrical Appliances: Apart from the HVAC system, there are many other electrical appliances in the house. Some of them (e.g. stoves, water heaters, refrigerators, clothes dryers) can be quite large consumers of electricity. Improper configuration of some appliances (e.g. clogged dryer vent) can cause poor performance. Most of these appliances require only simple commissioning.

Although only some of these facets of commissioning may need to be examined in each instance, it is important to recognize that they are not mutually exclusive and many of them interact. Therefore, the commissioning procedure must not only identify the energy and non-energy benefits associated with improving the performance of each component, but it must also indicate how these individual savings interact in the complete building system.

\section{Costs and Benefits of Commissioning}

The most common question after "what is commissioning?" is "what are its costs and benefits?". There are two ways to answer this question. Ideally, we would develop an answer by examining existing case studies of commissioning that describe how much was spent and quantitative assessments of the benefits. Unfortunately, these case studies are somewhat limited, especially those that quantify the benefits, even for commercial buildings.

An alternative method of answering the question is to examine hidden costs involved in not commissioning. The type of benefits one receives from commissioning includes items such as improved energy efficiency, better operations and maintenance, fewer change orders, and improved air quality. Heinz and McCray (1996 [210]) presented an 
excellent discussion of how a university engineering staff improved the commissioning process as they moved from their first to their second, third, and fourth building project. They suggest that the costs to commission a building are far less than the hidden costs that occur in cases where buildings are not commissioned.

Over the last few years, significant energy savings have been demonstrated by correcting problems in existing commercial buildings. For example, research at Texas A\&M (Claridge et al. 1998 [76]) has found that in almost all older commercial buildings, and even in many new buildings, use of the building is quite different from the original plan. Consequently, they developed a process of "continuous commissioning" that tunes the systems of the building for optimal comfort and peak efficiency based on the current use. Implementing that process has saved an average of over $20 \%$ of the total energy cost (over $30 \%$ of the heating and cooling cost) in more than 80 buildings in which it has been applied. Simple payback times under two years were achieved in nearly all of the 80 buildings.

Piette and Nordman (1996 [327]) carried out a study on the energy savings achievable with utility-funded commissioning of energy-efficiency measures in new buildings. On average, they found that commissioning costs of about $\$ 0.20 / \mathrm{ft}^{2}$ were marginally cost effective based on energy savings alone. These low costs were based on limiting the scope of the commissioning effort to only the energy-efficiency measures. Wholebuilding commissioning of all major energy-using systems would likely be even more cost effective.

For houses, one example of the energy savings potential of correcting problems during commissioning is sealing leaky ducts. Field tests and existing simulation tools have shown that about $15 \%$ (new construction) to $20 \%$ (existing houses) of the energy consumed to heat or cool a California house could be saved in this manner. Taking the conservative estimate of $15 \%$ savings, this is equivalent to about $7 \times 10^{15} \mathrm{~J}$ (or 7 Trillion Btu) if applied to all California housing. Associated reductions in peak demand are higher than these seasonal average values, and are typically about $25 \%$. The $15 \%$ savings in cooling costs correspond to about $\$ 42$ per year of the $\$ 700$ average annual residential electricity bill in California. These savings estimates are based on field data measured by LBNL and other researchers, as well as on data from the CEC (1995 [65]), Energy Information Administration (1999 [137]), California Department of Finance (CA State 1999 [63]), and F.W. Dodge (1996 [112]).

In general, improvements in indoor air quality and other non-energy benefits may be even more important than the energy saving benefits from commissioning. For example, the health, safety, and productivity of building occupants can be improved by ensuring there is proper airflow in the building (Sterling and Collett 1994 [413]). In office buildings, energy costs are around $\$ 1$ to $\$ 2$ per $\mathrm{ft}^{2}$ per year, while salaries of employees are two orders of magnitude greater. From a simple economic standpoint, clearly the ultimate concern should be the health and productivity of the occupants, both in these offices and in their homes. Showing quantified occupant productivity gains due to a well commissioned building compared to a building that is not commissioned is extremely difficult. However, many case studies have shown that the types of problems found during commissioning result in sub-optimal or unhealthy conditions for occupants when left uncorrected. 


\section{Who Should do the Commissioning?}

In addition to the important questions of "what is it?" and "how much does it cost?", a common question is "who is qualified and who should do it?" The most common method for commissioning commercial buildings today is to hire an independent third party (Commissioning Authority) to lead the commissioning effort. The independence allows the Commissioning Authority to maintain neutrality and avoid conflicts of interest, which is difficult if the design team also does the commissioning.

In spite of the benefits of independence, many design engineers argue that they are the best qualified to conduct the commissioning. One reason is that they are closest to the design. A second is that they understand the functional intent. A third reason is that they believe they should be involved in defining and performing test sequences. A problem with this arrangement is that the design team is less interested in uncovering design problems that an independent party might more fully explore.

Even when the Commissioning Authority is an independent third party, the job can be complicated by design problems. For example, the Commissioning Authority is supposed to ensure that the installed system functions in an optimal fashion, but is in a quandary when problems with the original design are found during that process. Commissioning Authorities are not usually responsible for the design. Therefore, to facilitate feedback to the designers on how building systems actually perform, the Commissioning Authority should be engaged early in the process.

Other problems can arise in commissioning when the Authority does not become involved until late during the design or early in construction. An example is that the collection of information (such as design specifications and drawings) required to perform commissioning is more difficult later in the process. Another example is that late scheduling of tests into a typically rushed and inflexible construction and start-up schedule is more difficult and therefore more expensive.

Many of these principles apply to houses as well, even though they are not typically "designed". Likely parties who will be involved in residential commissioning include the State through statewide energy codes, home energy raters, home inspectors, auditors, and weatherization contractors. Other parties involved may include utilities, realtors, financial and insurance institutions, and environmental groups. If independent parties are required in this process, then the contractors will not carry out commissioning themselves, but they would receive feedback from the others who do carry out the commissioning. Alternatively, the contractors might also do commissioning, if a certification and audit process is developed to ensure commissioning quality.

\section{LITERATURE REVIEW APPROACH}

This report is meant to be a stand-alone document to facilitate access to existing literature related to residential commissioning. Until now, there has been no single document that summarizes the readily available literature related to this issue.

Many literature sources were accessed, including:

- American Council for an Energy-Efficient Economy (ACEEE) conference proceedings. 
- Air Infiltration and Ventilation Centre (AIVC) technical notes and conference proceedings.

- American Society of Heating, Refrigerating, and Air-Conditioning Engineers (ASHRAE) IAQ conference proceedings; ASHRAE International Journal of HVAC\&R Research; ASHRAE Journal, Standards, and Transactions; and ASHRAE Thermal Performance of the Exterior Envelopes of Buildings conference proceedings.

- ASTM Standards and special publications.

- California Energy Commission (CEC) standards and statistics documents.

- Canadian General Standards Board (CGSB) standards.

- Home Energy magazine.

- Indoor Air conference proceedings.

- Lawrence Berkeley National Laboratory reports.

- National Association of State Energy Officials (NASEO) home energy rating guidelines.

- Portland Energy Conservation Institute (PECI) commissioning conference proceedings and guidelines.

- U.S. Department of Energy (DOE) commissioning documents and home energy rating guidelines, as well as the DOE International Performance Measurement \& Verification Protocol.

Apart from these sources, a search of the Internet was carried out to locate relevant documents and websites.

In searching for documents, we developed and used a set of keywords to locate information relevant to commissioning. Specifically, the search focused on metrics, diagnostics, and norms for components and systems that can be inspected to verify conformity with a specification, that can be "tweaked" or tuned during a residential commissioning process, or that can be modified later to improve the energy and indoor environmental performance of a house. Based on these principles, an outline of relevant issues was developed to guide the search and to help categorize reviewed documents. That outline is attached as Appendix C.

Emphasis was placed on locating documents published over the past 20 years, which represents the period of time over which building commissioning and closely-related issues have been actively reported.

\section{SUMMARY OF RELEVANT METRICS, DIAGNOSTICS, AND NORMS}

To commission the components and subsystems in California houses, we have preliminarily identified the following metrics, diagnostics, and norms as being relevant. This list is not static and is subject to modification as further information becomes available. Not included in the list below are standard measurement techniques, such as those for determining house geometry or for measuring temperature and pressure. The 
summary in each category is brief and does not include many references. The annotated references in Appendix A provide more detail.

\section{Building Envelope}

- Metrics: The literature reports several metrics of interest for commissioning the building envelope. A common one is the thermal conductance of individual windows and opaque elements, which is often denoted by the assembly R- or U-value. In its simplest form, the conductance metric is the insulation level and location. The insulation level can be defined in terms of its type, thickness, and/or density. Other related qualitative metrics include the presence of anomalies such as missing insulation, insulation settling in a wall, or uneven distribution over a ceiling. Christian and Kosny (1995 [73]) have refined the conductance metric for wall sections using terms such as center-of-cavity (not including framing or additional elements such as doors or windows), clear-wall (including framing but no additional elements such as doors or windows), and whole-wall conductance (including framing, doors, and windows). Window radiative behavior can be described by metrics such as emittance, solar heat gain coefficient, daylight transmittance, and UV transmittance. Subbarao et al. (1985 [418]) have attempted to combine the thermal conductance and,radiative behavior by characterizing the long-term thermal performance of the entire building using two short-term parameters: building heat loss coefficient for conductance and equivalent clear aperture area for solar radiation. Saunders et al. (1994 [363]) defined a similar metric (building load coefficient), but included infiltration as well.

The airtightness of the building envelope elements, both at the component level and together as a system are often described in the literature. They can be characterized by terms such as airflow or air change rate at a standard pressure differential (e.g. CFM50, CFM25, ACH50), or by effective leakage area (e.g. ELA4). In some cases, the intermediate parameters of equations used to calculate these metrics are used instead. They include terms such as the flow coefficient and pressure exponent. The airtightness metrics are sometimes normalized by floor area and/or building height to allow comparison between buildings. Normalized terms include specific leakage area, normalized leakage area, and leakage class. In rare cases, economic factors are included with the airtightness metrics (e.g. \$/CFM50). Another simple metric of interest with respect to airtightness is air barrier type and location. Many of these metrics can also be applied to describe the airtightness of interzone elements such as interior partition walls and doors, when that airtightness is of interest.

There are virtually no metrics described in the literature to characterize thermal mass in relation to the building envelope. One is the time constant of the building (Sonderegger et al. 1981 [409]), which represents how quickly internal temperatures within a building assembly respond to an external change in temperature or heat flux. Two others are capacity and availability. Capacity represents the maximum amount of thermal energy that can be stored or released due to a uniform change in temperature of the building assembly. Uniform temperatures are not achieved instantaneously, which leads to thermal gradients within a building assembly. This means that only part of the assembly is thermally charged or discharged initially. 
Availability represents the fraction of the capacity that remains available to store or release heat at any given time.

In terms of moisture-damage susceptibility, there are also few metrics and they are not commonly referred to in the literature we reviewed. Simple qualitative metrics include visible wetness or degradation of interior or exterior finishes and structural components. Degradation can include staining, streaking, mold or fungal growth, and wood rot. More complex and quantitative terms used by researchers involved with this issue include vapor partial pressure, condensation potential, mass of condensed water, surface water activity, water intrusion rate, diffusion path length, drying potential, and moisture content.

- Diagnostics: Standard techniques for evaluating the performance of the building envelope are often described in the literature. The simplest technique is visible inspection during construction, which can include thickness measurements and sample extractions of the insulation to assess its density. This technique can also be used for some ceilings and floors after construction. However, more complex techniques are generally required after construction to avoid dismantling envelope components such as walls. These techniques include infrared thermography combined with blower door pressurization to evaluate leak location and insulation homogeneity. Aerial thermography has also been used to rank roof insulation levels of buildings (Burch 1980 [61]) in broad surveys. Other techniques for assessing assembly conduction heat transfer include the use of non-contact spot radiometers, contact heat flow transducers, portable calorimeters, and guarded hot boxes. The latter two devices are better suited to laboratory use. An adaptation of the guarded hot box called the Envelope Thermal Test Unit (ETTU) has been developed for use in the field by Sonderegger et al. (1981 [409]). Three-dimensional simulation of building envelope elements has also been used to evaluate thermal conductance (Christian and Kosny 1995 [73]).

Janssen and Rasmussen (1985 [219]) developed a complex technique for determining the thermal conductance of the entire envelope. It relies upon temperature decay and rise during one- to two-hour-long furnace off and on periods respectively and the elimination of infiltration effects. Those effects are removed using infiltration diagnostics during the temperature decay and rise periods and using subsequent calculations. Sandberg and Jahnsson (1995 [361]) describe a similar technique that does not involve furnace cycling. Instead, it characterizes the total heat loss rate of a house as it is normally operated by its occupants. Actual indoor-outdoor temperature differences and energy consumption are measured. Average heat loss per unit temperature difference is calculated from these data. Saunders et al. (1994 [363]) also describe a related technique that is based on coheating. That technique involves maintaining constant indoor air temperatures using electric heaters and continuously measuring the input power for the heaters. Unlike Sandberg and Jahnsson, Saunders et al. remove infiltration effects. As a result, their technique separates out thermal conductance and is more useful for describing heat transfer characteristics at times other than just during the test.

Standard techniques for determining airtightness such as blower door pressurization are frequently described. Alternative techniques such as $\mathrm{AC}$ pressurization and pulse 
pressurization also exist, but are impractical for residential commissioning. The literature also describes techniques that use balancing fans (two blower doors operated simultaneously) or leakage variations to determine interzone and series leakage, such as between living spaces and the attic or between adjoining dwellings. In terms of air barrier location, blower doors can also be used to establish the boundaries of the pressure envelope (Fitzgerald et al. 1994 [153], Cummings 1998 [94]). Many of these techniques are already automated using computer-controlled fan speed and pressure sensing. Some of the literature focuses on issues surrounding test accuracy, such as single point versus multipoint tests. To identify leak locations, techniques other than using infrared thermography are available. They include the use of a blower door and smoke, tracer gases, draft sensation, anemometry, or in some cases acoustic transmitters and sensors (ASTM 1995 [38]).

To determine the emittance of windows, a prototype portable spectrometer is available (Griffith 1999 [181]). Well-developed simulation software is also available to characterize window performance, once the properties of the windows are known.

No diagnostic methods were found to quantify envelope thermal mass, except for the ETTU device developed by Sonderegger et al. (1981 [409]). That device has been used to evaluate the time constant metric for walls. A similar technique has been developed by Roulet et al. (1985 [356]).

Diagnostics for assessing moisture-damage susceptibility are less well developed. In particular, most diagnostics that were found can only evaluate the presence of moisture, rather then the susceptibility to moisture-damage. Thermography has been suggested as a way of assessing wet insulation (Knehans and Styer 1983 [238]). Moisture content of building assemblies can be measured using resistive- or impedance-type electrical devices or by determining weight changes due to drying extracted samples of insulation (NAHB 1997 [293]). Impermeable or absorbent materials can be placed over envelope sections and then, after a fixed period of time, can be visually inspected for wetness or weighed to determine absorbed moisture (Lichtman et al. 1999 [252]). To evaluate moisture-damage susceptibility, checklists can be used in visible inspections of likely defects that may lead to future damage. Computer simulations can be used to assess the condensation potential of windows.

We are quite familiar with all these technologies and no development in this area is anticipated. Because some envelope diagnostics are impractical in a commissioning environment, visual inspections will often play a key role.

- Norms: Most of the norms relevant to building envelopes are contained in Title 24 and ASHRAE Standards. Some are also contained in home energy rating guidelines. These norms include specifications for R- or U-values for opaque assemblies and for windows, solar heat gain coefficients, interior thermal mass, and whole-building airtightness.

There are a few references in the literature in addition to these documents that provide norms for opaque assembly conductance and for whole-building airtightness. In particular, there are large sets of data describing the airtightness of houses. Some of these datasets have been correlated with building type, wall construction, and climate. 
Other than the thermal mass capacity estimates for slabs and whole buildings in Title 24 , no norms related to the thermal mass of the envelope itself were found.

No norms other than inspection checklists for envelope defects and a few data from moisture conductance surveys were found that are related to moisture-damage susceptibility.

\section{Cooling Equipment and Heat Pumps}

- Metrics: Steady-state performance characteristics for air conditioners (and to some extent for heat pumps) are often referred to in the literature in terms of capacity and efficiency. Capacity is usually referred to in terms of the name plate rating or the ARI rating, but is sometimes called the "installed" capacity. A related metric is the required capacity that is determined using load calculations and that is used to size equipment. These capacities can represent the system as a whole or its components (e.g. evaporator, condensing unit). Common metrics associated with the efficiency issues are the energy-efficiency ratio (EER) and seasonal energy-efficiency ratio (SEER). A less common one is the integrated part load value (IPLV). For heat pumps in cooling mode, the term coefficient of performance (COP) is also a common metric. To account for equipment, installation, and operation deficiencies, Neal (1998 [298]) has proposed the use of another metric: field adjusted SEER (SEERFA). One other metric referred to is simply total electricity consumption over a fixed time period.

Heat pumps also provide a heating function. That performance can be characterized by the heat pump seasonal performance factor (HSPF). Associated with this type of performance are common metrics used for other space heating equipment such as furnaces and boilers. These metrics include steady-state and seasonal combustion efficiency. Regardless of heating equipment type, an important metric is the heat exchange efficiency, which is the ratio of the duct energy input to the total energy input to the equipment (Walker et al. 1998 [453]).

Because refrigerant has such an important impact on performance for cooling equipment and heat pumps without thermal expansion valves, its level or charge within the system is a metric in itself. Coil volume and refrigerant line length are related metrics, because they affect the amount of refrigerant that a system requires.

- Diagnostics: The steady-state capacity and efficiency of an air conditioning unit (or heat pump) can be measured under a single set of environmental conditions occurring at the test time. There are few diagnostic techniques currently described in the literature. Most are based on laboratory tests, which may be too complex and timeconsuming for commissioning. Some field tests to estimate performance metrics are available, but they also involve complex measurements. An example is the use of the REGCAP performance simulation software to evaluate performance metrics by interpolating within equipment manufacturer's performance data (Walker et al. 1998 [453]). A second example is the use of electric coheating to determine cooling efficiency (Sonderegger et al. 1980 [411]). A third example is the use of motor current signature analysis to correlate motor startup current waveforms to COP, as well as to refrigerant charge level (Miller et al. 1989 [272]). 
Refrigerant charge is known to have a significant impact on equipment performance. Several methods other than the one described above are available to assess the charge level. They include simple methods such as using temperature and humidity measurements, refrigerant gauge pressures, and lookup tables in superheat and subcooling tests, as well as the "approach" tests for Lennox equipment. More elaborate methods include software packages such as "Check-Me" that automate these methods and often can be used to find combined performance. An even more complex method to check charge level is to evacuate the system, weigh the removed charge, and then replace the charge into the system. This latter approach has the problem however that the amount of charge that should be in the system is unknown due to the use of evaporator coils that differ from that intended by the system manufacturer.

Modifications to these extant methods will be needed to make such diagnostics more practical in terms of equipment and time constraints.

- Norms: Most of the norms relevant to cooling equipment performance are contained in Title 24 and ASHRAE Standards. They include norms for EER, SEER, COP, HSPF. Title 24 also includes norms for integrated part load value (IPLV) for unitary air conditioners and heat pumps. Some norms, such as SEER, are also described in Energy Star literature. Norms for equipment sizing (in the form of sizing criteria) are contained in ACCA Manual J (Neal 1998 [298]).

The applicability of manufacturer specifications as a norm is questionable, given that mismatched indoor coils are installed in some cases. Beyond these specifications, there are no norms for refrigerant charge level.

\section{Air Distribution Systems}

- Metrics: There are numerous metrics related to the thermal performance of residential air distribution systems, most of which have been developed over the past ten years. These metrics include delivery effectiveness and distribution system efficiency, both on a design condition basis and on a seasonal basis. Other related metrics include duct leakage flows (e.g. CFM25, CFM50), duct leakage class, effective duct leakage area (e.g. ELA4, ELA25). These duct leakage metrics can be subdivided into leakage to indoors and outdoors, as well as into return, supply, cabinet, and register boot components. Thermal regain (ASHRAE 1999 [32]), "tons at the register", which is a measure of enthalpy flow delivered at each register (Walker et al. 1998 [449] [453]), as well as airflow and pressure drop within a duct, are also relevant metrics. Other metrics include power delivered to the duct system, power lost from supply ducts due to conduction and leakage, and fractional conduction loss (Walker et al. 1996 [446]).

Ventilation-related metrics are similarly numerous, and have been developed over a longer period (about 20 years). Many can be used at component, room, or wholehouse levels. They include metrics such as ventilation airflows and air exchange rates, temporal and spatial ventilation effectiveness and efficiency, and indooroutdoor and interzonal pressure differentials. Some of these metrics can be subdivided. In particular, the temporal distribution of air within a room or entire house can be represented by metrics such as age of air, turn-over time, and effective 
ventilation rate. $\mathrm{CO}_{2}$ levels indoors are sometimes used as a surrogate metric to quantify ventilation adequacy, but may be inappropriate when there are other pollutants of concern within the house. Ohnishi et al. (1998 [308]) has defined three metrics to describe whole-house ventilation performance: supply rate fulfillment, exhaust rate fulfillment, and overall ventilation rate fulfillment. An additional metric useful to discussing infiltration-based ventilation airflow potential is infiltration degree-days (IDD). Parameters used in infiltration or ventilation simulation models also represent metrics that can be used to characterize how a house will perform in terms of ventilation. Such terms include surface pressure coefficients, as well as terrain and shielding parameters, all of which are related to wind effects.

Several metrics represent the performance of heat recovery devices in ventilation processes. These include terms such as sensible, latent, and total energy recovery effectiveness; sensible and total heat recovery efficiency; temperature ratio; ventilation reduction factor; and exhaust-air-contamination ratio.

- Diagnostics: The performance of both the cooling and ventilating systems depends on airflow through the air-moving equipment. A flow measurement technique involving a calibrated perforated metal plate is being developed with DOE STTR funding for use in measuring the total flow through air handlers. Other devices and procedures are already in use to carry out this measurement. They include the use of pitot-tube traverses, tracer gas methods, or calibrated fans such as "duct blasters" and static pressure measurements at representative locations in the air moving system. In some cases, extrapolation of flow measurements to operating static pressures is necessary when the flow measuring fans have insufficient capacity. Commercially-available flow balancing stations are also available, but are impractical unless installed permanently in the air distribution system. Other techniques can be used that contain simplifications, such as those in ASHRAE Standard 152P (Andrews 1996 [5], ASHRAE 1999 [32]). The simplifications include using the fan curve (if known) and pressure difference measurements to estimate the airflow instead of directly measuring it.

Delivery efficiency and room by room distribution system effectiveness cannot be measured directly. Instead, they are calculated using the system flows described above, along with other diagnostic inputs such as duct location, surface area, and thermal resistance (obtained through a combination of observation and simple calculation), duct leakage (described below), and by determining the flow for each branch of the duct system. Airflow measurement using flow hoods (some of which are fan-assisted), vane or hot-wire anemometer samples, or simple inflation of a plastic bag of known volume are standard techniques for determining register flows. Some optimization may be necessary to make them more practical for the specific intended purpose. Andrews et al. (1996 [6]), as well as Siegel and Davis (1998 [403]) have suggested that coheating can be used to measure system efficiency before and after retrofits, but this technique may not be practical for commissioning. Airflows through individual ventilation devices can also be verified using the measurement techniques applied to thermal distribution systems.

Air leakage for duct systems is a key factor in determining their performance. There are currently several documented diagnostic options. One suggested method relies 
only on visual inspection, but this is unlikely to be adequate in many houses due to concealed duct systems. The others include using one or more calibrated fans such as blower doors and "Duct Blasters", as well as static pressure measurements at representative locations in the air moving system. Specific methods include the duct pressurization test ("Duct Blaster" test), the pressure pan test, the house pressure test, the nulling pressure test, and the delta-Q test (relies on differences in blower door flows with and without pressurization of the envelope by the air handler). The first test has the disadvantage that almost all registers need to be sealed to determine duct leakage. In the house pressure test, the return grille also needs to be partially or fully blocked for some parts of the test. Some of these tests also require more equipment and time than others, and all have some potential problems as documented in much of the literature on this subject. This is an active area of research and may require further development to be applied to commissioning.

Apart from simple pressure differential measurements, the literature reports a novel technique for determining pressure drop and assessing flow obstructions in ducts using acoustical methods (deSalis et al. 1996 [105]).

There is a substantial body of literature from the past 20 years related to determining room and whole-building air exchange rates, as well as ventilation effectiveness and efficiency. Most techniques rely upon the use of tracer gases in decay tests, constant concentration tests, or constant injection tests. Some of the techniques also use multiple tracers to determine interzone air exchange rates. All these techniques are problematic for determining ventilation effectiveness and efficiency of mechanical ventilation systems in houses, because they include infiltration effects that these metrics assume can be ignored. Two novel techniques that may help solve this problem rely upon video techniques to analyze either smoke transport or helium-filled zero-buoyancy balloon motion indoors (Ohba and Irie 1999 [307], Berckmans et al. 1993 [50], Pickering et al. 1987 [326]).

- Norms: Norms for duct thermal performance, including duct effectiveness and distribution system efficiency, are largely contained in Title 24 and ASHRAE Standard 152P. SMACNA standards, Title 24, and some home energy rating system guidelines (Cummings 1998 [94]) also contain norms for duct leakage. Treidler et al. (1996 [432]) report norms for duct insulation.

Ventilation and air exchange norms are largely represented by Title 24 and ASHRAE Standard 62, although the latter are currently being revised to provide specific requirements for houses (ASHRAE Standard 62.2). The literature reviewed contains considerable amounts of field data on infiltration, but those data are for older homes and are likely not applicable to newer construction. Limited data are available to serve as norms for residential ventilation effectiveness and efficiency (Sherman 1989 [387], Sherman et al. 1989 [379], Matson and Feustel 1998 [263]).

\section{Indoor Air Quality}

- Metrics: Indoor air quality (IAQ) is a broad concept that can encompass thermal comfort issues, as well as the behavior of pollutants such as non-biological gaseous 
ones (e.g. carbon monoxide, nitrogen oxides, formaldehyde, radon), particulates (e.g. dust), bioaerosols (e.g. molds, fungi, mites), and moisture.

Metrics for thermal comfort include room air temperature, radiant environment temperature, and room air velocity. Spatial asymmetry and cyclic or non-cyclic drift rates of these temperatures are other metrics related to thermal comfort. Another related metric is relative humidity. Metrics that combine several parameters in attempts to quantify occupant satisfaction with the indoor thermal environment include operative temperature (ASHRAE 1992 [23]), the "Overall Liking Score" of Levermore et al. (1999 [250]), standard effective temperature, predicted mean vote, and predicted percent dissatisfied. Pulldown time is another metric associate with thermal comfort (Walker et al. 1998 [453]). It represents the time it takes to reduce the air temperature to an acceptable level after cooling startup, such as when occupants return home on a hot summer afternoon.

For pollutants, generation rates (e.g. emission, desorption), concentration, level, index, and removal rates (e.g. sorption, absorption, deposition) are relevant metrics. Literature on specific metrics for the generation and removal of pollutants is sparse or non-existent, other than to describe pollutant sources in general. Most metrics reported in the literature for pollutants are in the form of a pollutant level or index. Depending on the type of pollutant, these metrics may be in standardized units of PPM, mass per unit volume of air, colony forming or biological units per unit volume, mass of allergen per unit of particulate, particulate mass deposited per unit area, and number of mites per sample sheet. Most of these metrics represent an integrated quantity over a desired period of time. Moisture itself has several wellknown metrics that include vapor partial pressure, relative and absolute humidity, humidity ratio, and dew-point temperature. Related metrics are condensation potential for windows and surface water activity (Flannigan 1992 [156]), both of which provide an indication of the availability of moisture for microbial growth. Moschandreas and Sofuoglu (1999 [289]) have suggested an "Indoor Pollution Index" metric that attempts to sum the effects of multiple pollutants to determine their synergistic effect.

- Diagnostics: Because the cooling distribution system can induce changes in indoor air quality (both in terms of thermal comfort and pollutant behavior), some diagnostics are needed in this area.

Some comfort diagnostics involve no measurements and only checklists or occupant satisfaction surveys. The surveys are not simple. They involve analyzing and interpreting human behavior, which can be difficult, as is good survey design to avoid biasing the results. More elaborate schemes monitor room air or radiant environment temperatures using simple portable data loggers as the space conditioning system operates. In some cases, these loggers also contain switches for occupants to record their comfort satisfaction. Temperature sensors can include aspirated shielded thermocouples or thermistors to measure room air temperature, globe thermometers that measure mean radiant temperature (MRT), or more sophisticated Kata probes that measure air motion effects. Vane or hot wire anemometers can also be used to measure air motion. Other related techniques include using a low thermal mass, porous fiberglass screen and infrared thermography to determine room air 
temperature distribution (Hassani and Stetz 1994 [207]). Humidity can be measured using a simple sling psychrometer (dry- and wet-bulb thermometer pair), an aspirated psychrometer, an electronic capacitive relative humidity sensor, or a dew-point hygrometer. Some development in the area of comfort diagnostics is anticipated to provide a simple rapid technique for characterizing the performance of each room in a house.

Standard techniques for measuring pollutant levels include grab sampling or passive pollutant sampling. As with the pollutant metrics, the sample technique used largely depends on the pollutant of interest. In some cases, automated samplers such as for carbon monoxide may be used. In other cases, the sampling equipment can be very sophisticated and expensive (e.g. portable gas analyzers for nitrogen oxides), which may reduce the likelihood that the technique would be used during commissioning (except perhaps by an IAQ commissioning specialist). Particulate sampling includes techniques such as vacuum collection and sampling tape or paper, with subsequent microscopic inspection to determine particle size and number. Other simpler assessment methods are available that simply determine total particle mass for the collected sample or that are based on optical transmission through the sample. Most of the techniques for bioaerosols involve field sampling and then subsequent culturing and laboratory analysis. Computer simulations can be used to assess the condensation potential of windows. In terms of diagnostics for pollutant generation or removal, it is likely most techniques will be limited to simple observation during commissioning. LBL is familiar with all these technologies and no development in this area in anticipated.

- Norms: Norms for thermal comfort are largely embodied within ASHRAE Standard 55. That standard defines temperature, air motion, and relative humidity limits to represent the range of comfort that $80 \%$ or more of occupants in a space will find acceptable, excluding the possible synergistic effects of pollutants other than moisture in the space.

For pollutants, the literature reports several norms for pollutant levels, depending on the pollutant of interest and the jurisdiction. Most are summarized within an appendix of ASHRAE Standard 62. Nagda et al. (1987 [292]) report norms for many pollutants as well. Other than Energy Star requirements that a building should be free of microbiological sources (EPA/DOE 1999 [140]), no norms for pollutant generation or removal were found in the reviewed literature.

\section{Combustion Appliances}

- Metrics: As with air conditioners and heat pumps, steady-state performance characteristics for combustion appliances are also often referred to in the literature in terms of capacity and efficiency. The capacity metric is the name plate output rating, but these appliances are often referred to in terms of their burner "input" capacity. A related metric is the required capacity that is determined using load calculations and that is used to size equipment. Common metrics associated with the efficiency issues are the steady-state combustion efficiency, the annual fuel utilization efficiency (AFUE) for space heating equipment, and the Energy Factor (EF) for water heating 
equipment. The Energy Factor includes other water heater metrics such as standby losses, recovery efficiency, and the tank volume.

Familiar metrics for installation and operation of combustion appliances include safety issues such as clearance to combustibles, vent sizing, and outdoor air flow rates to support combustion. Performance metrics that describe the ability of an appliance to properly vent its combustion gases or conversely its potential for backdrafting and spillage of these gases into a house are less familiar. They include house depressurization or the draft (pressure differential) in the attached vent. These metrics can apply either to startup (cold flue) conditions or to steady-state operation. For the startup case, a particular metric is the cold-vent establishment pressure (CVEP), which represents the maximum indoor-outdoor pressure differential against which the hot combustion gases from the combustion appliance can establish a proper flow through the vent.

Two other important metrics involved with this issue are the concentrations of carbon monoxide and nitrogen dioxide in the combustion gases. If the appliance backdrafts, exposure to elevated concentrations of carbon monoxide indoors can be lethal to occupants, while exposure to nitrogen dioxide can lead to chronic respiratory problems.

One other relevant metric is heat exchanger leakage, which involves the direct leakage of combustion gases into the space conditioning air flowing through the airhandling unit. This metric is more important for commissioning existing houses than for new houses. However, it may be desirable to check new equipment to detect manufacturing defects.

- Diagnostics: Diagnostic methods to assess the fuel-related performance of combustion appliances are well developed. They include temperature and carbon dioxide measurements to assess burner efficiency. Pressure differential measurements are used to adjust operating fuel pressures. Visual inspection is also used to assess flame conditions. Steady-state capacity can be derived using simple methods such as gas meter "clocking".

Methods to address backdrafting and combustion gas spillage are less well developed. These methods are principally contained within two documents (CGSB 1995 [67], ASTM 1998 [42]). Several methods with slight differences are used. The house depressurization test involves measuring the indoor-outdoor pressure differentials created by operating various combinations of installed air-handling equipment (for space conditioning and ventilation) and combustion appliances (off and then on). The downdrafting test involves similar conditions, but all combustion appliances are off and there is no measurement. Only simple observation (yes/no) is recorded of whether the appliance backdrafted. The appliance backdrafting test involves similar conditions again and involves determining how long it takes for the appliance to establish a draft after the combustion appliance is turned on. It requires that the combustion vents be cooled by house depressurization before the timing begins. The cold vent establishment pressure test (CVEP) involves similar conditions to the latter test and requires measurement of the indoor-outdoor pressure differential. In addition, it induces these pressure differentials with a blower door to identify the limit 
at which an appliance begins to backdraft under operating conditions. The ASTM document describes all these tests; the CGSB document only describes the first.

An additional method is reported in the ASTM document and in part by Fugler (1989 [171]). The ASTM method involves continuous monitoring of vent differential pressures, air temperature at the draft hood rim, carbon monoxide and dioxide concentrations, and appliance operation status over the period of about a week or more under natural conditions. The method reported by Fugler involves only the temperature monitoring. Although both methods provide definitive measurements of performance during the monitoring period, they are impractical for commissioning and do not necessarily identify houses at risk of backdrafting and spillage under all conditions.

All of the backdrafting and spillage tests are problematic, because they are susceptible to signal noise from wind effects, which can easily make the test results meaningless. Further development of these tests is required to make them usable and reliable during commissioning.

Measurement of carbon monoxide and nitrogen dioxide in the combustion gas can use the same diagnostics as for indoor air quality, although equipment may need to be more robust due to the higher temperature associated with sampling these hot gases. Oberholtzer (1993 [304]) provides a chimney inspection protocol that includes draft and carbon monoxide testing, as well as the use of a video camera to inspect the interior of the chimney.

DeWerth and Sobieski (1985 [109]) have described a three-step diagnostic method to detect combustion gas leakage in heat exchangers. It relies upon visual inspection of the heat exchanger, observation of burner flame patterns, and the use of tracer gas. Other less reliable methods exist, such as using smoke, salt spray, or odors as tracers to detect leakage.

- Norms: Most of the norms for fuel-related performance of combustion appliances are contained in Title 24, ASHRAE Standards, and building codes. They typically include norms for AFUE. Norms for equipment sizing (in the form of sizing criteria) are contained in ACCA Manual J (Neal 1998 [298]).

The norms reported in the literature for backdrafting and combustion gas spillage are contained within the same two documents that describe the diagnostics (CGSB 1995 [67], ASTM 1998 [42]). For the depressurization test, the norms are pre-established house depressurization limits that depend on appliance type. For the downdrafting and appliance backdrafting tests, the norms are simple observation of appliance behavior (i.e. whether backdrafting occurs in the first test and how long it takes to establish a draft in the second test). For the CVEP test, the norm is the CVEP. In this case, the CVEP must be greater than the maximum house depressurization achieved using installed equipment.

In support of the continuous monitoring method under natural conditions, no norms were found in the literature to indicate what constitutes an acceptable frequency and duration of backdrafting with combustion gas spillage. 
Other than a specification for the free-air carbon monoxide concentration provided by Conibear et al. (1995 [87]) and some test safety criteria described by ASTM (1998 [42]), none of the literature reviewed provides norms for carbon monoxide or nitrogen dioxide concentrations in the combustion gas stream. The ASTM criteria may not be suitable for normal operation.

No norms for heat exchanger leakage were found in the literature reviewed.

\section{Controls}

- Metrics: Except for Keithly (1999 [229]), no metrics were found in the literature to describe residential control performance. Even then, Keithly only describes common deficiencies with thermostat installations.

Some metrics that are relevant to thermostat performance include calibration, setup/setback strategy, and anticipator or temperature swing setting. Other controls in the space conditioning system include those for the burner of a heating system and the thermal expansion device in a cooling system. Specific metrics for the burner include fuel pressure, fuel orifice size, and primary air supply flow. For the thermal expansion devices, relevant metrics are the orifice size, thermal expansion valve (TXV) size, as well as the superheat bulb location and bulb-line contact resistance. Other metrics include heat pump outdoor thermostat and defrost timer settings, blower and burner thermal limit switch settings, blower motor speed, automatic control sequence for duct damper on outdoor air intake, and ventilation switch settings (e.g. humidistats or run and defrost timers).

- Diagnostics: Diagnostics in this area are often little more than checking configurations and settings. Apart from diagnostics intended for laboratory use or for energy management control systems (EMCS), the literature reviewed provides no useful information for residential commissioning.

- Norms: Other than Title 24 requirements for lighting controls, no norms related to controls were found in the literature. One slightly related document mentions that Energy Star homes must have a programmable thermostat (Werling et al. 1998 [460]).

\section{Other Electrical Appliances}

- Metrics: Only a few references were located that discuss metrics relevant to the commissioning of residential electrical appliances. For water heaters, one metric is its recovery efficiency. Others include its energy consumption, energy factor, standby energy loss, and how much insulation is located around the tank. For appliances associated with plug loads, such as refrigerators, metrics include energy consumption and interior compartment temperature. An important metric for electric water heaters and these appliances is the electric load, both at startup and while operating.

- Diagnostics: Diagnostics in this area are often little more than checking configurations and settings. Other than one reference on monitoring and modeling hot water system energy losses (Stewart et al. 1999 [415]), an ASHRAE Standard (1993 [25]) that provides a laboratory test method for rating water heater 
performance, and a few references on electric load monitoring, the literature that was reviewed contained no relevant information on quantitative tests for residential commissioning.

- Norms: Norms for water heaters are described in Title 24, by DOE (1995 [116] [117]), and by ASHRAE (1993 [27]). They include requirements that limit energy loss and for tank insulation. Other than a few data from Sherman et al. (1987 [401]), Meier (1993 [268] [269]), Parker and Stedman (1993 [312]) and Parker et al. (1998 [314]), no data were found to serve as performance norms for electrical appliances.

\section{LITERATURE GAPS}

There is a substantial amount of useful information in the literature about metrics, diagnostics, and norms that are relevant to residential commissioning. However, there are also some significant gaps. The following discusses those gaps.

- Building Envelope: Few metrics or diagnostics for thermal mass and moisturedamage susceptibility were found. Those that are available for thermal mass are complex and time consuming. All need further development work. Other than the thermal mass capacity estimates for slabs and whole buildings in Title 24 , no norms related to these two issues were found. These benchmarks will need to be established if either of these two issues are to be addressed by residential commissioning.

- Cooling Equipment and Heat Pumps: There are few diagnostic techniques currently described in the literature to determine steady-state capacity and efficiency of an air conditioning unit (or heat pump). Those that are available are complex and time consuming. There are several techniques to determine refrigerant charge, but they also often require too much time. All these methods will need to be modified to make them more practical in terms of equipment and time constraints for residential commissioning. Norms for refrigerant charge, other than manufacturer specifications, are lacking and need to be developed. The applicability of those specifications as a norm is questionable, given that mismatched indoor coils are installed in some cases.

- Air Distribution Systems: Several diagnostic methods exist now to evaluate duct leakage. However, this is an active area of research and most methods require some further development to be useful in residential commissioning.

Determining ventilation effectiveness and efficiency of mechanical ventilation systems in houses is problematic, as there is no appropriate diagnostic method available. Further development of such diagnostics is necessary, as is the development of corresponding norms, if these issues are to be considered during residential commissioning.

- Indoor Air Quality: Many diagnostic methods exist already to characterize thermal comfort. However, some development in this area is required to provide a simple rapid technique for characterizing the performance of each room in a house.

Although there are several norms for pollutant concentration, virtually none were located for pollutant generation or removal. If these latter two issues are to be 
considered in residential commissioning, then norms based most likely on visual observation will need to be developed.

- Combustion Appliances: Several methods for assessing the potential for backdrafting and combustion gas spillage are available in the literature. However, all of the tests are problematic, because they are susceptible to signal noise from wind effects, which can easily make the test results meaningless. It is important that these tests be further developed to make them usable and reliable during commissioning. In addition, norms for carbon monoxide or nitrogen dioxide concentrations in the combustion gas, as well as for heat exchanger leakage need to be developed.

- Controls: Metrics, diagnostics, and norms in this area are almost completely lacking. Extensive development work will be necessary so that issues associated with control performance can be addressed during residential commissioning.

- Other Electrical Appliances: There are few metrics, diagnostics, and norms in the literature we reviewed. If these appliances are to be dealt with during residential commissioning, then we need to locate and review more relevant literature.

Considerable work relating to appliance performance has already been carried out or is underway at LBL, particularly with respect to water heaters and plug loads.

Few (33) of the 469 references that we reviewed specifically addressed a house as a system, although many mentioned that this is an important issue. Of these 33 references, nine considered systemic links between either building envelope airtightness or ventilation and air distribution system performance. Eight considered the links between either airtightness or ventilation and envelope insulation performance or moisture damage. Four considered the links between ventilation or air distribution system related loads and air-conditioner performance (Sonderegger et al. 1980 [411], Cummings et al. 1990 [98], Proctor 1997 [338], Walker et al. 1999 [447]). Four directly considered the links between airtightness, ventilation, and combustion safety (CGSB 1995 [67], ASTM 1998 [42], Lstiburek 1998 [256], Grimsrud et al. 1999 [184]). Other references considered various links between the building envelope, HVAC system, indoor air quality, and controls, but usually only one link. It appears that more research is necessary to assess and describe the performance of a house as a system of interacting components.

\section{OTHER ISSUES}

In the course of the literature review, several non-technical documents were found on the subjects of general instrumentation, commissioning processes, HVAC installation, and economics. All these documents pertain to commercial buildings, but some of this information can be adapted to residential commissioning.

Most of the papers on instrumentation dealt with diagnostics involving short-term monitoring, which might be useful depending on the time available for commissioning or the issue to be resolved. Sometimes, such monitoring is the only way to detect or diagnose a performance problem.

Of the documents discussing commissioning processes, one described ten metrics that could be used to evaluate the effectiveness of commissioning (Tseng et al. 1994 [435]). These involved issues such as the number and severity of defects remaining after 
commissioning and the quality of maintenance training. Most of the other documents described specific processes to commission commercial buildings, the rationale for them, or ways to improve them.

The papers that relate directly to HVAC installation all list steps to follow or details to verify during commissioning after installation. Meckler (1991 [267]) also lists steps to follow during the design and occupancy phases of a building life cycle.

Several references specifically discuss economic issues involving building commissioning. Some describe economic metrics, which include the average or net present value for the cost of tuning or tweaking (duct sealing) and the associated energy savings, as well as simple-payback times. Some also present diagnostic methods, all of which involve the use of computer simulation to determine costs and savings associated with implementing energy efficiency measures. No literature was found that describes diagnostic methods to assess the value of non-energy costs and benefits. Some references also describe norms for use in economic analyses, such as equipment use and cost data and state-wide energy consumption data. 


\section{BUILDING ENVELOPE}

\subsection{Opaque Building Assemblies \\ Metric}

\section{ASSEMBly Thermal Conductance}

1. Christian and Kosny 1995 [73] described the thermal performance of walls in terms of the center-of-cavity R-value, clear-wall R-value, and whole-wall $\mathrm{R}$-value.

2. Christian and Kosny 1997 [74] discussed the importance of five elements ( $R$-value, thermal mass, air tightness, moisture tolerance, and sustainability) to evaluate whole-wall performance.

3. Christian and Kosny 1999 [72] defined and compared clear-wall and whole-wall R-values.

4. Condon et al. 1980 [85] used a wall's thermal resistance to relate the heat flux through a wall to the temperature difference across the wall.

5. Desjarlais et al. 1998 [108] defined the R-value of a window assembly.

6. Forest et al. 1991 [165] measured thermal resistance of porous insulation.

7. Isaacs and Trethowen 1985 [218] defined a "cumulative" method of determining thermal resistance from a series of heat-flux and temperature-difference measurements.

8. Lambert and Robison [244] measured wholehouse thermal loss in terms of a $\mathrm{K}$ factor (slope of line regressed to chart of measured space heat average energy use vs. inside-to-outside temperature difference).

9. Modera et al. 1986 [283] found through computer simulations that the dynamically measured thermal conductance of a wall was mostly likely to be inaccurate in the cases of (a) well-insulated walls; (b) large indoor and outdoor temperature fluctuations; (c) small average indoor-outdoor temperature differences; and (d) thermally massive walls.

10. Saunders et al. 1994 [363] defined "building load coefficient" (BLC), an area-integrated envelope thermal heat transfer coefficient $\left(U^{*} A\right)$ incorporating both conduction and infiltration effects.

11. Sherman et al. 1983 [380] described a wall's dynamic thermal performance by a small number of "Simplified Thermal Parameters," including a steady-state conductance, a time constant, and some storage terms.

12. Sonderegger et al. 1981 [409] described the thermal performance of an heterogeneous wall in terms of its conductance, its time constant, and two or three pairs of correction terms that express the wall's heterogeneity.

13. Subbarao et al. 1985 [418] reported on the early stages of a project to characterize the long-term thermal performance of a building using only two short-term-measurable parameters (building heat loss coefficient and equivalent clear aperture area).

\section{INSULATION LEVEL AND LOCATION}

1. BII 1998 [53] discussed insulation performance metrics including R-value, installation depth, and infiltration rate.

2. Grot and Chang 1983 [195] defined nine classes of envelope thermal anomalies (e.g., uninsulated exterior-wall cavity regions, improperlyinsulated ceiling areas, air leakage around door or windows) that thermographic inspection of buildings can find.

\section{Diagnostic}

\section{ASSEMBLy Thermal CONDUCTANCE}

1. Burch 1980 [61] used infrared thermography to rank roofs of residential and commercial buildings according to their thermal resistances, and found that it worked best under low-wind conditions.

\footnotetext{
* Each bracketed paper reference number in Appendix A (Annotated Bibliography) is hyperlinked to the paper's bibliographic reference in Appendix B (Alphabetized List of References). For example, [283] is a link to the bibliographic reference for paper 283 (Modera et al. 1986).
} 
2. Christian and Kosny 1999 [71] described Oak Ridge National Laboratory's web-based wholewall R-value calculator.

3. Christian and Kosny 1995 [73] described a method/procedure for the estimation of wholewall R-values considering both "clear wall" and envelope interface details. Generated an R-value database by 3-D heat-conduction simulation of 18 systems.

4. Christian and Kosny 1999 [72] described an Internet-based calculation tool that computes whole-wall values of thermal resistance for 40 different wall systems.

5. CMHC 1998 [79] described the physics and mechanisms of heat transfer in buildings. Also discussed general insulation strategies.

6. Condon et al. 1980 [85] discussed steady-state measurement of wall thermal resistance with (a) heat flux sensors and (b) a guarded hot box. Also discussed the use of transient heat transfer analysis with the envelope thermal testing unit (a portable guarded hot box) to determine a wall's complex conductance (a.k.a. admittance).

7. Creech and Tiller 1993 [92] described the "cookie cutter" technique to remove and weigh attic insulation samples to check insulation density and R-value.

8. Crowell 1992 [93] discussed visual signs of poor insulation installation quality.

9. Cvetkovic 1982 [99] successfully tested a compensated heat-flux meter (i.e., one with a heating element used to compensate for the flux reduction induced by the presence of the meter).

10. Fang et al. 1985 [141] measured the thermal resistance of the exterior envelopes of six test houses using (a) a portable calorimeter and (b) a heat-flux transducer. Laboratory tests showed that calorimeter and transducer results were within $9 \%$ of those yielded by a guarded hot box.

11. Fang and Grot 1985 [142] measured the thermal resistance of office-building envelopes using (a) heat-flux transducers (four-inch-diameter wafertype sensors with embedded thermopiles) and (b) a portable calorimeter.

12. Flanders 1992 [154] discussed the effect of changing the data time period for the two proposed tests for ASTM C1155-90 to measure $\mathrm{R}$-values of building envelope components.

13. Flanders et al. 1995 [155] discussed test protocols and results of two in-situ long-term tests (multiple-day long, with values calculated based on incremental 24 hour blocks of data) to determine R-values of building envelope components. Tests are two proposed for ASTM C1155-90: summation technique and sum of least squares. Found that the R-value agreement between the two techniques varied by material, but was within $3 \%$ for metal panels, $13 \%$ for metal panel/block walls, and $1 \%$ for masonry walls and attic insulation.

14. Grot et al. 1985 [194] discussed four tools (noncontact spot radiometer, contact heat flow transducer, portable calorimeter, and envelope thermal testing unit [guarded hot plate]) that can be used to measure the thermal resistance of building components.

15. Harrje et al. 1985 [205] described the use of fan pressurization and infrared thermography to detect convective loops in buildings.

16. Isaacs and Trethowen 1985 [218] measured the thermal resistances of roofs, walls, and floors with thermocouples and heat-flux sensors.

17. Janssen and Rasmussen 1985 [219] used computer simulations of the thermal performance of a house to analyze the errors associated with a transient procedure used to measure overall "building thermal resistance" (BTR). Also programmed the algorithm into a microprocessor-based meter and measured the BTR of three homes.

18. Lugano 1998 [257] discussed key air sealing and insulation locations by house type (colonial, contemporary, ranch, and finished half-attics).

19. Modera et al. 1984 [285] outlined two techniques for thermal testing of walls: one active and one passive. The active method uses heat generation to produce the necessary delta $\mathrm{T}$ across the wall, whereas the passive method uses weather conditions.

20. Modera et al. 1986 [283] found through computer simulations that the dynamically measured thermal conductance of a wall was mostly likely to be inaccurate in the cases of (a) well-insulated walls; (b) large indoor and outdoor temperature fluctuations; (c) small average indoor-outdoor temperature differences; and (d) thermally massive walls.

21. Persily et al. 1988 [323] described the use of calorimeters and heat flux transducers to measure envelope thermal resistance. 
22. Roeder 1992 [352] discussed the American Society for Non-Destructive Testing's (ASNT) guidelines for the voluntary qualification and certification of thermographers.

23. Roulet et al. 1985 [356] described both steadystate and dynamic methods for computing the thermal conductance and time constants of building assemblies. Presented a criterion for determining how close a dynamically computed thermal conductance is to its true value. Tested both steady-state and dynamic methods on various building elements (windows, light sandwich panels, and heavy elements).

24. Sandberg and Jahnsson 1995 [361] presented a simplified method (periodic electricity meter readings + indoor-outdoor air temperature measurements) for measuring the thermal loss factor (area-integrated conductance) of the envelope of an electrically-heated detached house with low thermal mass.

25. Saunders et al. 1994 [363] described the measured performance rating (MPR) method, an overnight coheating procedure that predicts building load coefficient (BLC), thermal time constant for the building mass, heating system efficiency, and annual fuel consumption of single-family detached home.

26. Sherman et al. 1982 [400] described wall thermal performance and temperature results using the envelope thermal test unit (ETTU).

27. Sherman et al. 1983 [380] described the Envelope Thermal Test Unit, a device (surface heater + surface-temperature sensor + heat-flux meter) that characterizes a wall's dynamic thermal performance by controlling and measuring heat flux.

28. Sonderegger et al. 1981 [409] discussed the Envelope Thermal Test Unit (ETTU), a tool developed to dynamically measure component U-values in the field. Also described in Condon et al. 1980 [85], Sherman et al. 1982 [401], and Sherman et al. 1983 [382].

29. Wishner 1996 [463] discussed a program to determine whether sufficient attic insulation is installed, based on the "cookie cutter" method; included a graph showing apparent thermal conductivity related to bulk density of four insulation materials.

\section{INSULATION LEVEL AND LOCATION}

1. ASTM 1990 [34] described the ASTM 1060-90 standard practice for using thermography to qualitatively inspect insulation installations in frame buildings.

2. Christian and Kosny 1997 [74] described how to determine whole-wall $\mathrm{R}$-values using a guarded hot box and computer simulations.

3. Grot and Chang 1983 [195] discussed the use of thermography to detect defects in cavity-wall insulation.

4. Harrje 1981 [203] described a technique (blower-door depressurization + infrared thermography) for detecting envelope leakage sites and insulation defects.

5. Harrje et al. 1979 [204] described an IR thermography method for determining insulation irregularities.

6. NAHB 1997 [293] measured air-dried density of wall insulation samples that had been extracted with a "cookie cutter". Also inspected wall insulation for defects using the NAHB Research Center Certified Insulation Contractor checklist (detailed in an appendix), and recorded time to install wall insulations.

7. NAHB 1997 [294] provided quality checklists for installation of wall insulation, including fiberglass batts, spray cellulose, blow-in blankets, and foam-in-place. Included 7 to 13 possible defects for each type of insulation.

8. Persily et al. 1988 [323] described the use of thermography to qualitatively analyze the performance of building envelope insulation.

9. Proskiw 1995 [340] discussed the use of thermography to detect envelope anomalies.

10. Snell 1993[408] explained how to choose an infrared thermography system for buildingenergy audits.

11. Treado and Burch 1983 [430] evaluated the effectiveness of aerial infrared thermography in detection of roofing insulation defects, finding it to be useful in comparing adjacent houses (same external climate). Factors to take into account when conducting tests are included.

12. Zmeureanu et al. 1998 [469] used infrared thermography to detect envelope insulation voids in nine row houses. 
$\underline{\text { Norm }}$

\section{ASSEMBLy Thermal CONDUCTANCE}

1. ASHRAE 1993 [27] specified how envelope tradeoff factors can be used in the prescriptive compliance path of ASHRAE Standard 90.21993: added heating or cooling loads imposed by a given envelope component can be offset by load savings from other envelope components.

2. ASHRAE 1995 [28] specified, based on local degree-days, overall thermal performance requirements for replacement building envelope components.

3. CEC 1999 [66] presented the Title 24 California building code that specifies $R$ - and $U$-values for residential and non-residential roofs, walls, and floors.

4. Christian and Kosny 1999 [71] presented clearand whole-wall R-values calculated using a webbased calculator, and provided examples of the effect of installation quality on insulation performance.

5. Christian and Kosny 1997 [74] presented wholewall R-values for 18 wall configurations, determined using a guarded hotbox and computer simulation procedure.

6. Conover 1992 [88] discussed laboratory test results of convective heat loss through loose fill fiberglass insulation, in relationship to temperature differentials for attics.

7. Creech and Tiller 1993 [92] discussed results from a study of attic insulation R-values using the "cookie cutter" method; $95 \%$ of the houses had loose-fill fiberglass insulation, the rest had loose-fill rock wool or fiberglass batts; $25 \%$ had $\mathrm{R}$-values less than claimed and $50 \%$ had Rvalues greater than claimed.

8. Greenberg 1994 [178] reported floor insulation techniques and their effect on insulation quality, based on work by Oak Ridge National Laboratory.

9. Isaacs and Trethowen 1985 [218] reprinted roof \& wall R-value standards from NZS 4218P (New Zealand, 1977).

10. Katz 1997 [226] discussed visual inspections of insulation installation in 100 homes. With a minimum code requirement of R-30 attic insulation, $23 \%$ of the homes had attic insulation levels below R-30; floor R-values were compromised by poor-to-mediocre installation.
11. McBride 1992 [264] listed ASHRAE 90.2P's (ASHRAE 1993 [27]) prescriptive requirements for ceiling, wall, slab, floor, door, and fenestration thermal conductances in single- and multi-family houses.

12. Modera et al. 1984 [285] gave data for the Uvalues of various wall types.

13. National Association of State Energy Officials (NASEO) 1999 [295] gave HERS referencehome R- and U-values.

14. Penn 1993 [319] noted Minnesota's building code revision that includes a requirement that "all insulation materials must achieve their stated performance of $75 \cdot \mathrm{F}$ and no less than stated performance at winter design conditions".

15. Rainer 1995 [341] compared field findings to default framing factors and proposed ways to index and rate wall systems.

16. Schalch and Fryer 1992 [364] discussed the Energy Crafted Home's performance-based requirements for shell insulation levels.

17. Uniacke 1996 [444] discussed framing and insulation quality goals to obtain quality construction.

18. Werling et al. 1998 [460] gave Energy-Star required performance levels for envelope R- and $\mathrm{U}$-values.

\section{INSULATION LEVEL AND LOCATION}

1. BII 1998 [53] described the proper installation of building-envelope insulation, with attention to insulation type, installation depth, and location.

2. ConSol 1999 [89] specified criteria for a quality thermal envelope, and detailed procedures (with checklist) for proper installation of wall, ceiling, and floor insulation. Included procedures for proper caulking and sealing.

\section{ENERGy EfFicient Frame DESIGN}

1. ConSol 1999 [89] specified procedures for energy efficient building frame design, with attention to insulation and HVAC system issues.

\subsection{Windows and Skylights}

\section{$\underline{\text { Metric }}$}

1. Dubrous and Wilson 1992 [127] described energy rating (ER) numbers, a window thermal performance metric that indicates whether a 
window arrangement increases or decreases a building's thermal load.

\section{Diagnostic}

\section{Assembly Thermal Conductance}

1. Arasteh et al. [8] described an infrared thermography laboratory that measures window temperature and is used to validate computer models of window heat transfer (more detailed version of [9]).

2. Arasteh et al. [9] described an infrared thermography laboratory that measures window temperature and is used to validate computer models of window heat transfer (less detailed version of [8]).

3. Desjarlais et al. 1998 [108] used a large guarded hot-box to measure window heat transfer in accordance with ASTM Standard C 236-89.

4. Dubrous and Wilson 1992 [127] presented a procedure and data tables for calculating the Energy Rating (ER) of a building's windows based on building location, type, orientation, and ratio of window area to floor area.

5. Energy Design Update 1986 [136] discussed inaccuracies in prediction of window heat transfer (i.e., frame effects).

6. Finlayson et al. 1995 [150] described the WINDOW5 software package for analysis of fenestration heat transfer.

7. McCabe 1987 [265] described calorimeter measurement of window heat transfer.

8. Roulet et al. 1985 [356] described both steadystate and dynamic methods for computing the thermal conductance of building assemblies. Presented a criterion for determining how close a dynamically computed thermal conductance is to its true value. Tested both steady-state and dynamic methods on various building elements (windows, light sandwich panels, and heavy elements).

\section{RADIATIVE BEHAVIOR}

1. Finlayson et al. 1995 [150] described the WINDOW5 software package for analysis of fenestration heat transfer.

2. Griffith 1999 [181] discussed a hand-held detector that uses an infrared light-emitting diode and a phototransistor to indicate whether a window is clear, regular low-e, or spectrallyselective low-e.

3. Griffith et al. 1998 [182] found that either a portable spectrometer or an inexpensive IR diode and a phototransistor could be used to identify the emittance of low-e window coatings.

4. Tinker and Al-Buijan 1998 [425] used the MoWitt/Passys test cell approach to measure the on-site solar control performance of glazing systems, and compared these results to those predicted by the ESP-r simulation model.

\section{Norm}

\section{AsSEmbly Thermal Conductance}

1. ASHRAE 1993 [27] specified how envelope tradeoff factors can be used in the prescriptive compliance path of ASHRAE Standard 90.21993: added heating or cooling loads imposed by a given envelope component can be offset by load savings from other envelope components.

2. BII 1998 [53] briefly specified procedures for proper window installation, including labeling, certification, thermal conductance, orientation, and shading.

3. CEC 1999 [66] presented the Title 24 California building code specification for window U-values for residential and non-residential buildings (also refers to National Fenestration Council's NFRC100-91 (1991) and NRFC 100 (1997)).

4. McBride 1992 [264] listed ASHRAE 90.2P (ASHRAE 1993 [27]) prescriptive requirements for ceiling, wall, slab, floor, door, and fenestration thermal conductances in single- and multi-family houses.

5. Shapiro and James 1997 [367] presented air tightness measurements and heat loss calculations (WINDOW 4.1) for different types of existing windows.

\section{Radiative BeHAVIOR}

1. CEC 1999 [66] presented the Title 24 California building code table for default values of solar heat gain coefficient.

\section{WINDOW INSTALLATION}

1. BII 1998 [53] briefly specified procedures for proper window installation, including labeling, certification, thermal conductance, orientation, and shading. 
2. ConSol 1999 [89] specified criteria for a quality window, and procedures for proper window installation.

\subsection{Thermal Mass}

\section{Metric}

1. Condon et al. 1980 [85] described a wall's dynamic thermal performance in terms of its admittance, which depends on its thermal conductance and thermal mass.

2. Roulet et al. 1985 [356] described both steadystate and dynamic methods for computing the thermal conductance and time constants of building assemblies. Presented a criterion for determining how close a dynamically computed thermal conductance is to its true value. Tested both steady-state and dynamic methods on various building elements (windows, light sandwich panels, and heavy elements).

3. Saunders et al. 1994 [363] described the measured performance rating (MPR) method, an overnight co-heating procedure that predicts building load coefficient (BLC), thermal time constant for the building mass, heating system efficiency, and annual fuel consumption of a single-family detached home.

4. Sherman et al. 1983 [380] described a wall's dynamic thermal performance by a small number of "Simplified Thermal Parameters," including a steady-state conductance, a time constant, and some storage terms.

5. Sonderegger et al. 1981 [409] defined a time constant based on thickness and thermal diffusivity that describes the dynamic thermal performance of a wall.

6. Subbarao et al. 1985 [419] used Fourier analysis to describe the thermal capacity of a building in terms of its thermal admittance, which relates the sinusoidal temperature response to the sinusoidal addition of heat to interior air.

\section{Diagnostic}

1. Christian and Kosny 1995 [73] outlined a procedure for measuring the energy-savings benefits yielded by wall systems with significant thermal mass.

2. Subbarao et al. 1985 [419] measured the thermal capacitance of a room-sized test cell, and discussed why a sinusoidal driving function is superior to a step function in the measurement of building capacitance.

\section{Norm}

1. CEC 1999 [66] presented the California Title 24 code that specifies minimum interior thermal mass for some residential prescriptive compliance packages (component-based list of energy-efficient features).

\subsection{Airtightness}

\section{$\underline{\text { Metric }}$}

\section{ENVELOPE AND INTERZONE LEAKAGE}

1. ASTM 1992 [35] defined leakage terms, including air changes per hour $(\mathrm{ACH})$ and effective leakage area (ELA) using fan pressurization.

2. ASTM 1995 [39] described the standard specification and performance of an air retarder for low-rise framed building walls, gaged by the rate of air leakage through the envelope $\left(\mathrm{cfm} / \mathrm{ft}^{2}\right)$ at a pressure difference of 0.3 in. w.g.

3. ASTM 1997 [41] defined leakage terms, including air changes per hour (ACH) and effective leakage area (ELA) using an orifice blower door.

4. Bahnfleth et al. 1999 [43] listed four metrics for envelope leakage (flow coefficients, $\mathrm{Q}_{50}, \mathrm{ELA}_{4}$, and $\mathrm{ACH}$ at some reference pressure), and defined whole-building pressure differential for tall buildings.

5. CMHC 1998 [79] described the physics and mechanisms of airflow in buildings. Also discussed how to do air sealing.

6. CMHC 1998 [80] discussed a test procedure to measure the air leakage rate and structural performance of air barrier systems in wood frame walls.

7. Cummings 1998 [94] compared leakage flow metrics evaluated at a single pressure difference (single-point $\mathrm{Q}_{\mathrm{env}}$ ) to those evaluated at several pressure differences (multi-point $Q_{\text {env }}$ ).

8. Cummings and Withers 1997 [96] defined $\mathrm{CFM}_{50}, \mathrm{ACH}_{50}$, and uncontrolled airflow (UAF).

9. Cummings and Withers 1998 [95] defined $\mathrm{ACH}_{50}, \mathrm{CFM}_{25}, \mathrm{CFM}_{25, \text { out }}, \mathrm{CFM}_{25, \text { tot }}$, and $\mathrm{CFM}_{50}$. 
10. Forest et al. 1991 [165] discussed metrics for evaluating moisture and airflow (moisture content, moisture release rates, infiltration rates, relative humidity, ambient conditions, thermal resistance). Also measured airflow resistance of porous insulation.

11. Grimsrud et al. 1979 [189] compared tracer-gas based infiltration measurements and predicted infiltration based on air leakage measurements using fan pressurization and on surface-pressuredifference measurements. Grimsrud et al. 1979 [191] presented a subset of these results.

12. Grimsrud et al. 1981 [188] defined the effective leakage area of a building envelope.

13. Grimsrud et al. 1981 [192] defined ELA4. Described fan pressurization techniques and the use of specific leakage areas, nomographs, and component leakage guides to be used by practitioners in determining building leakage and infiltration rates.

14. Harrje et al. 1990 [206] described metrics related to three tracer gas measurements (constant tracer gas method, multiple tracer measurement system [MTMS], and perfluorocarbon tracer measurement method [PFT]).

15. Jump and Modera 1993 [222] measured envelope leakage as part of a research project on zoned distribution systems.

16. Keefe 1994 [228] compared ACH vs. CFM as envelope leakage metrics (the latter can be measured without knowing the building volume), and noted that $\mathrm{CFM}_{50}$ measurements are made at a pressure low enough to be easily achievable and high enough to resist wind-induced errors. Mentioned $\$ / \mathrm{CFM}_{50}$ as an estimate of the cost or benefit of a leakage change.

17. Koles et al. 1996 [241] discussed airtightness as defined by normalized leakage area (ASHRAE Standard 119-1989).

18. Lambert and Robison [244] used four envelope leakage metrics: (1) specific leakage area at $4 \mathrm{~Pa}$ $\left(\mathrm{SLA}_{4}\right) ;(2)$ estimated seasonal infiltration at $4 \mathrm{~Pa}$ (infiltration $\mathrm{ACH}$ ); (3) $\mathrm{ACH}_{50}$; and (4) perfluorocarbon passive tracer gas infiltration rate ("PFT").

19. Lstiburek 1998 [256] presented an electrical circuit analog for envelope leakage.

20. Modera 1993 [279] discussed the merits of $\mathrm{CFM}_{25}$ vs. $\mathrm{CFM}_{50}$, noting that duct pressure is closer to $25 \mathrm{~Pa}$ when the system fan is running.
21. National Association of State Energy Officials (NASEO) 1999 [295] defined annual average $\mathrm{ACH}$, which is the normalized building leakage multiplied by $\mathrm{W}$, a local weather factor defined in ASHRAE Standard 136 (ASHRAE 1993 [26]).

22. Robison and Lambert 1989 [351] discussed measurement metrics, including duct pressures, duct leakage, airflows, whole-house air infiltration, and fan pressurization results.

23. Sherman 1986 [373] defined effective leakage area (ELA), infiltration rate, leakage class, infiltration degree-days, and air changes per hour $(\mathrm{ACH})$.

24. Sherman 1986 [374] defined a leakage area normalized by the floor area and height of a house. Normalized leakage area usually falls between 0.2 and 1.0, but large potential errors caused the authors to group leakage into classes. Classification ranges from $A$ to $J$.

25. Sherman and Grimsrud 1980 [390] measured envelope leakage using fan pressurization and weather data.

26. Sherman et al. 1986 [382] defined infiltration degree days, a weather-based value used to calculate envelope infiltration rates in the same fashion that degree days are used to calculate building heat transfer rates.

27. Sherman and Matson 1997 [402] defined specific infiltration rate, stack and wind factors, hourly infiltration rate, and effective leakage area.

28. Walker et al. 1998 [448] defined a singlepressure-differential envelope leakage metric $\left(\mathrm{Q}_{25}\right)$.

\section{AIR BARRIER TYPE AND LOCATION}

1. Cummings and Withers 1998 [95] discussed eight configurations of thermal and air boundaries in commercial buildings.

2. Finley 1997 [422] evaluated interzonal airtightness to determine its effect on indoor air problems (mold and moisture) and their mitigation strategies.

\section{Diagnostic}

\section{ENVELOPE LEAKAGE}

1. Anderson 1995 [3] presented a history of the blower door and case studies of current users. 
2. Anderson 1995 [4] in a letter to the editor, discussed how to diagnose and seal air leakage paths between conditioned space and the attic, using a blower door or pressure gages.

3. ASHRAE 1988 [26] specified a calculation methodology to determine annual effective ventilation rates, based on the weather factor (W), normalized leakage area (NL), and hourly ventilation fan airflows and schedules.

4. ASTM 1988 [33] presented a standard test method for airflow calibration of fan pressurization devices used for measuring air leakage rates through building envelopes.

5. ASTM 1992 [35] described multi-point fanpressurization measurement of envelope leakage.

6. ASTM 1995 [38] described the five ASTM E1186-87 (1992) methods to detect air leakage sites in building envelopes: building [de]pressurization + infrared scanning; building [de]pressurization + smoke tracers; building [de]pressurization + airflow measurement devices; sound; and tracer gas.

7. ASTM 1995 [39] described a test procedure for measuring the performance of air retarder materials and systems for low-rise framed building walls.

8. ASTM 1995 [40] described the ASTM Standard E741-95 tracer-gas measurement method for single-zone air change rates.

9. ASTM 1997 [41] described the ASTM E1827-96 multi-point fan-pressurization envelope leakage measurement using a blower door, and included an uncertainty analysis.

10. Bahnfleth et al. 1999 [43] applied fanpressurization and tracer gas methods to measure the envelope leakage of a tall building.

11. Berk et al. 1981 [51] discussed fanpressurization measurement of envelope airtightness.

12. BII 1998 [53] used blower door depressurization to measure $\mathrm{ACH}_{50}$.

13. Blasnik and Fitzgerald 1992 [55] proposed three blower-door methods to quantify zone leakage and better understand series leakage paths (interstitial leakage). Test 1: "add a hole" calculates leakage between living space and attic by using a "calibrated hole". Test 2: "opening a door" - measures leakage between living space and basement, garage, attics with doors or pulldown stairs. Test 3: "single point attic test for roof venting" - calculates "bypass leakage" from house to attic based on zone pressure differences and attic vent sizes.

14. Christian and Kosny 1995 [73] proposed using a combination of ASTM Standards (C236, C976, E1424, E283) to measure air leakage and heat loss through wall assemblies under simulated wind conditions ranging from 0 to $15 \mathrm{mph}$, and building pressure differentials ranging from 0 to 25 to $50 \mathrm{~Pa}$.

15. CMHC 1998 [80] discussed a test procedure to measure air leakage and structural performance of air barrier systems in wood-frame walls.

16. CMHC 1998 [79] described the physics and mechanisms of airflow in buildings. Also discussed how to do air sealing.

17. Cummings 1998 [94] recommended performing the blower-door test in depressurization mode because building pressurization overestimates leakiness by pushing open dampers, skylights, windows, and ceiling tiles. Also, in a study of 150 Central Florida homes, used tracer gas and blower door measurements to find that infiltration increased four-fold when the central air handler unit was on; infiltration rates went from 1.13 ach to 0.54 ach after duct sealing.

18. Cummings and Withers 1997 [96] gave an example of using building fans to measure $\mathrm{CFM}_{50}$, and included a chart used to determine $\mathrm{CFM}_{50}$ from CFM measured at some other pressure.

19. Downey and Proctor 1994 [125] briefly described blower-door measurement of $\mathrm{CFM}_{50}$.

20. EPA 1997 [138] listed four tests used to ensure that subcontractors are performing quality work: a blower-door test to detect excessive envelope leakage, a duct leakage test, an HVAC system inspection, and testing airflow across the inside coil to ensure proper airflow to the duct system.

21. Forest et al. 1991 [165] compared three techniques for tracer gas measurement.

22. Forest et al. 1991 [165]measured indoor infiltration, attic ventilation, and indoor-attic exchange rates with a dual tracer gas technique. Measured airflow through wall panels with a small orifice plate flowmeter. Measured flow air resistances of porous insulation panels.

23. Gadsby and Harrje 1985 [172] discussed calibration errors in measuring fan flow from fan pressure when measuring envelope leakage by fan pressurization. 
24. Gammage et al. 1986 [173] discussed tracer gas airflow measurements used to determine the effect of central fan operation and duct leakage on infiltration air change rates.

25. Grimsrud et al. 1981 [188] briefly described the Lawrence Berkeley Lab infiltration model relating total envelope infiltration to stack-, wind-, and mechanical-system-induced infiltration. In addition, related fanpressurization measurements of envelope leakage to actual heating-season infiltration rates, and briefly described the ASTM 779-81(5) fan pressurization technique.

26. Grimsrud et al. 1981 [192] described the LBL infiltration model predicting envelope infiltration from effective leakage area and local weather conditions. Included formulas and parameter tables for standard terrain classes. Described use of infiltration in an instrumented audit.

Described fan pressurization techniques and the use of specific leakage areas, nomographs, and component leakage guides by practitioners in determining building leakage and infiltration rates.

27. Grimsrud et al. 1999 [184] reported blower-door measurements of $\mathrm{ACH}_{50}$ rates in 111 homes.

28. Harrje 1981 [203] described a technique (blower-door depressurization + infrared thermography) for detecting envelope leakage sites and insulation defects.

29. Harrje et al. 1979 [204] used blower-door pressurization and infrared thermography to locate envelope leakage sites. These "bypass routes" by which warm air leaves the building include the furnace shaft, party-wall gap, partywall convection, attic, basement, and thermal bridges.

30. Infiltec 1999 [217] presented specifications for the Infiltec blower-door.

31. Jump et al. 1996 [223] used a slight variant on ASTM Standard 779 to measure envelope leakage by fan pressurization.

32. Keefe 1994 [228] presented a how-to guide to blower-door measurement of envelope leakage by fan pressurization.

33. Knight et al. 1995 [239] discussed the development and testing of a hand-held device to detect air leakage sites on building surfaces. Soap is applied to a building surface and the PACT unit is used to apply a vacuum to the surface. Air leakage sites are identified by the appearance of soap bubbles, created by the vacuum. The unit is calibrated, relating pressure differences to leakage area. The PACT unit is able to detect smaller and more leaks than the use of smoke, however has trouble with larger leakage sites, most of which are better detected visually.

34. Modera et al. 1987 [276] described the "pulse pressurization" technique for acoustic measurement of a building envelope's effective leakage area. This is the reference paper on the subject.

35. NAHB 1997 [293] measured $\mathrm{CFM}_{50}$ and $\mathrm{ACH}_{50}$ with the ASTM E-779 house depressurization test. Also measured corrected envelope leakage rate $\mathrm{ACH}_{50}{ }^{*}$, which is the envelope leakage minus the house-volume-normalized duct leakage.

36. Persily 1982 [321] measured the accuracy and repeatability of fan pressurization (blower-door) measurements of envelope airtightness by testing a home 80 times in one year. Discussed sources of error (fan calibrations, wind) and a temperature correction for blower door measurements.

37. Persily et al. 1988 [323] described tracer gas and fan pressurization measurements of air change rates.

38. Proctor 1997 [338] used a blower door test and Sherman's infiltration model (Sherman 1987 [384]) to estimate natural infiltration rate.

39. Reardon et al. 1987 [343] measured the envelope leakage of a home connected to another home by using a second, "balancing" fan to equalize the interior pressures in the two homes.

40. Retrotec 1998 [347] presented Retrotec's line of blower-door products and discussed their features.

41. Robison and Lambert 1989 [351] discussed fan pressurization, tracer gas, and flow hood measurement techniques to determine the relationships between duct leakage, envelope leakage, infiltration rates, and ventilation rates.

42. Saunders et al. 1994 [363] used manualsampling and automated-sampling $\mathrm{SF}_{6}$ tracer gas techniques to measure house infiltration rate (ACH), noting that the cost of automated sampling equipment is minor relative to labor costs. Also measured envelope ELA with a blower-door pressurization test. 
43. Shapiro and James 1997 [367] described a simple measurement device to measure air leakage around windows.

44. Sherman et al. 1980 [378] surveyed tracer-gas techniques for measuring air infiltration. Also discussed non-tracer-gas methods (e.g., the LBL infiltration model, which estimates hourly infiltration flow rates based on measured leakage area, building characteristics and local weather data).

45. Sherman and Grimsrud 1980 [390] combined fan pressurization measurements with simple weather data to determine envelope air infiltration.

46. Sherman and Modera 1986 [375] used the "AC pressurization" technique to measure leakage area by using fluctuating building pressure instead of a static building pressurization. Preliminary results agreed fairly well with conventional pressurization testing.

47. Sherman and Modera 1988 [376] presented theory related to the "AC pressurization" acoustic technique for measurement of envelope leakage.

48. Sherman et al. 1989 [397] presented a method (based on $\mathrm{AC}$ pressurization) for measuring envelope leakage at low pressures (below $10 \mathrm{~Pa}$ ) where traditional blower door tests become inaccurate.

49. Sherman and Palmiter 1994 [394] evaluated various standards and protocols for measuring ELA from a general perspective, looking at uncertainty (accuracy, measurement error, measurement uncertainty, precision, bias). Also proposed improved measurement procedures, including instrumentation specifications and analysis methods that lower uncertainties from the teens to $3-4 \%$.

50. Siegel and Davis 1998 [403] used a depressurization blower-door test to measure $\mathrm{CFM}_{50}$, and the LBL infiltration model to estimate natural infiltration, in eight manufactured (HUD-code) homes before and after retrofits.

51. Ternes 1987 [420] described data parameters to collect in single-family retrofit research projects and described data analysis approaches and issues. Data parameters include (a) basic data (house characteristics, leakage measurements, metered performance of HVAC systems, and verification of retrofit installation quality); (b) time-sequential data (submetered space- conditioning energy consumption, weather station measurements [dry bulb, horizontal solar radiation, humidity, wind speed and direction], indoor temperature and humidity, total fuel consumptions [billing meter data], wood heating usage, and submetered water heating energy consumption); (c) optional occupant-behavior data (additional indoor temperature and humidity, hourly heating and cooling thermostat setpoints); (d) geographic characteristics (terrain and shielding); and (e) distribution system data (duct leakage area measured using fan pressurization).

52. The Energy Conservatory 1998 [421] explained how to use their Automated Performance Testing (APT) system in conjunction with a blower door to automate blower-door leakage measurements.

53. The Energy Conservatory 1999 [422] answered FAQs related to using Energy-Conservatory's duct blaster, blower door, and Automated Performance Testing System (APT) to measure envelope leakage and duct leakage.

54. Tooley and Davis 1994 [428] discussed test methodology and problem diagnosis for attic ventilators, depressurization, moisture damage, and air barriers.

55. Torry 1994 [429] used a cruise-control blower door to measure envelope leakage by fan pressurization.

56. Tsongas and Nelson 1991 [439] located exterior wall air leaks via infrared thermography, and found wall moisture damage at the leakage sites.

57. Uniacke 1996 [444] discussed air sealing and testing strategies and priorities.

58. Walker et al. 1998 [448] specified single and multi pressure differential fan pressurization techniques for measuring envelope leakage.

59. Yuill and Yuill 1998 [466] used a blower-door test to measure the airtightness of several materials used to seal the outer surface of house walls.

60. Zmeureanu et al. 1998 [469] used infrared thermography and blower-door pressurization to locate leaks and measure the leakage area of nine row houses.

\section{AIR BARRIER TYPE AND LOCATION}

1. Bohac et al. 1996 [310] described a short-term monitoring protocol to determine the effectiveness of building envelope and/or mechanical system improvements. The protocol 
works better on a sample of houses than on an individual house.

2. CMHC 1998 [79] described air and vapor barriers, including air and moisture transport and related problems, including air and moisture transport physics and mechanisms, construction requirements, and evaluation checklists.

3. Cummings 1998 [94] described how to identify a building's primary air boundary with a blowerdoor building-pressurization test.

4. Fitzgerald et al. 1994 [153] presented detailed instructions for locating a building's air boundary by using a blower door to pressurize a building, and then measuring the building's airpressure distribution.

5. Lugano 1998 [257] discussed key air sealing and insulation locations by house type (colonial, contemporary, ranch, and finished half-attics).

6. Makepeace 1999 [261] described a technique to install the air barrier and insulation on the outside of the frame construction to minimize air leakage and moisture problems.

7. Obst and Hendricks 1991 [305] discussed air barriers and vapor retarders, providing construction details and specifications.

8. Tooley 1999 [426] discussed specifying and installing air barriers in houses. Provided installation details and responsibilities for each project team leader; discussed basics of air, moisture and heat movement. ([427] is Part 1 of this two-part article).

9. Tooley 1999 [427] explained thermal and air barrier basics, and provided examples using the $3 \mathrm{C}$ (continuous, contiguous and complete) method. ([426] is Part 2 of this two-part article).

\section{Norm}

\section{ENVELOPE AND INTERZONE LEAKAGE}

1. ASHRAE 1988 [15] described requirements for residential building airtightness performance to reduce air infiltration thermal loads (does not apply to buildings that are conditioned for human comfort less than 876 hours of the year). It also provided a method of classifying the airtightness of residential buildings.

2. ASHRAE 1993 [27] specified that the envelope leakage-related prescriptive requirements of ASHRAE Standard 90.2-1993 consist of measured air leakage (in compliance with
ASHRAE Standard 119-1981) or component leakage requirements (windows, doors, foundations, caulking and sealant, infiltration retardants).

3. ASTM 1995 [39] specified the minimum performance factor for air retarders for low-rise framed building walls, including air leakage, structural integrity, water resistance, and water vapor.

4. Berk et al. 1981 [51] presented envelope airtightness results for nine houses before and after retrofitting.

5. CEC 1999 [66] presented the California building code Title 24 standards for air leakage around exterior doors and windows.

6. CMHC 1998 [79] described the physics and mechanisms of airflow in buildings. Also discussed how to do air sealing.

7. CMHC 1998 [80] discussed proposed airtightness levels $\left(\mathrm{L} \mathrm{s}^{-1} \mathrm{~m}^{-2} @ 75 \mathrm{~Pa}\right)$ for three construction classifications.

8. Cummings 1998 [94] recommended and justified $\mathrm{ACH}_{50}$ values for commercial buildings. He also specified building areas that should operate at positive pressure with respect to outdoors to avoid infiltration by humid outside air.

9. Cummings et al. 1990 [98], in a study of $\mathbf{1 5 0}$ Central Florida homes, used tracer gas and blower door measurements to find that infiltration increased four-fold when the central air handler unit was on; infiltration rates went from 1.13 ach to 0.54 ach after duct sealing.

10. Cummings and Withers 1997 [96] recommended $\mathrm{ACH}_{50}$ values for commercial buildings.

11. DOE 1995 [116] discussed background information on HERS infiltration-related policy options, and included DOE's 1995 request for comments on the HERS normalized leakage and infiltration levels for the reference and rated homes. At the time of this document, DOE proposed using $0.35 \mathrm{ACH}$ as the minimum allowable air change rate on which energy savings may be calculated for the rated home. DOE proposed using ASHRAE Standards (119 for normalized leakage, 136 for effective ventilation) for the reference house, with a minimum of $0.35 \mathrm{ACH}$.

12. EPA 1998 [139] noted a commercial-building infiltration rate recommended by the National Association of Architectural Metal Manufacturers (not to exceed $0.06 \mathrm{cfm}$ per $\mathrm{ft}^{3}$. of 
exterior wall at a pressure difference of 0.3 in. w.g.). Referenced to the ASHRAE Fundamentals Handbook, 1997, p. 25.19.

13. Grimsrud et al. 1981 [188] reported the median value of heating-season-averaged infiltration rates measured in 300 houses in the U.S. and Canada, and tabulated heating-season specific infiltration in 59 U.S. cities.

14. Katz 1997 [226] discussed Advanced Energy's targets for air tightness (envelope leakage less than $0.30 \mathrm{CFM}_{50} / \mathrm{ft}^{2}$ of surface area) and presented results of air-tightness tests in 100 new homes.

15. Keefe 1994 [228] classified houses as tight or leaky based on values of $\mathrm{CFM}_{50}$ and $\mathrm{ACH}_{50}$.

16. Kiel et al. 1986 [232] analyzed a large envelopeleakage data set and found correlations between housing construction type and flow exponent.

17. Matson and Feustel 1998 [263] presented leakage characteristics (air change rate at $50 \mathrm{~Pa}$ and normalized leakage values) for post- 1980 construction homes ( 97 in New York and 66 in California) based on blower door tests.

18. Modera 1986 [277] described a database of 1,100 fan-pressurization test results ( 752 houses: 452 U.S. and 300 Canadian). Presented data included: leakage (averages of depressurization and pressurization test results such as leakage area, flow exponent, specific leakage area; the average flow at $100 \mathrm{~Pa}$ ), leakage characteristics (descriptions of the depressurization and pressurization leakage measurements and analysis: flow exponents, flow coefficients, regression correlation coefficients, leakage areas, and air changes at $50 \mathrm{~Pa}$ ), house characteristics (number of stories, floor type, roof type, wall type, building type [detached, duplex, townhouse], HVAC and fireplace descriptions, building height, shielding and terrain classes), and location (zip code).

19. Modera 1994 [280] presented envelope-leakage measurements performed in 31 California homes.

20. Murphy et al. 1991 [291] conducted studies to determine the repeatability of fan-pressurization measurements.

21. National Association of State Energy Officials (NASEO) 1999 [295] specified HERS-reference envelope leakage values for homes.

22. Parker 1989 [313] discussed blower-door and tracer-gas air-change-rate measurements of 1980-construction. Discussed conventional and Model Conservation Standards (MCS) for the construction of homes in the Pacific Northwest. Estimated mean seasonal air change rates were 0.55 ach for the conventional and 0.28 ach for the MCS homes. Using the tracer gas technique, average air change rates (December through March) were 0.31 ach (not corrected for nonuniform mixing) for the conventional homes and 0.35 (including heat recovery ventilation airflow) for the MCS homes.

23. Robison and Lambert 1989 [351] discussed the effect of duct leakage on house leakage, with duct leakage adding $10 \%$ to house leakiness in 20 Residential Standards Demonstration Program (RSDP) homes.

24. Schalch and Fryer 1992 [364] discussed the Energy Crafted Home's infiltration specifications (maximum of $1.0 \mathrm{in}^{2}$ of opening per $100 \mathrm{ft}^{2}$ of shell at $4 \mathrm{~Pa}$ of pressure difference).

25. Sherman 1986 [373] tabulated infiltration degree-days and acceptable envelope leakage classes in various U.S. cities. Also presented U.S. maps of infiltration degree-day zones, standard infiltration rates, and standard infiltration load.

26. Sherman et al. 1984 [395] surveyed leakage data from 500 houses. Flow coefficients and exponents were found to correlate with type of vapor barrier and wall construction. They did not correlate with age, but did correlate with climate; houses in cold climates were tighter.

27. Uniacke 1996 [444] discussed air sealing and airtightness goals to obtain quality construction.

28. Werling et al. 1998 [460] presented Energy-Star required performance levels for the air change rate of homes.

\section{AIr Barrier TYPE AND LOCATION}

1. ASHRAE 1995 [28] specified exterior joint sealing and optimizing ventilation openings.

2. Cummings 1998 [94] recommended locations for air and thermal barriers in commercial buildings. 


\subsection{Moisture Damage Susceptibility}

\section{Metric}

1. ASTM 1995 [39] specified water resistance testing procedures of air retarder (AR) materials or systems for low-rise framed building walls.

2. CMHC 1998 [79] described air and vapor barriers, including air and moisture transport physics and mechanisms, construction requirements, and evaluation checklists.

3. Forest and Walker 1991 [161] discussed measurement and model input variables to determine airflow and moisture content in attics. Forest and Walker 1992 [162], 1993 [163], 1993 [164], and Walker and Forest 1995 [452] also discussed this research.

4. Forest et al. 1991 [165] measured wood's moisture content by weight.

5. NAHB 1997 [293] measured the installed moisture content (moisture by dry weight) of spray-insulated systems

\section{Diagnostic}

1. CMHC 1996 [78] discussed non-destructive test methods and equipment to assess the strength, serviceability, and deterioration of buildings.

2. CMHC 1998 [79] described air and vapor barriers, including air and moisture transport physics and mechanisms, construction requirements, and evaluation checklists. Also described the physics and mechanisms of moisture transport and related problems, including a checklist of possible moisture problems (water vapor, capillary water, and bulk water-related). Provided figures showing how to diagnose moisture problems in exterior finishes and materials. Discussed window moisture problems, including a checklist of typical problems and solutions.

3. Dubose and Odon 1994 [126] discussed sources of moisture-related building damage (e.g., infiltration of moist outside air into depressurized building spaces); building commissioning techniques to identify the source of moisture damage (e.g., zone depressurization); and ways to prevent moisture damage (e.g., rebalancing flows to positively pressurize interior spaces).
4. Finley 1997 [422] described diagnostic methods, and provided lists of possible moisture and mold sources and mitigation strategies.

5. Foarde et al. 1996 [159] discussed the use of a moisture conductivity meter to determine the moisture content of materials in relationship to fungal growth; found that any non-zero reading generally was related to some level of fungal growth. The moisture conductivity meter can be used to select sampling sites during microbial investigations.

6. Forest and Walker 1991 [161] discussed measuring and modeling airflow and moisture content in attics. Forest and Walker 1992 [162], 1993 [163], 1993 [164], and Walker and Forest 1995 [452] also discussed this research.

7. Forest et al. 1991 [165] used moisture pins to measure the moisture content of wood-based building components.

8. Knehans and Styer 1983 [238] broadly described the process of detecting wet roofing insulation by IR thermography.

9. Larson and Huelman 1992 [246] discussed a case study where dark streaks appeared on the outside of siding material, caused by the improper installation of a vapor barrier and interior moisture problems. Provided a detailed list of the problems and the solutions proposed to the homeowner.

10. Lichtman et al. [252] described concrete slab moisture measurement techniques. Qualitative tests included the "mat test" (laying a piece of impermeable material on an exposed section of slab and, after a period of time, inspecting the concrete surface below for signs of wetness), and the "bond test" (fixing or bonding a sample piece of flooring material to the slab and observing any adverse reactions to the flooring due to moisture). Quantitative tests included electrical conductivity measurements, coring, and the Vapor Emission Test (VET) (a small, airtight container covering a sample of absorbent material is taped down on a small section of bare slab, after a period of time [60-72 hours], the weight of water absorbed by the material is determined). The VET method allows the determination of the quantity and rate of moisture transmission through the slab, and is included in ASTM Standard E1907-97: Standard Practices for Determining Moisture-Related Acceptability of Concrete Floors to Receive Moisture-Sensitive Finishes. 
11. Lstiburek and Carmody 1995 [255] provided moisture fundamentals, including definitions, explanation about conditions that are conducive to mold and moisture. Discussed diagnostic tests and tools, and discussed how to identify and control moisture problems.

12. NAHB 1997 [293] measured moisture content of wall insulation samples that had been extracted with a "cookie cutter".

13. National Research Council Canada 1996 [297] discussed applications of non-destructive test methods for assessing moisture and associated problems. Discussions include the advantages and limitations of methods, as well as the equipment required for the tests.

14. Tooley and Davis 1994 [428] presented test methodology and problem diagnosis for attic ventilators, depressurization, moisture damage, and air barriers.

15. Tsongas and Nelson 1991 [439] located exterior wall air leaks via infrared thermography, and found moisture damage at the leakage sites. They measured the moisture content of wooden wall sheathing with an electrical-resistance meter probe.

16. Walker 1993 [450] discussed an attic simulation model (airflow and moisture) and measured data to evaluate attic ventilation and moisture problems.

17. Walker et al. 1995 [454] presented the AVENT attic ventilation model and compared modeled results to measured data.

18. Warner 1991 [456] discussed how to avoid window condensation by increasing window $\mathrm{R}$ values, sealing cracks and joints around windows, or by increasing house ventilation rates.

\section{$\underline{\text { Norm }}$}

1. ASHRAE 1993 [27] specified that to meet the prescriptive requirements of ASHRAE Standard 90.2-1993, water vapor retarders and moisture barriers should be in accordance with chapters 20 and 21 of the 1989 ASHRAE Handbook of Fundamentals.

2. ASTM 2000 [36] discussed the prevention of moisture damage through proper design and construction of foundation systems, control of crawlspace moisture, prevention of rain penetration at exterior surfaces, condensation within wall construction, control of water leakage at the roof, and control of plumbing leaks.

3. Cheple and Heulman 1998 [70] discussed ways to decrease moisture problems in bathrooms, including "build tight, ventilation right"; included wall construction details.

4. Fisette 1996 [152] discussed how to prevent ice dams by air sealing, insulating, and providing attic ventilation; included construction details and specifications.

5. Foarde et al. 1996 [159] presented microbial and moisture conductance results from moisture investigations in homes and schools. Materials with higher moisture conductance values tended to have predominantly Aspergillus while materials with lower moisture conductance values tended to have predominantly Cladosporium. Corresponding room RH levels were in the $40-70 \%$ range.

6. Kirkland 1993 [236] discussed using spray foam insulation on floor trusses to prevent airborne moisture from coming in contact with building materials.

7. Lichtman et al. [252] described physical signs and conditions relating to moisture intrusion in concrete slabs. Discussed factors to consider and design specifications to put in place to minimize moisture intrusion.

8. Lstiburek 1999 [254] discussed un-vented attics in cold climates, including construction details.

9. Makepeace 1999 [261] described a technique to install the air barrier and insulation on the outside of the frame construction to minimize air leakage and moisture problems.

10. Obst and Hendricks 1991 [305] discussed air barriers and vapor retarders, providing construction details and specifications.

11. Schalch and Fryer 1992 [364] discussed the Energy Crafted Home's moisture control specifications, including vapor retarders and moisture retarders under floors and slabs.

12. Tsongas 1995 [437] discussed moisture damage found in manufactured houses (pre-1980) with vapor barriers on the outside of the wall cavity. No decay was found in homes without the vapor barrier. Defined conditions required for dry rot to occur, and briefly discussed an additional study to monitor moisture condensation, thermal performance and ventilation to determine how weatherization activities may cause or other affect moisture in houses. 
2. HEATING, VENTILATION AND AIR CONDITIONING

\subsection{Cooling Equipment - Air Conditioners and Heat Pumps}

\section{Metric}

\section{STEADY-STATE CAPACITY AND EFFICIENCY}

1. ASHRAE 1995 [29] defined the seasonable energy efficiency rating (SEER) for unitary air conditioners and heat pumps.

2. Bittle and Goldschmidt 1985 [54] analyzed heat pump test performance measurements on 98 units and found that various performance factors (SEER, EER, HSPF, COP) were linearly related, with correlation coefficients near 0.8 .

3. Farrar et al. 1998 [145] used AC power consumption as an indicator of the relative thermal performances of two side-by-side houses (one an energy-saving prototype, the other a control).

4. Kavanaugh 1992 [227] explained and compared metrics used to rate unitary air-source pumps, air-source (direct-expansion) cooling units, furnaces, and water-to-air heat pumps. These included seasonal energy efficiency ratio (SEER) and heating seasonal performance factor (HSPF) for air-source heat pumps and cooling units, and three Air-Conditioning and Refrigeration Institute (ARI) metrics used to rate groundsource heat pumps.

5. Neal 1998 [298] defined field-adjusted SEER (SEERFA), which can be appreciably lower than SEER, due to poor installation of AC equipment.

6. Nguyen et al. 1982 [303] found that the seasonal energy efficiency ratio (SEER) of a residential air conditioner is linearly related to its steadystate energy efficiency ratio.

7. Sherman et al. 1987 [401] measured EER and SEER using in-situ appliance efficiency measurements.

8. Walker et al. 1998 [449] concluded that nameplate ratings alone are a poor indicator of how much cooling will be delivered to the conditioned space, and that duct system efficiency is as important as SEER variations in cooling delivery.

9. Walker et al. 1998 [453] discussed REGCAP, a computer model that evaluates residential HVAC system component performance and whole house performance based on measured data (ducts, equipment, envelope, and climate) to provide an estimate of duct, equipment and envelope performance and net cooling delivered (tons at the register).

10. Walker et al. 1999 [447] compared installed capacity to nameplate and ARI ratings and to ACCA Manual J load estimates.

\section{REFrigerant ChaRge}

1. Neal 1998 [298] discussed the effect of improper refrigerant charge on SEER, and referred to other studies (Katz 1997 [226]; Proctor 1997 [338]) that measured refrigerant charge.

\section{Diagnostic}

\section{STEADY-STATE CAPACITY AND EFFICIENCY}

1. ASHRAE 1995 [28] described basic requirements for cooling equipment, including minimum equipment efficiency, field-assembled equipment and components, equipment controls, and maintenance.

2. ASHRAE 1995 [29] described measurements to determine the SEER of unitary air conditioners and heat pumps.

3. EPA 1998 [139] recommended a tune-up of a building's heat exchange equipment that includes (1) mechanically cleaning the air side of heating and cooling coils; (2) chemically cleaning the water side of heating and cooling systems; and (3) unblocking terminal fan coil units and baseboards. Noted that typical cooling and heating system savings can range up to $10 \%$. Also recommended a tune-up of a building's heating and cooling systems (chiller and boiler).

4. Farzad and O'Neal 1993 [146] placed air conditioners in an environmental test chamber (simulating indoor and outdoor temperature and humidity) and measured capacity, EER, and SEER according to DOE/ARI and ASHRAE standards.

5. Groff 1987 [193] described a method to rate air conditioning equipment that reflects part load operating characteristics, proposed as part of ASHRAE/IES 90.1P. 
6. LeRoy et al. 1998 [249] evaluated how well three heat exchanger simulation programs (PUREZ, HPSIM, and ACMODEL) predict the dehumidification performance of air conditioning systems over a wide range of conditions and off-design airflow rates. In general, PUREZ and HPSIM over-predicted the sensible heat ratio, while ACMODEL was able to accurately predict total capacity but overpredicted latent capacity.

7. Miller et al. 1989 [272] detailed an exploratory study in which motor-current signal analysis was used as a diagnostic tool for air conditioners and heat pumps, relating motor-current startup waveforms to level of refrigerant charge and coefficient of performance.

8. Proctor 1991 [333] discussed how to fieldmeasure cooling system efficiency using airflows, temperatures and electrical input rates. Discussed the superheat method to determine charge, and new and replacement equipment sizing and installation criteria.

9. Proctor 1997 [338] compared installed capacity to design load estimated by ACCA Manual J.

10. Sherman et al. 1987 [401] found that EER and SEER accuracies were unacceptable due to problems measuring condenser airflow.

11. Sonderegger et al. 1980 [411] measured cooling efficiency of a central air conditioning system with the electric co-heat technique.

12. Ternes 1987 [420] described data parameters to collect in single-family retrofit research projects and described data analysis approaches and issues. Data parameters include (a) basic data (house characteristics, leakage measurements, metered performance of HVAC systems, and verification of retrofit installation quality); (b) time-sequential data (sub-metered spaceconditioning energy consumption, weather station measurements [dry bulb, horizontal solar radiation, humidity, wind speed and direction], indoor temperature and humidity, total fuel consumptions [billing meter data], wood heating usage, and sub-metered water heating energy consumption); (c) optional occupant-behavior data (additional indoor temperature and humidity, hourly heating and cooling thermostat set-points); (d) geographic characteristics (terrain and shielding); and (e) distribution system data (duct leakage area measured using fan pressurization).
13. UL 1999 [442] named U.S. and Canadian test standards for measuring the energy efficiency of large and small air conditioners and heat pumps.

14. Walker et al. 1998 [453] discussed REGCAP, a computer model that evaluates residential HVAC system component performance and whole house performance based on measured data (ducts, equipment, envelope, and climate) to provide an estimate of duct, equipment and envelope performance and net cooling delivered (tons at the register).

\section{Refrigerant Charge}

1. CEC 1999 [66] presented California building code Title 24 energy efficiency requirements (EERs) and integrated part load values (IPLVs) for unitary air conditioners and heat pumps.

2. Damasceno et al. 1991 [102] discussed three modeling options (refrigerant mass inventory, coil circuitry mapping and internal volume calculations, and a void fraction model) used to correlate heat pump refrigerant charge to heating and cooling capacities.

3. EPA 1997 [138] listed Energy-Star qualifying energy efficiencies for HVAC devices including gas and oil furnaces, gas and oil boilers, central air conditioners, air source heat pumps, geothermal heat pumps, and gas-fired heat pumps.

4. Farzad and O'Neal 1993 [146] looked at the effect of the level of refrigerant charge and type of expansion device on AC system performance (total capacity, EER, SEER).

5. Kirby et al. 1998 [235] presented the results of research looking at non-uniform airflow across a room air conditioner condensing coil; over a wide range of operating conditions with superheated exit conditions, the resulting sensible and latent heat transfer and air-side pressure drop penalties were quite small.

6. Miller et al. 1989 [272] detailed an exploratory study in which motor-current signal analysis was used as a diagnostic tool for air conditioners and heat pumps, relating motor-current startup waveforms to level of refrigerant charge and coefficient of performance.

7. Neal 1998 [298] mentioned ACCA Manual J equipment sizing criteria.

8. Perry et al. 1999 [320] described a program to market the CheckMe! refrigerant-charge and airflow computer expert system (CES) to HVAC 
contractors, technicians, and customers.

Described the CES inputs, outputs, and apparatus, including the use of superheat and subcooling to determine refrigerant charge level on $\mathrm{AC}$ units with fixed and variable metering devices, respectively. Also described how the AC's measured superheat or subcooling can be compared to target values to determine if the unit is correctly charged.

9. Proctor and Downey 1999 [336] described a program to market the Check-Me! refrigerantcharge and airflow computer expert system (CES) to HVAC contractors, technicians, and customers. Briefly described the CES inputs, outputs, and apparatus. This material also covered in Proctor 1999 [334].

10. Rossi and Braun [355] presented a method designed to run in real-time for automated detection and diagnosis of faults in vapor compression air conditioners. It only requires temperature measurements and one humidity measurement. The differences between measured thermodynamic states and predicted states obtained from models for normal performance (residuals) are used as performance indices for both fault detection and diagnosis. For fault detection, uses statistical properties of the residuals for current and normal operation to classify the current operation as normal or faulty. Performs a diagnosis by comparing the directional change of each residual with a generic set of rules unique to each fault. States this diagnostic technique does not require equipment-specific learning, is capable of detecting about a $5 \%$ loss of refrigerant and can distinguish between refrigerant leaks, condenser fouling, evaporator fouling, liquids line restrictions and compressor valve leakage.

\section{Evaporative CoOlers}

1. Otterbein 1996 [309] discussed methods to determine evaporative cooler pad performance. Also presented cooler maintenance guidelines and sizing and installation guidelines for three evaporative cooling system types (air conditioner add-on, independent ducted and window mounted systems).

\section{EQUTPMENT SELECTION AND SIZING}

1. Neal 1992 [299] discussed air conditioning service call components (written report, coil cleaning, airflow, charge, capacity). Discussed factors to be taken into account to optimize performance when sizing and installing equipment in retrofit applications, including sensible/latent ratio, duct efficiency, charge, equipment location, and replacing indoor unit when replacing outdoor unit with higher efficiency condenser.

2. Parker 1991 [311] provided pointers for designing and installing whole house fan systems.

3. Proctor et al. 1995 [332] discussed different sizing methods, comparing various rules of thumb (for example, $\mathrm{ft}^{2} / \mathrm{ton}$ ) to ACCA Manual J and Manual S load calculations. Also discussed how oversized systems increase cost and decrease system efficiency.

4. Proctor and Albright 1996 [335] discussed sizing and retrofit recommendations to optimize cooling equipment performance (charge, sizing, airflow and ducts).

\section{Norm}

1. ASHRAE 1993 [27] specified equipment selection criteria, minimum equipmentefficiency levels, sizing procedures from ASHRAE Handbook of Fundamentals, sizing factors (not more than $125 \%$ of design sensible load, latent capacity not less than calculated design latent load), and design conditions to be used for compliance with the prescriptive requirements of ASHRAE Standard 90.2-1993.

2. ASHRAE 1995 [28] specified standard rating conditions, operating factors, applicable standards, and minimum performance factors for air conditioners and heat pumps.

3. BII 1998 [53] recommended a general procedure for sizing HVAC equipment, specifying who should perform the sizing.

4. Cummings et al. 1990 [98] found that after sealing duct leaks in 25 homes, cooling consumption dropped $18 \%$ in those homes.

5. DOE 1995 [116] discussed background information on HERS heating, air-conditioning and water heating equipment for HERS policy options being discussed in DOE's 1995 request for comments on fuel neutrality and adjustment factors, and standard efficiencies.

6. DOE 1995 [117] discussed (in greater detail than DOE 1995 [116]) the analysis of heating, airconditioning, and water-heating equipment adjustment factors for the HERS guidelines. 
7. Katz 1997 [226] discussed results of heat pump / air conditioner charge and sizing evaluations in 100 new homes; of 22 systems measured, 14 were over-charged, five were under-charged and only three were correctly charged. Of 50 house load calculations run ( 59 systems), one was undersized, six were within the correct range and 52 were oversized; median oversizing was 0.81 tons.

8. Parker 1991 [311] discussed and compared the thermal performance of whole house fans, air conditioning, and combined whole house fan / air conditioner systems in a Florida home. Discussed the impact of the systems on floor slab temperatures.

9. Perry et al. 1999 [320] reported the results of 264 CheckMe! refrigerant charge level tests performed in Fresno and Clovis, CA.

10. Proctor 1991 [333] discussed problems found in cooling systems in 15 existing Fresno, California homes.

11. Proctor 1997 [338] measured refrigerant charge level by weighing, compared levels to factory nameplate ratings and actual refrigerant line set lengths, and discussed demerits of various rules of thumb for using refrigerant gage pressure to predict charge level.

12. Skopek 1999 [406] described an alarm system triggered by a refrigerant leak.

13. Treidler and Modera 1994 [431] compared the energy impact of high-SEER AC units vs. the effect of downsized units with duct retrofits. Based on simulation results, high-SEER units saved energy over the cooling seasons while downsized units with duct retrofits saved peak demand consumption.

14. Walker et al. 1998 [453] discussed REGCAP, a computer model that evaluates residential HVAC system component performance and whole house performance based on measured data (ducts, equipment, envelope, and climate) to provide an estimate of duct, equipment and envelope performance and net cooling delivered (tons at the register). Applied in a Sacramento field test $\left(2,000 \mathrm{ft}^{2}\right.$ house $)$, they found that tight ducts could save almost a ton of cooling.

15. Werling et al. 1998 [460] specified Energy-Star home SEER level requirements for homes in hot, moderate, and cold climates.

\subsection{Heating Equipment - Furnaces, Boilers, and Heat Pumps}

\section{$\underline{\text { Metric }}$}

\section{STEADY-STATE CAPACITY AND EFficienCy}

1. Domanski et al. 1991 [124] defined heat pump performance metrics, including heating seasonal performance factor (HPSF), heating capacity at $47^{\circ} \mathrm{F}\left(\mathrm{Q}_{47}\right)$, and indoor coil scaling factor $\mathrm{F}_{\mathrm{c}}$ (ratio of condensing capacities of a mixed and matched coil).

2. Kweller 1985 [243] defined part-load efficiency and off-period sensible heat loss of vented heating equipment.

3. Phillips 1998 [325] discussed furnace performance factors including $\mathrm{cfm}$ per 1000 Btu/hr, pressure drops, fan power consumption, power factors, furnace efficiency, and sizing factors.

4. Sherman et al. 1987 [401] measured parameters to determine furnace steady-state and seasonal efficiency, including electric energy use by fans, cycling losses, and flue losses.

5. Walker and Modera 1998 [45.1] compared measured data to calculated duct system delivery effectiveness using the ASHRAE Standard 152P and the ASHRAE 1996 Handbook delivery effectiveness methods. On average, the $152 \mathrm{P}$ methods adequately estimate delivery efficiency as measured. Conducted pre- and post-duct leakage reduction measurements and calculations.

\section{Diagnostic}

\section{STEAdY-State CAPACITY AND EFFICIENCY}

1. ASHRAE 1993 [24] specified the ASHRAE test procedure for determining cyclic and part-load performance, methods for interpolating and extrapolating test data, and a calculation procedure for establishing seasonal performance using a test chamber and test rig. The test procedures can be used to compare energy consumption measures of various furnace and boiler models, rather than an absolute measure of performance of any specific installation configuration. 
2. Bohac et al. 1996 [310] described a short-term monitoring protocol to determine the effectiveness of building envelope and/or mechanical system improvements. The protocol works better on a sample of houses than on an individual house.

3. Domanski et al. 1991 [124] described a procedure for calculating heat pump's heat capacity at $47^{\circ} \mathrm{F}\left(\mathrm{Q}_{47}\right)$ and heating seasonal performance factor (HPSF) without laboratory testing of a complete system; evaluates impact of indoor coil, expansion device, and fan on system performance.

4. Dutton 1994 [129] discussed flame adjustments for furnace and water-heater burners. A diagnosis table for burner problems included possible conditions, symptoms, and how to correct the problem. Discussed flue gas analysis and combustion efficiency, acceptable limits, testing devices (chemical or electronic flue gas analyzers, $\mathrm{CO}_{2}$ and $\mathrm{O}_{2}$ analyzer, stack thermometer, $\mathrm{CO}$ tester, draft gage, combustion efficiency calculators, manometer), troubleshooting table (symptoms, causes and repair strategies).

5. EPA 1998 [139] recommended a tune-up of a building's heat exchange equipment that includes (1) mechanically cleaning the air side of heating and cooling coils; (2) chemically cleaning the water side of heating and cooling systems; and (3) unblocking terminal fan coil units and baseboards. Noted that typical cooling and heating system savings can range up to $10 \%$. Also recommended a tune-up of a building's heating and cooling systems (chiller and boiler).

6. Greely et al. 1992 [177] described the use of an elapsed-time meter to record furnace run time, the results of which are used with the measured firing rate and local weather data to determine pre- and post-retrofit furnace energy consumption.

7. Griffith 1983 [183] discussed measuring average furnace gas consumption using an inline gas meter. A year of weekly average gas consumption was plotted versus weekly average outdoor temperature to evaluate the effect of vent dampers on gas consumption. Also discussed the effect of pulse combustion furnaces and vent dampers on heating gas consumption in eight installations (seven in basements and one in a slab-on-grade house). The use of a pulse combustion furnace resulted in an $18.3 \%$ improvement in performance. The use of vent dampers resulted in an $8.8 \%$ improvement in performance in the slab-on-grade house, and a $3.8 \%$ improvement in performance for furnaces and water heaters located in the heated space of split-level houses. No improvement was seen in houses where the furnaces were located in unconditioned basements.

8. Hayden 1992 [209] discussed retrofit strategies (reduced firing rate, dilution air, delayed-action solenoid valve, flame retention head burner) to improve oil furnace efficiency.

9. Jenkins 1991 [220] discussed how to identify and troubleshoot heat pump heating performance problems (ducts, thermostats and controls, airflow, refrigerant charge and leakage), and how to measure heating efficiency.

10. Kweller 1985 [243] described an alternative to tracer-gas methods (controlled flow of gas to a small gas-fueled burned that simulates normal operating flue or stack temperatures) for measuring off-cycle energy loss from vented heating equipment.

11. Phillips 1998 [325] measured furnace performance factors including $\mathrm{cfm}$ per 1000 $\mathrm{Btu} / \mathrm{hr}$, pressure drops, fan power consumption, power factors, furnace efficiency, and sizing factors. Also, described a protocol for measuring the energy performance of residential forced-air heating systems installed in Canadian houses (occupant interview, collection of HVAC nameplate data, measurements of airflow, pressure, and power consumption). Also recommended that the minimum external static pressure rise used in furnace annualized fuel utilization efficiency (AFUE) tests be increased to at least $125 \mathrm{~Pa}$, and that consumer-oriented furnace efficiency ratings include information on furnace electrical consumption.

12. Shen 1991 [370] described the Minnesota LowIncome Weatherization Program's "energy buster" computerized auditor training program; includes the "energy buster" furnace audit form that covers general information, controls, gas supply, distribution, operational tests, venting and chimneys.

13. Sherman et al. 1987 [401] found that the steadystate seasonal efficiency test takes approximately 2 hours.

14. Walker et al. 1998 [453] compared measured data to calculated duct system delivery effectiveness using the ASHRAE Standard 152P and the ASHRAE 1996 Handbook delivery 
effectiveness methods. On average, the $152 \mathrm{P}$ methods adequately estimate delivery efficiency as measured. Conducted pre--and post- duct leakage reduction measurements and calculations.

\section{EQUIPMENT SELECTION AND SIZING}

1. Beers 1994 [47] discussed sizing and installation requirements for condensing furnaces (venting, chimney liners, condensate drainage, sizing, electrical consumption, filters and ductwork). Discussed how house indoor air quality may change due to upgrading to a condensing furnace, including higher humidity (the old naturally-vented furnace may have been acting as a continuously running exhaust fan because of stack effect), additional noise, and cooler air (due to higher airflow across the heat exchanger); provided troubleshooting recommendations.

2. Schalch and Fryer 1992 [364] discussed the Energy Crafted Home's requirement that heating and water heating equipment must have sealed or closed combustion.

\section{Norm}

\section{STEADY-STATE CAPACITY AND EFFICIENCY}

1. ASHRAE 1993 [27] specified equipment selection criteria, minimum equipment efficiency levels, sizing procedures (ASHRAE Handbook of Fundamentals), sizing factors (not more than $170 \%$ of design load), and design conditions to be used for compliance with the prescriptive requirements of ASHRAE Standard 90.2-1993.

2. ASHRAE 1995 [28] specified standard rating conditions, operating factors, applicable standards, and minimum performance factors for furnaces.

3. CEC 1999 [66] presented California building code Title 24 thermal efficiency requirements for warm-air furnaces.

4. Cummings et al. 1990 [98] found that after sealing duct leakage in 25 homes, heating capacity could be reduced $1.6 \mathrm{~kW}$ per house on average.

5. DOE 1995 [116] discussed background information on HERS heating, air-conditioning and water heating equipment for HERS policy options being discussed in DOE's 1995 request for comments on fuel neutrality and adjustment factors, and standard efficiencies.
6. DOE 1995 [117] discussed (in greater detail than DOE 1995 [116]) the analysis of heating, airconditioning, and water heating equipment adjustment factors for the HERS guidelines.

7. EPA 1997 [138] listed Energy-Star qualifying energy efficiencies for various HVAC devices, including gas and oil furnaces, gas and oil boilers, central air conditioners, air-source heat pumps, geothermal heat pumps, and gas-fired heat pumps.

8. Macriss and Zawacki 1981 [259] discussed the furnace-related energy savings achieved from five retrofit options: reducing gas input rate; reducing gas input rate and adding a baffle to the flue outlet; adding a vent restrictor; adding a vent damper; and adding electronic ignition.

9. Parker 1989 [313] discussed the effect of heating system type on air change rates and energy consumption in electrically heated homes. Found that forced air systems use $17 \%$ to $22 \%$ more energy than non-forced-air electric resistance systems. Possible causes included duct air leakage and associated heat transfer, induced air leakage from combustion systems with chimneys, and differential pressures within the building envelope.

10. Phillips 1998 [325] conducted a field study of furnace performance factors, including airflow per unit heating capacity (newer post-1990 furnaces have double the $\mathrm{cfm} / \mathrm{kW}$ of pre-1980 furnaces), duct sizing, system pressure drops and noise factors, fan power consumption, power factor, and furnace efficiency (AFUE). Reduced system airflow results in higher flue losses and lower AFUEs pressure drop across dirty filters are significant. Fan energy parasitics, static pressure drops over dirty filters, and effect of reduced airflow should be taken into account when determining AFUE values. Also, tabulated characteristics (fuel type, drive type, operation mode, rated output) of 71 furnaces surveyed in 68 Canadian homes.

11. Ternes 1987 [420] described data parameters to collect in single-family retrofit research projects and described data analysis approaches and issues. Data parameters include (a) basic data (house characteristics, leakage measurements, metered performance of HVAC systems, and verification of retrofit installation quality); (b) time-sequential data (submetered spaceconditioning energy consumption, weather station measurements [dry bulb, horizontal solar radiation, humidity, wind speed and direction], 
indoor temperature and humidity, total fuel consumptions [billing meter data], wood heating usage, and submetered water heating energy consumption); (c) optional occupant-behavior data (additional indoor temperature and humidity, hourly heating and cooling thermostat setpoints); (d) geographic characteristics (terrain and shielding); and (e) distribution system data (duct leakage area measured using fan pressurization).

\section{EQUiPMENT SELECTION ANd SizING}

1. ASHRAE 1993 [27] specified equipment selection criteria, minimum equipment efficiency levels, sizing procedures (ASHRAE Handbook of Fundamentals), sizing factors (not more than $170 \%$ of design load), and design conditions to be used for compliance with the prescriptive requirements of ASHRAE Standard 90.2-1993.

2. BII 1998 [53] recommended a general procedure for sizing HVAC equipment, specifying who should perform the sizing.

\subsection{Thermal Distribution Systems- Air and/or Water Flow}

\section{$\underline{\text { Metric }}$}

\section{DISTRIBUTION SYSTEM EFFICIENCY}

1. Andrews 1996 [5] defined delivery efficiency and distribution efficiency.

2. ASHRAE 1999 [32] defined and formulated delivery effectiveness, distribution system efficiency, equipment efficiency, equipment factor, equipment capacity, design efficiency, and seasonal efficiency.

3. Francisco and Palmiter 1998 [168] presented a general equation for steady-state delivery efficiency [same as in ASHRAE 152P (ASHRAE 1999 [32])].

4. Francisco et al. 1999 [169] defined FranciscoPalmiter delivery efficiency, distribution efficiency, and regain.

5. Jump et al. 1996 [223] defined delivery efficiency and equipment efficiency.

6. Modera et al. 1992 [282] proposed a framework for characterizing the thermal distribution system efficiency that accounts for (a) the interaction between the thermal distribution system and the building envelope; (b) interactions with the space conditioning equipment; and (c) weatherdependent energy loss.

7. Modera and Jump 1995 [274] defined system delivery efficiency, fractional energy loss due to conduction, and distribution efficiency.

8. Palmiter and Francisco 1996 [310] defined air leakage efficiency and overall duct efficiency.

9. Proctor 1998 [339] defined distribution system efficiency.

10. Siegel and Davis 1998 [403] verbally defined system efficiency.

11. Walker et al. 1996 [446] defined power delivered to duct system, power lost from ducts due to supply leakage, fractional leakage loss for supply ducts, power delivered by ducts to the conditioned space, power lost from the ducts by conduction, fractional conduction loss, return loss, and fractional return loss.

12. Walker et al. 1999 [447] defined delivery efficiency.

\section{Duct Leakage}

1. ASHRAE 1988 [14] defined duct leakage classifications.

2. ASTM 1994 [37] defined effective leakage area and compared $\mathrm{ELA}_{25}$ to $\mathrm{ELA}_{4}$.

3. Cummings 1998 [94] described duct leakage in terms of $\mathrm{CFM}_{25}$ per duct surface area and $\mathrm{CFM}_{25}$ per floor area.

4. Cummings and Tooley 1989 [97] measured duct leakage, as well as air change rates with and without the forced air system running, before and after duct sealing.

5. Cummings and Withers 1998 [95] defined $\mathrm{CFM}_{25}, \mathrm{CFM}_{25 \text {,out, }}$ and $\mathrm{CFM}_{25 \text {,tot }}$ duct leakage area metrics.

6. EPA 1997 [138] listed four tests used to ensure that subcontractors are performing quality work: a blower-door test to detect excessive envelope leakage, a duct leakage test, an HVAC system inspection, and testing airflow across the inside coil to ensure proper airflow to the duct system.

7. Kolb and Ternes 1995 [240] measured CFM $_{50}$ before and after duct sealing in 96 houses to gage the benefits of retrofit.

8. Modera and Byrne 1997 [275] gave formulas for supply and return duct leakage flows. 
9. National Association of State Energy Officials (NASEO) 1999 [295] discussed observable leakage pathways in relation to HERS rating.

10. Proctor et al. 1993 [337] discussed choice of leakage-flow exponent, and defined two duct leakage ratios (ratio of duct leakage inside envelope versus that outside envelope, and ratio of supply leakage area to return leakage area).

11. Siegel and Manclark 1998 [404] empirically related duct leakage to outdoors $\left(\mathrm{Q}_{50, \mathrm{ext}}\right)$ to pressure-pan measurements via a "pressure-pan equation".

12. Walker et al. 1998 [453] discussed REGCAP, a computer model that evaluates residential HVAC system component performance and whole house performance based on measured data (ducts, equipment, envelope, and climate) to provide an estimate of duct, equipment and envelope performance and net cooling delivered (tons at the register).

\section{Register AIrflow \& Thermal Capacity Flow}

1. Foltz 1984 [160] found from calibrations of six type of airflow measurement devices that a laboratory-developed correction coefficient (" $\mathrm{K}$ factor") is needed for each combination of measurement device and register type. However, he found that a flow hood could use a single correction coefficient for diffusers.

2. Walker et al. 1998 [449] defined tons at the register (TAR), a measure of the enthalpy flow delivered to the register.

3. Walker et al. 1998 [453] discussed REGCAP, a computer model that evaluates residential HVAC system component performance and whole house performance based on measured data (ducts, equipment, envelope, and climate) to provide an estimate of duct, equipment and envelope performance and net cooling delivered (tons at the register).

\section{Thermal Distribution GLOSSARY}

1. Home Energy 1993 [213] defined common terms associated with forced air distribution systems and their testing, and presented a schematic of a typical distribution system.

\section{Diagnostic}

\section{DISTRIBUTION SYSTEM EFFICIENCY}

1. Andrews 1996 [5] compared three ASHRAE $152 \mathrm{P}$ techniques for measuring duct efficiencies. Method $\mathrm{A}=$ directly measure heat input and output. Method B = use "Design Pathway" tool to estimate from measured fan flow and duct blaster + blower door duct leakage; Level $2=$ replace duct-pressurization test of Method $B$ with a faster technique based on $P_{\text {space }}-P_{\text {attic }}$ and envelope leakage, and replace the fan flow measurement with an estimate based on the fan curve and the pressure difference across the fan.

2. Andrews et al. 1998 [7] compared design and seasonal distribution efficiencies measured for the same house by five teams using ASHRAE 152P; included error analysis.

3. ASHRAE 1999 [32] provided forms, procedure, and spreadsheet to compute forced-air ductsystem efficiencies.

4. Francisco and Palmiter 1998 [168] measured and modeled delivery efficiency of seven manufactured homes, and evaluated the effect of ASHRAE 152P default values compared to measured data. As more default variables were used, greater variation from the measured results was observed.

5. Jump et al. 1993 [69] measured duct leakage areas, house and duct static pressure differences under different system configurations, leakage flow rate, system airflows, duct conduction losses, and duct thermal delivery efficiencies.

6. Jump et al. 1996 [223] monitored characteristic temperatures, weather, and HVAC power consumption for two weeks before and after duct retrofits of 24 Sacramento homes to measure the effect of retrofit on delivery efficiency and equipment efficiency.

7. Modera and Jump 1995 [274] measured distribution system efficiency by monitoring plenum, register, attic, house, and outdoor temperatures, as well as heat-pump strip-heat electricity demand, for two weeks.

8. Proctor 1998 [339] reported a verification test of ASHRAE 152P that found that the standard correctly predicted the change in cooling load induced by a supply leak, but underestimated by half that induced by a return leak. 
9. Saunders et al. 1994 [363] described the measured performance rating (MPR) method, an overnight co-heat test that predicts building load coefficient (BLC), heating system efficiency, and annual fuel consumption of single-family detached home.

10. Siegel and Davis 1998 [403] used co-heating to measure system efficiency before and after retrofits.

\section{DuCt Leakage}

1. Andrews 1996 [5] briefly described the blower door + flow hood and duct blaster + blower door methods, discussing sources of error and comparing the methods.

2. Andrews et al. 1996 [6] described an electric coheat test.

3. Andrews et al. 1998 [7] summarized and illustrated the house pressure test (HPT).

4. ASHRAE 1999 [32] specified procedures for duct leakage measurement (duct pressurization + blower door, house pressure test).

5. ASTM 2000 [36] discussed duct leakage criteria and evaluation methods using ASTM E1554. Measured duct leakage, expressed as an airflow rate at $25 \mathrm{~Pa}$, should be no more than $5 \%$ of the total system airflow rate. Alternatively, the effective leakage area associated with duct leakage should be no more than 5\% of the effective leakage area of the whole house as measured using ASTM E779.

6. BII 1998 [53] briefly described Duct Blaster measurement of $\mathrm{CFM}_{25}$ and $\mathrm{CFM}_{50}$.

7. Coito et al. 1998 [83] briefly described blowerdoor subtraction, blower door + flow hood, and duct blaster test methods for measuring duct leakage.

8. Cummings 1998 [94] briefly described the ductblaster test method.

9. Cummings and Tooley 1989 [97] described ductleakage tests, as well as tracer-gas and blowerdoor tests to measure the effect of forced-air system operation on infiltration.

10. Davis et al. 1998 [103] used a screening protocol to determine if a home's duct system was leaky enough to warrant retrofit. Criteria included external supply duct $\mathrm{CFM}_{50}$, fraction of ducts accessible, existence of safety/furnace problems, and the presence of duct and floor insulations.
11. EPA 1997 [138] discussed three duct-leakage measurement procedures: the house pressure test, the blower-door subtraction method, and the duct blaster test. Also listed four tests used to ensure that subcontractors are performing quality work: a blower-door test to detect excessive envelope leakage, a duct leakage test, an HVAC system inspection, and testing airflow across the inside coil to ensure proper airflow to the duct system.

12. Fugler 1989 [170] described the Duct Test Rig, a calibrated fan device for purposes including measurement of duct leakage (in the fashion of a duct blaster).

13. Gammage et al. 1986 [173] discussed tracer gas airflow measurements used to determine the effect of central fan operation and duct leakage on infiltration air change rates.

14. Jump and Modera 1993 [222] discussed distribution system tests, including register flow tests, duct leakage tests, and air-distributionsystem performance tests. Also, measured duct leakage areas, house and duct static pressure differences under different system configurations, leakage flow rate, system airflows, duct conduction losses, and duct thermal delivery efficiencies.

15. Jump et al. 1996 [223] noted that the House Pressure Test used in their study was a slightly modified version of ASTM 779-91.

16. Kolb and Ternes 1995 [240] measured duct leakage in 96 homes via blower-door subtraction.

17. Modera 1993 [278] compared ASTM blowerdoor only and blower-door / capture-hood duct leakage measurement techniques.

18. Modera 1994 [280] described a 31-house field study of distribution system performance (including fan pressurization \& flow-capture hood duct leakage measurements; duct pressure measurements; and pressure imbalance measurements). Also described a simulation tool designed to evaluate peak-load mitigation and overall energy conservation potential for improved distribution systems.

19. Modera and Byrne 1997 [275] presented a detailed and illustrated general-audience description of the House Pressure Test (HPT) duct leakage test.

20. NAHB 1997 [293] measured total and unconditioned duct leakage with the ASTM E1554 duct pressurization tests. 
21. National Association of State Energy Officials (NASEO) 1999 [295] briefly described the HERS procedure for visual inspection of duct system (i.e., looking for leaks).

22. Proctor 1997 [338] applied duct blaster and duct blaster + blower door test methods to determine duct leakage for 28 systems.

23. Proctor et al. 1993 [337] described a wide range of quantitative and qualitative duct leakage diagnostics, including (a) the blower door + flow hood, blower door subtraction, and duct blaster methods, comparing the methods and discussing their error sources; (b) the Blasnik method for calculating the ratio of duct leakage to outdoors versus leakage to indoors, and the "Half Nelson" method for estimating the ratio of supply leakage area to return leakage area; (c) the smoke stick method for determining which branches have major leaks; (d) the pressure-pan method for detecting duct leaks; and (e) a "blocked register pressure" extension of the pressure-pan technique that can be used while the registers are taped shut. This information is also presented in Downey and Proctor 1994 [125].

24. Retrotec 1998 [346] noted some issues to be aware of when sealing duct systems: (1) consider static pressure changes due to duct sealing (less airflow, increased noise at the registers due to higher velocities); (2) know how tight the house is (the duct leakage may be the primary driving force behind air infiltration, install a controlled ventilation system if the envelope is tight); (3) resolve existing health and safety issues; (4) address pressure imbalances caused by closed internal doors; (5) pursue comprehensive training (interactive effects between duct leakage, system static pressures, house tightness, interior door closure, moisture and combustion safety); (6) do pre- and post- testing to show leakage reduction; (7) address inaccessible duct leaks; (8) pay attention to the thermal envelope; (9) replace ductwork when appropriate; and (10) provide duct repair, not just duct sealing.

25. Robison and Lambert 1989 [351] measured duct leakage via (1) whole-house ELA measurement with ducts open and ducts sealed; (2) $\mathrm{Q}_{50}$ airflow measured similarly by blower door; (3) duct contribution to ELA extrapolated from flow hood measurements; and (4) duct contribution to $\mathrm{Q}_{50}$ extrapolated similarly. Also, discussed fan pressurization, tracer gas, and flow hood measurement techniques to determine the relationships between duct leakage, envelope leakage, infiltration rates, and ventilation rates.
26. Siegel and Manclark 1998 [404] described in detail the pressure-pan duct-leakage detection method and its associated errors.

27. Ternes 1987 [420] described data parameters to collect in single-family retrofit research projects and described data analysis approaches and issues. Data parameters include (a) basic data (house characteristics, leakage measurements, metered performance of HVAC systems, and verification of retrofit installation quality); (b) time-sequential data (submetered spaceconditioning energy consumption, weather station measurements [dry bulb, horizontal solar radiation, humidity, wind speed and direction], indoor temperature and humidity, total fuel consumptions [billing meter data], wood heating usage, and submetered water heating energy consumption); (c) optional occupant-behavior data (additional indoor temperature and humidity, hourly heating and cooling thermostat setpoints); (d) geographic characteristics (terrain and shielding); and (e) distribution system data (duct leakage area measured using fan pressurization).

28. The Energy Conservatory 1999 [422] answered FAQs related to using Energy-Conservatory's duct blaster, blower door, and Automated Performance Testing System (APT) to measure envelope leakage and duct leakage.

29. Walker et al. 1998 [448] described in detail (and in most cases with extensive uncertainty analysis) various duct leakage measurement methods, including the Irvine Quality Plus (IQ+) Duct Pressurization, Duct and House Pressurization, House Pressure Test, and Nulling Pressure Test.

30. Walker et al. 1998 [453] discussed REGCAP, a computer model that evaluates residential HVAC system component performance and whole house performance based on measured data (ducts, equipment, envelope, and climate) to provide an estimate of duct, equipment and envelope performance and net cooling delivered (tons at the register).

31. Walker et al. 1999 [447] described in detail the Delta $Q$ duct leakage test.

32. West et al. 1998 [461] referred to (but does not detail) the Eugene (Oregon) Water \& Electric Board program called "Comfort S.E.A.L." (Stop Expensive Air Leaks) that uses simplified field protocols to identify duct-seal opportunities quickly and inexpensively. 


\section{SYSTEM AIRFLOW}

1. ASHRAE 1988 [14] described air balancing stations, airflow measurement techniques (pitottube traverse of ducts, vane-anemometer readings of register flows), and estimation of flow rates at volume/pressure control assemblies for HVAC airflow measurement.

2. ASHRAE 1992 [21] described laboratory techniques for airflow measurement.

3. ASHRAE 1999 [32] included a fan-flow measurement procedure for air handler total flow.

4. Bevirt 1994 [52] listed nine airflowmeasurement instruments, specifying recommended uses and limitations.

5. Cheong and Riffat 1993 [69] described an active (pumped) tracer gas system for measuring duct airflow.

6. Cohen 1995 [82] provided checklists and information to consider at all project phases (design, construction, start-up, final test and balance, final acceptance tests) to test performance of the HVAC system for air quality.

7. Cummings and Withers 1997 [96] discussed (a) shortcomings of TAB practices that neglect air leakage (equating register flow to system flow); (b) airflow measurement methods (flow hood, pitot-tube traverse, capture tent, building as capture tent, calibrated fan attached to HVAC system, and tracer gas injection); and (c) choice of method for HVAC airflow measurement.

8. EPA 1997 [138] listed four tests used to ensure that subcontractors are performing quality work: a blower-door test to detect excessive envelope leakage, a duct leakage test, an HVAC system inspection, and testing airflow across the inside coil to ensure proper airflow to the duct system.

9. EPA 1998 [139] recommended a building TAB analysis that includes both a complete review of a building's design documentation, and investigation of (1) air system flow rates; (2) water system flow rates; (3) temperatures of heating and cooling delivery systems (air and water side); (4) positions and functioning of flow control devices (air and water); (5) control settings and operation; and (6) fan and pump speeds and pressures. It noted that heating and cooling savings can range up to $10 \%$.

10. Jump and Modera 1993 [222] discussed distribution system tests, including register flow tests, duct leakage tests, and air-distributionsystem performance tests.

11. Modera and Jump 1995 [274] measured residential system-fan airflow with a constantinjection tracer-gas technique (ASTM Standard E741).

12. Perry et al. 1999 [320] described a program to market the CheckMe! refrigerant-charge and airflow computer expert system (CES) to HVAC contractors, technicians, and customers. Described the CES inputs, outputs, and apparatus, including how the AC's temperature split (difference between supply and return plenums' dry bulb temperatures) can be compared to target values to determine if the airflow is correct.

13. Phillips 1998 [325] described a protocol for measuring the energy performance of residential forced-air heating systems installed in Canadian houses (occupant interview, collection of HVAC nameplate data, measurements of airflow, pressure, and power consumption). Also recommended that the minimum external static pressure rise used in furnace annualized fuel utilization efficiency (AFUE) tests be increased to at least $125 \mathrm{~Pa}$, and that consumer-oriented furnace efficiency ratings include information on furnace electrical consumption.

14. Proctor and Downey 1999 [336] described a program to market the Check-Me! refrigerantcharge and airflow computer expert system (CES) to HVAC contractors, technicians, and customers. Briefly described the CES inputs, outputs, and apparatus. This material also covered in Proctor 1999 [334].

15. Robison and Lambert 1989 [351] measured fandriven air exchange via $\mathrm{SF}_{6}$ tracer gas testing.

16. Sauer et al. 1996 [362] compared different methods to measure airflow through a short outside air duct (commercial application).

17. Walker et al. 1998 [449] described register flow measurement with a fan-assisted flow hood, fan flow measurement using supply ducts as a flowmeter (as proposed in ASHRAE Standard 152P (ASHRAE 1999 [32]) and CEC ACM appendix F), and tracer gas measurement of fan flow.

\section{REgister AIRfLOW \& ThERMAL CAPACITY FLOW}

1. Berckmans et al. 1993 [50] discussed a method to visualize and quantify the airflow pattern in a 
ventilated room using smoke, a camera, and a computer.

2. BII 1998 [53] briefly described flow-hood measurement of register flow.

3. CMHC 1998 [79] described an inexpensive test to measure the flow out of heating registers using a wire coat hanger and a garbage bag.

4. EPA 1997 [138] listed four tests used to ensure that subcontractors are performing quality work: a blower-door test to detect excessive envelope leakage, a duct leakage test, an HVAC system inspection, and testing airflow across the inside coil to ensure proper airflow to the duct system.

5. Foltz 1984 [160] measured systematic and random errors of devices used to measure register flows (a rotating vane anemometer, three types of deflecting vane anemometer, a flow hood, and a hotwire anemometer).

6. Karki and Karjalainen 1999 [225] discussed performance factors for life-cycle analysis of commercial air handlers and practical faultdetection methods.

7. Modera and Jump 1995 [274] measured residential register airflows (low) with a calibrated fan + flow hood.

8. Ngo and Dexter 1999 [301] discussed cooling coil automated fault detection for commercial building air handlers.

9. Walker et al. 1996 [446] measured register flows in apartment buildings with a fan-assisted flowcapture hood.

10. Walker et al. 1996 [446] measured the system fan airflow in apartment buildings by blocking off the return from the system fan, attaching a flow hood + fan-assisted flowmeter to the air handler, and adjusting the flow through the fanassisted flowmeter to recreate the operatingcondition supply-plenum pressure.

11. Walker et al. 1998 [449] used the REGCAP software package to simulate initial and final delivered capacity at the registers (TAR). Also described in Walker et al. 1999 [447].

\section{Duct Pressure Drop}

1. de Salis et al. 1996 [105] discussed an acoustic technique used to measure duct pressure drop and detect duct obstructions.

\section{Thermal Distribution Glossary}

1. Home Energy 1993 [213] defined common terms associated with forced-air distribution systems and their testing, and included a schematic of a typical distribution system.

\section{WATER Flow MEASUREMENT}

1. Bevirt 1994 [52] listed four instruments for measuring water flow and specified recommended uses and limitations.

\section{SYSTEM SELECTION AND SIZING}

1. SMACNA 1993 [407] discussed air system basics, including duct systems and fluid dynamics, and ducted air system testing and balancing procedures, checklists and troubleshooting pointers.

\section{Norm}

\section{DUCT LEAKage}

1. Andrews 1996 [5] mentioned that ASHRAE Draft Standard 152P specifies acceptable duct leakage flows.

2. ASHRAE 1995 [28] specified that energy distribution system leaks should be repaired. Specified minimum duct and plenum insulation levels; specified performance and energy factors for replacement motors.

3. Bevirt 1994 [52] presented a table of predicted leakage classes for sealed and unsealed ducts of various types.

4. BII 1998 [53] noted that several California utilities use $140 \mathrm{CFM}_{50}$ as the maximum criterion leakage allowed for a tight duct system, and that CIEE's HVAC design states that acceptable $\mathrm{CFM}_{25}$ is 6-7\% of fan flow.

5. Cummings 1998 [94] stated the SMACNA standard for duct leakage in terms of $\mathrm{CFM}_{25}$ per $100 \mathrm{ft}^{2}$ of duct surface area, and a HERS standard for duct leakage flow per floor area. He recommended $50 \mathrm{CFM}_{25}$ per $1000 \mathrm{ft}^{2}$ floor area for commercial buildings. Also recommended certain ducting practices.

6. Cummings and Tooley 1989 [97] found that average infiltration rate increased from 0.14 $\mathrm{ACH}$ to $1.42 \mathrm{ACH}$ with the forced-air system operating. After duct sealing, the average infiltration rate dropped to $0.31 \mathrm{ACH}$. 
7. Cummings et al. 1990 [98] discussed test procedures to determine the relationship between duct leakage and infiltration and leakage sites using tracer gas tests, blower door testing, smoke testing and visual inspections. Found that, on average, infiltration rates measured with tracer gas correlated to blower-door test results for air handler fan on and off conditions. Also, found that return duct leakage equaled $10 \%$ of the air handler airflow and that repairing duct leakage reduced whole house infiltration.

8. Davis et al. 1998 [103] reported pre- and postretrofit values of envelope leakage $\left(\mathrm{CFM}_{50}\right)$, supply duct leakage to outside $\left(\mathrm{CFM}_{25}, \mathrm{CFM}_{50}\right)$ and average supply-side pressure-pan measurement ( $\mathrm{Pa})$ for 95 homes.

9. Hammon et al. 1999 [200] discussed changes, based on their study, to the CEC Title 24 criteria for tight ducts from a ratio of leakage to floor area to a ratio of leakage to fan flow. The leakage in a finished home must be less than $6 \%$ of fan flow to be considered tight. Fan flow can either be determined by direct measurement or by substituting measured return airflow. Also discussed in Hammon and Modera 1996 [199].

10. Jump and Modera 1993 [222] discussed duct leakage areas, house and duct static pressure differences under different system configurations, leakage flow rate, system airflows, duct conduction losses, and duct delivery efficiencies.

11. Katz 1997 [226] discussed Advanced Energy's target for duct leakage (in $\mathrm{CFM}_{25}$, less than $3 \%$ of conditioned floor area in $\mathrm{ft}^{2}$ ). Presented results of duct leakage tests in 100 new homes; of 130 systems in 96 houses. The median leakage measured was $261 \mathrm{CFM}_{25}$ per system and $360 \mathrm{CFM}_{25}$ per house (or a median leakage of $19.5 \%$ as a percentage of floor area).

12. Modera 1994 [280] presented duct-leakage measurements performed in 31 California homes.

13. Parker 1989 [313] discussed the effect of distribution systems on air change rates and energy consumption in electrically heated homes. Found that forced air systems used $17 \%$ to $22 \%$ more energy than non-forced-air electric resistance systems. Possible causes included duct air leakage and associated heat transfer, induced air leakage from combustion systems with chimneys, and differential pressures within the building envelope.
14. Retrotec 1998 [345] said that a new, wellinstalled supply and return residential duct system should have an ELA not exceeding 10 in $^{2}$.

15. Rose 1999 [353] reviewed SMACNA leakage classes.

16. Walker et al. 1998 [453] discussed REGCAP, a computer model that evaluates residential HVAC system component performance and whole house performance based on measured data (ducts, equipment, envelope, and climate) to provide an estimate of duct, equipment and envelope performance and net cooling delivered (tons at the register). Applied in a Sacramento field test $\left(2,000 \mathrm{ft}^{2}\right.$ house), they found that almost a ton of cooling could be saved by with tight ducts.

\section{REgister AIrFLow}

1. BII 1998 [53] provided rule of thumb for airflow requirements (1 CFM per $\mathrm{ft}^{2}$ in living areas), and recommended use of CIEE HVAC design, installation, and test guidelines to prevent excess duct leakage.

\section{SYSTEM AIRFLOW}

1. BII 1998 [53] noted that a typical air handler is designed to operate at 0.5 in. w.g.

\section{DUCT INSULATION}

1. EPA 1997 [138] listed typical and cost-effective insulation levels in moderate climates for attics, exterior walls, floors (over garage), basement walls (above grade), and ducts.

2. Treidler et al. 1996 [432] said that ducts should be better insulated.

\section{SYSTEM SizING}

1. ASHRAE 1993 [27] specified distributionsystem sizing methods (1989 ASHRAE Handbook of Fundamentals or ACCA's Manual D), installation methods (SMACNA, NAIMA), and air balancing methods required for compliance with the prescriptive requirements of ASHRAE Standard 90.2-1993.

2. Hammon et al. 1999 [200] discussed that, based on LBNL's longevity study of duct closure systems, cloth-backed rubber-adhesive tape would not to be permitted under Title 24. Also discussed in Hammon and Modera 1996 [199]. 
3. Treidler et al. 1996 [432] stated that when a duct system is sealed, resizing the HVAC system can reduce energy use by 20 to $30 \%$.

\subsection{Combustion Safety}

\section{Metric}

\section{BACKDRAFTING \& SPILlaGE}

1. ASTM 1998 [42] noted that the house depressurization level can be compared to continuous and intermittent pressure differentials (house level depressurizations).

2. CGSB 1995 [67] noted that House Depressurization Level can be compared to both continuous and intermittent pressure limits to predict backdrafting

3. Grimsrud et al. 1999 [184] noted that house depressurization level may be compared to preset limits to predict backdrafting.

4. Keefe 1994 [228] noted that the draw from a combustion device's exhaust is what prevents backdrafting into the room.

5. Persily 1999 [322] described an IAQ performance guide being developed by ASTM that may include venting of naturally-vented water- and space-heating appliances, house depressurization, unvented space heaters, downdrafting, appliance backdrafting and cold vent establishment.

6. Wilson et al. 1986 [462] related flue gas spillage to depressurization conditions, indoor/outdoor temperature differences, and furnace conditions (standby, pilot light only). Provided depressurization limits for spaces with naturallyvented gas appliances.

\section{Diagnostic}

\section{BaCKDRAfting \& SPILlage}

1. ASTM 2000 [36] discussed visual inspection and ASTM E1998 house depressurization, downdrafting, appliance backdrafting and cold vent establishment pressure tests.

2. ASTM 1998 [42] described (a) four tests conducted under induced conditions (house depressurization test with preset criteria, downdrafting test, appliance backdrafting test, and cold vent establishment pressure); (b) a continuous (natural condition) spillage test; and (c) a continuous backdrafting test.
3. CGSB 1995 [67] described a spillage test procedure for vented, fuel-fired, space-heating appliances; water heaters; and fireplaces. Included a checklist and a report form.

4. CMHC 1998 [79] discussed the physics, mechanisms, and corrective measures relating to backdrafting and spillage of combustion appliances.

5. Conibear et al. 1995 [87] discussed protocol and study to evaluate backdrafting, spillage, and $\mathrm{CO}$ levels in homes in Chicago. Protocols are based on CGSB 51.71-94 (pressure-induced spillage / backdrafting from vented fuel-fired appliances) and ANSI Standard Z 21.1-1993 (carbon monoxide measurements and determination of free-air $\mathrm{CO}$ from ovens).

6. deKieffer 1995 [106] discussed how to conduct combustion safety checks; included furnace and water heater inspection and performance specifications.

7. Dumont and Snodgrass 1990 [128] presented and experimentally validated a simplified theory that quantitatively predicts the conditions under which backdrafting will occur.

8. Dutton 1994 [129] described gas and combustion-related test procedures, including spillage, backdrafting, and gas line leaks.

9. Fugler 1989 [171] listed a variety of tests (flame motion, flue temperature, smoke pencil, flue-tohouse pressure) to determine whether building exhaust could induce chimney backdrafting. An inexpensive heat sensor was made of temperature-sensitive color-changing dots, and heat sensing was used as a proxy for combustion gas spillage. This paper also presented a table of house depressurization limits for various appliances and chimneys.

10. Greiner 1997 [179] discussed how to evaluate new furnaces for $\mathrm{CO}$ problems, including vent failures, over-firing and heat exchanger failures.

11. Greiner 1997 [180] discussed detecting the presence and source of high CO levels associated with downdrafting.

12. Grimsrud et al. 1999 [184] presented a table summarizing the tests in ASTM 1998 [42].

13. Keefe 1994 [228] briefly described the nature of a worst-case induced-condition backdrafting test.

14. Moffatt 1991 [286] discussed factors leading to furnace and fireplace spillage and backdrafting, 
and discussed possible solutions. Described chimney backdrafting tests.

15. NAHB 1997 [293] measured worst-case depressurization of the combustion zone by varying fan status and door positions. Also summarized backdrafting research.

16. Ponessa 1999 [330] discussed a moisture problem case study; the moisture was due to leaking furnace flue gas from a masonry chimney; included diagnostics specific to testing vented appliances.

17. Rajhans 1989 [342] presented a checklist to detect IAQ problems including problems related to combustion (CO), other pollutant sources, HVAC, maintenance, and design.

18. Wilson et al. 1986 [462] discussed depressurization conditions, indoor/outdoor temperature differences, and furnace conditions (standby, pilot light only) in relationship to flue gas spillage. Provided depressurization limits for spaces with naturally-vented gas appliances.

\section{HeAT EXChanger LeAKage}

1. DeWerth and Sobieski 1985 [109] described a three-step method for detecting unacceptable flue gas leakage from furnace heat exchangers (visual examination of heat exchanger, observation of burner flame pattern, and use of tracer gas).

Method was field-tested by seven utility companies and found to be more reliable and accurate than their currently-used leak-detection methods (smoke bombs, odor tracing, and salt sprays).

2. Greiner 1997 [179] discussed how to evaluate new furnaces for $\mathrm{CO}$ problems, including vent failures, over-firing and heat exchanger failures.

\section{Chimney Condition}

1. Oberholtzer 1993 [304] provided a step-by-step inspection protocol to diagnose chimney (flue) problems. Techniques included chim-scan tv monitoring check, combustion analyzer, rightsizing the vent, checking for pyrolysis problems, excess condensation development check, excess soot or creosote deposit check, downdraft problem diagnostics, $\mathrm{CO}$ testing for fume leakage, and pressure dynamics.

\section{COMBUSTION AIR SUPPLY SizING AND LOCATION}

1. Dutton 1994 [129] discussed combustion air supply sizing, supply locations, and design factors for gas appliances (furnaces, water heaters, boilers).

\section{VENTING SIZING AND LOCATION}

1. ASTM 2000 [36] discussed the design and installation of venting systems in compliance with codes and standards.

2. Dutton 1994 [129] discussed vent sizing, draft control equipment and installation requirements.

\section{Norm}

\section{BACKDRAFTING \& SPILLAGE}

1. CGSB 1995 [67] specified continuous and intermittent depressurization limits for various combustion appliances.

2. Conibear et al. 1995 [87] discussed results of a study to evaluate backdrafting, spillage, and $\mathrm{CO}$ levels in homes in Chicago. Found that $10.7 \%$ of the single-family detached homes tested showed evidence of depressurization conditions that could lead to backdrafting. $7 \%$ of homes showed visual evidence of spillage or poor drafting; indoor $\mathrm{CO}$ levels equaled or exceeded $10 \mathrm{ppm}$ in $11 \%$ of the homes tested; many ovens were not functioning within manufacturer's guidelines.

3. Fugler 1989 [171] listed a variety of tests (flame motion, flue temperature, smoke pencil, flue-tohouse pressure) to determine whether building exhaust could induce chimney backdrafting. An inexpensive heat sensor was made of temperature-sensitive color-changing dots, and heat sensing was used as a proxy for combustion gas spillage. This paper also presented a table of house depressurization limits for various appliances and chimneys.

4. Keefe 1994 [228] warned that backdrafting will occur if the room air pressure is more negative than the draw of a combustion device's exhaust (typically only 3 to $5 \mathrm{~Pa}$ ).

5. Wilson et al. 1986 [462] related flue gas spillage to depressurization conditions, indoor/outdoor temperature differences, and furnace conditions (standby, pilot light only). Provided depressurization limits for spaces with naturallyvented gas appliances.

\section{COMbustion AIR SUPPLy Sizing}

1. ASHRAE 1993 [27] specified combustion air and automatic vent dampers for combustion 
appliances and fireplace requirements (tightfitting damper, doors and outside combustion air) required for compliance with the prescriptive requirements of ASHRAE Standard 90.2-1993.

\section{Chimney Condition}

1. Oberholtzer 1993 [304] discussed the accelerated deterioration of chimney (flue) materials due to lower venting temperatures and shorter furnace run cycles.

\subsection{Ventilation}

\section{Metric}

\section{VENTILATION AIRFLOWS AND AIR EXCHANGE RATES}

1. Bearg 1999 [46] discussed the use of indoor $\mathrm{CO}_{2}$ levels as an indicator of ventilation rate.

2. Dale and Ackerman 1993 [101] discussed the change in attic ventilation rate and effect on living space from attic turbine ventilators. Dale and Ackerman 1991 [100] also discussed this research.

3. Forest and Walker 1991 [161] discussed measurement and model input variables to determine airflow and moisture content in attics. Forest and Walker 1992 [162], 1993 [163], 1993 [164], and Walker and Forest 1995 [452] also discussed this research.

4. Koles et al. 1996 [241] discussed ventilation-fan energy efficiency $(\mathrm{kW} / \mathrm{cfm})$.

5. Li et al. 1996 [251] defined mean age of air, corrected mean age of air, and outdoor air exchange rate.

6. Mansson 1999 [253] discussed simplified tools for the evaluation of ventilation systems and their effects in new and existing residences.

7. Mudarri 1997 [290] noted several sources of error in estimating outdoor-air ventilation rates from "steady-state" indoor $\mathrm{CO}_{2}$ levels, including (a) measurement before reaching steady-state state, which overestimates ventilation; (b) overestimation of $\mathrm{CO}_{2}$ generation by women, children, and the elderly, which overestimates ventilation; and (c) underestimation of outdoor $\mathrm{CO}_{2}$ levels, which underestimates ventilation. Presented a 10-step process and an assortment of tables to improve the accuracy of ventilation rates estimated from $\mathrm{CO}_{2}$ levels.
8. Persily 1999 [322] described an IAQ performance guide being developed within ASTM, including a ventilation performance statement that includes whole-building air change rates, outdoor ventilation air distribution, and kitchen and bathroom exhaust rates, all based on ASHRAE Standard 62-1989 [18].

9. Rajhans 1989 [342] recommended using $\mathrm{CO}_{2}$ level as a surrogate for fresh air supply.

10. Schell 1995 [365] noted that indoor $\mathrm{CO}_{2}$ levels indicate ventilation rate, and provided tables of $\mathrm{CO}_{2}$ level equilibrium setpoints for control of ventilation using $\mathrm{CO}_{2}$.

11. Sherman et al. 1981 [399] validated the LBL air infiltration model with leakage measurements made in a small trailer (Mobile Infiltration Testing Unit) and in an occupied house.

12. Sherman and Grimsrud 1982 [393] calculated a pressure coefficient (relating the wind pressure on the face of a building to the dynamic pressure of the wind) from pressure measurements made with the Mobile Infiltration Test Unit. This study also used a terrain parameter to represent primarily large-scale effects caused by the roughness of the boundary layer in the region surrounding the structure.

13. Yuill and Lovatt 1986 [467] discussed determination of effective ventilation rates using a set pollutant concentration (pre-cursor to ASHRAE Standard 136).

\section{Temporal and SPatial Ventilation EFFECTIVENESS AND EFFICIENCY}

1. ASHRAE 1988 [26] specified a calculation methodology to determine annual effective ventilation rates, based on the weather factor (W), normalized leakage area (NL), and hourly ventilation fan airflows and schedules.

2. ASHRAE $198^{\circ} 9$ [18] defined spatial ventilation effectiveness (i.e., the effectiveness with which outside air is circulated to occupied space).

3. ASHRAE 1993 [26] defined air change rate, effective air change rate, infiltration, mechanical and natural ventilation, normalized leakage, outdoor air change rate, and weather factor.

4. ASHRAE 1997 [31] defined air-change spatial and temporal effectiveness in terms of exhaust airflows and the tracer-gas-determined "age" of indoor air.

5. Ohnishi et al. 1998 [308] defined existing indices (ventilation rate, air change rate, room mean age 
of air, air change efficiency) that deal with single spaces, and proposed new indices (supply rate fulfillment, exhaust rate fulfillment, overall ventilation rate fulfillment) that apply to an entire house with multiple rooms.

6. Sherman and Wilson 1986 [392] defined temporal ventilation efficiency, which takes into account the time variation of the ventilation; turnover time, which is the reciprocal of the ventilation rate; and instantaneous effective ventilation rate, which is the ratio of source concentration to room concentration.

\section{IndoOR-OUtdoor AND INTERzonal Pressures}

1. Finley 1997 [151] evaluated airflow paths to determine their effect on indoor air problems (mold and moisture) and to determine mitigation strategies.

2. Grimsrud et al. 1999 [184] discussed the use of building indoor-outdoor pressurization level as a metric.

\section{Air to Air Heat Exchanger Performance}

1. Ciepliski et al. 1998 [75] defined metrics for the performance efficiency of air-to-air heat exchangers, including sensible, latent, and total energy effectivenesses, sensible heat recovery efficiency, total heat recovery efficiency, temperature ratio, and humidity ratio. Also compared the performance factors used in 10 test standards from ASHRAE, CHA, ENV, and ASME.

2. Johnson et al. 1998 [221] defined performance metrics for air-to-air heat exchangers, including sensible, latent, and total effectivenesses.

3. Simonson et al. 1999 [405] discussed latent, sensible, and total energy recovery effectivenesses of energy wheels.

\section{$\underline{\text { Diagnostic }}$}

\section{VeNTILATION AIRFLOWS AND AIR ExCHANGE RATES}

1. ASTM 1992 [35] described the ASTM E779-87 (1992) multi-point fan-pressurization measurement technique for envelope-leakage.

2. ASTM 1995 [40] described the tracer-gas measurement of single-zone air change rates.

3. Bearg 1999 [46] discussed the use of indoor $\mathrm{CO}_{2}$ levels as an indicator of ventilation rate.
4. BII 1998 [53] used the LBL Infiltration Model to convert $\mathrm{ACH}_{50}$ to $\mathrm{ACH}_{\text {natural }}$.

5. CMHC 1996 [77] outlined builder responsibilities to make sure ventilation systems meet the National Building Code (NBC) prescriptive requirements or CAN/CSA-F326 'Residential Mechanical Ventilation Systems'. Provided design, installation, and inspection checklists and figures for each of the six recommended system types.

6. CMHC 1998 [79] described the physics and mechanisms of airflow in buildings.

7. Fletcher and Johnson 1992 [157] described tracer-gas measurement of ventilation rates of several small factory units.

8. Grimsrud et al. 1978 [187] measured a house's envelope leakiness via fan pressurization, and measured its infiltration rate using nitrous oxide as a tracer gas.

9. Grimsrud et al. 1979 [186] compared building infiltration rates measured with various tracer gases (concentration decay method), and found that those measured with $\mathrm{SF}_{6}$ slightly exceeded those made with $\mathrm{CH}_{4}$ or $\mathrm{N}_{2} \mathrm{O}$.

10. Grimsrud et al. 1979 [189] compared tracer gas and fan pressurization based infiltration measurements in energy-efficient and standardconstruction homes. Grimsrud et al. 1979 [191] presented a subset of these results.

11. Grimsrud et al. 1980 [190] found that air exchange rates measured using $\mathrm{SF}_{6}$ as a tracer gas were slightly larger that those measured using $\mathrm{CH}_{4}$ or $\mathrm{N}_{2} \mathrm{O}$.

12. Harrje 1981 [203] described a manual technique for tracer-gas sampling (squeeze bottles), for measuring building ventilation rate.

13. Harrje et al. 1979 [204] described a homeownerperformed tracer-gas technique for measuring the ventilation rate of a home (house is seeded with $\mathrm{SF}_{6}$, then samples are taken every 30 minutes by squeezing a plastic sample bottle.)

14. Harrje et al. 1990 [206] compared three techniques for tracer gas measurement.

15. Nguyen Thi et al. 1995 [302] described the use of a portable tracer gas analyzer to measure air change rate via tracer gas decay.

16. Ohba and Irie 1999 [307] presented a videographic method of measuring air change rate using smoke tracers. 
17. Rajhans 1989 [342] recommended using $\mathrm{CO}_{2}$ level as surrogate for fresh air supply.

18. Roulet et al. 1999 [357] discussed using tracergas measurements to measure envelope exfiltration.

19. Saffell 1995 [359] compared two technologies (non-dispersive infrared gas cells and electrochemical cells) for the measurement of equilibrium $\mathrm{CO}_{2}$ concentration, which in turn is used as an indicator of ventilation rate.

20. Sherman 1987 [383] reported that tracer gas methods underpredict ventilation rates.

21. Sherman 1989 [371] presented a highly mathematical analysis of the uncertainties associated with tracer-gas measurement of airflow calculations.

22. Sherman 1989 [385] described a multi-tracer measurement system (MTMS) for multizone ventilation measurement.

23. Sherman 1989 [386] noted that, although performing a tracer-gas decay test is straightforward, the analysis is more complicated. Methods discussed include (a) tracer gas constant injection; (b) tracer gas long constant concentration, which uses an active control system to control the gas release; (c) tracer gas long-term integral (a.k.a. long-term average method), which can be used with various injection patterns; and (d) tracer gas pulse technique, in which the measurement begins before the gas is injected.

24. Sherman et al. 1979 [396] evaluated the relationship between infiltration rates and surface pressures on a building.

25. Sherman et al. 1980 [378] surveyed various tracer-gas infiltration measurement techniques, including (a) decay - simple to conduct, uses minimum of equipment, is good for short term measurements; (b) constant flow - will run up to several days and give continuous infiltration measurements; (c) continuous flow - expensive to build apparatus; and (d) long-term average yields average infiltration over a long period of time (e.g., a month).

26. Sherman et al. 1989 [379] described the MultiTracer Measurement System (MTMS), a tracer gas measurement system that uses multiple gases.

27. Sherman et al. 1989 [398] measured interzonal airflows with a multiple tracer-gas measurement system (MTMS).
28. Sherman 1990 [388] reviewed tracer gas literature (comparing the merits of various gases) and compared various tracer-gas techniques (decay, pulse, constant injection, long-term integral, constant concentration) for measurement of single-zone air change rate.

29. Sonderegger et al. 1980 [411] used the constantinjection tracer-gas technique to continuously monitor envelope infiltration.

30. Tseng et al. 1994 [434] recommended energy management system (EMS) monitoring stations for both supply and return airflows to ensure adequate outside airflow in VAV systems.

31. Walker et al. 1995 [454] presented the AVENT attic ventilation model and compared modeled results to measured data.

\section{TEMPORAL AND SPATIAL VenTILATION EFFECTIVENESS AND EFFICIENCY}

1. ASHRAE 1993 [26] described determining the effective air change rate in a detached dwelling by combining shell leakage with a local weather factor. Included weather factor tables.

2. ASHRAE 1997 [31] described a method for the tracer-gas measurement of spatial and temporal air-change effectiveness.

3. ASTM 2000 [36] discussed performance statements (objectives, criteria, evaluation methods, and commentary) for whole-building ventilation, based on ASHRAE Standard 62 . Evaluation methods include tracer gas techniques, fan pressurization test, and singlezone or multi-zone airflow models. Discussed airflow distribution within the building along with the need for evaluation methods. In addition, discussed kitchen, bath, and toilet exhaust systems and occupant control of ventilation components.

4. Condon et al. 1980 [86] described and compared tracer gas airflow measurement techniques using concentration decay, continuous flow in a single chamber, and continuous flow in multiple chambers.

5. Dale and Ackerman 1993 [101] discussed the change in attic ventilation rate and effect on living space from attic turbine ventilators. Dale and Ackerman 1991 [100] also discussed this research.

6. Federspiel and Wenger 1998 [147] described a methodology for modeling commercial multizone ventilation systems using flow rate 
standards such as ASHRAE 62-1989 [18] with the age-of-air concept. The model can be used to model ventilation effectiveness, translating outdoor air requirements to age-of-air requirements and vice versa, and to develop new ventilation strategies for multizone systems.

7. Forest and Walker 1991 [161] discussed measuring and modeling airflow and moisture content in attics. Forest and Walker 1992 [162], 1993 [163], 1993 [164], and Walker and Forest 1995 [452] also discussed this research.

8. Modera et al. 1981 [284] collected infiltration data to verify an envelope leakage model (described in Sherman and Grimsrud 1980 [390]).

9. Pickering et al. 1987 [326] found that the videotaped motion of helium-filled, zero-netbuoyancy balloons was a useful indicator of indoor airflow (and worked better than smoke or bubbles).

10. Sandberg 1987 [360] discussed the accuracy of different tracer gas methods (constant concentration and decay methods) to predict mean airflow rates in naturally ventilated houses.

11. Sherman 1989 [385] described a portable MultiTracer Measurement System (MTMS) capable of measuring ventilation between different zones of a multiple zone building.

12. Sherman 1989 [386] discussed single and multizone tracer gas techniques for measuring airflow rates, including decay, pulse, constant injection, long-term integral, long-constant concentration; discussed analysis techniques and compared strategies.

13. Sherman 1989 [387] presented a method for estimating multizone ventilation rates from tracer-gas measurements.

14. Sherman 1994 [389] discussed how to determine $\mathrm{ACH}$ rates from blower door measurements.

15. Sherman and Dickerhoff 1989 [391] described the multi-tracer measurement system (MTMS) to measure time-varying interzonal flows and presented MTMS results for two houses.

16. Sherman et al. 1989 [398] described a portable MultiTracer Measurement System (MTMS) capable of measuring ventilation between different zones of a multiple zone building.

17. Tooley and Davis 1994 [428] discussed test methodology to diagnose problems with attic ventilators, zonal depressurization, moisture damage, and air barriers.

18. Turner and Bearg 1989 [440] discussed $\mathrm{CO}_{2}$ and tracer gas determinations of outside air ventilation for an office building, including limitations, benefits, and appropriateness.

\section{INDOOR-OUTdOOR AND INTERZONAL PRESSURES}

1. ASHRAE 1989 [16] described pressure measurement.

2. Cummings 1998 [94] described how to map building air pressures.

3. Cummings and Withers 1997 [96] presented a brief overview of building pressure mapping.

4. Lstiburek 1998 [256] extensively discussed building air-pressure distribution and its relation to building airflow, including envelope leakage. Also discussed measurement of air pressure fields and air pressure differentials, and induction of pressure differentials.

5. Robison and Lambert 1989 [351] discussed fan pressurization, tracer gas, and flow hood measurement techniques to determine the relationships between duct leakage, envelope leakage, infiltration rates, and ventilation rates.

\section{Air to Air Heat Exchanger Performance}

1. Buchan Lawton Parent Ltd 1996 [60] discussed field-inspection and occupant-survey methodologies to determine heat recovery ventilator performance factor.

2. Ciepliski et al. 1998 [75] compared 10 performance-efficiency test standards from ASHRAE, CHA, ENV, and ASME, discussing required test facilities and instrumentation. Also discussed test uncertainty and proposed revisions to ASHRAE Standard 84-1991.

3. Federspiel and Wenger 1998 [147] described a methodology for modeling commercial multizone ventilation systems using flow rate standards such as ASHRAE 62-1989 [18] with the age-of-air concept. The model can be used to model ventilation effectiveness, translating outdoor-air requirements to age-of-air requirements and vice versa, and to develop new ventilation strategies for multizone systems.

4. Johnson et al. 1998 [221] analyzed uncertainty in the calculation of air-to-air heat exchanger effectiveness calculations due to bias and precision uncertainties in the measurements of air pressures and temperatures. 
5. Simonson et al. 1999 [405] described a computer model for predicting the performance (energy recovery effectiveness) of energy wheels; and a laboratory experiment for validating the model. Included extensive error analysis.

\section{EQUIPMENT SELECTION AND SIZING}

1. Schalch and Fryer 1992 [364] discussed the Energy Crafted Home's ventilation requirements (systems must provide $60 \mathrm{cfm}$ continuously in small homes and $100 \mathrm{cfm}$ in larger homes).

\section{Norm}

\section{VENTILATION AIRFLOWS AND AIR EXCHANGE RATES}

1. ASHRAE 1989 [18] specified outdoor air requirements for residential and commercial buildings.

2. ASHRAE 1993 [27] specified the attic and crawlspace ventilation (free area per unit floor area) requirements, minimum house ventilation requirements (supplemental ventilation via kitchen and bathroom exhaust fans, mechanical ventilation systems, or operable windows if summer design infiltration rate is below 0.35 air changes per hour), and ventilation equipment performance factors (rated airflow performance in accordance with HVI-916 and HVI-924) for compliance with the prescriptive requirements of ASHRAE Standard 90.2-1993.

3. Berk et al. 1981 [51] presented tracer gas measurements $\left(\mathrm{SF}_{6}\right)$ of air change rates of two houses, with and without the central forced air systems running.

4. CEC 1999 [66] presented the California building code Title 24 outdoor air requirements for nonresidential, high-rise residential, and hotel/motel buildings.

5. CMHC 1996 [77] described ventilation requirements for residential buildings falling under Part 9 of Canada's 1995 National Building Code (NBC), including required system elements and required ventilation capacity based on number and types of rooms.

6. Cummings 1998 [94] briefly discussed sizing of outside airflows, noting that ventilation airflows should be sized appropriately (minimizing exhaust airflow and using as much indoor air as possible).
7. Dale and Ackerman 1993 [101] discussed the change in attic ventilation rate and effect on living space from attic turbine ventilators. Dale and Ackerman 1991 [100] also discussed this research.

8. Dols et al. 1995 [122] specified recommended outdoor-airflow rates.

9. EPA 1997 [138] mentioned that ASHRAE Standard 62-1989 [18] required rate for residential ventilation. It also specified prescriptive and performance standards for continuous exhaust fan sizing.

10. EPA/DOE 1999 [140] specified that the standard for ventilation and control of indoor air pollutants is ANSI/ASHRAE 62-1989 Ventilation for Acceptable Indoor Air Quality [18].

11. Feustel et al. 1986 [149] discussed TRNSYS modeling of the economic and ventilation performance (average and effective ventilation rates) of natural ventilation and several ventilation strategies (exhaust ventilation, heat recovery ventilation, exhaust ventilation with heat pump heat recovery, and exhaust air heat pump water heating).

12. Grimsrud et al. 1983 [185] gathered infiltration data for 300 houses; this data formed the basis of ASHRAE Standard 62 (ASHRAE 1989 [18]).

13. Matson and Feustel 1998 [263] presented effective annual air change rates for post-1980 construction homes (97 in New York and 66 in California) based on blower door tests. Also presented COMIS multi-zone airflow modeling results for ventilation strategies (single and multi-port exhaust fans with inlet louvers, single and multi-port exhaust fans with outside air ducts, balanced heat recovery) in one and two story houses in California and New York climates.

14. Modera and Jansky 1992 [281] discussed computer-simulated estimates of changes in building infiltration and interzonal airflow due to central ducted HVAC systems operating conditions (fan off, fan on, duct leakage).

15. NAHB 1997 [293] tabulated calculated monthly and seasonal air change rates for a range of house tightness in four U.S. cities.

16. Parker 1989 [313] discussed blower door and tracer gas air change rate measurements of 1980construction conventional and Model Conservation Standards (MCS) construction 
homes in the Pacific Northwest. Estimated mean seasonal air change rates were 0.55 ach for the conventional and 0.28 ach for the MCS homes; using the tracer gas technique, average air change rates (December through March) were 0.31 ach (not corrected for non-uniform mixing) for the conventional homes and 0.35 (including heat recovery ventilation airflow) for the MCS homes.

17. Dols et al. 1995 [120] specified an outdoor airflow rate for office buildings (source unknown).

18. Rajhans 1989 [342] specified recommended outdoor air rates for non-residential buildings.

19. Sherman 1986 [374] discussed the development of ASHRAE Standard 119: Air Leakage Performance for Detached Single-Family Residential Buildings (ASHRAE 1988 [15]).

\section{INDOOR-OUTDOOR AND INTERZONE AIR Pressures}

1. Dols et al. 1995 [122] recommended various interzonal pressures.

2. EPA/DOE 1999 [140] specified that certain spaces use (e.g. printing facilities, smoking lounges, restrooms) must be directly exhausted to the outdoors and be negatively pressurized relative to occupied spaces.

\section{EQUIPMENT SELECTION AND SIZING}

1. ASHRAE 1995 [28] specified exterior joint sealing and optimizing ventilation openings.

2. ConSol 1999 [89] briefly specified procedures for sizing and installation of residential mechanical ventilation to provide an "intentional and controllable" intake of outside air into the conditioned space. Touched on energy efficiency, IAQ, and noise.

\subsection{Controls}

\section{Metric}

\section{Energy Management Control System (EMCS)}

1. Keithly 1999 [229] discussed control installation, listing common deficiencies in control system specifications.

\section{Diagnostic}

\section{ROOM THERMOSTATS}

1. EPA 1998 [139] recommended that a tune-up of building controls include calibrating indoor and outdoor building sensors (e.g., thermostats, humidistats); inspection of damper and valve controls; review of building operating schedules; and review of utility rate schedule (to seek opportunities to use cheaper off-peak power). It noted that typical cooling and heating savings can range up to $30 \%$.

2. Madsen et al. 1990 [260] found in laboratory and field tests that temperature variation in a living space can be reduced when the room thermostat is moved from the wall to a location within the room.

\section{THERMAL EXPansION DEVICES}

1. Farzad and O'Neal 1993 [146] found that the TXV system performance variables showed a small variation with the refrigerant charge but a strong dependence on the outdoor temperature.

\section{EMCS MONITORING}

1. Brohard and Krieg 1994 [59] listed a series of steps for contractor commissioning of air, chilled-water, chiller, evaporative condenser, and DDC control systems.

2. Cole and Holness 1989 [84] discussed the use of programmable logic controllers (PLCs) to control HVAC equipment in a manufacturing plant, and compared them to pneumatic and direct digital control (DDC) systems.

3. Elovitz 1986 [134] discussed control installation, giving examples of EMCS sensor calibration and how it can go wrong.

4. Koran 1994 [242] used a building's energy management control system (EMCS) to monitor over 200 building performance parameters (e.g., chiller flows, temperatures, and powers) for a year.

5. Sabeff 1994 [358] described how an EMCS can be used for commissioning, but only the EMCS itself is commissioned first.

6. Tseng et al. 1994 [434] listed EMCS monitoring points for an air handling unit, an electric hot water thermal storage system, an ice harvester thermal cool storage system, and a cooling tower 
for the ice harvester. Also discussed when to use hardware and software monitoring points.

\section{VENTILATION CONTROL}

1. Schell 1995 [365] noted that ventilation rates may be adjusted using $\mathrm{CO}_{2}$ controls to achieve a desired indoor $\mathrm{CO}_{2}$ level indicative of good air quality.

\section{CoILS AND MiXING Boxes}

1. Haves et al. 1996 [208] used automated techniques for fault detection in HVAC coils and mixing box controls.

\section{HVAC}

1. Cole and Holness 1989 [84] described the use of programmable logic controllers for HVAC control, comparing the relative merits of such devices vs. pneumatic or direct digital control systems.

2. SMACNA 1993 [407] discussed HVAC electrical and thermostatic control basics.

\section{Norm}

\section{ROOM THERMOSTATS}

1. Werling et al. 1998 [460] noted that an Energy Star Home must have a programmable thermostat.

\subsection{HVAC Installation Process}

\section{Metric}

1. Allen Consultants 1996 [1] discussed potential changes in design and construction of forced-air duct systems.

2. Gupton 1986 [196] listed HVAC installation details to verify, and gave instructions on how to specify HVAC commissioning.

3. Hammon and Modera 1996 [199] discussed strategies and provided key action items to integrate tight duct construction parameters and factors into HERS, Title 24, and energy-efficient mortgages. Also provided material and performance metrics.

4. Persily 1999 [322] described an IAQ performance guide being developed within ASTM that stated that condensate from air conditioning equipment should be able to drain freely and completely. Also stated that HVAC equipment design and installation should ensure accessibility for inspection, maintenance, and cleaning.

\section{Diagnostic}

1. Brohard and Krieg 1994 [59] listed a series of steps for contractor commissioning of air, chilled-water, chiller, evaporative condenser, and DDC control systems.

2. EPA 1997 [138] listed four tests used to ensure that subcontractors are performing quality work: a blower-door test to detect excessive envelope leakage, a duct leakage test, an HVAC system inspection, and testing airflow across the inside coil to ensure proper airflow to the duct system.

3. Hammon and Modera 1996 [199] discussed strategies and provided key action items to integrate tight duct construction parameters and factors into HERS, Title 24, and energy-efficient mortgages. Also provided material and performance metrics.

4. Han et al. 1999 [201] discussed automated diagnostic techniques for DDC VAV systems in commercial buildings.

5. Meckler 1991 [267] detailed steps that contractors should take in the design, construction, and occupancy phases of HVAC installation to avoid IAQ problems.

\section{Norm}

1. Hammon and Modera 1996 [199] discussed costs and energy savings attributable to tight duct construction in new construction.

2. Persily 1999 [322] described an IAQ performance guide being developed within ASTM that stated that to prevent water vapor and dust from entering the building interior, exhaust from clothes dryers should be vented to the outdoors. 


\section{INDOOR AIR QUALITY}

\subsection{Room Air Temperature and Velocity (Occupant Comfort)}

\section{Metric}

\section{OCCUPANT COMFORT}

1. ASHRAE 1992 [23] defined operative temperature range for thermal comfort (the temperature range in which no more than $10 \%$ of a building's occupants performing light activity will find the environment thermally unacceptable).

2. Fanger 1992 [143] described indoor air and thermal comfort metrics (percent mean vote [PMV], percent people dissatisfied [PPD], olfs, draft risk).

3. Fountain and Huizenga 1997 [167] discussed computer-predicted thermal comfort indices, including predicted mean vote (PMV), predicted percent dissatisfied (PPD), new effective temperature (ET), standard effective temperature (SET), and nine others.

4. Koles et al. 1996 [241] discussed a thermal comfort metric (Predicted Percent Dissatisfied [PPD]).

5. Levermore et al. 1999 [250] defined an Overall Liking Score that gages occupants' overall satisfaction with the building environment, and a Likeness Fingerprint that shows what in particular occupants like or dislike.

6. Persily 1999 [322] described an IAQ performance guide being developed within ASTM, including thermal comfort parameters based on ASHRAE Standard 55 and ISO 7730.

7. Rajhans 1989 [342] listed field measurements made with simple instruments (temperature, $\mathrm{RH}$, $\mathrm{CO}_{2}$, formaldehyde, $\mathrm{CO}$, air movement) and those made with complex instruments (microorganisms, respirable suspended particulates, organic vapor, ozone, $\mathrm{NO}_{\mathrm{x}}$, asbestos).

8. Rajhans 1989 [342] listed field measurements made with simple instruments (temperature, $\mathrm{RH}$, $\mathrm{CO} 2$, formaldehyde, $\mathrm{CO}$, air movement) and those made with complex instruments (microorganisms, respirable suspended particulates, organic vapor, ozone, $\mathrm{NO}_{x}$, asbestos.)
9. Sherman 1984 [372] defined simplified expressions for thermal comfort, including predicted mean vote (PMV), effective temperatures, and comfort temperatures. Provided tables of comfort of effective temperature coefficients, and charts of comfort temperatures versus various factors.

10. Sherman and Ashley 1984 [377] defined LBL effective temperature (an environmental temperatures that depends on air temperature, mean radiant temperature, dew point, and wind speed), NCEL effective temperature, and comfort temperature.

11. Walker et al. 1998 [453] discussed REGCAP, a computer model that evaluates residential HVAC system component performance and whole house performance based on measured data (ducts, equipment, envelope, and climate) to provide an estimate of duct, equipment and envelope performance and net cooling delivered (tons at the register).

\section{Diagnostic}

\section{OCCUPANT COMFORT}

1. Arens et al. 1986 [10] updated a 1950's-vintage "bioclimatic" human-comfort chart to reflect current (1986) ASHRAE comfort criteria, and to use a "rationally-derived" index for determining comfort. Parameters include dry bulb temperature, humidity, wind speed, and radiation intensity.

2. ASTM 2000 [36] discussed performance statements (objectives, criteria, evaluation methods, and commentary) for thermal comfort, referencing ASHRAE Standard 55 and mentioning the need to develop evaluation criteria suited for residential applications.

3. Chan et al. 1999 [68] described a portable indoor environmental quality data logger that monitors the indoor environment and lets occupants register their comfort satisfaction with the environment on panel switches.

4. CMHC 1998 [79] discussed thermal comfort issues related to inefficient mechanical systems, poor quality or poorly installed materials, poor maintenance or faulty equipment, or building envelope problems. A thermal comfort checklist was included to help diagnose problem.

5. Dols et al. 1995 [120] described a methodology to measure IAQ effectiveness in commercial building commissioning, including ventilation 
performance (outdoor airflow rate and pressure relationships between zones), pollutants $\left(\mathrm{CO}_{2}\right.$, $\mathrm{CO}$, formaldehyde, particulates, radon and VOCs), and thermal comfort (temperature, relative humidity, and operative temperature).

6. Fountain and Huizenga 1996 [166] described a software tool for thermal comfort prediction that may be integrated into tools to model thermal comfort conditions for research, design, and system operation.

7. Fountain and Huizenga 1997 [167] developed a user-friendly computer program that uses three heat-balance, three empirical, and two adaptive models to predict thermal comfort given input parameters including temperature, humidity, air speed, clothing, and metabolic rate.

8. Hassani and Stetz 1994 [207] used a lowthermal- mass, porous, fiberglass screen in conjunction with an infrared camera to measure room air temperature.

9. Lane et al. 1989 [245] discussed four main components of a procedure to diagnose a sick building or confirm a healthy building: knowledge of what to measure, availability of appropriate instrumentation, expertise in interpreting results of measurements, and capability of predicting building performance.

10. Levermore et al. 1999 [250] described an occupant comfort satisfaction feedback questionnaire that yields a "fingerprint" and score indicating their liking of their environment.

11. Mansson 1999 [262] described a tool that inputs parameters describing a building's ventilation system, envelope, and climate, and outputs ratings of IAQ (material, hours with too high $\mathrm{CO}_{2}$, tobacco smoke, cooking emission); level of condensation; energy required to heat indoor air; dryness feeling (low RH); high winter RH (leading to dust mite growth), and indooroutdoor pressure difference.

12. Rajhans 1989 [342] listed field measurements made with simple instruments (temperature, $\mathrm{RH}$, $\mathrm{CO}_{2}$, formaldehyde, $\mathrm{CO}$, air movement) and those made with complex instruments (microorganisms, respirable suspended particulates, organic vapor, ozone, $\mathrm{NO}_{\mathrm{x}}$, asbestos). Also provided an occupant IAQ survey.

13. Ross and Sterling 1997 [354] presented, for a commercial building, the results of pre- and postoccupancy measurements of TVOC, formaldehyde, respirable suspended particles
(RSP), $\mathrm{CO}_{2}, \mathrm{CO}$, temperature, and relative humidity. Testing apparatus included integrated sampling and direct reading (instantaneous) automated analyzers. Plans and materials specifications were reviewed prior to the on-site testing.

14. Walker et al. 1998 [453] discussed REGCAP, a computer model that evaluates residential HVAC system component performance and whole house performance based on measured data (ducts, equipment, envelope, and climate) to provide an estimate of duct, equipment and envelope performance and net cooling delivered (tons at the register).

15. Zmeureanu et al. 1998 [469] monitored room and register air temperatures with a data logger.

\section{Norm}

\section{OCCUPANT COMFORT}

1. ASHRAE 1992 [23] specified the combinations of indoor space environment and personal factors that will produce thermal environmental conditions acceptable to $80 \%$ or more of the occupants within a space (temperature, thermal radiation, humidity and air speed; excludes IAQ, acoustics, illumination).

2. Dols et al. 1995 [120] presented a table of existing IAQ criteria including outdoor airflow rate, pressure relationships between zones, $\mathrm{CO}_{2}$, $\mathrm{CO}$, formaldehyde, particulates, radon, total VOCs and thermal comfort.

3. Dols et al. 1994 [121] included, in an indoor air quality commissioning protocol, thermal comfort and ventilation norms based on the BOCA National Mechanical Code, ASHRAE Standard 62-1989 and ASHRAE Standard 55-1992. Dols et al. [123] discussed this protocol, subsequent commissioning results, and lessons learned.

4. EPA/DOE 1999 [140] specified that the standard for thermal comfort is ANSI/ASHRAE Standard 55-1992, Thermal Comfort Conditions for Human Occupancy [23].

5. Odom 1997 [306] discussed the types of IAQ problems (high-frequency/low-consequence vs. low-frequency/high-consequence). Also discussed how IAQ problems are more apt to be seen in the first few years of occupancy in new buildings or in older buildings were usage patterns and occupancy has changed. 
6. Zhivov et al. 1994 [468] discussed the international differences in thermal comfort, ventilation and energy-efficient construction standards and codes.

\subsection{Non-Biological Gaseous Pollutant Generation, Transport, and Concentration}

\section{Metric}

\section{Pollutant Level OR IndeX}

1. ASHRAE 1989 [18] specified CO exposure level limits in terms of average concentration and cumulative concentration over a particular measurement period.

2. Bearg 1999 [46] noted that $\mathrm{CO}$ levels in occupied areas can indicate the extent to which the HVAC system is removing vehicle exhaust from building loading docks and parking areas. Also noted that $\mathrm{CO}_{2}$ concentrations are an indicator of ventilation performance.

3. CMHC 1998 [79] described soil gas transport and indoor air quality physics and mechanisms.

4. Dols et al. 1995 [122] noted that CO levels can be monitored to detect the transport of garage fumes into a building.

5. Karg 1999 [224] discussed metrics for $\mathrm{CO}$ levels.

6. Moschandreas and Sofuoglu 1999 [289] defined an Indoor Air Pollution Index (IAPI), a metric for overall air quality that sums the effects of multiple pollutants.

7. Su et al. 1999 [417] measured pollutant levels in units of PPM or $\mu \mathrm{g} \mathrm{m}^{-3}$.

\section{Diagnostic}

\section{POllutant Level or INDEX}

1. ASTM 2000 [36] discussed performance statements (objectives, criteria, evaluation methods, and commentary) for radon control, referencing ASTM Standard E1465 and testing to make sure indoor radon concentrations are less than $4 \mathrm{pCi} / \mathrm{L}$. Discussed reducing pollutant transport from unconditioned spaces, garages, and outside the building, as well as reducing emissions within the building.
2. Barbat et al. 1999 [44] measured $\mathrm{CO}_{2}$ levels with a B\&K 1302 gas analyzer.

3. Bearg 1998 [45] noted that CO level can be used to detect building infiltration by vehicle exhaust.

4. Bearg 1999 [46] discussed $\mathrm{CO}_{2}$ level measurement techniques, including grab samples, one monitor at one location, several monitors at several locations, or a shared-sensor system with many sample lines; the author prefers the latter. Measured $\mathrm{CO}_{2}, \mathrm{CO}$, and dew point to track commercial building HVAC performance during commissioning.

5. Benton et al. 1996 [49] mentioned a particular $\mathrm{CO}_{2}$ monitor that costs $\$ 450$.

6. Berk et al. 1981 [51] discussed gas measurements (formaldehyde, radon, $\mathrm{CO}, \mathrm{CO}_{2}$, $\mathrm{SO}_{2}, \mathrm{NO}, \mathrm{NO}_{\mathrm{x}}, \mathrm{O}_{3}$ ) conducted in nine houses, pre- and post-retrofit.

7. Cheong and Riffat 1993 [69] measured $\mathrm{CO}_{2}, \mathrm{CO}$, and $\mathrm{HCHO}$ with a Miran Portable Ambient Analyzer (accuracy $+/-15 \%$ ).

8. Dols et al. 1995 [122] measured CO levels with an unspecified automated $\mathrm{CO}$ monitoring system.

9. Lane et al. 1989 [245] discussed four main components of a procedure to diagnose a sick building or confirm a healthy building: knowledge of what to measure, availability of appropriate instrumentation, expertise in interpreting results of measurements, and capability of predicting building performance.

10. Rajhans 1989 [342] recommended instrumentation for simple field IAQ measurements (including pollutant levels), and specified when and where to measure pollutant levels.

11. Ross and Sterling 1997 [354] presented, for a commercial building, the results of pre- and postoccupancy measurements of TVOC, formaldehyde, respirable suspended particles (RSP), $\mathrm{CO}_{2}, \mathrm{CO}$, temperature, and relative humidity. Testing apparatus included integrated sampling and direct reading (instantaneous) automated analyzers. Plans and materials specifications were reviewed prior to the on-site testing.

12. Schalch and Fryer 1992 [364] discussed the Energy Crafted Home's indoor air quality recommendations (avoid materials with high urea-formaldehyde content and provide a sub- 
slab layer of stone that permits the installation of a sub-slab depressurization system if necessary).

13. Schell 1995 [365] noted that indoor $\mathrm{CO}_{2}$ levels indicate the ventilation rate, and that a controller can be used to control ventilation rates to maintain a $\mathrm{CO}_{2}$ level setpoint.

14. Stock et al. 1999 [416] compared the performance of $3 \mathrm{M}$ OVM diffusive (passive) VOC sampler with a reference VOC monitoring method (canister sampling). Found a good correlation for 8 of 12 target compounds; however, the passive sampler exhibited a statistically significant low bias for all but two of the VOCs.

15. Su et al. 1999 [417] specified techniques used to measure many pollutants.

16. Tsongas 1995 [436] recommended equipment for monitoring $\mathrm{CO}$ levels and specified an oven $\mathrm{CO}$ test protocol. Also stated the US EPA, WHO, and Health Canada recommended limits for $\mathrm{CO}$ exposure.

\section{CONTAMINANT SOURCES}

1. Persily 1999 [322] described an IAQ performance guide being developed within ASTM, including radon-related construction requirements and measurement of indoor radon concentration after construction (not to exceed 4 $\mathrm{pCi} / \mathrm{L}$ ). Also included emission rates from furnishings and materials using tests based on ASTM D5116.

2. Rajhans 1989 [342] discussed indoor and outdoor sources of indoor air contaminants. Also presented a checklist to detect IAQ problems related to combustion $(\mathrm{CO})$, other pollutant sources, HVAC, maintenance and design.

3. Tsongas and Hager 1994 [438] discussed testing procedures to measure $\mathrm{CO}$ from gas ovens.

\section{CONDENSATION POTENTIAL}

1. CMHC 1998 [79] discussed window moisture problems, including a checklist of typical problems and solutions.

2. Warner 1991 [456] discussed how to avoid window condensation by increasing window $\mathrm{R}$ values, sealing cracks and joints around windows, or by increasing house ventilation rates.

\section{$\underline{\text { Norm }}$}

\section{Pollutant Level or INDEX}

1. ASHRAE 1989 [18] specified indoor, outdoor, and industrial-workplace $\mathrm{CO}$ exposure limits.

2. Berk et al. 1981 [51] presented gas measurement results (formaldehyde, radon, $\mathrm{CO}, \mathrm{CO}_{2}, \mathrm{SO}_{2}$, $\mathrm{NO}, \mathrm{NO}_{\mathrm{x}}, \mathrm{O}_{3}$ ) from nine houses, pre- and postretrofit.

3. Dols et al. 1994 [121] included, in an indoor air quality commissioning protocol, pollutant exposure levels and maximum concentration levels for carbon dioxide, carbon monoxide, formaldehyde, radon and volatile organic compounds. Dols et al. [123] discussed this protocol, subsequent commissioning results, and lessons learned.

4. Dols et al. 1995 [122] presented recommended office-building pollutant levels $\left(\mathrm{CO}_{2}, \mathrm{CO}\right.$, formaldehyde, particulates, radon, TVOC) predicted to satisfy $90 \%$ of occupants.

5. Nagda et al. 1987 [292] described an IAQmonitoring guideline that lists exposure limits (from various organizations) to biological, nonbiological, and particulate airborne pollutants.

6. Odom 1997 [306] discussed the types of IAQ problems (high-frequency/low-consequence vs. low-frequency/high-consequence). Also discussed how IAQ problems are more apt to be seen in the first few years of occupancy in new buildings or in older buildings were usage patterns and occupancy has changed.

7. Rajhans 1989 [342] provided indoor air quality guidelines prepared by the World Health Organization (1984).

8. Seifert et al: 1999 [366] presented German government guidelines for Lowest Observed Adverse Effect Level (LOAEL) of various pollutants (toluene, styrene, dichloromethane, penetachlorophenol, carbon monoxide, nitrogen dioxide), and also presented guidelines value for the indicator total volatile organic compounds (TVOC).

9. Tsongas and Hager 1994 [438] presented EPA 1hour and 8-hour limits for $\mathrm{CO}$ exposure. 


\subsection{Moisture Generation, Storage, Transport, Concentration, and Absorption}

\section{$\underline{\text { Metric }}$}

\section{HUMIDITY LEVEL}

1. Bearg 1998 [45] noted that dew point (humidity level) can be monitored with a shared sensor (for comfort, to prevent fungal growth, and to check that the humidification systems are working properly).

2. Forest and Walker 1991 [161] discussed measurement and model input variables to determine airflow and moisture content in attics. Forest and Walker 1992 [162], 1993 [163], 1993 [164], and Walker and Forest 1995 [452] also discussed this research.

3. Moschandreas and Sofuoglu 1999 [289] defined an Indoor Air Pollution Index (IAPI), a metric for overall air quality that sums the effects of multiple pollutants.

4. Persily 1999 [322] described an IAQ performance guide being developed within ASTM, including issues related to excessive condensation within exterior wall construction. Criteria are based on the analysis of the design, followed by a lack of evidence of condensation after construction. Also included issues relating to moisture (foundation, crawl space, grade enclosures, roofs, exterior walls, windows, and doors) and minimization of water entry. Referenced ASTM E241 and the ASTM Moisture Control in Buildings Manual.

\section{Diagnostic}

\section{HUMIDITY LEVEL}

1. Bearg 1998 [45] noted that dew point (humidity level) can be monitored with a shared sensor (for comfort, to prevent fungal growth, and to check that the humidification systems are working properly).

2. Bearg 1999 [46] measured $\mathrm{CO}_{2}, \mathrm{CO}$, and dew point to track commercial building HVAC performance during commissioning.

3. Finley 1997 [151] evaluated airflow paths to determine their effect on indoor air problems (mold and moisture) and to determine mitigation strategies.
4. Forest and Walker 1991 [161] discussed measuring and modeling airflow and moisture content in attics. Forest and Walker 1992 [162], 1993 [163], 1993 [164], and Walker and Forest 1995 [452] also discussed this research.

5. Lane et al. 1989 [245] discussed four main components of a procedure to diagnose a sick building or confirm a healthy building: knowledge of what to measure, availability of appropriate instrumentation, expertise in interpreting results of measurements, and capability of predicting building performance.

6. Tooley et al. 1994 [428] presented testing methodology to diagnose problems with attic ventilators, house or zone depressurization, moisture damage, and air barriers.

7. Walker 1993 [450] discussed an attic simulation model (airflow and moisture) and measured data to evaluate attic ventilation and moisture problems.

\section{$\underline{\text { Norm }}$}

\section{HUMIDITY LeVEL}

1. Odom 1997 [306] discussed how buildings in hot and humid climates are more prone to failure due to problems with the building envelope and related barriers.

\subsection{Bioaerosol (Fungi/Molds/Mites) Generation, Transport, and Concentration}

\section{Metric}

\section{Pollutant LeVel OR INDEX}

1. Deng et al. 1999 [107] measured dust mite concentration by counting the number of microscopically-observable dust mites per sticky sampling sheet.

2. Fluckiger et al. 1999 [158] measured fungal concentration in terms of colony forming units (CFU) per $\mathrm{m}^{-3}$, and biological units (BU) per $\mathrm{m}^{-3}$.

3. Moschandreas and Sofuoglu 1999 [289] defined an Indoor Air Pollution Index (IAPI), a metric for overall air quality that sums the effects of multiple pollutants.

4. Rajhans 1989 [342] listed field measurements made with simple instruments (temperature, $\mathrm{RH}$, $\mathrm{CO}_{2}$, formaldehyde, $\mathrm{CO}$, air movement) and 
those made with complex instruments (microorganisms, respirable suspended particulates, organic vapor, ozone, $\mathrm{NO}_{\mathrm{x}}$, asbestos).

5. Su et al. 1999 [417] used $\mathrm{CFU} \mathrm{m}^{-3}$ as a metric for fungal concentration, and $\mu \mathrm{g}$ allergen per $\mathrm{g}$ dust for allergens.

6. Womble et al. 1999 [464] used CFU m ${ }^{-3}$ as a metric for fungal concentration.

\section{Diagnostic}

\section{Pollutant LeVEL OR INDEX}

1. CMHC 1998 [79] described the physics, mechanisms, health hazards of mold growth and transport, including a checklist of ways to reduce and control moisture and mold growth.

2. Deng et al. 1999 [107] collected dust mites from air by deposition on sticky sampling tape.

3. Finley 1997 [151] evaluated airflow paths to determine their effect on indoor air problems (mold and moisture) and to determine mitigation strategies.

4. Fluckiger et al. 1999 [158] sampled mold using slit-samplers. Petri dishes filled with malt extract agar collected viable mold spores and allergens from air, and multistage liquid impingers with phosphate buffered saline were used for multi-stage sampling.

5. Kemp et al. 1999 [231] compared three methods of extracting fungi from dust samples, and was satisfied only with sprinkling dust onto agar plates.

6. Lane et al. 1989 [245] discussed four main components of a procedure to diagnose a sick building or confirm a healthy building: knowledge of what to measure, availability of appropriate instrumentation, expertise in interpreting results of measurements, and capability of predicting building performance.

7. Rajhans 1989 [342] recommended instrumentation for simple field IAQ measurements (including pollutant levels), and specified when and where to measure pollutant levels.

8. Womble et al. 1999 [464] collected airborne fungi on an inertial impactor and sent the samples to a lab for culture and analysis.

\section{Contaminant SOURCES}

1. Flannigan 1992 [156] discussed microbial sampling techniques, including pros and cons, potential problems; highlights need for simpler techniques that can be used in the field.

2. Morey and Horner 1997 [287] discussed measurement and mitigation strategies for microbiological VOCs (MVOCs); included references to documents on diagnostic and mitigation.

3. Rajhans 1989 [342] discussed indoor and outdoor sources of indoor air contaminants.

\section{Norm}

\section{POLLUTANT LEVEL OR INDEX}

1. Morey and Horner 1997 [287] presented microbiological VOC (MVOC) sampling results from buildings in all major geographical areas of the U.S.

2. Nagda et al. 1987 [292] described an IAQmonitoring guideline that lists exposure limits (from various organizations) to biological, nonbiological, and particulate airborne pollutants.

\section{Contaminant Sources}

1. EPA/DOE 1999 [140] specified that a building should be free of microbiological sources (e.g., no visible microbial growth on walls).

2. Flannigan 1992 [156] discussed classifications of microbial species based on $a_{w}$ ("water activity," a ratio of vapor pressures, which provides a truer indication of moisture availability for microbial growth).

3. Odom 1997 [306] discussed how biological pollutants are often more expensive to mitigate as removal of building materials that have significant infestations of mold and mildew must be conducted very carefully to prevent contamination of additional surfaces and prevent exposure of workers or adjacent occupants. 


\subsection{Particulate Generation, Transport, and Concentration}

\section{$\underline{\text { Metric }}$}

\section{POLLUTANT LeVEl OR INDEX}

1. ASHRAE 1989 [18] described pollutant level in terms of concentration averaged over a particular measurement period.

2. Holopainen et al. 1999 [212] gaged the dust concentration in duct air in terms of dust deposition on the duct wall $\left(\mathrm{g} \mathrm{m}^{-2}\right)$.

3. Moschandreas and Sofuoglu 1999 [289] defined an Indoor Air Pollution Index (IAPI), a metric for overall air quality that sums the effects of multiple pollutants.

4. Rajhans 1989 [342] listed field measurements made with simple instruments (temperature, $\mathrm{RH}$, $\mathrm{CO}_{2}$, formaldehyde, $\mathrm{CO}$, air movement) and those made with complex instruments (microorganisms, respirable suspended particulates, organic vapor, ozone, $\mathrm{NO}_{\mathrm{x}}$, asbestos). Also provided IAQ guidelines prepared by the World Health Organization (1984).

5. Turner et al. 1996 [441] compared particlesampling methodologies (PM-10, PM-2.5) to near real-time particle samplers (laser diodebased counter) in three commercial settings (preand post- IAQ remediation).

\section{Diagnostic}

\section{Pollutant Level or Index}

1. Berk et al. 1981 [51] discussed particulate measurements conducted in nine houses, preand post-retrofit.

2. Deng et al. 1999 [107] collected dust (settled particles and fibers) for a week on glass covered with a thin Vaseline layer, then examined the collection with a $150 \mathrm{X}$ optical microscope.

3. Fluckiger et al. 1999 [158] collected dust samples with an allergen mouthpiece attached to a household vacuum cleaner.

4. Holopainen et al. 1999 [212] compared three duct-air sampling methods: vacuum collection onto a pre-weighed filter, mass of dust deposited on a sampling tape, and optical transmission through a dust sampling tape.
5. Lane et al. 1989 [245] discussed four main components of a procedure to diagnose a sick building or confirm a healthy building: knowledge of what to measure, availability of appropriate instrumentation, expertise in interpreting results of measurements, and capability of predicting building performance.

6. Rajhans 1989 [342] recommended instrumentation for simple field IAQ measurements (including pollutant levels), and specified when and where to measure pollutant levels.

7. Ross and Sterling 1997 [354] presented, for a commercial building, the results of pre- and postoccupancy measurements of TVOC, formaldehyde, respirable suspended particles (RSP), $\mathrm{CO}_{2}, \mathrm{CO}$, temperature, and relative humidity. Testing apparatus included integrated sampling and direct reading (instantaneous) automated analyzers. Plans and materials specifications were reviewed prior to the on-site testing.

8. Turner et al. 1996 [441] compared particlesampling methodologies (PM-10, PM-2.5) to near real-time particle samplers (laser diodebased counter) in three commercial settings (preand post- IAQ remediation).

\section{CONTAMINANT SOURCES}

1. Rajhans 1989 [342] discussed indoor and outdoor sources of indoor air contaminants.

\section{$\underline{\text { Norm }}$}

\section{Pollutant Level or Index}

1. ASHRAE 1989 [18] specified indoor, outdoor, and industrial workplace asbestos exposure limits.

2. Berk et al. 1981 [51] presented particulate measurements from nine houses, pre- and postretrofit.

3. Dols et al. 1994 [121] included, in an indoor air quality commissioning protocol, pollutant exposure levels and maximum concentration levels for particulates. Dols et al. [123] discussed this protocol, subsequent commissioning results, and lessons learned.

4. Dols et al. 1995 [122] presented recommended office-building pollutant levels $\left(\mathrm{CO}_{2}, \mathrm{CO}\right.$, formaldehyde, particulates, radon, TVOC) predicted to satisfy $90 \%$ of occupants. 
5. Nagda et al. 1987 [292] described an IAQmonitoring guideline listing exposure limits (from various organizations) to biological, nonbiological, and particulate airborne pollutants.

\section{OTHER}

\subsection{Domestic Hot Water}

\section{Metric}

1. Sherman et al. 1987 [401] discussed water-heater recovery efficiency (gas only), and water-heater standby losses (gas and electric).

\section{Diagnostic}

1. ASHRAE 1993 [25] specified the ASHRAE test procedure for rating the efficiency of residential water heaters. Test procedures include measuring water and ambient temperatures (nine thermocouples), water flow, energy supply (electric, gas, oil), and tank storage capacity; test results include an energy factor and the hot water delivery capability in terms of a first-hour rating.

2. Sherman et al. 1987 [401] discussed water-heater recovery efficiency (gas only), and water-heater standby losses (gas and electric).

3. Stewart et al. 1999 [415] discussed modeling techniques to determine system losses in residential and commercial hot water systems, using the transient convective energy equation and Fourier's conduction model along with system characteristics and usage patterns. Calculated system losses can be taken into account when sizing hot water heaters and boilers.

\section{Norm}

1. ASHRAE 1993 [27] specified domestic water heater selection (efficiency, performance) and installation requirements for compliance with the prescriptive requirements of ASHRAE Standard 90.2-1993.

2. ASHRAE 1995 [28] described basic and prescriptive requirements for water heating systems, including sizing of systems, equipment efficiency, piping insulation, and controls. Also specified standard rating conditions, operating factors, applicable standards, and minimum performance factors for boilers and water- heating equipment; specified minimum pipeinsulation levels for distribution piping.

3. BII 1998 [53] briefly specified procedures for water heater jackets and pipe insulation.

4. CEC 1999 [66] presented the California building code Title 24 requirements for insulation of and heat loss from water heater tanks.

5. DOE 1995 [116] discussed background information on HERS heating, air-conditioning and water heating equipment for HERS policy options being discussed in DOE's 1995 request for comments on fuel neutrality and adjustment factors, and standard efficiencies.

6. DOE 1995 [117] discussed (in greater detail than DOE 1995 [116]) the analysis of heating, airconditioning, and water heating equipment adjustment factors for the HERS guidelines.

7. Schalch and Fryer 1992 [364] discussed the Energy Crafted Home's requirement that heating and water heating equipment must have sealed or closed combustion.

8. Weingarten and Weingarten [457] discussed water heater types, maintenance tasks, and options and specifications related to installing and upgrading water heaters.

9. Weingarten and Weingarten 1996 [458] in a response to a letter to the editor, discussed how to remove and replace water heater anodes.

\subsection{Lighting}

\section{Metric}

NONE

\section{$\underline{\text { Diagnostic }}$}

1. EPA 1998 [139] detailed a three-step process for a lighting system tune-up: (1) green lights (follow a strategic lighting maintenance plan of schedule groups relamping and fixture cleaning);

(2) measure and ensure proper light levels; and

(3) calibrate lighting controls. It noted that savings from cleaning fixtures can range from 10 to $60 \%$, and that calibration of occupancy sensors and photocells can reduce energy use in served areas by $50 \%$ or more.

2. UL 1999 [442] names U.S. and Canadian test standards for the energy efficiency of fluorescent lamp ballasts. 


\section{$\underline{\text { Norm }}$}

1. CEC 1999 [66] presented the California building code Title 24 standards for lighting controls.

2. EPA 1997 [138] listed both standard and energyefficient choices for lighting living spaces, bathrooms, laundry areas, and garage/utility areas.

3. Schalch and Fryer 1992 [364] discussed the Energy Crafted Home's lighting requirements, including hard-wired fluorescents and compact fluorescents in bare bulb and decorative fixtures.

\subsection{Plug Loads}

\section{Metric}

1. Sherman et al. 1987 [401] discussed monthly refrigerator energy consumption. Long-term monitoring was needed due to large daily fluctuation in energy consumption. This included measuring fridge and freezer compartment temperatures, door openings/closings, and the ambient temperature.

\section{Diagnostic}

1. Coyle 1999 [91] extended building commissioning to electric systems, listing representative electric integrity tests, representative functional performance tests, who should performs the tests, and specifications for said tests.

2. EPA 1998 [139] noted opportunities for improving the efficiencies of a building's electric power systems, including evaluating and correcting voltage imbalances, voltage deviations, poor connections, undersized conductors, poor power factors, insulation leakage, and harmonics.

3. Mixon and Meier 1990 [273] compared and listed sources for four different electric-load monitoring methods.

4. Sharp 1994 [369] discussed the hardware, installation, capabilities, and application of nonintrusive (electric) load monitoring systems (NILMS).

5. Sherman et al. 1987 [401] discussed refrigerator energy consumption, including measuring refrigerator and freezer compartment temperatures, openings and closing of compartment doors, ambient temperature, and electric energy use.

\section{Norm}

1. Meier 1993 [268] reported that the Energy Guide labels affixed to new refrigerators predict actual energy consumption fairly well, though they may under predict energy use in warm southern U.S. states.

2. Meier 1993 [269] listed typical month power consumption of many common household appliances.

3. Parker and Stedman 1993 [312] measured kitchen, refrigerator, and freezer temperatures, door openings, and plug loads to determine the refrigeration performance improvements and energy savings achieved by replacing an old refrigerator with a new, similarly-featured, energy efficient model.

4. Parker et al. 1998 [314] measured miscellaneous energy loads (e.g. security system, portable phones, aquarium pump, computer), reporting watts, hours/day, and annual kWh.

5. Sherman et al. 1985 [381] examined the overall energy impacts of two energy-efficient refrigerators in four types of houses with and without space cooling equipment. The heating and cooling loads of each of the houses are determined with an hour-by-hour simulation program (TRNSYS) for three climates in the Pacific Northwest.

\subsection{Air Filters and Cleaners}

\section{$\underline{\text { Metric }}$}

1. ASHRAE 1992 [22] defined arrestance (ability of a device to remove dust from air), dustholding capacity, dust-spot opacity (percentage decrease in light transmission due to dust buildup on target), opacity index.

2. Persily 1999 [322] described an IAQ performance guide being developed within ASTM, including objectives related to filtration (particulate filtration should be provided in forced-air heating and cooling systems in order to control particulate levels in the indoor air and the maintain the cleanliness of HVAC components). 


\section{$\underline{\text { Dagnostic }}$}

1. ASHRAE 1992 [22] described gravimetric and dust-spot procedures for measuring the efficiency with which air-cleaning devices arrest (remove) dust.

2. ASTM 2000 [36] discussed HVAC-system airfiltration criteria and visual inspection requirements.

3. Hanley et al. 1994 [202] described a laboratory test method to test fractional filtration efficiency of air cleaners used in general ventilation. The test method requires a test rig that pre-filters air, adds potassium chloride as a test particulate, and measures and differentiates penetration rates based on particulate size.

\section{Norm}

1. Hanley et al. 1994 [202] presented fractional filtration efficiency test results, based on particulate size, using a laboratory test rig. Provided results for pleated-paper filters, electronic air cleaners (electrostatic precipitator type), and fiberglass furnace filters.

\subsection{Noise}

\section{Metric}

\section{NONE}

\section{Diagnostic}

1. CMHC 1998 [79] discussed noise transmission in houses and mitigation through house layout and installation of insulation.

\section{Norm}

NONE

\subsection{Maintenance Ease and Necessity}

Metric

NONE

\section{Diagnostic}

NONE

Norm

NONE

\subsection{Instrumentation}

\section{Metric}

NONE

\section{Diagnostic}

1. Arney and Frey 1995 [12] explained why shortterm monitoring is better than one-time functional performance tests when evaluating HVAC system temperatures, humidity levels, fan energy, and evaporative cooler pump energy.

2. ASHRAE 1989 [17] presented the ASHRAE standard orifice-flowmeter method for measurement of liquid flow in pipes, for use with fluids associated with HVAC systems.

3. ASHRAE 1991 [19] presented the ASHRAE standard method for measuring temperatures.

4. ASHRAE 1991 [20] presented the ASHRAE standard method for measurement of gas flow.

5. Benton et al. 1996 [49] described assorted data loggers and sensors for short-term monitoring.

6. Bevirt 1994 [52] listed six temperaturemeasurement instruments, specifying recommended uses and limitations.

7. Bowman and Goldberg 1994 [58] extensively discussed how to choose electric-load monitoring instruments suitable for a particular project. 
8. Cummings et al. 1990 [98] discussed tracer gas, blower door, smoke and visual inspection methods to study the effects of duct leakage on airflow, infiltration, heating and cooling.

9. Davis 1995 [104] discussed the use of colorcoded pressure tubing, rather than all clear tubing, to keep track of measurements and reduce errors.

10. Dodier and Kreider 1999 [113] described an Energy Consumption Index (ECI) that can be used with a neural net to track and detect energy usage problems in commercial buildings, based on usage patterns and weather factors.

11. Dutton 1994 [129] discussed gas and combustion-related testing and measuring device, including pressure gages, portable explosion meters, regulators, chemical or electronic flue gas analyzers, $\mathrm{CO}_{2}$ and $\mathrm{O}_{2}$ analyzer, stack thermometer, $\mathrm{CO}$ tester, draft gage, combustion efficiency calculators, and manometers.

12. Farrar et al. 1998 [145] used a data logger, weather tower, and indoor sensors to form a thermal performance monitoring system that measured outside weather, indoor climate, and electric power consumption over several weeks.

13. Griffith 1993 [183] discussed the use of an inline gas meter to measure gas consumption over a set period of time.

14. Home Energy 1997 [216] presented a discussion about data loggers with Danny Parker (Florida Solar Energy Center), Frederic Goldner (Energy Management and Research Associates), Jonathon Beers (Madison Gas \& Electric), and David Springer (Davis Energy Group).

15. Kelley and Keefe [230] described the telltale house, an interactive exhibit to demonstrate how pressure differences affect different parts of a house.

16. Kinney 1993 [234] discussed the use of elapsed time meters and/or thermostats with run-hour memory to evaluate the effectiveness of weatherization work.

17. Kinney 1995 [233] discussed the use of a wiring analyzer to check electric circuits before installing blown-in insulation.

18. Knight et al. 1995 [239] discussed the development and testing of a hand-held device to for detecting air leakage sites on building surfaces. Soap is applied to a building surface and the PACT unit is used to apply a vacuum to the surface. Air leakage sites are identified by the appearance of soap bubbles, created by the vacuum. The unit is calibrated, relating pressure differences to leakage area. The PACT unit is able to detect smaller and more leaks than the use of smoke, however has trouble with larger leakage sites, most of which are better detected visually.

19. Koles et al. 1996 [241] listed various instruments for measuring temperature, airflow, air motion, and humidity. These included (a) for temperature, a liquid-in-glass thermometer, resistance thermometer, thermocouple or bimetallic thermometer; mean radiant temperature (MRT) measurement with a globe thermometer or a two-sphere radiometer; (b) for air motion, a hot-wire anemometer, heater sphere anemometer, heater resistance anemometer, vane anemometer or a cup anemometer; (c) for humidity, a psychrometer, dew-point hygrometer, electrical conductivity or capacity hygrometer, radiant temperature asymmetry measured with a net radiometer or a directional radiometer; and (d) for surface temperature, a contact thermometer or an infrared sensor.

20. Lawton 1992 [247] gave methods for and case examples of short-term monitoring (here, pressure gages, temperature sensors and humidity sensors used to characterize buildingenvelope heat flow).

21. Lutz 1991 [258] described and discussed tools for use in audits, including knowledge, senses, utility bills, heat loss calculations, thermometers, psychrometers, wood moisture meters, $\mathrm{CO}$ testers, pressure gages, duct flow measurement tools, combustion analyzers, blower door, infrared camera, short-term monitoring, mirrors and flashlights.

22. Modera and Jump 1995 [274] used a cellular modem to upload data acquired by an on-site data logger to laboratory computer each night, allowing remote monitoring of the experiment.

23. Reichmuth 1992 [344] discussed lighting audit tools and how to use them in residential settings. Lighting auditing tools discussed include portable wattmeters, watt loggers, CT loggers, current loggers, and occupancy analyzers.

24. Sherman and Dickerhoff 1989 [391] describe the multi-tracer measurement system (MTMS) to measure time-varying interzonal flows and presented MTMS results for two houses. 
25. SMACNA 1993 [407] described testing and balancing equipment, including: airflow measuring instruments (manometers, pitot tubes, pressure gages, anemometers, flow hoods, and smoke devices), hydronic measuring instruments (manometers and pressure gages), rotation measuring instruments (tachometers), temperature measuring devices (thermometers, thermocouples, electronic thermometers, psychrometers and electronic thermohygrometers), electrical measuring instruments (volt-ammeter), communication devices, and hydronic flow measuring devices (venturi tube and orifice plate, annular flow indicator, calibrated balancing valves and location of flow devices).

26. Ternes 1987 [420] described data parameters to collect in single-family retrofit research projects and described data analysis approaches and issues. Data parameters included (a) basic data (house characteristics, leakage measurements, metered performance of HVAC systems, and verification of retrofit installation quality); (b) time-sequential data (sub-metered spaceconditioning energy consumption, weather station measurements [dry bulb, horizontal solar radiation, humidity, wind speed and direction], indoor temperature and humidity, total fuel consumptions [billing meter data], wood heating usage, and sub-metered water heating energy consumption); (c) optional occupant behavior data (additional indoor temperature and humidity, hourly heating and cooling thermostat set-points); (d) geographic characteristics (terrain and shielding); and (e) distribution system data (duct leakage area measured using fan pressurization).

27. The Energy Conservatory 1999 [422] presented specifications of its Automated Performance Testing System (APT), an eight pressure channel data logger.

28. Trombly 1991 [433] discussed a hand-held lowE window coating detector device.

\section{$\underline{\text { Norm }}$}

1. ASHRAE 1993 [24] specified test apparatus tolerance requirements for temperature, pressure, draft, weight, time, energy consumption and energy flow rate, heating value, combustion products, and smoke measuring devices and instruments to be used with the ASHRAE test procedure for rating the efficiency of residential central furnaces and boilers.
2. ASHRAE 1993 [25] specified test apparatus tolerance requirements for temperature, pressure, draft, weight, time, energy consumption and energy flow rate, heating value, water flow, combustion products, and smoke measuring devices and instruments to be used with the ASHRAE test procedure for rating the efficiency of residential water heaters.

3. Snell 1993 [408] discussed infrared imaging system pros and cons, and how to select a system.

\section{Non-Technical}

\subsection{Commissioning Process}

\section{Metric}

1. Tseng et al. 1994 [435] specified 10 criteria to assess the effectiveness of a commissioning program (e.g., number $\&$ severity of defects, quality of maintenance training).

\section{Diagnostic}

1. Allen 1999 [2] discussed Canada's rating system, based on a site evaluation and HOT2XP analysis, which provides homeowners with an energy-efficiency rating label and provided energy-efficiency improvements suggestions for their house.

2. Arney 1998 [11] discussed using calibrated models and short-term monitoring to reduce risk and increase the confidence of energy savings estimates for complex retrofit projects by ESCos in non-residential buildings.

3. Arney and Frey 1999 [13] discussed tune-ups (retro-commissioning) as a way to increase energy savings, including short-term diagnostic testing, measurement and verification, and performance service system (maintenance tracking system).

4. ASHRAE 1995 [28] specified requirements and procedures to survey total energy use in existing buildings, including building type classification, building area, energy use and electric demand data, data requirements, and data analysis. Energy survey results include electric index (EI, total electricity used annually per unit floor area), fuel usage, Energy Utilization Index (EUI, total energy used annually for all fuels [in $\mathrm{kBtu} / \mathrm{yr}$ or $\mathrm{kWh} / \mathrm{yr}$ ] per unit floor area), and the 
Cost Index (CI, total cost for all fuels used annually per unit floor area).

5. ASHRAE 1996 [30] specified a recommended process to use when commissioning HVAC equipment. Procedures, methods, and document requirements described cover each phase of the commissioning process, from pre-design through final acceptance and post-occupancy, including changes in building and occupancy requirements after initial occupancy. Documentation procedures include owner's assumptions and requirements; design intent, Basis of Design, and expected performance; verification and functional performance testing; and operation and maintenance criteria. Process-related details include conducting verification and functional performance testing and maintaining system performance to meet the current design intent after initial occupancy. Outlined a training program for operation and maintenance personnel.

6. Benner and Stum 1993 [48] discussed commissioning and re-commissioning opportunities in buildings, giving examples of the needs for commissioning (e.g., duct leakage, improper refrigerant charge levels). Also listed costs and benefits to builders, contractors, and utilities. Provided guidelines to buildings and utilities for incorporating commissioning and recommissioning into their programs.

7. Bevirt 1994 [52] described the services of TAB professionals and their role in the commissioning process, with an emphasis on very large buildings.

8. BII 1998 [53] described a classroom and on-site program to train builders to comply with building energy codes.

9. Boner and Dasher 1997 [57] briefly described a Oregon Office of Energy commissioning toolkit developed to help state agencies commission their buildings, including boilerplate prefunctional and functional tests.

10. Brohard and Krieg 1994 [59] listed a four-part commissioning plan for EEMs (static installation test, functional performance test, site environmental quality test, recommissioning test) that enumerates the tests needed to determine whether EEMs are properly installed and operating correctly.

11. Cavallo 1999 [64] compared side-by-side HERS ratings on two houses (one new and one old). For the older house, ratings varied based on the raters' interpretation of what defined conditioned space. However, the spread of rating values did not affect the suggested energy-efficiency improvements.

12. CMHC 1998 [79] provided a checklist of potential problems and retrofit activities relating to different parts of a house (for example: foundation problems and construction techniques, structural considerations, water damage, air leakage).

13. Cohen and Goldman 1991 [81] discussed technical recommendations that have been included in various weatherization programs: blower-door guided infiltration reduction and infrared scanning, high-density blown cellulose wall insulation, high-efficiency condensing furnaces, additional attic insulation, low-cost water heater retrofits, and duct sealing.

14. Cooper et al. 1997 [90] discussed opportunities for performance contracting in the Canadian residential sector, primarily in multi-family buildings.

15. Dodds et al. 1994 [111] described a procedure for evaluating the commissioning process in commercial buildings (objectives, scope, steps, responsibilities).

16. Dodds et al. 1998 [110] gave flowcharts for the new-construction commissioning and retrocommissioning processes. Also identified commissioning providers and providers of technical, information, and training services.

17. Dodge 1996 [112] described the outlook for U.S. residential construction, including forecasts of single family, multi family, attached, low-rise, and high-rise homes in various regions of the country.

18. DOE 1995 [116] discussed background information and request for comments regarding DOE's 1995 proposed phased-in compliance period for the HERS program. DOE's 1995 proposal included one year to come into "basic compliance" by meeting a specific set of guideline provisions, and two years to come into "full accreditation" by meeting all the guideline provisions.

19. DOE 1997 [118] presented the components of the International Performance Measurement and Verification Protocol (IPMVP), which is used to measure and verify energy and water efficiency savings related to energy efficiency retrofits and energy savings performance contracts (ESPCs). 
20. DOE 1998 [119] discussed commissioning practices, protocols, and techniques for existing buildings and retrofit activities. Provided examples, cost analyses, checklists, and projectphase specific information.

21. DOE 1999 [114] presented DOE's summary of building energy software tools, including energy simulations, load calculation, renewable energy, retrofit analysis, and sustainability/green buildings.

22. DOE 1999 [115] discussed model energy code, the MECcheck program, state-by-state information on buildings, links to other building codes, and standards-related web sites.

23. Dols et al. 1994 [121] described an indoor air quality commissioning protocol, including specific testing protocols and instrumentation requirements. The protocol included comparing ventilation system design with codes and standards, determining reference indoor environment parameter values and measuring the indoor environment parameters at three construction phases. Indoor environment parameters relate to ventilation performance (outdoor airflow rate and relative pressurization between zones), pollutants (carbon dioxide, carbon monoxide, formaldehyde, particulates, radon and volatile organic compounds), and thermal comfort (temperature, relative humidity and operative temperature). Dols et al. 1995 [123] discussed this protocol, subsequent commissioning results, and lessons learned.

24. Dols et al. 1995 [120] described a methodology to measure IAQ effectiveness in commercial building commissioning, including ventilation performance (outdoor airflow rate and pressure relationships between zones), pollutants $\left(\mathrm{CO}_{2}\right.$, $\mathrm{CO}$, formaldehyde, particulates, radon and VOCs), and thermal comfort (temperature, relative humidity, and operative temperature).

25. Elberling et al. 1998 [132] presented lessons learned in a retrofit process, including choice of building design team, design constraints, equipment selection, contractors and subcontractors, and commissioning errors.

26. Elovitz 1986 [134] described a series of commissioning case studies of problems found with system design, combined design/installation, installation, balancing and controls, equipment, and calibration and monitoring. Discussed how commissioning requires a systems approach and viewing the building as a whole.
27. Elovitz 1992 [135] discussed the why and how of the HVAC commissioning process and procedures, including preparing for commissioning, developing a commissioning plan, who commissions mechanical systems, and commissioning and Design/Build. Also gave examples from actual HVAC commissioning experiences (e.g. with heat exchangers, thermostats, pumps, and fans) to illustrate the processes of investigation and analysis.

28. EPA 1998 [139] recommended that a building tune-up should be implemented in the following order: (1) lighting; (2) building envelope; (3) controls; (4) testing adjusting, and balancing; (5) heat exchange equipment; and (6) heating and cooling system.

29. EPA/DOE 1999 [140] described the Energy Star Benchmarking Tool, a computer program that rates a building based on physical attribute, operating characteristic, and energy consumption data.

30. FEMP 1999 [148] discussed the measurement and verification procedures and options for FEMP's Super Energy Savings Performance Contract program.

31. Gardiner and Piette 1985 [174] discussed the benefits and limitations of using whole-building energy data. Also discussed the additional benefits of sub-metered data to assess the impacts of energy efficiency retrofits in commercial buildings.

32. Gerardi and Sweeney 1994 [175] summarized the instrumented audit technique (software tool) developed for use in weatherization procedures. The protocol included health and safety, blower door measurements, and heating systems problem diagnostics; the software leads the auditor through a decision tree to determine most important issues to address.

33. Greely et al. 1992 [176] discussed recommended installation standards and checklists for weatherization programs (heating, insulation, water heating, air tightness and repairs).

34. Grimsrud et al. 1981 [192] described utility bill and weather data analyses to predict building energy performance.

35. Guven and Spaeth 1994 [197] described the process of large building commissioning through a detailed example of the commissioning of a thermal energy storage unit. Included a glossary of commissioning-related terms. 
36. Hammon and Modera 1996 [199] discussed strategies and provided key action items to integrate tight duct construction parameters and factors into HERS, Title 24, and energy-efficient mortgages. Provided material and performance metrics.

37. Haberl et al. 1998 [198] presented a general diagnostic for discovery of problem areas affecting energy savings, and states that an occupant training program is necessary to obtain and maintain energy savings.

38. Heinz and McCray 1996 [210] discussed the commissioning of four new teaching and research science buildings at the University of Washington, with attention to problems encountered.

39. Hitchcock et al. 1997 [211] discussed the conceptual development of tools for use in commissioning and life-cycle tracking of commercial building performance, including a tool for capturing design intent, a chiller commissioning tool kit to assist in verifying and documenting installed chiller performance, building design advisor, and a performance evaluation and tracking tool (chiller emulator and data visualization module). Also discussed interoperability (concurrent access to project/building information relating to building design, construction, commissioning and use) via BLISS (Building Life-cycle Information Support System).

40. Kjellman et al. 1996 [237] assessed building commissioning practices by reviewing the literature of 72 organizations that have or plan to publish commissioning guidelines, standards, or data; found that 42 organizations had published approximately 44 guidelines, standards, manuals, and codes. Also conducted a phone survey of 16 building-commissioning firms, $75 \%$ of whom had commissioned primarily office buildings; found that all but one described their activities as systems commissioning, rather than wholebuilding commissioning. Found that performance testing occupied 40 to $80 \%$ of the time required for the commissioning project. Presented table showing the construction phases in which the various commissioning firms were involved.

41. Koles et al. 1996 [241] discussed an energy-use index as a metric to determine if a given building is performing within reason for its climate and size.
42. Koran 1994 [242] presented a case study of a large building energy conservation measure (ECM) verification project, noting the unintended benefits of finding (and solving) problems not anticipated.

43. Lane et al. 1989 [245] discussed four main components of a procedure to diagnose a sick building or confirm a healthy building: knowledge of what to measure, availability of appropriate instrumentation, expertise in interpreting results of measurements, and capability of predicting building performance.

44. Linder et al. 1999 [253] discussed standards of performance for commercial HVAC\&R equipment, plumbing systems, and building envelope systems, and described the components of the standards of performance (general information, standards of performance, information to be recorded, calculations, interpretation, other information, and corrective action).

45. Meyers et al. 1995 [270] presented the use of building data visualization (the acquisition and graphical and statistical analysis and presentation of building operational data) to evaluate and serve as a feedback loop to building operators in commercial buildings.

46. Mill et al. 1985 [271] described the need for trans-disciplinary efforts (i.e., cooperation among various professional design and measurement disciplines) to ensure total building performance (i.e., meeting the functional and comfort needs of the occupants, and maintaining building integrity over time). Listed a five-level plan for building envelope analysis: (1) plan/archive; (2) expert walkthrough; (3) occupancy and use; (4) simple instrumentation; and (5) complex instrumentation.

47. Morrison Hershfield Ltd 1996 [288] discussed a procedure for commissioning the building envelope, from design intent to post-installation.

48. National Institute of Building Sciences and the Florida State University Energy Center 1999 [296] provided a detailed overview of the general principles and procedures of total building commissioning, including a description of the processes, plans, specifications, validation reports related to commissioning. They also provided a discussion of the responsibilities of commissioning participants, a model request for commissioning services, and a set of model building-system guidelines. Also provided a glossary of terms. 
49. NEBB 1999 [300] presented a guide for development and implementation of commercial HVAC system commissioning plans. Included a model specification, HVAC systems commissioning procedures and sample reporting forms. Also provided procedural standards for building system commissioning (i.e. guidance for organizing, planning, verifying, and documenting building performance). Included model reporting forms, check sheets, and functional performance checklists.

50. Peach 1992 [315] discussed contractual and other factors to take into account when doing residential performance contracting.

51. PECI 1992 [316] presented building commissioning guidelines, including procedures, forms, protocols, performance tests, minimum test plan requirements, monitoring requirements, report outline, design intent document, commissioning specification, O\&M specification, and commissioning agent qualifications. Included a detailed manual with specifications, guidelines, and test procedures for the commissioning of commercial buildings. Chapters include Commissioning $(\mathrm{Cx})$ Overview, Integrating $\mathrm{Cx}$ into the Building Project, Roles of the Cx Team Members, The Cx Process, Cx Plan, Cx Test Plans. Appendices include Sample Cx Specification, Sample List of Cx Agent Qualifications, Operation and Maintenance Manuals, Sample Design Intent Documentation, Sample Cx Final Report Outline, Sample Forms, Sample Cx Plan, Sample Pump Pre-functional Performance Test Checklist, Sample Minimum Test Plan Requirements Outline, Sample Cooling Tower Test Plan Packet, and The Thought Process of $\mathrm{Cx}$.

52. PECI 1997 [317] provided a detailed manual with specifications, guidelines, and test procedures for commissioning of commercial buildings. It covers the design, specification, and construction phases of a project.

53. PECI 1999 [318] overviewed procedures for commissioning of commercial buildings.

54. Piette and Nordman 1996 [327] discussed commissioning benefits, procedures, examples of non-energy benefits, cost-effectiveness, and commissioning techniques considered in a 16 commercial building study.

55. Richalet and Henderson 1999 [348] discussed the progress of European home energy rating systems.
56. Rieger 1993 [349] described the CHEERS program, procedures, and implementation plans.

57. Robison and Reichmuth 1999 [350] discussed a spreadsheet tool that allows quick adjustment of a simplified engineering model to match utility bills. The tool can be used to diagnose energy patterns and end use consumption, calibrate savings estimates to agree with actual usage; verify vendor claims regarding performance factors; and generate performance targets and compare against actual bills.

58. Rose 1999 [353] reviewed potential problems related to testing and balancing of commercial HVAC system.

59. Schalch and Fryer 1992 [364] discussed the Energy Crafted Home's program design, which allows for design flexibility along with prescriptive measures.

60. Sonderegger 1998 [410] analyzed utility bills for non-residential facilities by correlating past utility bills to observable variables, then projecting that correlation into the future. Techniques included variable-base degree days synchronized to utility bills, incorporating other independent variables, tuning the baseline equation, accounting for the degree-day threshold, and regression analysis.

61. Sterling et al. 1992 [414] presented, for each commissioning phase, a checklist of tests, issues and questions to consider to help avoid IAQ problems.

62. Sterling and Collett 1994 [413] discussed the role of commissioning as quality assurance; commissioning activities at the various project phases (program, design, construction, acceptance, post-acceptance); the commissioning team; and commissioning costs $(0.25 \%$ to $2 \%$ of construction budget).

63. Ternes 1987 [420] described data parameters to collect in single-family retrofit research projects and described data analysis approaches and issues. Data parameters included (a) basic data (house characteristics, leakage measurements, metered performance of HVAC systems, and verification of retrofit installation quality); (b) time-sequential data (sub-metered spaceconditioning energy consumption, weather station measurements [dry bulb, horizontal solar radiation, humidity, wind speed and direction], indoor temperature and humidity, total fuel consumptions [billing meter data], wood heating usage, and sub-metered water heating energy 
consumption); (c) optional occupant behavior data (additional indoor temperature and humidity, hourly heating and cooling thermostat set-points); (d) geographic characteristics (terrain and shielding); and (e) distribution system data (duct leakage area measured using fan pressurization).

64. Thomas 1992 [423] discussed performancecontracting guidelines, including standard contracts, evaluation of bids, comprehensive programs, and guarantees.

65. Thomas 1999 [424] discussed the state of the U.S. home energy rating systems, the number of houses tested under the Energy Star program, financing tie-ins and marketing efforts.

66. Uniacke 1992 [443] discussed how important it is to use field-based hands-on training to educate builders. Discussed how the effectiveness of building education should be based on the builders' willingness to integrate new strategies into their work. Also discussed how the building science perspective can be used to synthesize efficiency, comfort, indoor air quality, health, safety, affordability, and durability and show builders how a home should perform. N.B.: this reference consists only of an abstract.

67. Weir 1996 [459] discussed the results of a survey and assessment of current Canadian commissioning procedures.

68. Yoder and Kaplan 1992 [465] described a utilitysponsored program (Energy FinAnswer) that provides financing and engineering services for new large commercial buildings and for major remodels that include energy efficiency improvements. The utility works with the owner to commission the building to ensure that the funded measures are properly implemented. Details commissioning $(\mathrm{Cx})$ protocol (scoping meeting, design intent documentation, $\mathrm{Cx}$ outline, pre-Cx tests, functional performance testing, end-use monitoring and seasonal testing, operations and maintenance summary and training, documentation) and attributes of the $\mathrm{Cx}$ agents. Also, discussed, based on knowledge gained in Bonneville Power's Energy Edge program, the role of building commissioning in the application of demand-side technologies; commissioning strategies and protocols; liability, and payment and commissioning schedules.

\section{$\underline{\text { Norm }}$}

1. Eash 1998 [130] discussed the Irvine IQ+ program, a voluntary program to improve energy-efficiency of new homes; presented 1998 results ( 53 homes certified by third party inspector).

2. EPA 1997 [138] recommended that one person, rather than multiple subcontractors, take responsibility for all air sealing in a building.

3. Gardiner and Piette 1985 [174] discussed the commissioning process and the evaluation of whole-building energy savings.

4. Kjellman et al. 1996 [237] discussed some problems encountered in commercial buildings. Also discussed the necessity for recommissioning to keep energy savings.

5. Prince 1986 [331], as an experienced contractor, identified common commissioning problems and the parties responsible. Recommended specific personnel and procedures needed for successful HVAC system startup and final building commissioning.

6. Sterling and Collett [413] described the phases of the building commissioning process (program, design, construction, acceptance, postacceptance), the composition of the commissioning team, and the costs and benefits of commissioning.

\subsection{Economics}

\section{$\underline{\text { Metric }}$}

1. Eley and Wilcox 1992 [133] detailed the costeffectiveness analysis used to develop energy efficiency levels required by the 1992 California low-rise residential building energy-efficiency standards (Title 24). Charted the costeffectiveness of attic, ceiling, wall, and floor, and slab-edge insulation.

2. Lerman 1998 [248] found little correlation between the cost of duct sealing and the energy savings yielded (and the same for change in energy use vs. change in duct leakage).

3. Piette et al. 1995 [328] discussed simplepayback time metrics (years, ratio of first costs to annual energy savings) and average present value of energy saving measures estimates $\left(\$ / \mathrm{ft}^{2}\right)$, and commissioning cost $\left(\$ / \mathrm{ft}^{2}\right)$. 
4. Vieira et al. 1998 [445] defined several costbenefit indicators (e.g. simple payback, NPV) useful for ranking energy conservation measures.

\section{Diagnostic}

1. ASHRAE 1993 [27] specified how the annual energy cost method is used to show compliance with ASHRAE Standard 90.2-1993. The annual cost method compares the annual energy cost of the proposed design to the annual energy cost of a prescriptive design (same floor plan and design) whose characteristics meet the prescriptive requirements of the Standard.

2. Byrne 1995 [62] proposed HERS guidelines (as of 1995) and discussed California-related issues.

3. CEC 1995 [65] detailed California historical energy statistics, including supply, demand, and prices of petroleum, petroleum products, natural gas, and electricity. Demand was subdivided by sectors, including residential vs. commercial.

4. Greely et al. 1992 [176] compared program costs and energy savings for the existing and pilot weatherization programs in Virginia.

5. Greely et al. 1992 [177] described the evaluation of various weatherization techniques and materials considered for mild-climate weatherization activities. Evaluation included PRISM savings and cost-effectiveness evaluation, literature reviews, engineering and economic calculations, and short-term monitoring of furnace performance.

6. Grimsrud et al. 1983 [185] presented a computer program for evaluating the cost-effectiveness of energy efficiency measures for a particular house, for use at an energy audit.

7. Home Energy 1999 [214] provided a resource list of North American trainers, training opportunities, and conferences related to home performance.

8. Home Energy 1999 [215] listed education, government, and organizational resources related to home energy issues.

9. PECI 1999 [318] presented examples of costs and benefits of commissioning in commercial buildings.

10. Peterson and Haasl 1994 [324] used a tuned DOE2.1 building simulation model to estimate the additional energy and monetary saving that would have been possible had a building retrofitted with ECMs been commissioned at the design phase, rather than after the retrofit.

11. Sharp 1995 [368] discussed North Carolina's weatherization programs. Measure costs and related savings were broken down by measure (insulation, repairs, air sealing, storm windows, labor, other).

12. Stein 1997 [412] evaluated the accuracy of four states' HERS programs, and suggested ways to improves HERS, including training, fool proofing the process, and educating homeowners about HERS results.

13. Vieira et al. 1998 [445] described a Florida computer program (Energy Gauge/Optimization) that measures and reports the economic and financial impacts of home energy technology decisions.

14. Walter and Lewis 1996 [455] described a "whole-house" service provider and the provider's work plan, including house diagnostics, tune-ups, installation, troubleshooting, and duct sealing.

15. Yoder and Kaplan 1992 [465] described a utilitysponsored program (Energy FinAnswer) that provides financing and engineering services for new large commercial buildings and for major remodels that include energy efficiency improvements. The building owner receives $50 \%$ of the ECM cost upon presentation of process billings from contractors, $20 \%$ after passing pre-commissioning tests, and $30 \%$ upon passing functional performance tests.

\section{Norm}

1. Bodzin 1999 [56] discussed energy and cost savings of specific Building America components and energy-efficient measures.

2. CA State 1999 [63] provided estimates of California population and housing.

3. CEC 1999 [66] presented historical California energy statistics including supply, demand, and price of energy resources by sector.

4. Claridge et al. 1998 [76] found that in almost all older commercial buildings, and even in many new buildings, use of the building is quite different from the original plan. Consequently, they developed a process of "continuous commissioning" that tunes the systems of the building for optimal comfort and peak efficiency based on the current use. Implementing that process has saved an average of over $20 \%$ of the 
total energy cost (over $30 \%$ of the heating and cooling cost) in more than 80 buildings in which it has been applied. Simple payback times under two years were achieved in nearly all of the 80 buildings.

5. Cohen and Goldman 1991 [81] discussed the energy and cost savings performance of several weatherization programs.

6. Cummings et al. 1990 [98] discussed repair costs and energy savings (consumption and peak demand) related to duct leakage repair.

7. Dodge 1996 [112] presented a quarterly housing forecast, by state and dwelling type, for 1994 to. 2000 .

8. Energy Information Administration 1999 [137] presented statistics on the types of air conditioners, heating units, water heaters, and lighting equipment found in U.S. homes.

9. Feustel et al. 1986 [149] discussed TRNSYS modeling of the economic and ventilation performance (average and effective ventilation rates) of natural ventilation and several ventilation strategies (exhaust ventilation, heat recovery ventilation, exhaust ventilation with heat pump heat recovery, and exhaust air heat pump water heating).

10. Hammon and Modera 1996 [199] discussed costs and energy savings attributable to tight duct construction in new construction.

11. Hayden 1992 [209] discussed energy savings due to oil-furnace retrofit options.

12. Jenkins 1991 [220] discussed economic impact of heat pump system retrofits (percent heating savings, repair cost, life cycle benefits to the homeowner and utility).

13. Kjellman et al. 1996 [237] discussed the cost effectiveness of commissioning a building, presenting a table of commissioning cost data ( $\$ 0.10$ to $\$ 2.50$ per $\mathrm{ft}^{2}$ ) for 12 buildings supplied by surveyed commissioning practitioners. In addition, tabulated energy savings results from deficiency repairs in seven buildings, including annual savings ( $\left.\mathrm{kWh}, \$, \mathrm{kWh} / \mathrm{ft}^{2}\right)$, \% energy savings, and simple payback time.

14. Matson and Feustel 1998 [263] presented equipment costs, installation costs, annual operating costs and life cycle costs, based on RESVENT airflow modeling, for ventilation strategies (single and multi-port exhaust fans with inlet louvers, single and multi-port exhaust fans with outside air ducts, balanced heat recovery) in one and two story houses in California and New York elimates.

15. McBride 1992 [264] discussed the energy conservation measure cost/savings analysis used to form the residential building performance prescriptive criteria in ASHRAE 90.2P (ASHRAE 1993 [27]).

16. Parker 1991 [311] discussed cost savings possible by coupling whole house fan operation with air conditioning systems.

17. Parker et al. 1998 [314] discussed the economics of various installed measures, including installed cost, estimated annual savings ( $\mathrm{kWh}, \$$ ), and simple payback time (years) of radiant barrier systems, high-SEER AC, solar water heaters, efficient pool pumps, high-efficiency refrigerators, high-efficiency lighting, and attic ventilation.

18. Piette et al. 1995 [329] discussed the energy savings found in the Energy Edge project (commercial) buildings; savings would be higher with commissioning and feedback to the building owners.

19. Piette and Nordman 1996 [327] presented commissioning results for a 16 commercial building sample. Results included average present value of energy saving measures $\left(\$ 0.21 / \mathrm{ft}^{2}\right)$; average commissioning cost $\left(\$ 0.23 / \mathrm{ft}^{2}\right)$; and median simple payback $(6.5$ years for Pacific Northwest energy prices, 3 years for national average energy prices).

20. Proctor 1991 [333] discussed project program savings and costs for improving the efficiency of existing cooling systems in Fresno, California.

21. Robison and Lambert 1989 [351] discussed annual energy savings estimates, retrofit costs, simple paybacks, and benefit cost ratio for duct sealing in 20 Residential Standards Demonstration Program (RSDP) homes.

\section{Not Annotated}

1. Edwards and Irwin 1994 [131] is just an abstract.

2. Farhar and Coburn 1999 [144] discussed homeowner attitudes toward electricity providers.

3. Meal et al. 1985 [266] is relevant only to commercial buildings. 


\begin{tabular}{|c|c|c|c|c|}
\hline & & \multicolumn{3}{|c|}{ Links } \\
\hline & & $\mathbf{M}$ & D & $\mathrm{N}$ \\
\hline$[1]$ & $\begin{array}{l}\text { Allen Consultants. 1996. "Optimizing Residential Forced-Air HVAC Systems". } \\
\text { Ottawa, ON, Canada; Canadian Mortgage and Housing Corporation Technical } \\
\text { Series 96-218. }\end{array}$ & 2.7 & & \\
\hline [2] & $\begin{array}{l}\text { Allen, D.R. 1999. "Canadian Ratings Warm Up". Home Energy Magazine, Vol. 16, } \\
\text { No. 5, September/October, pp. 19-20. Berkeley, CA; Energy Auditor \& Retrofitter, } \\
\text { Inc. }\end{array}$ & & 5.1 & \\
\hline [3] & $\begin{array}{l}\text { Anderson, A. 1995. "The History of the Blower Door". Home Energy Magazine, } \\
\text { Vol. 12, No. 6. Berkeley, CA; Energy Auditor \& Retrofitter, Inc. }\end{array}$ & & 1.4 & \\
\hline$[4]$ & $\begin{array}{l}\text { Anderson, G.D. 1995. Letter to the Editor: "More on Ventilating Attics". Home } \\
\text { Energy Magazine, Vol. 12, No. 4, July/August, pp. 3-4. Berkeley, CA; Energy } \\
\text { Auditor \& Retrofitter, Inc. }\end{array}$ & & 1.4 & \\
\hline [5] & $\begin{array}{l}\text { Andrews, J.W. 1996. "Field Comparison of Design and Diagnostic Pathways for } \\
\text { Duct Efficiency Evaluation". Proceedings of the } 1996 \text { ACEEE Summer Study on } \\
\text { Energy Efficient Buildings, 1.21. Washington, D.C.; American Council for an } \\
\text { Energy-Efficient Economy. }\end{array}$ & 2.3 & $\begin{array}{l}2.3 \\
2.3\end{array}$ & 2.3 \\
\hline [6] & $\begin{array}{l}\text { Andrews, J.W., R.F. Krajewski, and J.J. Strasser. 1996. "Electric coheating in the } \\
\text { ASHRAE standard method of test for thermal distribution efficiency-Test results } \\
\text { on two New York State homes". ASHRAE Transactions, Vol. 102, Part 1, pp. } 870 \text { - } \\
880 \text {. }\end{array}$ & & 2.3 & \\
\hline [7] & $\begin{array}{l}\text { Andrews, J.W., R.L. Hedrick, M.R. Lubliner, B.P. Reid, B.L. Pierce, and D.W. } \\
\text { Saum. 1998. "Reproducibility of ASHRAE Standard 152P: Results of a Round- } \\
\text { Robin Test". ASHRAE Transactions, Vol. 104, Part 1B, pp.1376-1388. }\end{array}$ & & $\begin{array}{l}2.3 \\
2.3\end{array}$ & \\
\hline [8] & $\begin{array}{l}\text { Arasteh, D.K., F.A. Beck, B.T. Griffith, N. Byars, and M. Acevedo-Ruiz. } 1992 . \\
\text { "Using infrared thermography for the study of heat transfer through building } \\
\text { envelope components". ASHRAE Transactions, Vol. 98, Part 1, pp. 819-824. }\end{array}$ & & 1.2 & \\
\hline [9] & $\begin{array}{l}\text { Arasteh, D.K., F.A. Beck, B.T. Griffith, N. Byars, and M. Acevedo-Ruiz. } 1992 . \\
\text { "Using infrared thermography to study building heat transfer". ASHRAE Journal, } \\
\text { October, Vol. 34, No. 10, pp. 34-36. }\end{array}$ & & 1.2 & \\
\hline [10] & $\begin{array}{l}\text { Arens, E., R. Gonzalez, and L. Berglund. 1986. "Thermal comfort under an ext } \\
\text { ended range of environmental conditions". ASHRAE Transactions, Vol. } 92 \text {, Part } \\
\text { 1B, pp. 18-26. }\end{array}$ & & 3.1 & \\
\hline
\end{tabular}

\footnotetext{
* Section numbers in columns labeled M, D, and N are hyperlinks to Metrics, Diagnostics, and Norms in Appendix A (Annotated Bibliography). For example, the entry "3.1" in the column " $D$ " is a link to a diagnostic in Section 3.1 [Room Air Temperature and Velocity (Occupant Comfort)].
} 


\begin{tabular}{|c|c|c|c|c|}
\hline & & \multicolumn{3}{|c|}{ Links } \\
\hline & & $\mathrm{M}$ & $\mathrm{D}$ & $\mathrm{N}$ \\
\hline [11] & $\begin{array}{l}\text { Arney, W.M. 1998. "Utilizing Calibrated Computer Models to Reduce Risk in } \\
\text { Performance Contracting". Proceedings of the 6th National Conference on } \\
\text { Building Commissioning, Lake Buena Vista, Florida, Lake Buena Vista, Florida. } \\
\text { Portland, OR; Portland, OR; Portland Energy Conservation Institute. }\end{array}$ & & 5.1 & \\
\hline [12] & $\begin{array}{l}\text { Arney, W.M. and D.J. Frey. 1995. "Short-Term Diagnostic Testing to Streamline } \\
\text { Commissioning". Proceedings of the } 3^{\text {rd }} \text { National Conference on Building } \\
\text { Commissioning, Sacramento, CA. Portland, OR; Portland Energy Conservation } \\
\text { Institute. }\end{array}$ & & 4.7 & \\
\hline [13] & $\begin{array}{l}\text { Arney, W.M. and D.J. Frey. 1999. "Long-Term Energy Efficiency Strategy: } \\
\text { Building Tune-ups and Performance-based Maintenance". Proceedings of the 7th } \\
\text { National Conference on Building Commissioning, Portland, OR. Portland, OR; } \\
\text { Portland Energy Conservation Institute. }\end{array}$ & & 5.1 & \\
\hline [14] & $\begin{array}{l}\text { ASHRAE. 1988. "ANSI/ASHRAE Standard 111-1988 Practices for Measurement, } \\
\text { Testing, Adjusting, and Balancing of Building Heating, Ventilation, Air- } \\
\text { Conditioning and Refrigeration Systems". Atlanta, GA; American Society of } \\
\text { Heating, Refrigerating, and Air-Conditioning Engineers, Inc. }\end{array}$ & 2.3 & 2.3 & \\
\hline [15] & $\begin{array}{l}\text { ASHRAE. 1988. "ANSI/ASHRAE Standard 119-1988 (RA 94), Air Leakage } \\
\text { Performance for Detached Single-Family Residential Buildings". Atlanta, GA; } \\
\text { American Society of Heating, Refrigerating, and Air-Conditioning Engineers, Inc. }\end{array}$ & & & $\begin{array}{l}1.4 \\
2.5\end{array}$ \\
\hline [16] & $\begin{array}{l}\text { ASHRAE. 1989. "ANSI/ASHRAE Standard 41.3-1989 Standard Method for } \\
\text { Pressure Measurement". Atlanta, GA; American Society of Heating, Refrigerating, } \\
\text { and Air-Conditioning Engineers, Inc. }\end{array}$ & & 2.5 & \\
\hline [17] & $\begin{array}{l}\text { ASHRAE. 1989. "ANSI/ASHRAE Standard } 41.8-1989, \text { Standard Methods of } \\
\text { Measurement of Flow of Liquids in Pipes Using Orifice Flowmeters". Atlanta, } \\
\text { GA; American Society of Heating, Refrigerating, and Air-Conditioning Engineers, } \\
\text { Inc. }\end{array}$ & & 4.7 & \\
\hline [18] & $\begin{array}{l}\text { ASHRAE. 1989. "ANSI/ASHRAE Standard 62-1989, Ventilation for Acceptable } \\
\text { Indoor Air Quality". Atlanta, GA; American Society of Heating, Refrigerating, and } \\
\text { Air-Conditioning Engineers, Inc. }\end{array}$ & $\begin{array}{l}2.5 \\
2.5 \\
3.2 \\
3.5\end{array}$ & $\begin{array}{l}2.5 \\
2.5\end{array}$ & $\begin{array}{l}2.5 \\
2.5 \\
2.5 \\
2.5 \\
3.2 \\
3.5\end{array}$ \\
\hline [19] & $\begin{array}{l}\text { ASHRAE. 1991. "ANSI/ASHRAE Standard 41.1-1986 (RA 91), Standard Method } \\
\text { for Temperature Measurement". Atlanta, GA; American Society of Heating, } \\
\text { Refrigerating, and Air-Conditioning Engineers, Inc. }\end{array}$ & & 4.7 & \\
\hline$[20]$ & $\begin{array}{l}\text { ASHRAE. 1991. "ANSU/ASHRAE Standard 41.7-1984 (RA 91), Standard Method } \\
\text { for Measurement of Flow of Gas". Atlanta, GA; American Society of Heating, } \\
\text { Refrigerating, and Air-Conditioning Engineers, Inc. }\end{array}$ & & 4.7 & \\
\hline
\end{tabular}




\begin{tabular}{|c|c|c|c|c|}
\hline & & \multicolumn{3}{|c|}{ Links } \\
\hline & & $\mathrm{M}$ & $\mathrm{D}$ & $\mathrm{N}$ \\
\hline [21] & $\begin{array}{l}\text { ASHRAE. 1992. "ANSI/ASHRAE Standard 41.2-1987 (RA 92), Standard } \\
\text { Methods for Laboratory Airflow Measurement". Atlanta, GA; American Society of } \\
\text { Heating, Refrigerating, and Air-Conditioning Engineers, Inc. }\end{array}$ & & 2.3 & \\
\hline [22] & $\begin{array}{l}\text { ASHRAE. 1992. "ANSUASHRAE Standard 52.1-1992, Gravimetric and Dust- } \\
\text { Spot Procedures for Testing Air-Cleaning Devices Used in General Ventilation for } \\
\text { Removing Particulate Matter". Atlanta, GA; American Society of Heating, } \\
\text { Refrigerating, and Air-Conditioning Engineers, Inc. }\end{array}$ & 4.4 & 4.4 & \\
\hline [23] & $\begin{array}{l}\text { ASHRAE. 1992. "ANSI/ASHRAE Standard 55-1992, Thermal Environmental } \\
\text { Conditions for Human Occupancy". Atlanta, GA; American Society of Heating, } \\
\text { Refrigerating, and Air-Conditioning Engineers, Inc. }\end{array}$ & 3.1 & & $\begin{array}{l}3.1 \\
3.1\end{array}$ \\
\hline [24] & $\begin{array}{l}\text { ASHRAE. 1993. "ANSVASHRAE Standard 103-1993, Method of Testing for } \\
\text { Annual Fuel Utilization Efficiency of Residential Central Furnaces and Boilers". } \\
\text { Atlanta, GA; American Society of Heating, Refrigerating, and Air-Conditioning } \\
\text { Engineers, Inc. }\end{array}$ & & 2.2 & 4.7 \\
\hline [25] & $\begin{array}{l}\text { ASHRAE. 1993. "ANSI/ASHRAE Standard 118.2-1993, Method of Testing for } \\
\text { Rating Residential Water Heaters". Atlanta, GA; American Society of Heating, } \\
\text { Refrigerating, and Air-Conditioning Engineers, Inc. }\end{array}$ & & 4.1 & 4.7 \\
\hline [26] & $\begin{array}{l}\text { ASHRAE. 1993. "ANSU/ASHRAE Standard 136-1993, A method of determining } \\
\text { air change rates in detached dwellings". Atlanta, GA; American Society of } \\
\text { Heating, Refrigerating, and Air-Conditioning Engineers, Inc. }\end{array}$ & $\begin{array}{l}1.4 \\
2.5 \\
2.5\end{array}$ & $\begin{array}{l}1.4 \\
2.5\end{array}$ & \\
\hline [27] & $\begin{array}{l}\text { ASHRAE. 1993. "ANSI/ASHRAE Standard 90.2-1993, Energy-Efficient Design } \\
\text { of New Low-Rise Residential Buildings". Atlanta, GA; American Society of } \\
\text { Heating, Refrigerating, and Air-Conditioning Engineers, Inc. }\end{array}$ & & 5.2 & $\begin{array}{l}1.1 \\
1.1 \\
1.2 \\
1.2 \\
1.4 \\
1.5 \\
2.1 \\
2.2 \\
2.2 \\
2.3 \\
2.4 \\
2.5 \\
4.1 \\
5.2\end{array}$ \\
\hline [28] & $\begin{array}{l}\text { ASHRAE. 1995. "ANSU/ASHRAE Standard 100-1995, Energy Conservation in } \\
\text { Existing Buildings". Atlanta, GA; American Society of Heating, Refrigerating, and } \\
\text { Air-Conditioning Engineers, Inc. }\end{array}$ & & $\begin{array}{l}2.1 \\
5.1\end{array}$ & $\begin{array}{l}1.1 \\
1.4 \\
2.1 \\
2.2 \\
2.3 \\
2.5 \\
4.1\end{array}$ \\
\hline
\end{tabular}




\begin{tabular}{|c|c|c|c|c|}
\hline & & \multicolumn{3}{|c|}{ Links } \\
\hline & & $\mathbf{M}$ & D & $\mathrm{N}$ \\
\hline [29] & $\begin{array}{l}\text { ASHRAE. 1995. "ANSI/ASHRAE Standard 116-1995, Methods of Testing for } \\
\text { Rating Seasonal Efficiency of Unitary Air Conditioners and Heat Pumps". Atlanta, } \\
\text { GA; American Society of Heating, Refrigerating, and Air-Conditioning Engineers, } \\
\text { Inc. }\end{array}$ & 2.1 & 2.1 & \\
\hline [30] & $\begin{array}{l}\text { ASHRAE. 1996. "ASHRAE Guideline 1-1996, The HVAC Commissioning } \\
\text { Process". Atlanta, GA; American Society of Heating, Refrigerating, and Air- } \\
\text { Conditioning Engineers, Inc. }\end{array}$ & & 5.1 & \\
\hline [31] & $\begin{array}{l}\text { ASHRAE. } 1997 \text { "ANSI/ASHRAE Standard 129-1997, Measuring Air-Change } \\
\text { Effectiveness". Atlanta, GA; American Society of Heating, Refrigerating, and Air- } \\
\text { Conditioning Engineers, Inc. }\end{array}$ & 2.5 & 2.5 & \\
\hline [32] & $\begin{array}{l}\text { ASHRAE. 1999. "BSR/ASHRAE Draft Standard 152P-1999, Method of Test for } \\
\text { Determining the Design and Seasonal Efficiencies of Residential Thermal } \\
\text { Distribution Systems". Atlanta, GA; American Society of Heating, Refrigerating, } \\
\text { and Air-Conditioning Engineers, Inc. }\end{array}$ & $\begin{array}{l}2.3 \\
2.3\end{array}$ & $\begin{array}{l}2.3 \\
2.3 \\
2.3 \\
2.3\end{array}$ & \\
\hline [33] & $\begin{array}{l}\text { ASTM. 1988. "Standard Test Method for Airflow Calibration of Fan Pressurization } \\
\text { Devices, ASTM Standard E1258-88 (RA 92)". Philadelphia, PA; American Society } \\
\text { for Testing and Materials. }\end{array}$ & & 1.4 & \\
\hline [34] & $\begin{array}{l}\text { ASTM. 1990. "ASTM Standard C1060-90, Standard Practice for Thermographic } \\
\text { Inspection of Insulation Installations in Envelope Cavities of Frame Buildings". } \\
\text { Philadelphia, PA; American Society for Testing and Materials. }\end{array}$ & & 1.1 & \\
\hline [35] & $\begin{array}{l}\text { ASTM. 1992. "ASTM Standard E779-87, Standard Test Method for Determining } \\
\text { Air Leakage Rate by Fan Pressurization". Philadelphia, PA; American Society for } \\
\text { Testing and Materials. }\end{array}$ & 1.4 & $\begin{array}{l}1.4 \\
2.5\end{array}$ & \\
\hline [36] & $\begin{array}{l}\text { ASTM. 2000. "ASTM Draft Standard Guide for Specifying and Evaluating } \\
\text { Performance of Single Family Attached and Detached Dwellings - Indoor Air } \\
\text { Quality". Philadelphia, PA; American Society for Testing and Materials. }\end{array}$ & & $\begin{array}{l}2.3 \\
2.4 \\
2.4 \\
2.5 \\
3.1 \\
3.2 \\
4.4\end{array}$ & 1.5 \\
\hline [37] & $\begin{array}{l}\text { ASTM. 1994. "Standard Test Methods for Determining External Air Leakage of } \\
\text { Air Distribution Systems by Fan Pressurization". Philadelphia, PA; American } \\
\text { Society for Testing and Materials. }\end{array}$ & 2.3 & & \\
\hline [38] & $\begin{array}{l}\text { ASTM. 1995. "ASTM Standard E1186-87, Standard Practices for Air Leakage Site } \\
\text { Detection in Building Envelopes". Philadelphia, PA; American Society for Testing } \\
\text { and Materials. }\end{array}$ & & 1.4 & \\
\hline [39] & $\begin{array}{l}\text { ASTM. 1995. "ASTM Standard E1677-95, Standard specification for an air } \\
\text { retarder (AR) material or system for low-rise framed building walls". Philadelphia, } \\
\text { PA; American Society for Testing and Materials. }\end{array}$ & $\begin{array}{l}1.4 \\
1.5\end{array}$ & 1.4 & 1.4 \\
\hline
\end{tabular}




\begin{tabular}{|c|c|c|c|c|}
\hline & & \multicolumn{3}{|c|}{ Links } \\
\hline & & \multirow[t]{2}{*}{$M$} & \multirow{2}{*}{$\begin{array}{l}\mathrm{D} \\
1.4 \\
2.5\end{array}$} & \multirow[t]{2}{*}{$N$} \\
\hline [40] & $\begin{array}{l}\text { ASTM. 1995. "ASTM Standard E71-95, Standard Test Method for Determining } \\
\text { Air Change in a Single Zone By Means of a Tracer Gas Dilution". Philadelphia, } \\
\text { PA; American Society for Testing and Materials. }\end{array}$ & & & \\
\hline [41] & $\begin{array}{l}\text { ASTM. 1997. "ASTM Standard E1827-96, Standard Test Methods for Determining } \\
\text { Airtightness of Buildings Using an Orifice Blower Door". Philadelphia, PA; } \\
\text { American Society for Testing and Materials. }\end{array}$ & 1.4 & 1.4 & \\
\hline [42] & $\begin{array}{l}\text { ASTM. 1998. "Guide For Assessing Depressurization-Induced Backdrafting and } \\
\text { Spillage From Vented Combustion Appliances". Philadelphia, PA; American } \\
\text { Society for Testing and Materials. }\end{array}$ & 2.4 & $\begin{array}{l}2.4 \\
2.4\end{array}$ & \\
\hline [43] & $\begin{array}{l}\text { Bahnfleth, W.P., G.K. Yuill, and B. Lee. 1999. "Protocol for Field Testing of Tall } \\
\text { Buildings to Determine Envelope Air Leakage Rate". ASHRAE Transactions, Vol. } \\
\text { 105, Part. 2, } 4275 \text { (RP-935). Atlanta, GA; American Society of Heating, } \\
\text { Refrigerating, and Air-Conditioning Engineers, Inc. }\end{array}$ & 1.4 & 1.4 & \\
\hline [44] & $\begin{array}{l}\text { Barbat, M., V. Richalet, and G. Guarracino. 1999. "Experimental Studies of the Air } \\
\text { Quality Evaluation". Proceedings of the } 8^{\text {th }} \text { International Conference on Indoor Air } \\
\text { Quality and Climate, Edinburgh, Scotland. }\end{array}$ & & 3.2 & \\
\hline [45] & $\begin{array}{l}\text { Bearg, D.W. 1998. "Commissioning and Indoor Air Quality". Proceedings of the } \\
\text { 6th National Conference on Building Commissioning, Lake Buena Vista, Florida. } \\
\text { Portland, OR; Portland Energy Conservation Institute. }\end{array}$ & 3.3 & $\begin{array}{l}3.2 \\
3.3\end{array}$ & \\
\hline [46] & $\begin{array}{l}\text { Bearg, D.W. 1999. "The Use of Multipoint Monitoring as a Tool for } \\
\text { Commissioning Buildings for IAQ". ASHRAE Transactions, Vol. 105, Part 1, CH- } \\
\text { 99-19-3. }\end{array}$ & $\begin{array}{l}2.5 \\
3.2\end{array}$ & $\begin{array}{l}2.5 \\
3.2 \\
3.3\end{array}$ & \\
\hline [47] & $\begin{array}{l}\text { Beers, J. 1994. “Condensing Furnaces: Lessons from a Utility”. Home Energy } \\
\text { Magazine, Vol. 11, No. 6, November/December, pp. 13-17. Berkeley, CA; Energy } \\
\text { Auditor \& Retrofitter, Inc. }\end{array}$ & & 2.2 & \\
\hline [48] & $\begin{array}{l}\text { Benner, N. and K. Stum. 1993. "Commissioning and Recommissioning } \\
\text { Opportunities in Residential Buildings". Proceedings of the } 1 \text { st Innovative Housing } \\
\text { Conference, Vancouver, BC, Canada, Vol. 4, pp. 126-137. Canada National } \\
\text { Research Council. }\end{array}$ & & 5.1 & \\
\hline [49] & $\begin{array}{l}\text { Benton, C.C., C. Huizenga, R. Marcial, M. Hydeman, and J. Chace. 1996. "Taking } \\
\text { a Building's Vital Signs: A Lending Library of Handheld Instruments". } \\
\text { Proceedings of the 1996 ACEEE Summer Study on Energy Efficient Buildings, } \\
\text { 4.11. Washington, D.C.; American Council for an Energy-Efficient Economy. }\end{array}$ & & $\begin{array}{l}3.2 \\
4.7\end{array}$ & \\
\hline [50] & $\begin{array}{l}\text { Berckmans, D., K. Van De Weyer, and M. De Moor. 1993. "Visualization and } \\
\text { quantification of the airflow pattern using image analysis". ASHRAE Building } \\
\text { Design, Technology, and Occupant Well-Being in Temperate Climates, Brussels, } \\
\text { February, pp. 207-215. Atlanta, GA; American Society of Heating, Refrigerating, } \\
\text { and Air-Conditioning Engineers, Inc. }\end{array}$ & & 2.3 & \\
\hline
\end{tabular}




\begin{tabular}{|c|c|c|c|c|}
\hline & & \multicolumn{3}{|c|}{ Links } \\
\hline & & $\mathrm{M}$ & $\mathrm{D}$ & $N$ \\
\hline [51] & $\begin{array}{l}\text { Berk, J.V., R.A.Young, S.R. Brown, and C.D. Hollowell. 1981. "Impact of energy- } \\
\text { conserving retrofits on indoor air quality in residential housing". Berkeley, CA; } \\
\text { Lawrence Berkeley Laboratory report LBL-12189. }\end{array}$ & & $\begin{array}{l}1.4 \\
3.2 \\
3.5\end{array}$ & $\begin{array}{l}1.4 \\
2.5 \\
3.2 \\
3.5\end{array}$ \\
\hline [52] & $\begin{array}{l}\text { Bevirt, W.D. 1994. "What engineers need to know about testing and balancing". } \\
\text { ASHRAE Transactions, Vol. 100, Part 1, pp. 705-714. }\end{array}$ & & $\begin{array}{l}2.3 \\
2.3 \\
4.7 \\
5.1\end{array}$ & 2.3 \\
\hline [53] & $\begin{array}{l}\text { BII. 1998. "Building Energy Code Training: Final Report 1995-1998". } \\
\text { Sacramento, CA; Building Industry Institute. }\end{array}$ & 1.1 & $\begin{array}{l}1.4 \\
2.3 \\
2.3 \\
2.5 \\
5.1\end{array}$ & $\begin{array}{l}1.1 \\
1.2 \\
1.2 \\
2.1 \\
2.2 \\
2.3 \\
2.3 \\
2.3 \\
4.1\end{array}$ \\
\hline [54] & $\begin{array}{l}\text { Bittle, B.R. and V.W. Goldschmidt. 1985. "Trends of residential heat pump cyclic } \\
\text { tests". ASHRAE Transactions, Vol. 91, Part 1A, pp. 64-79. }\end{array}$ & 2.1 & & \\
\hline [55] & $\begin{array}{l}\text { Blasnik, M. and J. Fitzgerald. 1992. "In Search of the Missing Leak". Home } \\
\text { Energy Magazine, Vol. 9, No. 6. Berkeley, CA; Energy Auditor \& Retrofitter, Inc. }\end{array}$ & & 1.4 & \\
\hline [56] & $\begin{array}{l}\text { Bodzin, S. 1999. "Builders Find New Technologies Paying Off". Home Energy } \\
\text { Magazine, Vol. 16, No. 1, January/February, pp.18-27. Berkeley, CA; Energy } \\
\text { Auditor \& Retrofitter, Inc. }\end{array}$ & & & 5.2 \\
\hline [57] & $\begin{array}{l}\text { Boner, A. and C. Dasher. 1997. "Oregon's Commissioning Toolkit". Proceedings } \\
\text { of the 5th National Conference on Building Commissioning, Huntington Beach, } \\
\text { CA. Portland, OR; Portland Energy Conservation Institute. }\end{array}$ & & 5.1 & \\
\hline [58] & $\begin{array}{l}\text { Bowman, M. and M.L. Goldberg. 1994. "Turning Lead into Gold: Trends in } \\
\text { Metering for Studies of Load and Load Impacts". Proceedings of the 1994 ACEEE } \\
\text { Summer Study on Energy Efficient Buildings, 2.31. Washington, D.C.; American } \\
\text { Council for an Energy-Efficient Economy. }\end{array}$ & & 4.7 & \\
\hline [59] & $\begin{array}{l}\text { Brohard, G.J. and B.L. Krieg. 1994. "Commissioning the } \mathrm{ACT}^{2} \text { Project Pilot } \\
\text { Demonstration". ASHRAE Transactions, Vol. 100, Part 1, pp. 1371-1381. }\end{array}$ & & $\begin{array}{l}2.6 \\
2.7 \\
5.1\end{array}$ & \\
\hline [60] & $\begin{array}{l}\text { Buchan Lawton Parent Ltd. 1996. "Field Survey of Heat Recovery Ventilation } \\
\text { Systems". Ottawa, ON, Canada; Canadian Mortgage and Housing Corporation } \\
\text { Technical Series 96-215. }\end{array}$ & & 2.5 & \\
\hline [61] & $\begin{array}{l}\text { Burch, D.M. 1980. "Infrared audits of roof heat loss". ASHRAE Transactions, Vol. } \\
\text { 86, Part 2, pp. 209-226. }\end{array}$ & & 1.1 & \\
\hline
\end{tabular}




\begin{tabular}{|c|c|c|c|c|}
\hline & & \multicolumn{3}{|c|}{ Links } \\
\hline & & \multirow{2}{*}{ M } & \multirow{2}{*}{$\frac{\mathrm{D}}{5.2}$} & \multirow[t]{2}{*}{$\mathrm{N}$} \\
\hline [62] & $\begin{array}{l}\text { Byrne, J. 1995. "DOE Proposes Guidelines for Home Energy Ratings". Home } \\
\text { Energy Magazine, Vol. 12, No. 6. Berkeley, CA; Energy Auditor \& Retrofitter, Inc. }\end{array}$ & & & \\
\hline [63] & $\begin{array}{l}\text { CA State. 1999. "City/County Population and Housing Estimates, 1991-1999, } \\
\text { with census counts". Sacramento, California; Department of Finance, State of } \\
\text { California. }\end{array}$ & & & 5.2 \\
\hline [64] & $\begin{array}{l}\text { Cavallo, J. 1999. "HERS Experiment Cause for Confidence". Home Energy } \\
\text { Magazine, Vol. 16, No. 5, September/October, pp. 17-18. Berkeley, CA; Energy } \\
\text { Auditor \& Retrofitter, Inc. }\end{array}$ & & 5.1 & \\
\hline [65] & $\begin{array}{l}\text { CEC. 1995. "California Historical Energy Statistics". Sacramento, CA; California } \\
\text { Energy Commission Publication \# P300-95-020. Also, } \\
\text { http://www.energy.ca.gov/reports/stats }\end{array}$ & & 5.2 & \\
\hline [66] & $\begin{array}{l}\text { CEC. 1999. "Energy Efficiency Standards for Residential and Nonresidential } \\
\text { Buildings". Sacramento, CA; California Energy Commission. }\end{array}$ & & 2.1 & $\begin{array}{l}1.1 \\
1.2 \\
1.2 \\
1.3 \\
1.4 \\
2.2 \\
2.5 \\
4.1 \\
4.2 \\
5.2\end{array}$ \\
\hline [67] & $\begin{array}{l}\text { CGSB. 1995. "CAN/CGSB-51.71-95, Method To Determine The Potential For } \\
\text { Pressure-Induced Spillage From Vented, Fuel-Fired, Space Heating Appliances, } \\
\text { Water Heaters and Fireplaces". National Standard of Canada. Ottawa, CA; } \\
\text { Canadian General Standards Board. }\end{array}$ & 2.4 & 2.4 & 2.4 \\
\hline [68] & $\begin{array}{l}\text { Chan, D.W.T., J. Burnett, and H.K.W. Mui. 1999. "Use of a Portable Indoor } \\
\text { Environmental Quality Logger for Indoor Environmental Quality Assessment". } \\
\text { ASHRAE Transactions, Vol. 105, Part 2, SE-99-5-4. }\end{array}$ & & 3.1 & \\
\hline [69] & $\begin{array}{l}\text { Cheong, K.W. and S.B Riffat. 1993. "Development of a New Tracer-Gas Sampling } \\
\text { System for Measuring Airflow in Ducts". Proceedings of the } 14^{\text {th }} \text { AIVC } \\
\text { Conference, Copenhagen, Denmark, pp. } 407-420 \text {. Coventry, Great Britain; Air } \\
\text { Infiltration and Ventilation Centre. }\end{array}$ & & $\begin{array}{l}2.3 \\
3.2\end{array}$ & \\
\hline$[70]$ & $\begin{array}{l}\text { Cheple, M. and P. Heulman. 1998. "Moisture Control in Bathrooms". Home } \\
\text { Energy Magazine, Vol. 15, No. 2, March/April, pp. 21-26. Berkeley, CA; Energy } \\
\text { Auditor \& Retrofitter, Inc. }\end{array}$ & & & 1.5 \\
\hline [71] & $\begin{array}{l}\text { Christian, J. and J. Kosny. 1999. "Calculating Whole Wall R-Values on the Net". } \\
\text { Home Energy Magazine, Vol. 16, No. 6, November/December, pp. 22-25. } \\
\text { Berkeley, CA; Energy Auditor \& Retrofitter, Inc. }\end{array}$ & & 1.1 & 1.1 \\
\hline
\end{tabular}




\begin{tabular}{|c|c|c|c|c|}
\hline & & \multirow{2}{*}{\multicolumn{3}{|c|}{ Links }} \\
\hline & & & & \\
\hline & & $\mathrm{M}$ & D & $\mathrm{N}$ \\
\hline [72] & $\begin{array}{l}\text { Christian, J. and J. Kosny. 1999. "Calculating whole wall R-values on the net". } \\
\text { Home Energy Magazine, November/December. Berkeley, CA; Energy Auditor \& } \\
\text { Retrofitter, Inc. }\end{array}$ & 1.1 & 1.1 & \\
\hline [73] & $\begin{array}{l}\text { Christian, J.E. and J. Kosny. 1995. "Toward a national opaque wall rating label". } \\
\text { Proceedings of Thermal Performance of the Exterior Envelopes of Buildings VI, } \\
\text { Clearwater Beach, FL, pp. 221-239. Atlanta, GA; American Society of Heating, } \\
\text { Refrigerating, and Air-Conditioning Engineers, Inc. }\end{array}$ & 1.1 & $\begin{array}{l}1.1 \\
1.3 \\
1.4\end{array}$ & \\
\hline [74] & $\begin{array}{l}\text { Christian, J.E. and J. Kosny. 1997. "Wall R-Values That Tell It Like It Is". Home } \\
\text { Energy Magazine, Vol. 14, No. 2, March/April, pp. 15-20. Berkeley, CA; Energy } \\
\text { Auditor \& Retrofitter, Inc. }\end{array}$ & 1.1 & 1.1 & 1.1 \\
\hline [75] & $\begin{array}{l}\text { Ciepliski, D.L., R.W. Besant, and C.J. Simonson. 1998. "Some recommendations } \\
\text { for improvements to ASHRAE Standard 84-1991". ASHRAE Transactions, Vol. } \\
\text { 104, Part 1B, pp.1651-1665. }\end{array}$ & 2.5 & 2.5 & \\
\hline [76] & $\begin{array}{l}\text { Claridge, D.E., M. Liu, W.D. Turner, Y. Zhu, M. Abbas, and J.S. Haberl. } 1998 . \\
\text { "Energy and Comfort Benefits of Continuous Commissioning in Buildings". } \\
\text { Proceedings of the International Conference Improving Electricity Efficiency in } \\
\text { Commercial Buildings, 21-23 September, Amsterdam, The Netherlands, pp. } \\
\text { 12.5.1-12.5.17. }\end{array}$ & & & 5.2 \\
\hline [77] & $\begin{array}{l}\text { CMHC. 1996. "Complying With Residential Ventilation Requirements in the } 1995 \\
\text { National Building Code". Ottawa, Ontario, Canada; Canada Mortgage and } \\
\text { Housing Corporation }\end{array}$ & & 2.5 & 2.5 \\
\hline [78] & $\begin{array}{l}\text { CMHC. 1996. "Review of Non-Destructive Test Methods for Assessing Strength, } \\
\text { Serviceability and Deterioration in Buildings". Institute for Research in } \\
\text { Construction, National Research Council Canada technical series } 96-233 \text {. }\end{array}$ & & 1.5 & \\
\hline [79] & $\begin{array}{l}\text { CMHC. 1998. "Renovator's Technical Guide". Ottawa, Ontario, Canada; Canada } \\
\text { Mortgage and Housing Corporation. }\end{array}$ & $\begin{array}{l}1.4 \\
1.5 \\
3.2\end{array}$ & $\begin{array}{l}1.1 \\
1.4 \\
1.4 \\
1.5 \\
2.3 \\
2.4 \\
2.5 \\
3.1 \\
3.2 \\
3.4 \\
4.5 \\
5.1\end{array}$ & 1.4 \\
\hline [80] & $\begin{array}{l}\text { CMHC. 1998. "Testing of Air Barrier Systems for Wood Frame Walls". Ottawa, } \\
\text { ON, Canada; Canada Mortgage and Housing Corporation Technical Series 98-110. }\end{array}$ & 1.4 & 1.4 & 1.4 \\
\hline [81] & $\begin{array}{l}\text { Cohen, S. and C. Goldman. 1991. "Between Two Decades: Weatherization Report } \\
\text { Card". Home Energy Magazine, Vol. 8, No. 4, July/August, pp. 30-36. Berkeley, } \\
\text { CA; Energy Auditor \& Retrofitter, Inc. }\end{array}$ & & 5.1 & 5.2 \\
\hline
\end{tabular}




\begin{tabular}{|c|c|c|c|c|}
\hline & & \multicolumn{3}{|c|}{ Links } \\
\hline & & $M$ & $\mathrm{D}$ & $\mathrm{N}$ \\
\hline [82] & $\begin{array}{l}\text { Cohen, T. 1995. Performance Testing of HVAC Systems for Air Quality. } \\
\text { Proceedings IAQ95: Practical Engineering for IAQ, Denver, Colorado; October } \\
\text { 22-24, 1995; pp. 43-45. Atlanta, GA; American Society of Heating, Refrigerating, } \\
\text { and Air-Conditioning Engineers. }\end{array}$ & & 2.3 & \\
\hline [83] & $\begin{array}{l}\text { Coito, F., G. Syphers, A. Lekov, and V. Richardson. 1998. "Are Your Ducts All in a } \\
\text { Row? Duct Efficiency Testing and Analysis for } 150 \text { New Homes in Northern } \\
\text { California". Proceedings of the } 1998 \text { ACEEE Summer Study on Energy Efficient } \\
\text { Buildings, 1.33. Washington, D.C.; American Council for an Energy-Efficient } \\
\text { Economy. }\end{array}$ & & 2.3 & \\
\hline [84] & $\begin{array}{l}\text { Cole, J.P. and G.V.R. Holness. 1989. "Use of programmable controllers for HVAC } \\
\text { control and facilities monitoring systems". ASHRAE Transactions, Vol. 95, Part 1, } \\
\text { pp. 492-497. }\end{array}$ & & $\begin{array}{l}2.6 \\
2.6\end{array}$ & \\
\hline [85] & $\begin{array}{l}\text { Condon, P.E. W.L. Carroll, and R.C. Sonderegger. 1980. "A New Measurement } \\
\text { Strategy For in Situ Testing of Wall Thermal Performance". Berkeley, CA; } \\
\text { Lawrence Berkeley Laboratory report LBL-8822. }\end{array}$ & $\begin{array}{l}1.1 \\
1.3\end{array}$ & $\begin{array}{l}1.1 \\
1.1\end{array}$ & \\
\hline [86] & $\begin{array}{l}\text { Condon, P.E., D.T. Grimsrud, M.H. Sherman, and R.C. Kammerud. 1980. "An } \\
\text { Automated Controlled Flow Air Infiltration Measurement System". In Building } \\
\text { Air Change Rate and Infiltration Measurements, Hunt/King/Trechsel Eds., pp. } 60- \\
\text { 72. Philadelphia, PA; American Society of Testing and Materials. Also Berkeley, } \\
\text { CA; Lawrence Berkeley Laboratory report LBL-6849. }\end{array}$ & & 2.5 & \\
\hline [87] & $\begin{array}{l}\text { Conibear, S.A., S. Geneser, and B.W. Carnow. 1995. "Carbon Monoxide Levels } \\
\text { and Sources Found in a Random Sample of Households in Chicago During the } \\
\text { 1994-1995 Heating Season". Proceedings IAQ95: Practical Engineering for IAQ; } \\
\text { Denver, Colorado; October 22-24, 1995; pp. 111-118. Atlanta, GA; American } \\
\text { Society of Heating, Refrigerating, and Air-Conditioning Engineers. }\end{array}$ & & 2.4 & 2.4 \\
\hline [88] & $\begin{array}{l}\text { Conover, D.W. 1992. "Convective Loss in Loose-Fill Attic Insulation". Home } \\
\text { Energy Magazine, Vol. 9, No. 3, May/June, pp. 27-30. Berkeley, CA; Energy } \\
\text { Auditor \& Retrofitter, Inc }\end{array}$ & & & 1.1 \\
\hline [89] & $\begin{array}{l}\text { ConSol. 1999. "CIEE Final Project Report: Protocols for Energy Efficient } \\
\text { Residential Building Envelopes". Stockton, CA; Consol. }\end{array}$ & & & $\begin{array}{l}1.1 \\
1.1 \\
1.2 \\
2.5\end{array}$ \\
\hline [90] & $\begin{array}{l}\text { Cooper, K. C. Mattock, and D. Rousseau. 1997. "Energy Performance Contracting } \\
\text { and the Residential Sector Technical Report".. Ottawa, ON, Canada; Canadian } \\
\text { Mortgage and Housing Corporation Technical Series 97-109. }\end{array}$ & & 5.1 & \\
\hline [91] & $\begin{array}{l}\text { Coyle, T. 1999. "Electrical Testing: A Key Component of Building } \\
\text { Commissioning". Proceedings of the } 7 \text { th National Conference on Building } \\
\text { Commissioning. Portland, OR; Portland Energy Conservation Institute. }\end{array}$ & & 4.3 & \\
\hline
\end{tabular}




\begin{tabular}{|c|c|c|c|c|}
\hline & & \multicolumn{3}{|c|}{ Links } \\
\hline & & \multirow[t]{2}{*}{$\mathbf{M}$} & \multirow{2}{*}{$\mathrm{D}$} & \multirow{2}{*}{$\mathrm{N}$} \\
\hline [92] & $\begin{array}{l}\text { Creech, D. and J. Tiller. 1993. "Attic Insulation R-Values - Who's Fluffing?" Home } \\
\text { Energy Magazine, Vol. 10, No. 1, January/February, pp. 6-7. Berkeley, CA; Energy } \\
\text { Auditor \& Retrofitter, Inc. }\end{array}$ & & & \\
\hline [93] & $\begin{array}{l}\text { Crowell, L.A. 1992. Letter to the Editor: "Picture This: Decent Installation". Home } \\
\text { Energy Magazine, Vol. 9, No. 4, July/August, p. 3. Berkeley, CA; Energy Auditor } \\
\text { \& Retrofitter, Inc. }\end{array}$ & & 1.1 & \\
\hline [94] & $\begin{array}{l}\text { Cummings, J.B. 1998. "Standards and Verification Protocols for Commissioning } \\
\text { Airflows in Buildings". Proceedings of the 6th National Conference on Building } \\
\text { Commissioning, Lake Buena Vista, Florida. Portland, OR; Portland Energy } \\
\text { Conservation Institute. }\end{array}$ & $\begin{array}{l}1.4 \\
2.3\end{array}$ & $\begin{array}{l}1.4 \\
1.4 \\
2.3 \\
2.5\end{array}$ & $\begin{array}{l}1.4 \\
1.4 \\
2.3 \\
2.5\end{array}$ \\
\hline [95] & $\begin{array}{l}\text { Cummings, J.B. and C.R. Withers, Jr. 1998. "Building Cavities Used as Ducts: Air } \\
\text { Leakage Characteristics and Impacts in Light Commercial Buildings". ASHRAE } \\
\text { Transactions, Vol. 104, Part 2, pp. 743-752. }\end{array}$ & $\begin{array}{l}1.4 \\
1.4 \\
2.3\end{array}$ & & \\
\hline [96] & $\begin{array}{l}\text { Cummings, J.B. and C.R. Withers. 1997. "Identifying Air Failure Modes in Small } \\
\text { Commercial Buildings: Tools and Methodologies for Building Commissioning } \\
\text { Diagnostics". Proceedings of the 5th National Conference on Building } \\
\text { Commissioning, Huntington Beach, CA. Portland, OR; Portland Energy } \\
\text { Conservation Institute. }\end{array}$ & 1.4 & $\begin{array}{l}1.4 \\
2.3 \\
2.5\end{array}$ & 1.4 \\
\hline [97] & $\begin{array}{l}\text { Cummings, J.B. and J.J. Tooley. 1989. "Infiltration and pressure differences } \\
\text { induced by forced air systems in Florida residences". ASHRAE Transactions, Vol. } \\
\text { 95, Part 2, pp. 551-560. }\end{array}$ & 2.3 & 2.3 & 2.3 \\
\hline [98] & $\begin{array}{l}\text { Cummings, J.B., J. Tooley, and R. Dunsmore. 1990. "Impacts of Duct Leakage on } \\
\text { Infiltration Rates, Space Conditioning Energy Use, and Peak Electrical Demand in } \\
\text { Florida Homes". Proceedings of the } 1990 \text { ACEEE Summer Study on Energy } \\
\text { Efficiency in Buildings, Vol. 9, pp. } 65-76 \text {. Washington D.C.; American Council for } \\
\text { an Energy Efficient Economy. }\end{array}$ & & 4.7 & $\begin{array}{l}1.4 \\
2.2 \\
2.3 \\
5.2\end{array}$ \\
\hline [99] & $\begin{array}{l}\text { Cvetkovic, M. 1982. "Thermal flux measurements with a compensated heat-flow } \\
\text { meter". Proceedings of Thermal Performance of the Exterior Envelopes of } \\
\text { Buildings II, Las Vegas, NV, pp. 749-766. Atlanta, GA; American Society of } \\
\text { Heating, Refrigerating, and Air-Conditioning Engineers, Inc. }\end{array}$ & & 1.1 & \\
\hline$[100]$ & $\begin{array}{l}\text { Dale, J.D..and M.Y. Ackerman. 1990. "Evaluation of the Performance of Attic } \\
\text { Turbine Ventilators". Department of Mechanical Engineering, University of } \\
\text { Alberta, Canada. }\end{array}$ & 2.5 & 2.5 & 2.5 \\
\hline [101] & $\begin{array}{l}\text { Dale, J.D. and M.Y. Ackerman. 1993. "Evaluation of the Performance of Attic } \\
\text { Turbine Ventilators". ASHRAE Transactions, Vol. 99, Part 1, pp. 14-22. }\end{array}$ & 2.5 & 2.5 & 2.5 \\
\hline [102] & $\begin{array}{l}\text { Damasceno, G.S., P.A. Domanski, S. Rooke, and V.W. Goldschmidt. } 1991 . \\
\text { "Refrigerant charge effects on heat pump performance". ASHRAE Transactions, } \\
\text { Vol. 97, Part 1, pp. 304-310. }\end{array}$ & & 2.1 & \\
\hline
\end{tabular}




\begin{tabular}{|c|c|c|c|c|}
\hline & & & Link & \\
\hline & & $\mathbf{M}$ & $\mathrm{D}$ & $\mathrm{N}$ \\
\hline [103] & $\begin{array}{l}\text { Davis, B., D. Baylon, and A. Houseknecht. 1998. "Developing a Market-Based } \\
\text { Utility Duct Sealing Program". Proceedings of the } 1998 \text { ACEEE Summer Study on } \\
\text { Energy Efficient Buildings, 2.21. Washington, D.C.; American Council for an } \\
\text { Energy-Efficient Economy. }\end{array}$ & & 2.3 & 2.3 \\
\hline [104] & $\begin{array}{l}\text { Davis, B.E. 1995. "Dazzling Color Hoses - More Than a Fashion Statement". } \\
\text { Home Energy Magazine, Vol. 12, No. 4, July/August, pp. 9-10. Berkeley, CA; } \\
\text { Energy Auditor \& Retrofitter, Inc. }\end{array}$ & & 4.7 & \\
\hline [105] & $\begin{array}{l}\text { de Salis, M.H.F., D.J. Oldham, and G.J. Levermore. 1996. "The Application of } \\
\text { Acoustic Techniques to the Commissioning and Control of Mechanical Ventilation } \\
\text { Systems". Proceedings of the CIBSE/ASHRAE Joint National Conference } 1996 \\
\text { Harrogate, Part 2, Volume 1, pp. 256-262. }\end{array}$ & & 2.3 & \\
\hline [106] & $\begin{array}{l}\text { deKieffer, R. 1995. "Combustion Safety Checks: How Not to Kill Your Clients". } \\
\text { Home Energy Magazine, Vol. 12, No. 2, March/April, pp. 19-44. Berkeley, CA; } \\
\text { Energy Auditor \& Retrofitter, Inc. }\end{array}$ & & 2.4 & \\
\hline$[107]$ & $\begin{array}{l}\text { Deng, X., T. Irie, and M. Ohmura. 1999. "Field Survey of Living Mites and } \\
\text { Airborne Allergens in Dwellings in Shinshu District, Japan". Proceedings of the } \\
\text { 8th International Conference on Indoor Air Quality and Climate, Edinburgh, } \\
\text { Scotland. }\end{array}$ & 3.4 & $\begin{array}{l}3.4 \\
3.5\end{array}$ & \\
\hline [108] & $\begin{array}{l}\text { Desjarlais, A.O., K.W. Childs, and J.E. Christian. 1998. "To Storm or Not to } \\
\text { Storm: Measurement Method to Quantify Impact of Exterior Envelope Airtightness } \\
\text { on Energy Usage Prior to Construction". Proceedings of the Thermal Performance } \\
\text { of the Exterior Envelopes of Buildings VII, Clearwater Beach, FL, pp. } 607 . \\
\text { Atlanta, GA; American Society of Heating, Refrigerating, and Air-Conditioning } \\
\text { Engineers, Inc. }\end{array}$ & 1.1 & 1.2 & \\
\hline [109] & $\begin{array}{l}\text { DeWerth, D.W. and S.M. Sobieski. 1985. "A three step method for detecting } \\
\text { unacceptable flue gas leakage from furnace heat exchangers". ASHRAE } \\
\text { Transactions, Vol. 91, Part 2B, pp. 760-772. }\end{array}$ & & 2.4 & \\
\hline [110] & $\begin{array}{l}\text { Dodds, D., C. Dasher, and M. Brenneke. 1998. "Building Commissioning: Maps, } \\
\text { Gaps \& Directions". Proceedings of the } 1998 \text { ACEEE Summer Study on Energy } \\
\text { Efficient Buildings, 4.133. Washington, D.C.; American Council for an Energy- } \\
\text { Efficient Economy. }\end{array}$ & & 5.1 & \\
\hline [111] & $\begin{array}{l}\text { Dodds, D., T. Haasl, C. Chappell, and C. Kjellman. 1994. "How Much Does } \\
\text { Commissioning Cost and How Much Does It Save?" Proceedings of the } 1994 \\
\text { ACEEE Summer Study on Energy Efficient Buildings, 5.89. Washington, D.C.; } \\
\text { American Council for an Energy-Efficient Economy. }\end{array}$ & & 5.1 & \\
\hline [112] & $\begin{array}{l}\text { Dodge, F.W. 1996. "Quarterly State Housing Forecast, 3rd Quarter 1996”. The } \\
\text { McGraw-Hill Companies, Inc. }\end{array}$ & & 5.1 & 5.2 \\
\hline [113] & $\begin{array}{l}\text { Dodier, R.H. and J.F. Kreider. 1999. "Detecting whole building energy problems". } \\
\text { ASHRAE Transactions, Vol. 105, Part 1, pp. } 579-589 .\end{array}$ & & 4.7 & \\
\hline
\end{tabular}




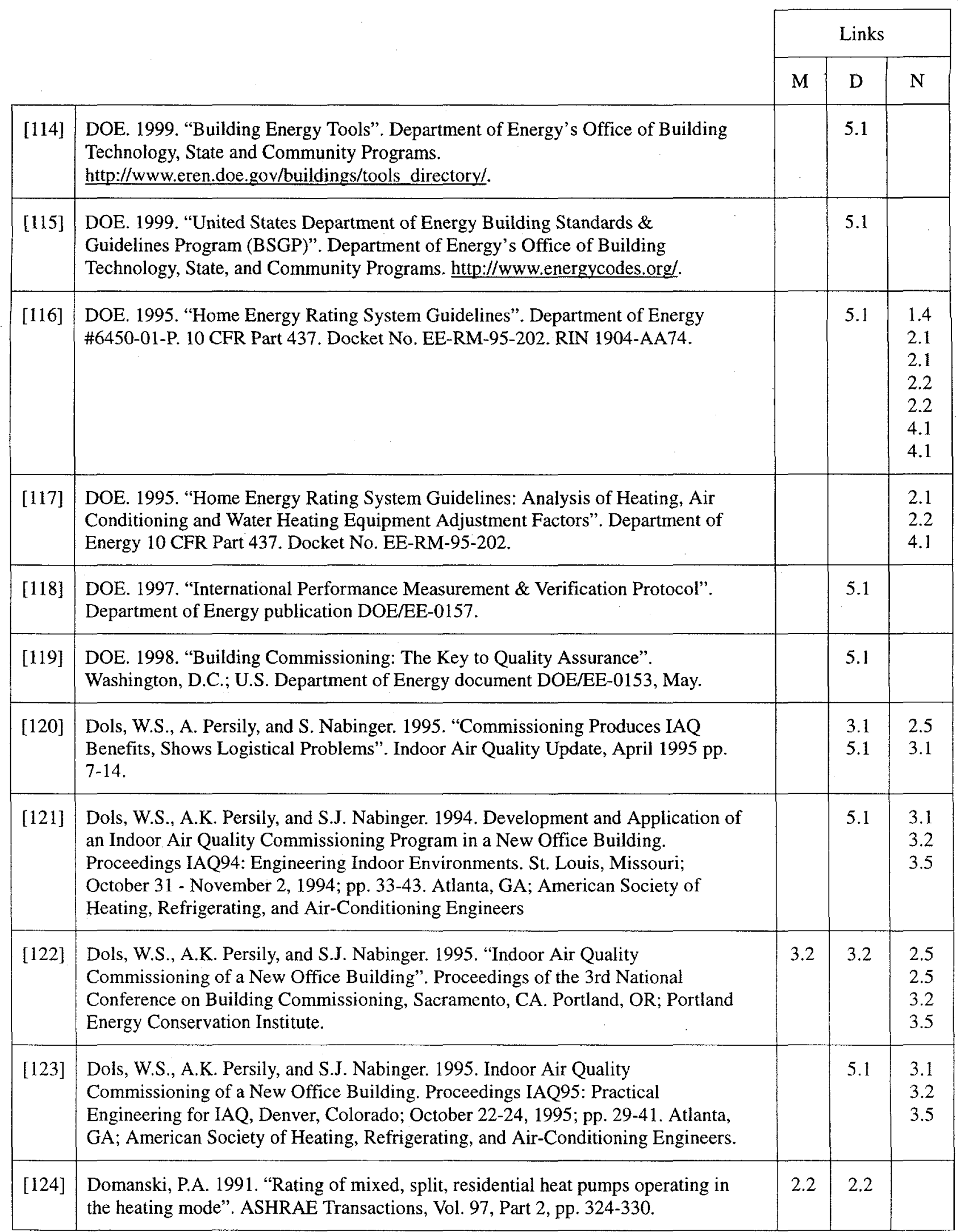




\begin{tabular}{|c|c|c|c|c|}
\hline & & & Link & \\
\hline & & $M$ & $\mathrm{D}$ & $\mathrm{N}$ \\
\hline [125] & $\begin{array}{l}\text { Downey, T. and J. Proctor. 1994. "Blower Door Guided Weatherization Test } \\
\text { Project Final Report". San Rafael, CA; Proctor Engineering Group. }\end{array}$ & & $\begin{array}{l}1.4 \\
2.3\end{array}$ & \\
\hline [126] & $\begin{array}{l}\text { Dubose, G. and J.D. Odon. 1994. "Forget Everything You've Heard About } \\
\text { Building Commissioning Procedures-They Don't Work in Hot, Humid Climates". } \\
\text { Proceedings of the } 2^{\text {nd }} \text { National Conference on Building Commissioning, St. } \\
\text { Petersburg Beach, Florida. Portland, OR; Portland Energy Conservation Institute. }\end{array}$ & & 1.5 & \\
\hline$[127]$ & $\begin{array}{l}\text { Dubrous, F.M. and A.G. Wilson. 1992. "A simple method for computing window } \\
\text { energy performance for different locations and orientations". ASHRAE } \\
\text { Transactions, Vol. } 98 \text {, Part 1, pp. } 841-849 \text {. }\end{array}$ & 1.2 & 1.2 & \\
\hline$[128]$ & $\begin{array}{l}\text { Dumont, R.S. and L.J. Snodgrass. 1990. "Investigation of chimney backflow } \\
\text { conditions: a case study in a well-sealed house". ASHRAE Transactions, Vol. } 96 \text {, } \\
\text { Part 1, pp. 53-59. }\end{array}$ & & 2.4 & \\
\hline [129] & $\begin{array}{l}\text { Dutton, J. 1994. "Fundamentals of Gas Utilization, Third Edition". Scarborough, } \\
\text { Ontario, Canada; Centennial College Press }\end{array}$ & & $\begin{array}{l}2.2 \\
2.4 \\
2.4 \\
2.4 \\
4.7\end{array}$ & \\
\hline$[130]$ & $\begin{array}{l}\text { Eash, J. 1998. "IQ+ Report: Irvine Home Builders Get Smarter". Home Energy } \\
\text { Magazine, Vol. 15, No. 6, November/December, pp. 13-14. Berkeley, CA; Energy } \\
\text { Auditor \& Retrofitter, Inc. }\end{array}$ & & & 5.1 \\
\hline$[131]$ & $\begin{array}{l}\text { Edwards, R.E. and C. Irwin. 1994. "A Suggested Standard Methodology for } \\
\text { Assessment of the Performance of Domestic Ventilation Systems". Proceedings of } \\
\text { the } 15^{\text {th }} \text { AIVC Conference, Buxton, Great Britain. }\end{array}$ & & & 5.2 \\
\hline [132] & $\begin{array}{l}\text { Elberling, L.E., G.J. Brohard, M.L. Brown, R. Cavanagh, G. R. Hernandez, A. } \\
\text { Lovins, and A.H. Rosenfeld. 1998. "Advanced Customer Technology Test for } \\
\text { Maximum Energy Efficiency (ACT²) Project: The Final Report". Proceedings of } \\
\text { the } 1998 \text { ACEEE Summer Study on Energy Efficient Buildings, 1.67. Washington, } \\
\text { D.C.; American Council for an Energy-Efficient Economy. }\end{array}$ & & 5.1 & \\
\hline [133] & $\begin{array}{l}\text { Eley, C. and B. Wilcox. 1992. "Setting the criteria for the } 1992 \text { California } \\
\text { residential energy standards". Proceedings of Thermal Performance of the Exterior } \\
\text { Envelopes of Buildings V, Clearwater Beach, FL, pp. 288-297. Atlanta, GA; } \\
\text { American Society of Heating, Refrigerating, and Air-Conditioning Engineers, Inc. }\end{array}$ & 5.2 & & \\
\hline [134] & $\begin{array}{l}\text { Elovitz, K.M. 1986. "Building Commissioning: What If You Want To Skip It?". } \\
\text { ASHRAE Transactions, Vol. 92, Part 2B, pp. } 469-475 .\end{array}$ & & $\begin{array}{l}2.6 \\
5.1\end{array}$ & \\
\hline [135] & $\begin{array}{l}\text { Elovitz, K.M. 1992. "Commissioning Building Mechanical Systems". ASHRAE } \\
\text { Transactions, Vol. 92, Part 2, pp. 543-552. }\end{array}$ & & 5.1 & \\
\hline [136] & $\begin{array}{l}\text { Energy Design Update. 1986. "The Measured Performance of Windows". Energy } \\
\text { Design Update, November } 1986 .\end{array}$ & & 1.2 & \\
\hline
\end{tabular}




\begin{tabular}{|c|c|c|c|c|}
\hline & & \multicolumn{3}{|c|}{ Links } \\
\hline & & $\mathbf{M}$ & $\mathrm{D}$ & $N$ \\
\hline [137] & $\begin{array}{l}\text { Energy Information Administration. 1999. "Residential Energy Consumption } \\
\text { Survey: Housing Characteristics 1993". } \\
\text { http://www.eia.doe.gov/emeu/recs/recs } 2 \mathrm{~g} \sim 1 \text {.html. }\end{array}$ & & & 5.2 \\
\hline [138] & $\begin{array}{l}\text { EPA. 1997. Energy Star Homes Builder Guide. "A systems approach to building } \\
\text { more profitable homes". }\end{array}$ & 2.3 & $\begin{array}{l}1.4 \\
2.1 \\
2.3 \\
2.3 \\
2.3 \\
2.7\end{array}$ & $\begin{array}{l}2.2 \\
2.3 \\
2.5 \\
4.2 \\
5.1\end{array}$ \\
\hline [139] & $\begin{array}{l}\text { EPA. 1998. "Energy Star Building Manual - Stage Two Building Tune-up". } \\
\text { Washington, D.C.; Environmental Protection Agency document EPA 430-B-98- } \\
\text { 004B, June. }\end{array}$ & & $\begin{array}{l}2.1 \\
2.2 \\
2.3 \\
2.6 \\
4.2 \\
4.3 \\
5.1\end{array}$ & 1.4 \\
\hline [140] & $\begin{array}{l}\text { EPA/DOE. 1999. "Licensed Building Professional Guidance to the ENERGY } \\
\text { STAR Label for Buildings". }\end{array}$ & & 5.1 & $\begin{array}{l}2.5 \\
2.5 \\
3.1 \\
3.4\end{array}$ \\
\hline [141] & $\begin{array}{l}\text { Fang J B., R.A. Grot, and H.S. Park. 1985. "The assessment of accuracy on the in- } \\
\text { situ methods for measuring building-envelope thermal resistance". Proceedings of } \\
\text { Thermal Performance of the Exterior Envelopes of Buildings III, Clearwater } \\
\text { Beach, FL, pp. 675-688. Atlanta, GA; American Society of Heating, Refrigerating, } \\
\text { and Air-Conditioning Engineers, Inc. }\end{array}$ & & 1.1 & \\
\hline [142] & $\begin{array}{l}\text { Fang, J.B. and R.A. Grot. 1985. "In-situ measurement of the thermal resistance of } \\
\text { building envelope of office buildings". ASHRAE Transactions, Vol. 91, Part 1B, } \\
\text { pp. 543-557. }\end{array}$ & & 1.1 & \\
\hline [143] & $\begin{array}{l}\text { Fanger, P.O. 1992. "Efficient ventilation for human comfort". Proceedings of } \\
\text { ASHRAE International Symposium: Room Air Convection and Ventilation } \\
\text { Effectiveness, Tokyo, Japan, July } 22-24, \text { pp. } 67-73 \text {. Atlanta, GA; American Society } \\
\text { of Heating, Refrigerating, and Air-Conditioning Engineers, Inc. }\end{array}$ & 3.1 & & \\
\hline [144] & $\begin{array}{l}\text { Farhar, B.C. and T.C. Coburn. 1999. "Colorado Homeowner Preferences on } \\
\text { Energy and Environmental Policy". Golden, CO; National Renewable Energy } \\
\text { Laboratory technical report NREL/TP-550-25285. }\end{array}$ & & & 5.2 \\
\hline [145] & $\begin{array}{l}\text { Farrar, S., E. Hancock, and R. Anderson. 1998. "System Interactions and Energy } \\
\text { Savings in a Hot Dry Climate". Proceedings of the } 1998 \text { ACEEE Summer Study } \\
\text { on Energy Efficient Buildings, 1.79. Washington, D.C.; American Council for an } \\
\text { Energy-Efficient Economy. }\end{array}$ & 2.1 & 4.7 & \\
\hline
\end{tabular}




\begin{tabular}{|c|c|c|c|c|}
\hline & & & Link & \\
\hline & & $\mathrm{M}$ & $\mathrm{D}$ & $\mathrm{N}$ \\
\hline [146] & $\begin{array}{l}\text { Farzad, M. and D.L. O'Neal. 1993. "Influence of the expansion device on air } \\
\text { conditioner system performance characteristics under a range of charging } \\
\text { conditions". ASHRAE Transactions, Vol. 99, Part 1, pp. 3-13. }\end{array}$ & & $\begin{array}{l}2.1 \\
2.1 \\
2.6\end{array}$ & \\
\hline [147] & $\begin{array}{l}\text { Federspiel, C.C. and J.D. Wenger. 1998. "Control and performance analysis of } \\
\text { ventilation systems". ASHRAE Design, Construction, and Operation of Healthy } \\
\text { Buildings: solutions to global and regional concerns, pp. 9-13. Atlanta, GA; } \\
\text { American Society of Heating, Refrigerating, and Air-Conditioning Engineers, Inc. }\end{array}$ & & $\begin{array}{l}2.5 \\
2.5\end{array}$ & \\
\hline [148] & $\begin{array}{l}\text { FEMP. 1999. "Measurement and Verification (M\&V) Guideline for Federal Energy } \\
\text { Projects and Summary of Super ESPC Implementation Procedures, Version 2.1: } \\
\text { Review Draft". Washington, D.C.; Federal Energy Management Program } \\
\text { (Department of Energy). }\end{array}$ & & 5.1 & \\
\hline [149] & $\begin{array}{l}\text { Feustel, H.E., M.P. Modera, and A.H. Rosenfeld. 1986. "Ventilation strategies for } \\
\text { different climates". Proceedings IAQ 86: Managing Indoor Air for Health and } \\
\text { Energy Conservation. American Society of Heating, Refrigerating, and Air } \\
\text { Conditioning Engineers. Atlanta, Georgia, 20-23 April. } 1986 \text { pp. 342-363. }\end{array}$ & & & $\begin{array}{l}2.5 \\
5.2\end{array}$ \\
\hline [150] & $\begin{array}{l}\text { Finlayson, E., D. Arasteh, M. Rubin, J. Sadlier, R. Sullivan, C. Huizenga, D. } \\
\text { Curcija, and M. Beall. 1995. "Advancements in Thermal and Optical Simulations } \\
\text { of Fenestration Systems: The Development of Window 5". Proceedings of the } \\
1995 \text { Thermal Performance of the Exterior Envelopes of Buildings VII, Clearwater } \\
\text { Beach, FL, pp. 549-557. Atlanta, GA; American Society of Heating, Refrigerating, } \\
\text { and Air-Conditioning Engineers, Inc. }\end{array}$ & & $\begin{array}{l}1.2 \\
1.2\end{array}$ & \\
\hline$[151]$ & $\begin{array}{l}\text { Finley, S. 1997. "Sick Houses: Using Diagnostic Tools to Improve Indoor Air } \\
\text { Quality". Home Energy Magazine, Vol. 14, No. 6. Berkeley, CA; Energy Auditor } \\
\text { \& Retrofitter, Inc. }\end{array}$ & 2.5 & $\begin{array}{l}3.3 \\
3.4\end{array}$ & . \\
\hline [152] & $\begin{array}{l}\text { Fisette, P. 1996. "Out, Out Damned Ice!" Home Energy Magazine, Vol. 13, No. 6, } \\
\text { November/December, pp. 21-23. Berkeley, CA; Energy Auditor \& Retrofitter, Inc. }\end{array}$ & & & 1.5 \\
\hline [153] & $\begin{array}{l}\text { Fitzgerald, J., R. Nevitt, and M. Blasnik. 1994. "User-Friendly Pressure } \\
\text { Diagnostics". Home Energy Magazine, Vol. 11, No. 5. Berkeley, CA; Energy } \\
\text { Auditor \& Retrofitter, Inc. }\end{array}$ & & 1.4 & \\
\hline [154] & $\begin{array}{l}\text { Flanders, S.N. 1992. The Convergence Criterion in Measuring Building R-Values. } \\
\text { Proceedings Thermal Performance of the Exterior Envelopes of Buildings V, } \\
\text { Clearwater Beach, Florida; December 7-10; pp. 204-209. Atlanta, GA; American } \\
\text { Society of Heating, Refrigerating, and Air-Conditioning Engineers }\end{array}$ & & 1.1 & \\
\hline$[155]$ & $\begin{array}{l}\text { Flanders, S.N., A.O. Desjarlais, and T.J. Kunz, 1995. A Comparison of Two } \\
\text { Techniques for R-Value Calculation, Using Winter In-Situ Data. Proceedings } \\
\text { Thermal Performance of the Exterior Envelopes of Buildings VI, Clearwater } \\
\text { Beach, Florida; December 4-8, 1995; pp. 151-161. Atlanta, GA; American Society } \\
\text { of Heating, Refrigerating, and Air-Conditioning Engineers. }\end{array}$ & & 1.1 & \\
\hline
\end{tabular}




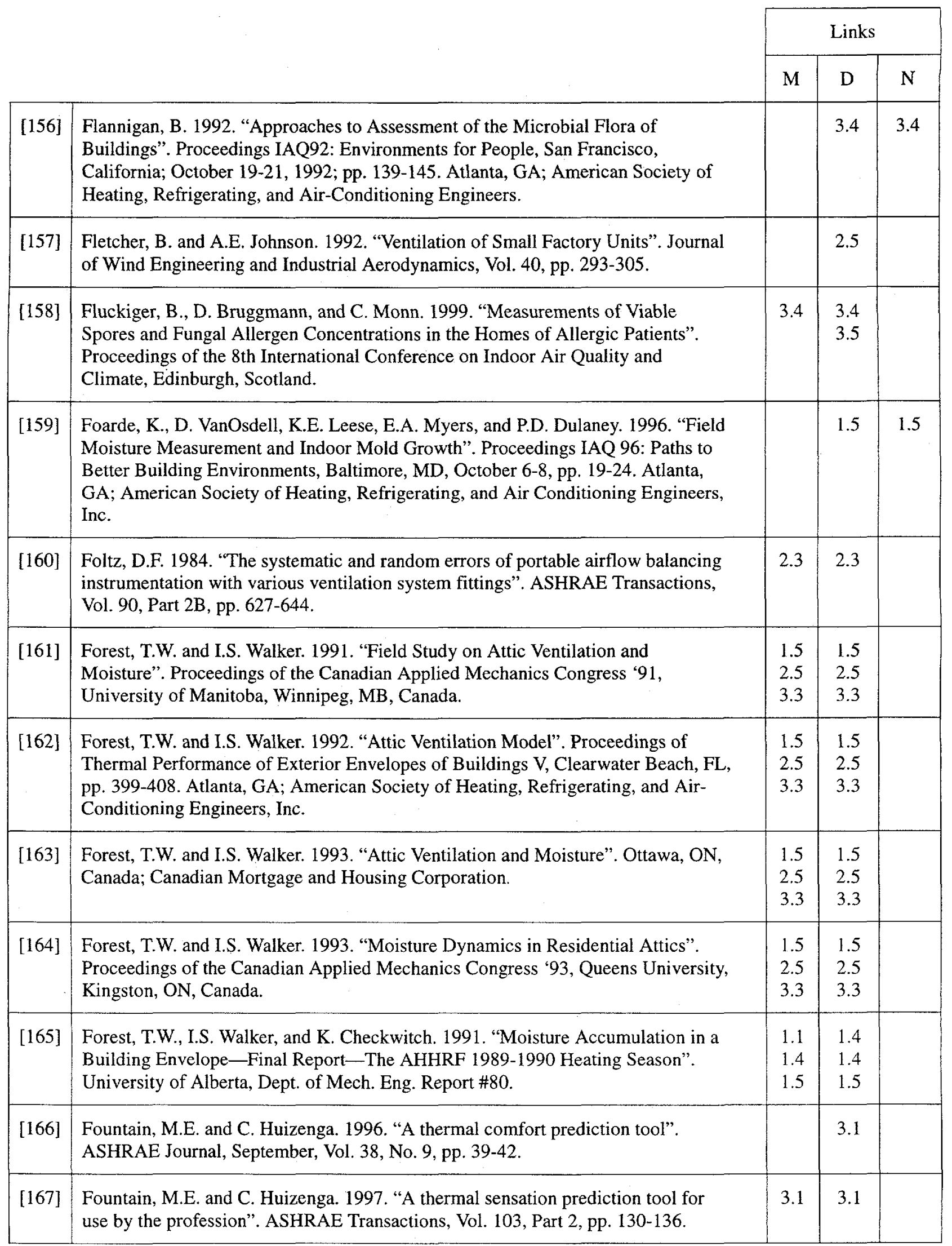




\begin{tabular}{|c|c|c|c|c|}
\hline & & & Link & \\
\hline & & $\mathrm{M}$ & $\mathrm{D}$ & $\mathrm{N}$ \\
\hline [168] & $\begin{array}{l}\text { Francisco, P.W. and L. Palmiter. 1998. "Measured and Modeled Duct Efficiency in } \\
\text { Manufactured Homes: Insights for Standard 152P". ASHRAE Transactions, Vol. } \\
\text { 104, Part 1B, pp.1389-1401. }\end{array}$ & 2.3 & 2.3 & \\
\hline [169] & $\begin{array}{l}\text { Francisco, P.W., L. Palmiter, and B. Davis. 1999. "Modeled vs. Measured Duct } \\
\text { Distribution Efficiency in Six Forced-Air Gas-Heated Homes". Proceedings of the } \\
1998 \text { ACEEE Summer Study on Energy Efficient Buildings, 1.103. Washington, } \\
\text { D.C.; American Council for an Energy-Efficient Economy. }\end{array}$ & 2.3 & & \\
\hline$[170]$ & $\begin{array}{l}\text { Fugler, D. 1989. "Testing of Heating and Ventilating Equipment with the Duct Test } \\
\text { Rig". Proceedings of the } 10^{\text {th }} \text { AIVC Conference, Dipoli, Finland. Coventry, Great } \\
\text { Britain; Air Infiltration and Ventilation Centre. }\end{array}$ & & 2.3 & \\
\hline [171] & $\begin{array}{l}\text { Fugler, D.W. 1989. "Canadian residential combustion spillage monitoring". } \\
\text { ASHRAE Transactions, Vol. 95, Part 1, pp. 100-106. }\end{array}$ & & 2.4 & 2.4 \\
\hline$[172]$ & $\begin{array}{l}\text { Gadsby, K.J. and D.T. Harrje. 1985. "Fan pressurisation of buildings - standards, } \\
\text { calibration and field experience". ASHRAE Transactions, Vol. } 91 \text {, Part 2B, pp. } 95 \text { - } \\
104 .\end{array}$ & & 1.4 & \\
\hline$[173]$ & $\begin{array}{l}\text { Gammage, R.B., A.R. Hawthorne, and D.A. White. 1986. "Parameters affecting air } \\
\text { infiltration and air tightness in thirty-one east Tennessee homes". Measured Air } \\
\text { Leakage of Buildings, ASTM STP 904, H.R. Trechsel and P.L. Lagus, Eds., pp. 61- } \\
\text { 69. Philadelphia PA; American Society for Testing and Materials. }\end{array}$ & & $\begin{array}{l}1.4 \\
2.3\end{array}$ & \\
\hline$[174]$ & $\begin{array}{l}\text { Gardiner, B. L. and M. A. Piette. 1985. "Measured Results of Energy-Conservation } \\
\text { Retrofits in Nonresidential Buildings: Interpreting Metered Data" ASHRAE } \\
\text { Transactions, Vol. 91, Part 2B, pp. 1488-1498. }\end{array}$ & & 5.1 & 5.1 \\
\hline$[175]$ & $\begin{array}{l}\text { Gerardi, R. and P. Sweeney. 1994. "New York's Targeted Investment Protocol } \\
\text { System". Home Energy Magazine, Vol. 11, No. 3, May/June, pp. 30-31. Berkeley, } \\
\text { CA; Energy Auditor \& Retrofitter, Inc. }\end{array}$ & & 5.1 & \\
\hline [176] & $\begin{array}{l}\text { Greely, K., J. Randolph, and B. Hill. 1992. "A Warm Wind Blows South: } \\
\text { Virginia's Weatherization Evaluation". Home Energy Magazine, Vol. 9, No. 1, } \\
\text { January/February, pp. 15-21. Berkeley, CA; Energy Auditor \& Retrofitter, Inc. }\end{array}$ & & $\begin{array}{l}5.1 \\
5.2\end{array}$ & \\
\hline [177] & $\begin{array}{l}\text { Greely, K.M., J. Randolph, and W.W. Hill. 1992. "Using Short-Term Monitoring to } \\
\text { Improve Virginia's Weatherization Program". ASHRAE Transactions, Vol. 98, Part } \\
\text { 1, pp. 853-864. }\end{array}$ & & $\begin{array}{l}2.2 \\
5.2\end{array}$ & \\
\hline [178] & $\begin{array}{l}\text { Greenberg, S. 1994. "Does Floor Insulation Performance Meet Expectations?" } \\
\text { Home Energy Magazine, Vol. 11, No. 2, March/April, pp. 8-9. Berkeley, CA; } \\
\text { Energy Auditor \& Retrofitter, Inc. }\end{array}$ & & & 1.1 \\
\hline [179] & $\begin{array}{l}\text { Greiner, T.H. 1997. “Carbon Monoxide Problems from New Furnaces”. Home } \\
\text { Energy Magazine, Vol. 14, No. 3, May/June, pp. 19-23. Berkeley, CA; Energy } \\
\text { Auditor \& Retrofitter, Inc. }\end{array}$ & & $\begin{array}{l}2.4 \\
2.4\end{array}$ & \\
\hline
\end{tabular}




\begin{tabular}{|c|c|c|c|c|}
\hline & & \multirow{2}{*}{\multicolumn{3}{|c|}{ Links }} \\
\hline & & & & \\
\hline & & \multirow[t]{2}{*}{$\mathbf{M}$} & \multirow{2}{*}{$\mathrm{D}$} & \multirow[t]{2}{*}{$\mathrm{N}$} \\
\hline$[180]$ & $\begin{array}{l}\text { Greiner, T.H. 1997. "The Case of the CO Leak: Solving the Mysteries of Carbon } \\
\text { Monoxide Exposure". Home Energy Magazine, Vol. 14, No. 6, pp. 21-28. } \\
\text { Berkeley, CA; Energy Auditor \& Retrofitter, Inc. }\end{array}$ & & & \\
\hline [181] & $\begin{array}{l}\text { Griffith, B.T. 1999. "Field Verification of Components: Hand-Held Detector for } \\
\text { Low-E and Spectrally Selective Coatings". Berkeley, CA; Lawrence Berkeley } \\
\text { National Laboratory, Environmental Energy Technologies Division, Building } \\
\text { Technologies Department, Windows \& Daylighting Group website } \\
\text { http://windows.lbl.gov/win_prop/component_verification. }\end{array}$ & & 1.2 & . \\
\hline$[182]$ & $\begin{array}{l}\text { Griffith, B.T., C.J. Kohler, D. Turler, and D. Arasteh. 1998. "Rapid Field Testing of } \\
\text { Low-Emittance Coated Glazings for Product Verification". Proceedings of the } \\
1998 \text { Thermal Performance of the Exterior Envelopes of Buildings VII, Clearwater } \\
\text { Beach, FL, pp. 329-335. Atlanta, GA; American Society of Heating, Refrigerating, } \\
\text { and Air-Conditioning Engineers, Inc. }\end{array}$ & & 1.2 & \\
\hline [183] & $\begin{array}{l}\text { Griffith, J.E. 1983. "Field test and performance evaluation of automatic dampers } \\
\text { installed on gas fired residential heating systems". ASHRAE Transactions, Vol. } 89 \text {, } \\
\text { Part 1B, pp. 683-692. }\end{array}$ & & $\begin{array}{l}2.2 \\
4.7\end{array}$ & \\
\hline$[184]$ & $\begin{array}{l}\text { Grimsrud, D.T., D.E. Hadlich, M.D. Koontz, R.J. Hemphill, N.P. Leslie, Z. Li, and } \\
\text { N.L. Nagda. 1999. "Survey on Depressurization-Induced Backdrafting and } \\
\text { Spillage". Proceedings of the 8th International Conference on Indoor Air Quality } \\
\text { and Climate, Edinburgh, Scotland. }\end{array}$ & $\begin{array}{l}2.4 \\
2.5\end{array}$ & $\begin{array}{l}1.4 \\
2.4\end{array}$ & \\
\hline [185] & $\begin{array}{l}\text { Grimsrud, D.T., M. H. Sherman, and R. C. Sonderegger. 1983. "Calculating } \\
\text { Infiltration: Implications for a Construction Quality Standard". Berkeley, CA; } \\
\text { Lawrence Berkeley Laboratory report LBL-9416. }\end{array}$ & & 5.2 & 2.5 \\
\hline [186] & $\begin{array}{l}\text { Grimsrud, D.T., M. H. Sherman, J. E. Janssen, A. N. Pearman, and D. T. Harrje. } \\
\text { 1979. "An Intercomparison of Tracer Gases Used for Air Infiltration } \\
\text { Measurements". Berkeley, CA; Lawrence Berkeley Laboratory report LBL-8394. }\end{array}$ & & 2.5 & \\
\hline [187] & $\begin{array}{l}\text { Grimsrud, D.T., M. H. Sherman, R. C. Diamond, P. E. Condon,and A. H. } \\
\text { Rosenfeld. 1978. "Infiltration - Pressurization Correlations: Detailed Measurement } \\
\text { on a California House". Berkeley, CA; Lawrence Berkeley Laboratory report LBL- } \\
7824 \text {. }\end{array}$ & & 2.5 & \\
\hline [188] & $\begin{array}{l}\text { Grimsrud, D.T., M. Sherman, and R.C. Sonderegger. 1981. "Prediction and } \\
\text { measurement of infiltration in residential buildings: in application to a construction } \\
\text { quality standard". Proceedings of the 3rd Joint Symposium on the Performance } \\
\text { Concept in Building, Lisbon, Portugal, March 29-Apr. 2, } 1982 .\end{array}$ & 1.4 & 1.4 & 1.4 \\
\hline [189] & $\begin{array}{l}\text { Grimsrud, D.T., M.H. Sherman, A.K. Blomsterberg, and A.H. Rosenfeld. } 1979 . \\
\text { "Infiltration and Air-Leakage Comparisons: Conventional and Energy-Efficient } \\
\text { Housing Designs". Proceedings of the International Conference on Energy Use } \\
\text { Management, Los Angeles, CA. Also Berkeley, CA; Lawrence Berkeley } \\
\text { Laboratory report LBL-9157. }\end{array}$ & 1.4 & 2.5 & \\
\hline
\end{tabular}




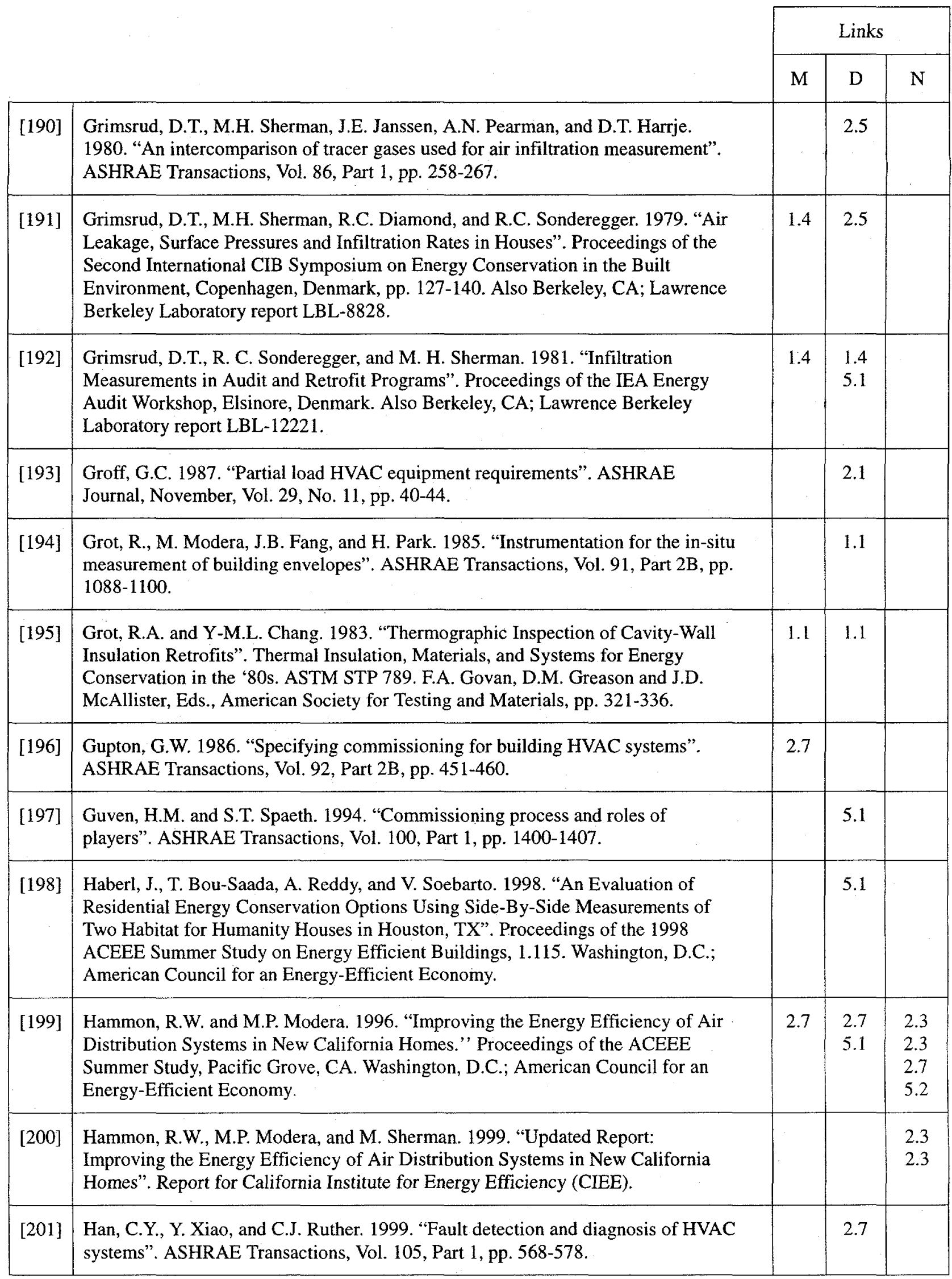




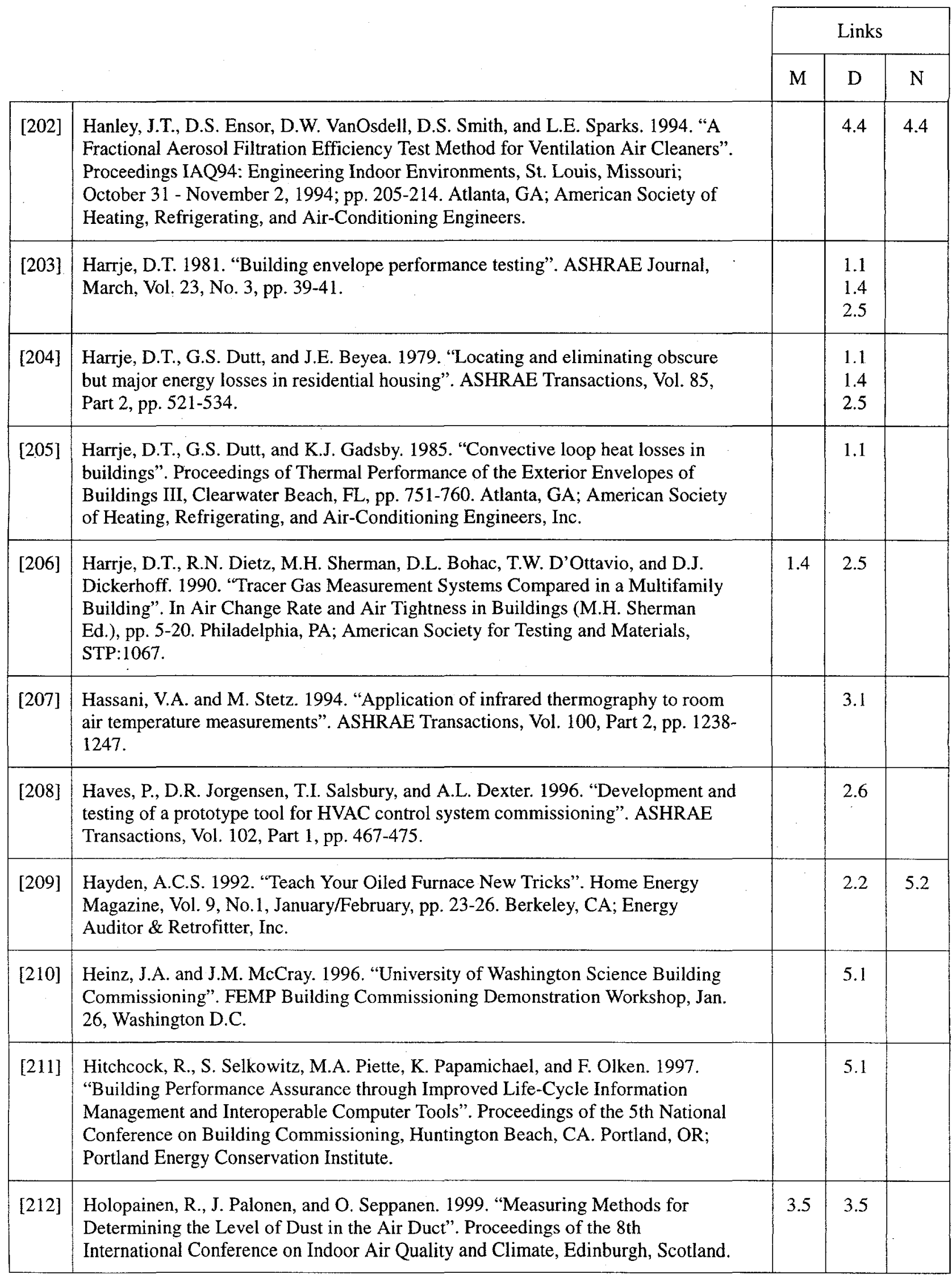




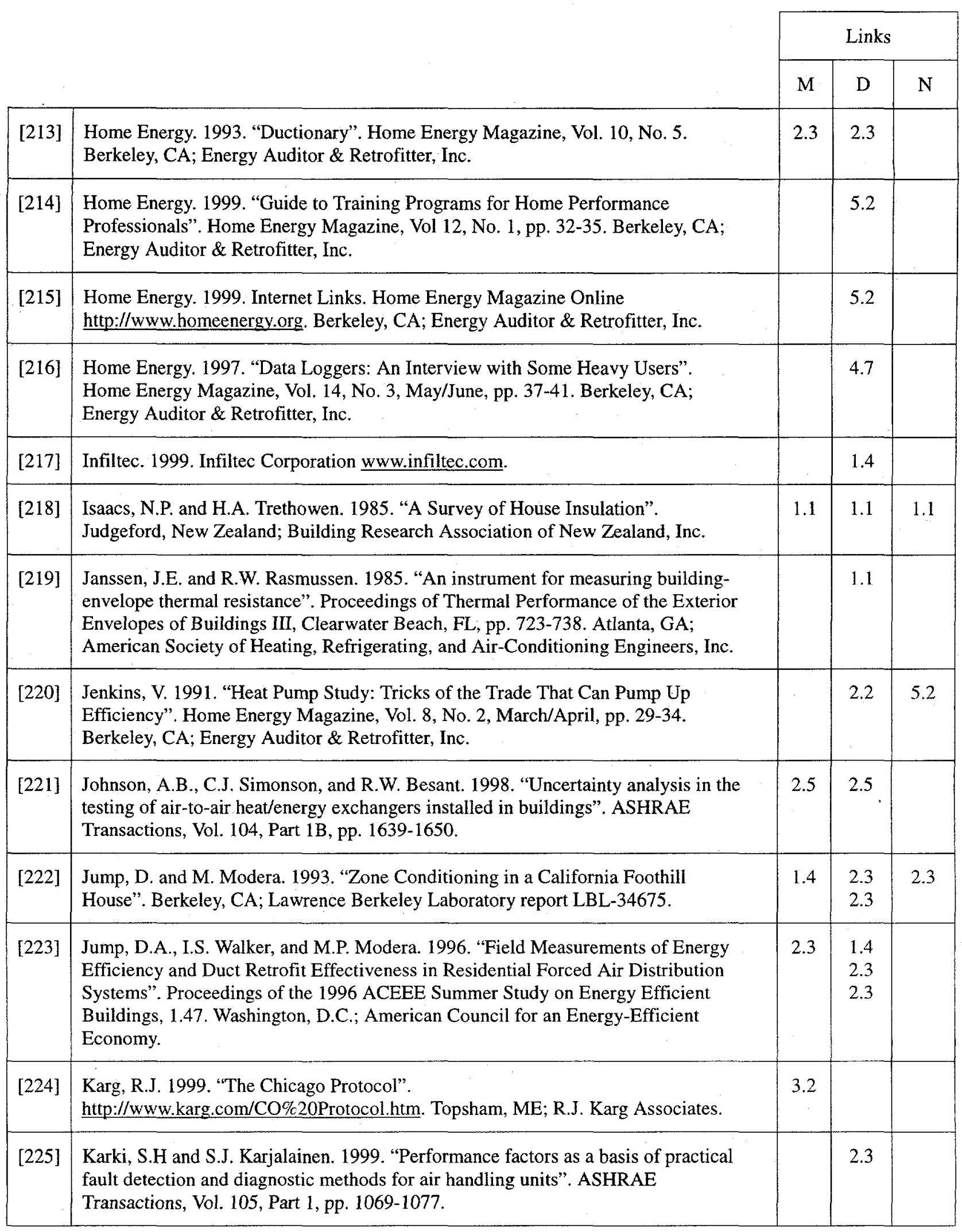




\begin{tabular}{|c|c|c|c|c|}
\hline & & & & \\
\hline & & & Links & \\
\hline & & $\mathrm{M}$ & $\mathrm{D}$ & $\mathrm{N}$ \\
\hline [226] & $\begin{array}{l}\text { Katz, A. 1997. "What's Being Built Out There? Performance Tests of } 100 \text { New } \\
\text { Homes". Home Energy Magazine, Vol. 14, No. 5, September/October, pp. 29-34. } \\
\text { Berkeley, CA; Energy Auditor \& Retrofitter, Inc. }\end{array}$ & 2.1 & & $\begin{array}{l}1.1 \\
1.4 \\
2.1 \\
2.3\end{array}$ \\
\hline [227] & $\begin{array}{l}\text { Kavanaugh, S.P. 1992. "Using existing standards to compare energy consumption } \\
\text { of ground-source heat pumps with conventional equipment". ASHRAE } \\
\text { Transactions, Vol. 98, Part 2, pp. 599-606. }\end{array}$ & 2.1 & & \\
\hline [228] & $\begin{array}{l}\text { Keefe, D. 1994. "Introduction to Blower Doors". Home Energy Magazine, Vol. 11, } \\
\text { No. 1. Berkeley, CA; Energy Auditor \& Retrofitter, Inc. }\end{array}$ & $\begin{array}{l}1.4 \\
2.4\end{array}$ & $\begin{array}{l}1.4 \\
2.4\end{array}$ & $\begin{array}{l}1.4 \\
2.4\end{array}$ \\
\hline [229] & $\begin{array}{l}\text { Keithly, P. 1999. "HVAC Controls Specifications: The Good, The Bad, and the } \\
\text { Ugly". Proceedings of the 7th National Conference on Building Commissioning, } \\
\text { Portland, OR. Portland, OR; Portland Energy Conservation Institute. }\end{array}$ & 2.6 & & \\
\hline [230] & $\begin{array}{l}\text { Kelly, A. and D. Keefe. 1999. "Training Made Easy with The Telltale House } \\
\text { Exhibit". Home Energy Magazine, Vol. 16, No. 4, July/August, pp. 33-36. } \\
\text { Berkeley, CA; Energy Auditor \& Retrofitter, Inc. }\end{array}$ & & 4.7 & \\
\hline [231] & $\begin{array}{l}\text { Kemp, P.C., H.G. Neumeister-Kemp, A. Nickelmann, and F. Murray. 1999. "Fungi } \\
\text { in the Dust Extracted from Fabric Covered Furnishings: Preliminary Results } \\
\text { During Method Standarisation". Proceedings of the 8th International Conference } \\
\text { on Indoor Air Quality and Climate, Edinburgh, Scotland. }\end{array}$ & & 3.4 & \\
\hline [232] & $\begin{array}{l}\text { Kiel, D., D. Wilson, and M. Sherman. 1986. "Air Leakage Flow Correlations for } \\
\text { Varying House Construction Types". Berkeley, CA; Lawrence Berkeley Laboratory } \\
\text { report LBL-18732. }\end{array}$ & & & 1.4 \\
\hline [233] & $\begin{array}{l}\text { Kinney, L. 1995. "Assessing the Integrity of Electrical Wiring". Home Energy } \\
\text { Magazine, Vol. 12, No. 5, September/October, pp. 5-6. Berkeley, CA; Energy } \\
\text { Auditor \& Retrofitter, Inc. }\end{array}$ & & 4.7 & \\
\hline$[234]$ & $\begin{array}{l}\text { Kinney, L.F.. 1993. "Read Me Your Thermostat: Short-Term Evaluation Tools", } \\
\text { Home Energy Magazine, Vol. 10, No. 2, March/April, pp. 31-36. Berkeley, CA; } \\
\text { Energy Auditor \& Retrofitter, Inc. }\end{array}$ & & 4.7 & \\
\hline [235] & $\begin{array}{l}\text { Kirby, E.S., C.W. Bullard, and W.E. Dunn. 1998. "Effect of airflow non-uniformity } \\
\text { on evaporator performance". ASHRAE Transactions, Vol. 104, Part 2, pp. 755-762. }\end{array}$ & & 2.1 & \\
\hline [236] & $\begin{array}{l}\text { Kirkland, G. 1993. Letter to the Editor: "More Insulation Damage". Home Energy } \\
\text { Magazine, Vol. 10, No. 6, November/December, pp. 4. Berkeley, CA; Energy } \\
\text { Auditor \& Retrofitter, Inc. }\end{array}$ & & & 1.5 \\
\hline [237] & $\begin{array}{l}\text { Kjellman, C.R., R.G. Haasl, and C.A. Chappell. 1996. "Evaluating commissioning } \\
\text { as an energy-saving measure". ASHRAE Transactions, Vol. 102, Part 1, pp. 492- } \\
501 .\end{array}$ & & 5.1 & $\begin{array}{l}5.1 \\
5.2\end{array}$ \\
\hline
\end{tabular}




\begin{tabular}{|c|c|c|c|c|}
\hline & & & Links & \\
\hline & & $\mathbf{M}$ & $\mathrm{D}$ & $\mathrm{N}$ \\
\hline [238] & $\begin{array}{l}\text { Knehans, A.H. and P.E. Styer. 1983. "Thermography-a diagnostic tool to locating } \\
\text { wet insulation in built-up roofing systems". ASHRAE Transactions, Vol. 89, Part } \\
\text { 2B, pp. 112-117. }\end{array}$ & & 1.5 & \\
\hline [239] & $\begin{array}{l}\text { Knight, K., G. Knight, J. Sharp, J. Guerriero, and B. Phillips. 1995. "Evaluating } \\
\text { Test Equipment for Air Tightness of Construction Details". Retro-Specs Ltd. For } \\
\text { Canada Mortgage and Housing Corporation. }\end{array}$ & & $\begin{array}{l}1.4 \\
4.7\end{array}$ & \\
\hline [240] & $\begin{array}{l}\text { Kolb, J.O. and M.P. Ternes. 1995. "Investigation of Air Distribution System } \\
\text { Deficiencies and Repair Benefits in Phoenix, Arizona". Proceedings of the } \\
\text { Thermal Performance of the Exterior Envelopes of Buildings VI, Clearwater } \\
\text { Beach, Florida, pp. 379-387. Atlanta, GA; American Society of Heating, } \\
\text { Refrigerating, and Air-Conditioning Engineers, Inc. }\end{array}$ & 2.3 & 2.3 & \\
\hline [241] & $\begin{array}{l}\text { Koles, G., R. Hitchcock, and M.H. Sherman. 1996. "Metrics for Building } \\
\text { Performance Assurance". Berkeley, CA; Lawrence Berkeley Laboratory report } \\
\text { LBL-39203. }\end{array}$ & $\begin{array}{l}1.4 \\
2.5 \\
3.1\end{array}$ & $\begin{array}{l}4.7 \\
5.1\end{array}$ & \\
\hline [242] & $\begin{array}{l}\text { Koran, W.E. 1994. "Expanding the scope of commissioning - monitoring shows the } \\
\text { benefits". ASHRAE Transactions, Vol. 100, Part 1, pp. 1393-1399. }\end{array}$ & & $\begin{array}{l}2.6 \\
5.1\end{array}$ & \\
\hline [243] & $\begin{array}{l}\text { Kweller, E.R. 1985. "Off-cycle energy loss measuring methods for vented heating } \\
\text { equipment". ASHRAE Transactions, Vol. 91, Part 2B, pp. 773-787. }\end{array}$ & 2.2 & 2.2 & \\
\hline [244] & $\begin{array}{l}\text { Lambert, L.A. and D.H. Robison. 1989. "Effects of ducted forced air heating } \\
\text { systems on residential air leakage and heating energy use". ASHRAE Transactions, } \\
\text { Vol. 95, Part 2, pp. 534-541. }\end{array}$ & $\begin{array}{l}1.1 \\
1.4\end{array}$ & & \\
\hline [245] & $\begin{array}{l}\text { Lane, C.A., J.E. Woods, and T.A. Bosman. 1989. "Indoor Air Quality Diagnostic } \\
\text { Procedures for Sick and Healthy Buildings". Proceedings of the ASHRAE Indoor } \\
\text { Air Quality Conference ' } 89 \text {, San Diego, CA, pp. 237-240. Atlanta, GA; American } \\
\text { Society of Heating, Refrigerating, and Air-Conditioning Engineers, Inc. }\end{array}$ & & $\begin{array}{l}3.1 \\
3.2 \\
3.3 \\
3.4 \\
3.5 \\
5.1\end{array}$ & \\
\hline [246] & $\begin{array}{l}\text { Larson, T.D. and P. Huelman. 1992. Siding Moisture Problems - an Excerpt from } \\
\text { Cold Climate Housing News. Home Energy Magazine, Vol. 9, No. 1, } \\
\text { January/February, pp. 12-13. Berkeley, CA; Energy Auditor \& Retrofitter, Inc. }\end{array}$ & & 1.5 & \\
\hline$[247]$ & $\begin{array}{l}\text { Lawton, M.D. 1992. "Diagnosing Envelope Problems by Field Performance } \\
\text { Monitoring". Proceedings of the Thermal Performance of the Exterior Envelopes } \\
\text { of Buildings V, Clearwater Beach, Florida, pp. } 675-683 \text {. Atlanta, GA; American } \\
\text { Society of Heating, Refrigerating, and Air-Conditioning Engineers, Inc. }\end{array}$ & & 4.7 & \\
\hline [248] & $\begin{array}{l}\text { Lerman, D. 1998. "Getting Our Ducts in a Row: Evaluation of the Tacoma Duct } \\
\text { Sealing Program". Proceedings of the 1998 ACEEE Summer Study on Energy } \\
\text { Efficient Buildings, 2.115. Washington, D.C.; American Council for an Energy- } \\
\text { Efficient Economy. }\end{array}$ & 5.2 & & \\
\hline
\end{tabular}




\begin{tabular}{|c|c|c|c|c|}
\hline & & \multirow{2}{*}{\multicolumn{3}{|c|}{ Links }} \\
\hline & & & & \\
\hline & & $\mathrm{M}$ & $\mathrm{D}$ & $\mathrm{N}$ \\
\hline [249] & $\begin{array}{l}\text { LeRoy, J.T., E.A. Groll, and J.E. Braun. 1998. "Computer model predictions of } \\
\text { dehumidification performance of unitary air conditioners and heat pumps under } \\
\text { extreme operating conditions". ASHRAE Transactions, Vol. 104, Part 2, pp. 773- } \\
788 .\end{array}$ & & 2.1 & \\
\hline [250] & $\begin{array}{l}\text { Levermore, G.J., D.J. Lowe, and J.W. Ure. 1999. “Occupant Feedback } \\
\text { Questionnaire Producing a Fingerprint and a Score”. ASHRAE Transactions, Vol. } \\
\text { 105, Part 2, SE-99-5-3. }\end{array}$ & 3.1 & 3.1 & \\
\hline [251] & $\begin{array}{l}\text { Li, Z., J.S. Zhang, L.L. Christianson, R.N. Kulp, and L.E. Sparks. 1996. "Outdoor } \\
\text { air delivery rates to occupants and age of air". ASHRAE Transactions, Vol. 102, } \\
\text { Part 2, pp. 313-321. }\end{array}$ & 2.5 & & \\
\hline [252] & $\begin{array}{l}\text { Lichtman., G., R. Johnson, and D. Steussy. 1999. "Construction Defects } \\
\text { Underfoot: Concrete Slab Foundations Affected by Moisture Intrusion, } \\
\text { Deterioration". Claims Magazine, June. Seattle, Washington }\end{array}$ & & 1.5 & 1.5 \\
\hline [253] & $\begin{array}{l}\text { Linder, R.J., C.B. Dorgan, and C.E. Dorgan. 1999. "Indoor Air Quality Standards } \\
\text { of Performance Applications Guide". ASHRAE Transactions, } 1999 \text { Vol. 105, Part } \\
\text { 1, CH-99-19-1 (4270) (RP-853). }\end{array}$ & & 5.1 & \\
\hline [254] & $\begin{array}{l}\text { Lstiburek, J. 1999. "Unventing Attics in Cold Climates". Home Energy Magazine, } \\
\text { Vol. 16, No. 6, November/December, pp. 27-28. Berkeley, CA; Energy Auditor \& } \\
\text { Retrofitter, Inc. }\end{array}$ & & & 1.5 \\
\hline [255] & $\begin{array}{l}\text { Lstiburek, J. and J. Carmody. 1995. "Fundamentals of Moisture in Houses". Home } \\
\text { Energy Magazine, Vol. 12, No. 6, November/December, pp. 11-16. Berkeley, CA; } \\
\text { Energy Auditor \& Retrofitter, Inc. }\end{array}$ & & 1.5 & \\
\hline [256] & $\begin{array}{l}\text { Lstiburek, J.W. 1998. "The Pressure Response of Buildings". Proceedings of the } \\
1998 \text { Thermal Performance of the Exterior Envelopes of Buildings VII, Clearwater } \\
\text { Beach, FL, pp. 799. Atlanta, GA; American Society of Heating, Refrigerating, and } \\
\text { Air-Conditioning Engineers, Inc. }\end{array}$ & 1.4 & 2.5 & \\
\hline [257] & $\begin{array}{l}\text { Lugano, F. 1998. "First Step in Cellulose Sealing: Spot the Style". Home Energy } \\
\text { Magazine, Vol. 15, No. 3, May/June, pp. 14-21. Berkeley, CA; Energy Auditor \& } \\
\text { Retrofitter, Inc. }\end{array}$ & & $\begin{array}{l}1.1 \\
1.4\end{array}$ & \\
\hline [258] & $\begin{array}{l}\text { Lutz, K. 1991. "Smoke and Mirrors: The Essentials of an Auditor's Toolbox". } \\
\text { Home Energy Magazine, Vol. 8, No. 2, March/April, pp. 12-17. Berkeley, CA; } \\
\text { Energy Auditor \& Retrofitter, Inc. }\end{array}$ & & 4.7 & \\
\hline [259] & $\begin{array}{l}\text { Macriss, R.A. and T.A. Zawacki. 1981. "Effect of retrofits on combustion } \\
\text { characteristics and seasonal efficiency of gas-fired furnaces and boilers". ASHRAE } \\
\text { Transactions, Vol. 87, Part 1, pp. 805-816. }\end{array}$ & & & 2.2 \\
\hline$[260]$ & $\begin{array}{l}\text { Madsen, T.L., T.P. Schmidt, and U. Helk. 1990. "How important is the location of } \\
\text { the room thermostat". ASHRAE Transactions, Vol. 96, Part 1, pp. } 847-852 \text {. }\end{array}$ & & 2.6 & \\
\hline
\end{tabular}




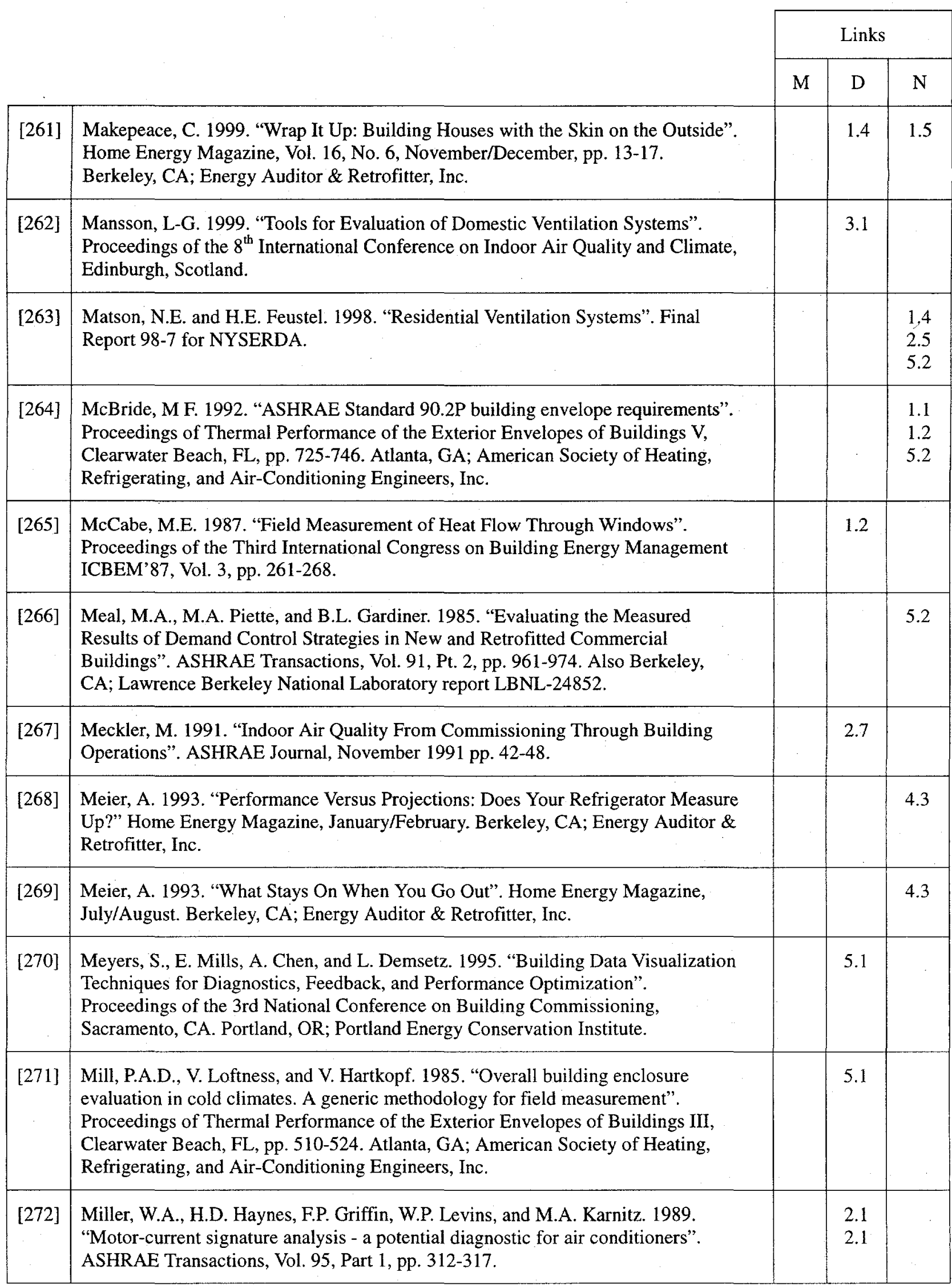




\begin{tabular}{|c|c|c|c|c|}
\hline & & \multirow{2}{*}{\multicolumn{3}{|c|}{ Links }} \\
\hline & & & & \\
\hline & & \multirow[t]{2}{*}{$\mathrm{M}$} & \multirow{2}{*}{ D } & \multirow[t]{2}{*}{$N$} \\
\hline [273] & $\begin{array}{l}\text { Mixon, B. and A. Meier. 1990. "Monitoring Made Easier". Home Energy } \\
\text { Magazine, Vol. 7, No. 5, pp. 36. Berkeley, CA; Energy Auditor \& Retrofitter, Inc. }\end{array}$ & & & \\
\hline [274] & $\begin{array}{l}\text { Modera, M. and D. Jump. 1995. "Field measurement of the interactions between } \\
\text { heat pump and attic duct systems in residential buildings". Proceedings of the } \\
\text { ASME International Solar Energy Conference, Maui, HI. Also Berkeley, CA; } \\
\text { Lawrence Berkeley Report LBL } 36047 \text {. }\end{array}$ & 2.3 & $\begin{array}{l}2.3 \\
2.3 \\
2.3 \\
4.7\end{array}$ & \\
\hline [275] & $\begin{array}{l}\text { Modera, M. and J. Byrne. 1997. "Can a New Duct Test Take the Pressure". Home } \\
\text { Energy Magazine, Vol. 14, No. 1, pp. 29-33. Berkeley, CA; Energy Auditor \& } \\
\text { Retrofitter, Inc. }\end{array}$ & 2.3 & 2.3 & \\
\hline [276] & $\begin{array}{l}\text { Modera, M., M. Sherman, and P. Vacheron. 1987. "Pulse pressurization: a } \\
\text { technique for measuring building air leakage". Berkeley, CA; Lawrence Berkeley } \\
\text { Laboratory Report LBID-1321. }\end{array}$ & & 1.4 & \\
\hline [277] & $\begin{array}{l}\text { Modera, M.P. 1986. "Final Report: Residential Air Leakage Database } \\
\text { Compilation". Berkeley, CA; Lawrence Berkeley Laboratory Report LBL-23740. }\end{array}$ & & & 1.4 \\
\hline [278] & $\begin{array}{l}\text { Modera, M.P. 1993. "Field comparison of alternative techniques for measuring air } \\
\text { distribution system leakage". Proceedings of the ASTM Symposium on Airflow } \\
\text { Performance of Building Envelopes Components and Systems, Ft. Worth TX. } \\
\text { Philadelphia PA; American Society for Testing and Materials. }\end{array}$ & & 2.3 & \\
\hline [279] & $\begin{array}{l}\text { Modera, M.P. 1993. "Two Favorite Test Methods, By the Book". Home Energy } \\
\text { Magazine, Vol. 10, No. 5. Berkeley, CA; Energy Auditor \& Retrofitter, Inc. }\end{array}$ & 1.4 & & \\
\hline [280] & $\begin{array}{l}\text { Modera, M.P. 1994. "Characterizing the performance of residential air distribution } \\
\text { systems". Energy and Buildings, Vol. 20, No. 1, pp. 65-75. }\end{array}$ & & 2.3 & $\begin{array}{l}1.4 \\
2.3\end{array}$ \\
\hline [281] & $\begin{array}{l}\text { Modera, M.P. and R. Jansky. 1992. "Residential Air-Distribution Systems: } \\
\text { Interactions with the Building Envelope." Proceedings of Thermal Performance of } \\
\text { the Exterior Envelopes of Buildings V, Clearwater Beach, FL, pp. 623-631. } \\
\text { Atlanta, GA; American Society of Heating, Refrigerating, and Air-Conditioning } \\
\text { Engineers, Inc. Also Berkeley, CA; Lawrence Berkeley Laboratory report LBL- } \\
31311 \text {. }\end{array}$ & & & 2.5 \\
\hline [282] & $\begin{array}{l}\text { Modera, M.P., J. Andrews, and E. Kweller. 1992. "A Comprehensive Yardstick for } \\
\text { Residential Thermal Distribution Efficiency". Berkeley, CA; Lawrence Berkeley } \\
\text { Laboratory report LBL-31579. }\end{array}$ & 2.3 & & \\
\hline [283] & $\begin{array}{l}\text { Modera, M.P., M. Sherman, and R.C. Sonderegger. 1986. "Determining the U- } \\
\text { value of a wall from field measurements of heat flux and surface temperatures". } \\
\text { Proceedings of the ASTM Workshop on Heat Flow Sensors, Philadelphia, PA, Sept } \\
\text { 19-23, 1986. Also published in ASTM STP } 885 \text {. }\end{array}$ & 1.1 & 1.1 & \\
\hline [284] & $\begin{array}{l}\text { Modera, M.P., M.H. Sherman, and D.T. Grimsrud. 1981. "Long-Term Infiltration } \\
\text { Measurements in a Full-Scale Test Structure". Berkeley, CA; Lawrence Berkeley } \\
\text { Laboratory report LBL-13504. }\end{array}$ & & 2.5 & \\
\hline
\end{tabular}




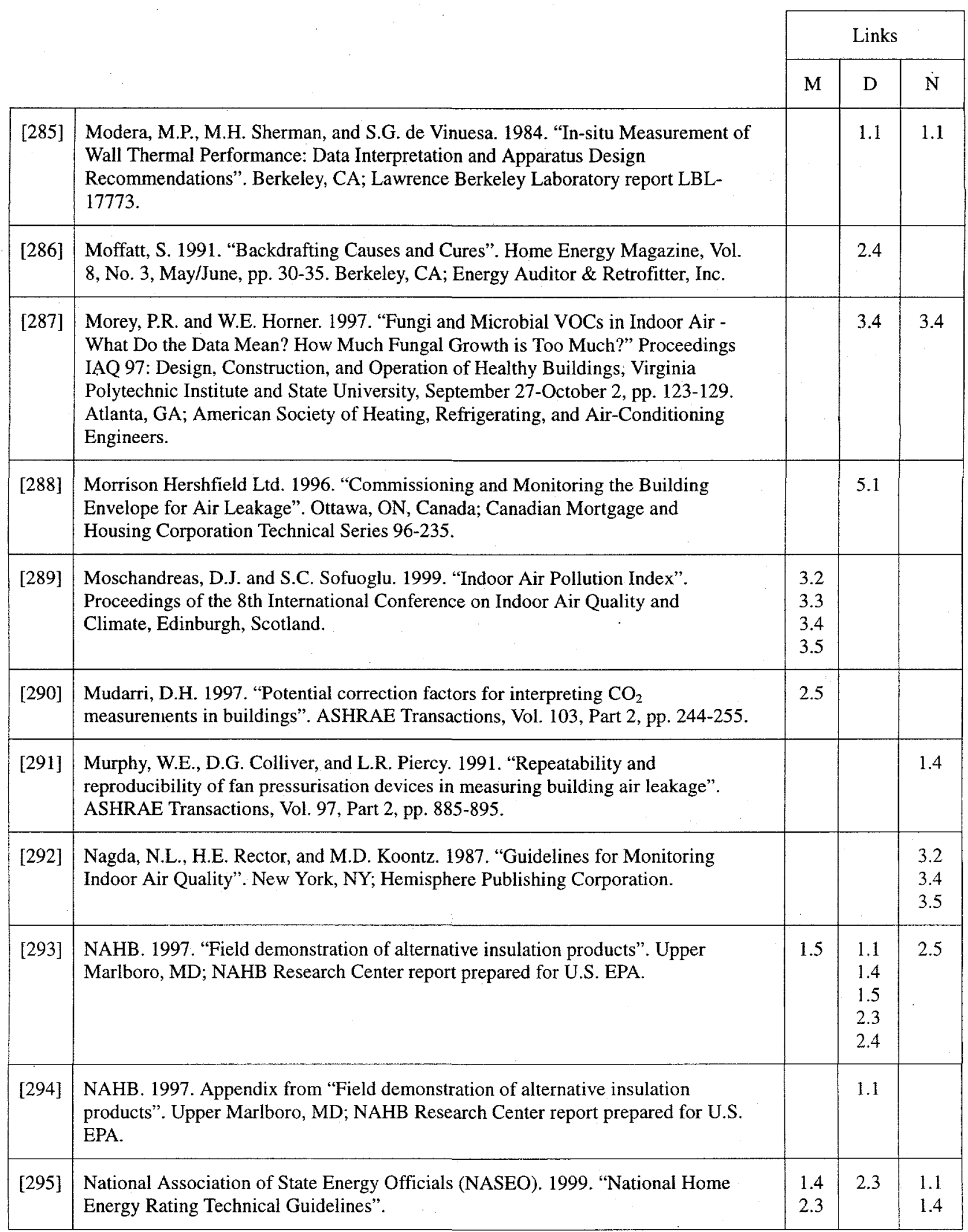




\begin{tabular}{|c|c|c|c|c|}
\hline & & & & \\
\hline & & & Links & \\
\hline & & $\mathbf{M}$ & $\mathrm{D}$ & $\mathrm{N}$ \\
\hline [296] & $\begin{array}{l}\text { National Institute of Building Sciences and the Florida State University Energy } \\
\text { Center. 1999. "Total Building Commissioning General Principles and Procedures". } \\
\text { Florida State University Energy Center, } \\
\text { http://sustainable.state.fl.us/fdi/edesign/resource/totalbcx/index.html. }\end{array}$ & & 5.1 & \\
\hline [297] & $\begin{array}{l}\text { National Research Council Canada. 1996. "Review of Non-Destructive Test } \\
\text { Methods for Assessing Strength, Serviceability and Deterioration in Buildings". } \\
\text { Ottawa, ON, Canada; Canada Mortgage and Housing Corporation Technical Series } \\
\text { 96-233. }\end{array}$ & & 1.5 & \\
\hline [298] & $\begin{array}{l}\text { Neal, C.L. 1998. "Field Adjusted SEER [SEERFA] Residential Buildings: } \\
\text { Technologies, Design, and Performance Analysis". Proceedings of the } 1998 \\
\text { ACEEE Summer Study on Energy Efficient Buildings, 1.197. Washington, D.C.; } \\
\text { American Council for an Energy-Efficient Economy. }\end{array}$ & $\begin{array}{l}2.1 \\
2.1\end{array}$ & 2.1 & \\
\hline [299] & $\begin{array}{l}\text { Neal. L. 1992. "Air Conditioner Efficiency in the Real World". Home Energy } \\
\text { Magazine, Vol. 9, No. 3, May/June, pp. 32-39. Berkeley, CA; Energy Auditor \& } \\
\text { Retrofitter, Inc. }\end{array}$ & & 2.1 & \\
\hline [300] & $\begin{array}{l}\text { NEBB. 1999. "NEBB Procedural Standards for Building Systems } \\
\text { Commissioning". Gaithersburg, MD; National Environmental Balancing Bureau. }\end{array}$ & & 5.1 & \\
\hline [301] & $\begin{array}{l}\text { Ngo, D. and A.L. Dexter. 1999. "A robust model-based approach to diagnosing } \\
\text { faults in air-handling units". ASHRAE Transactions, Vol. 105, Part 1, pp. 1078- } \\
1086 .\end{array}$ & & 2.3 & \\
\hline [302] & $\begin{array}{l}\text { Nguyen Thi, L.C., G. Kerr, G. Clunis, J. Zhang, and B. Magee. 1995. "Evaluation } \\
\text { of Portable Equipment for Monitoring the Delivery of Supply Air by Tracer Gas } \\
\text { Measurement Techniques". Proceedings of the } 2 \text { nd International Conservation in } \\
\text { Buildings Conference, Montréal, Québec, Canada, Volume 1, pp. 345-352. }\end{array}$ & & 2.5 & \\
\hline [303] & $\begin{array}{l}\text { Nguyen, H.V., V.W. Goldschmidt, S.B. Thomas, and D.R. Tree. 1982. "Trends of } \\
\text { residential air-conditioning cyclic tests". ASHRAE Transactions, Vol. 88, Part } 2 \text {, } \\
\text { pp. 954-972. }\end{array}$ & 2.1 & & \\
\hline [304] & $\begin{array}{l}\text { Oberholtzer, D.L. 1993. "Chimney Diagnostics for Safer and Healthy Appliance } \\
\text { Venting". Proceedings of the ASHRAE Indoor Air Quality Conference ' } 93 \text {, } \\
\text { Philadelphia, PA, pp. 249-253. Atlanta, GA; American Society of Heating, } \\
\text { Refrigerating, and Air-Conditioning Engineers, Inc. }\end{array}$ & & 2.4 & 2.4 \\
\hline [305] & $\begin{array}{l}\text { Obst, J. and L.T. Hendricks. 1991. "Stop Energy Loss and Moisture Build-up- } \\
\text { Cold!" Home Energy Magazine, Vol. 8, No. 4, July/August, pp. 14-20. Berkeley, } \\
\text { CA; Energy Auditor \& Retrofitter, Inc. }\end{array}$ & & 1.4 & 1.5 \\
\hline [306] & $\begin{array}{l}\text { Odom, J.D. III. 1997. "Building Failures and Indoor Air Quality Problems: Who's } \\
\text { at Risk and Why". Proceedings of the 5th National Conference on Building } \\
\text { Commissioning, Huntington Beach, CA. Portland, OR; Portland Energy } \\
\text { Conservation Institute. }\end{array}$ & & & $\begin{array}{l}3.1 \\
3.2 \\
3.3 \\
3.4\end{array}$ \\
\hline
\end{tabular}




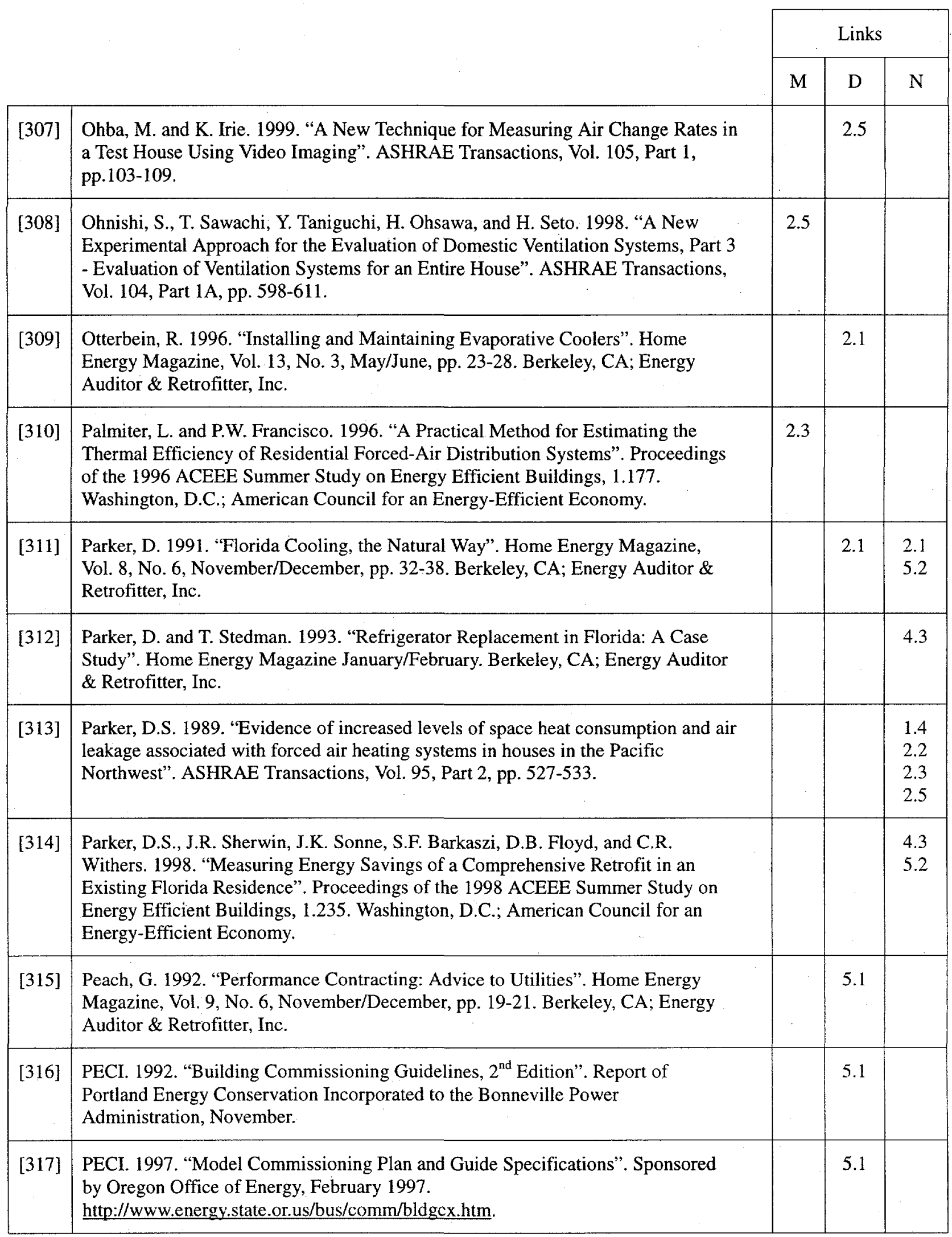




\begin{tabular}{|c|c|c|c|c|}
\hline & & \multicolumn{3}{|c|}{ Links } \\
\hline & & $\mathbf{M}$ & $\mathrm{D}$ & $\mathrm{N}$ \\
\hline [318] & $\begin{array}{l}\text { PECI. 1999. "Commissioning for better buildings in Oregon". } \\
\text { http://www.cbs.state.or.us/external/ooe/cons/bldgex.htm. Portland, OR; Portland } \\
\text { Energy Conservation Institute. }\end{array}$ & & $\begin{array}{l}5.1 \\
5.2\end{array}$ & \\
\hline [319] & $\begin{array}{l}\text { Penn, C. 1993. "Minnesota Tightens". Home Energy Magazine, Vol. 10, No. 1, } \\
\text { January/February, pp. 6-7. Berkeley, CA; Energy Auditor \& Retrofitter, Inc. }\end{array}$ & & & 1.1 \\
\hline [320] & $\begin{array}{l}\text { Perry, L., T. Downey, and J. Proctor. 1999. "Residential Central Air Conditioner } \\
\text { Service Program Final Report". San Rafael, CA; Proctor Engineering Group. }\end{array}$ & & $\begin{array}{l}2.1 \\
2.3\end{array}$ & 2.1 \\
\hline [321] & $\begin{array}{l}\text { Persily, A. 1982. "Repeatability and accuracy of pressurisation testing". } \\
\text { Proceedings of Thermal Performance of the Exterior Envelopes of Buildings II, } \\
\text { Las Vegas NV, pp. 380-390. Atlanta, GA; American Society of Heating, } \\
\text { Refrigerating, and Air-Conditioning Engineers, Inc. }\end{array}$ & & 1.4 & \\
\hline [322] & $\begin{array}{l}\text { Persily, A.K. 1999. “An Indoor Air Quality Performance Standard for Single- } \\
\text { Family Residential Buildings”. Proceedings of the 8th International Conference on } \\
\text { Indoor Air Quality and Climate, Edinburgh, Scotland. }\end{array}$ & $\begin{array}{l}2.4 \\
2.5 \\
2.7 \\
3.1 \\
3.3 \\
4.4\end{array}$ & 3.2 & 2.7 \\
\hline [323] & $\begin{array}{l}\text { Persily, A.K., R.A. Grot, J.B. Fang, and Y.M. Chang. 1988. "Diagnostic techniques } \\
\text { for evaluating office building envelopes". ASHRAE Transactions, Vol. 94, Part 1, } \\
\text { pp. } 987-1006 .\end{array}$ & & $\begin{array}{l}1.1 \\
1.1 \\
1.4\end{array}$ & \\
\hline [324] & $\begin{array}{l}\text { Peterson, J.C. and T. Haasl. 1994. "A Commissioning Cost-Effectiveness Case } \\
\text { Study". Proceedings of the } 1994 \text { ACEEE Summer Study on Energy Efficient } \\
\text { Buildings, 5.201. Washington, D.C.; American Council for an Energy-Efficient } \\
\text { Economy. }\end{array}$ & & 5.2 & \\
\hline$[325]$ & $\begin{array}{l}\text { Phillips, B.G. 1998. "Impact of Blower Performance on Residential Forced-Air } \\
\text { Heating System Performance". ASHRAE Transactions, Vol. 104, Part 1B, } \\
\text { pp.1817-1825. }\end{array}$ & 2.2 & $\begin{array}{l}2.2 \\
2.3\end{array}$ & 2.2 \\
\hline [326] & $\begin{array}{l}\text { Pickering, P.L., A.L. Cucchiara, M. Gonzales, and J.L. McAtee. 1987. "Test } \\
\text { ventilation with smoke, bubbles, and balloons". ASHRAE Transactions, Vol. } 93 \text {, } \\
\text { Part 2, pp. 898-907. }\end{array}$ & & 2.5 & \\
\hline [327] & $\begin{array}{l}\text { Piette, M. A. and B. Nordman. 1996. "Costs and Benefits from Utility-Funded } \\
\text { Commissioning of Energy-Efficiency Measures in } 16 \text { Buildings". ASHRAE } \\
\text { Transactions, Vol. 102, Part 1, pp. 482-491. }\end{array}$ & & 5.1 & 5.2 \\
\hline [328] & $\begin{array}{l}\text { Piette, M.A., B. Nordman, and S. Greenberg. 1995. "Commissioning of Energy } \\
\text { Efficiency Measures: Costs and Benefits for } 16 \text { Buildings". Berkeley, CA; } \\
\text { Lawrence Berkeley National Laboratory LNL-36448. Also Berkeley, CA; } \\
\text { University of California paper UC-1600. }\end{array}$ & 5.2 & & \\
\hline
\end{tabular}




\begin{tabular}{|c|c|c|c|c|}
\hline & & & Links & \\
\hline & & $M$ & $D$ & $\mathrm{~N}$ \\
\hline [329] & $\begin{array}{l}\text { Piette, M.A., B. Nordman, O. deBuen, and R. Diamond. 1995. "Findings from a } \\
\text { Low-Energy New Commercial Buildings Research and Demonstration Project". } \\
\text { Energy-The International Journal, Vol. 20, No. 6, pp. } 471-482 \text {. Also Berkeley, } \\
\text { CA; Lawrence Berkeley National Laboratory report LBNL-36506. }\end{array}$ & & & 5.2 \\
\hline [330] & $\begin{array}{l}\text { Ponessa, J. 1999. "Solving a Chimney Moisture Problem". Home Energy } \\
\text { Magazine, Vol. 16, No. 5, September/October, pp. 40-44. Berkeley, CA; Energy } \\
\text { Auditor \& Retrofitter, Inc. }\end{array}$ & & 2.4 & \\
\hline [331] & $\begin{array}{l}\text { Prince, J.T. 1986. "Building commissioning - a contractor's viewpoint”. ASHRAE } \\
\text { Transactions, Vol. 92, Part 2B, pp. 461-468. }\end{array}$ & & & 5.1 \\
\hline [332] & $\begin{array}{l}\text { Proctor, J, Z. Katsnelson, and B. Wilson. 1995. "Bigger is Not Better: Sizing Air } \\
\text { Conditioners Properly". Home Energy Magazine, Vol. 12, No. 3, May/June, pp. 19- } \\
\text { 26. Berkeley, CA; Energy Auditor \& Retrofitter, Inc. }\end{array}$ & & 2.1 & \\
\hline [333] & $\begin{array}{l}\text { Proctor, J. 1991. "An Ounce of Prevention: Residential Cooling Repairs". Home } \\
\text { Energy Magazine, Vol. 8, No. 3, May/June, pp. 23-28. Berkeley, CA; Energy } \\
\text { Auditor \& Retrofitter, Inc. }\end{array}$ & & 2.1 & $\begin{array}{l}2.1 \\
5.2\end{array}$ \\
\hline [334] & $\begin{array}{l}\text { Proctor, J. 1999. "Computer Expert System to Obtain Optimal AC Performance". } \\
\text { San Rafael, CA; Proctor Engineering Group. }\end{array}$ & & $\begin{array}{l}2.1 \\
2.3\end{array}$ & \\
\hline [335] & $\begin{array}{l}\text { Proctor, J. and P. Albright. 1996. "Sizing Air Conditioners: If Bigger is Not Better, } \\
\text { What is?" Home Energy Magazine, Vol. 13, No. 5, September/October, pp. 13-18. } \\
\text { Berkeley, CA; Energy Auditor \& Retrofitter, Inc. }\end{array}$ & & 2.1 & \\
\hline [336] & $\begin{array}{l}\text { Proctor, J. and T. Downey. 1999. "Transforming Routine Air Conditioner } \\
\text { Maintenance Practices to Improve Equipment Efficiency and Performance". } 1999 \\
\text { Energy Program Evaluation Conference, Denver. }\end{array}$ & & $\begin{array}{l}2.1 \\
2.3\end{array}$ & \\
\hline [337] & $\begin{array}{l}\text { Proctor, J., M. Blasnik, B. Davis, T. Downey, M.P. Modera, G. Nelson, and J.J. } \\
\text { Tooley, Jr. 1993. "Diagnosing Ducts". Home Energy Magazine, Vol. 10, No. } 5 . \\
\text { Berkeley, CA; Energy Auditor \& Retrofitter, Inc. }\end{array}$ & 2.3 & 2.3 & \\
\hline [338] & $\begin{array}{l}\text { Proctor, J.P. 1997. "Field Measurements of New Residential Air Conditioners in } \\
\text { Phoenix, Arizona". ASHRAE Transactions, Vol. 103, Part 2, pp. 406-415. }\end{array}$ & 2.1 & $\begin{array}{l}1.4 \\
2.1 \\
2.3\end{array}$ & 2.1 \\
\hline [339] & $\begin{array}{l}\text { Proctor, J.P. 1998. "Verification Test of ASHRAE Standard 152P". ASHRAE } \\
\text { Transactions, 1998 Part 1, SF-98-17-5. Atlanta, GA; American Society of Heating, } \\
\text { Refrigerating, and Air-Conditioning Engineers, Inc. }\end{array}$ & 2.3 & 2.3 & \\
\hline [340] & $\begin{array}{l}\text { Proskiw, G. 1995. "The Performance of Energy-Efficient Residential Building } \\
\text { Envelope Systems". Proceedings of the } 1995 \text { Thermal Performance of the Exterior } \\
\text { Envelopes of Buildings VI, pp. } 343 \text {. Atlanta, GA; American Society of Heating, } \\
\text { Refrigerating, and Air-Conditioning Engineers, Inc. }\end{array}$ & & 1.1 & \\
\hline [341] & $\begin{array}{l}\text { Rainer, L. 1995. "Is an R-19 Wall Really R-19?" Home Energy Magazine, Vol. 12, } \\
\text { No. 2, March/April, pp. 5-6. Berkeley, CA; Energy Auditor \& Retrofitter, Inc. }\end{array}$ & & & 1.1 \\
\hline
\end{tabular}




\begin{tabular}{|c|c|c|c|c|}
\hline & & \multicolumn{3}{|c|}{ Links } \\
\hline & & $\mathbf{M}$ & $\mathrm{D}$ & $\mathrm{N}$ \\
\hline [342] & $\begin{array}{l}\text { Rajhans, G.S. 1989. "Findings of the Ontario Inter-Ministerial Committee on } \\
\text { Indoor Air Quality". Proceedings of the ASHRAE/SOEH Conference IAQ 89. San } \\
\text { Diego, CA. }\end{array}$ & $\begin{array}{l}2.5 \\
3.1 \\
3.1 \\
3.4 \\
3.5\end{array}$ & $\begin{array}{l}2.4 \\
2.5 \\
3.1 \\
3.2 \\
3.2 \\
3.4 \\
3.4 \\
3.5 \\
3.5\end{array}$ & $\begin{array}{l}2.5 \\
3.2\end{array}$ \\
\hline [343] & $\begin{array}{l}\text { Reardon, J.T., A.K. Kim, and C.Y. Shaw. 1987. "Balanced fan depressurisation } \\
\text { method for measuring component and overall air leakage in single and multifamily } \\
\text { dwellings". ASHRAE Transactions, Vol. 93, Part 2, pp. 137-152. }\end{array}$ & & 1.4 & \\
\hline [344] & $\begin{array}{l}\text { Reichmuth, H. 1992. "Light Loggers - Who Needs ‘Em?” Home Energy } \\
\text { Magazine, Vol. 9, No. 2, March/April, pp. 21-26. Berkeley, CA; Energy Auditor \& } \\
\text { Retrofitter, Inc. }\end{array}$ & & 4.7 & \\
\hline$[345]$ & $\begin{array}{l}\text { Retrotec. 1998. "Take the Total System Approach". Retrotec Corporation, } \\
\text { www.retrotec.com. }\end{array}$ & & & 2.3 \\
\hline [346] & $\begin{array}{l}\text { Retrotec. 1998. "The Ten Keys to Residential Duct Sealing". Retrotec's } \\
\text { Corporation, www.retrotec.com. }\end{array}$ & & 2.3 & \\
\hline [347] & Retrotec. 1998. www.retrotec.com. & & 1.4 & \\
\hline [348] & $\begin{array}{l}\text { Richalet, V. and G. Henderson. 1999. "European Union Not Unified on Home } \\
\text { Ratings". Home Energy Magazine, Vol. 16, No. 5, September/October, pp. 20-23. } \\
\text { Berkeley, CA; Energy Auditor \& Retrofitter, Inc. }\end{array}$ & & 5.1 & \\
\hline [349] & $\begin{array}{l}\text { Rieger, T. 1993. "Home Energy Ratings in California". Home Energy Magazine, } \\
\text { Vol. 10, No. 5, September/October, pp. 7-9. Berkeley, CA; Energy Auditor \& } \\
\text { Retrofitter, Inc. }\end{array}$ & & 5.1 & \\
\hline [350] & $\begin{array}{l}\text { Robison, D. and H. Reichmuth. 1999. "Use of Billing Simulation Tool For } \\
\text { Commissioning". Proceedings of the 7th National Conference on Building } \\
\text { Commissioning, Portland, OR. Portland, OR; Portland Energy Conservation } \\
\text { Institute. }\end{array}$ & & 5.1 & \\
\hline [351] & $\begin{array}{l}\text { Robison, D.H. and L.A. Lambert. 1989. "Field investigation of residential } \\
\text { infiltration and heating duct leakage". ASHRAE Transactions, Vol. 95, Part 2, pp. } \\
542-550 .\end{array}$ & 1.4 & $\begin{array}{l}1.4 \\
2.3 \\
2.3 \\
2.5\end{array}$ & $\begin{array}{l}1.4 \\
5.2\end{array}$ \\
\hline [352] & $\begin{array}{l}\text { Roeder, K.K. 1992. New Guidelines for Thermographers. Home Energy Magazine, } \\
\text { Vol. 9, No. 5, September/October, pp. 11-12. Berkeley, CA; Energy Auditor \& } \\
\text { Retrofitter, Inc. }\end{array}$ & & 1.1 & \\
\hline
\end{tabular}




\begin{tabular}{|c|c|c|c|c|}
\hline & & \multicolumn{3}{|c|}{ Links } \\
\hline & & $M$ & $\mathrm{D}$ & $\mathrm{N}$ \\
\hline [353] & $\begin{array}{l}\text { Rose, R. 1999. "Engineering and specifications for HVAC systems relating to } \\
\text { testing and balancing". ASHRAE Transactions, Vol. 105, Part 1, pp. } 750-765 \text {, pp. } \\
750-765 \text {. }\end{array}$ & & 5.1 & 2.3 \\
\hline [354] & $\begin{array}{l}\text { Ross, J.A. and E.M. Sterling. 1997. "IAQ Commissioning in New Construction: A } \\
\text { Case Study". Proceedings of the 5th National Conference on Building } \\
\text { Commissioning, Huntington Beach, CA. Portland, OR; Portland Energy } \\
\text { Conservation Institute. }\end{array}$ & & $\begin{array}{l}3.1 \\
3.2 \\
3.5\end{array}$ & \\
\hline [355] & $\begin{array}{l}\text { Rossi, T.M. and J E. Braun. 1997. "A statistical, rule-based fault detection and } \\
\text { diagnostic method for vapour compression air conditioners". International Journal } \\
\text { of HVAC\&R Research, Vol. 3, no.1, pp. 19-37. }\end{array}$ & & 2.1 & \\
\hline [356] & $\begin{array}{l}\text { Roulet, C., J. Gass, and I. Markus. 1985. "In-situ U-value measurement. Reliable } \\
\text { results in shorter time by dynamic interpretation of measured data". Proceedings of } \\
\text { Thermal Performance of the Exterior Envelopes of Buildings III, Clearwater } \\
\text { Beach, FL, pp. 777-784. Atlanta, GA; American Society of Heating, Refrigerating, } \\
\text { and Air-Conditioning Engineers, Inc. }\end{array}$ & 1.3 & $\begin{array}{l}1.1 \\
1.2\end{array}$ & \\
\hline [357] & $\begin{array}{l}\text { Roulet, C.A., F. Foradini, and L. Deschamps. 1999. "Measurement of Airflow } \\
\text { Rates and Ventilation Efficiency in Air Handling Units". Proceedings of the 8th' } \\
\text { International Conference on Indoor Air Quality and Climate, Edinburgh, Scotland. }\end{array}$ & & 2.5 & \\
\hline$[358]$ & $\begin{array}{l}\text { Sabeff, P. 1994. "Energy Management Control Systems (EMCS) as a } \\
\text { Commissioning Tool". Proceedings of the } 2^{\text {nd }} \text { National Conference on Building } \\
\text { Commissioning, St. Petersburg Beach, Florida. Portland, OR; Portland Energy } \\
\text { Conservation Institute. }\end{array}$ & & 2.6 & \\
\hline [359] & $\begin{array}{l}\text { Saffell, J.R. 1995. "Measuring Ventilation Rates and Air Quality Using Carbon } \\
\text { Dioxide Monitoring Equipment". Healthy Buildings '95, Milan, Italy, pp. 833-842. }\end{array}$ & & 2.5 & \\
\hline [360] & $\begin{array}{l}\text { Sandberg, M.G. 1987. "Predicting a time varying flow rate using the constant } \\
\text { concentration and decay technique". ASHRAE Transactions, Vol. 93, Part 1, pp. } \\
\text { 1381-1393. }\end{array}$ & & 2.5 & \\
\hline [361] & $\begin{array}{l}\text { Sandberg, P.I. and S. Jahnsson. 1995. "Development of a method for the } \\
\text { measurement of specific heat loss in occupied detached houses". Proceedings of } \\
\text { Thermal Performance of the Exterior Envelopes of Buildings VI, Clearwater } \\
\text { Beach, FL, pp. } 425-430 \text {. Atlanta, GA; American Society of Heating, Refrigerating, } \\
\text { and Air-Conditioning Engineers, Inc. }\end{array}$ & & 1.1 & \\
\hline [362] & $\begin{array}{l}\text { Sauer, H.J., R. George, and E.G. Utterson. 1996. "Airflow sensing-toward } \\
\text { providing indoor air quality". Proceedings of the ASHRAE Indoor Air Quality } \\
\text { Conference '96, Baltimore, MD, pp. 67-77. Atlanta, GA; American Society of } \\
\text { Heating, Refrigerating, and Air-Conditioning Engineers, Inc. }\end{array}$ & & 2.3 & \\
\hline [363] & $\begin{array}{l}\text { Saunders, D.H., J.J. Duffy, F.S. Luciani, W. Clarke, D. Sherman, L. Kinney, and } \\
\text { N.H. Karins. 1994. "Measured performance rated method for weatherised homes". } \\
\text { ASHRAE Transactions, Vol. 100, Part 1, pp. 1554-1566. }\end{array}$ & $\begin{array}{l}1.1 \\
1.3\end{array}$ & $\begin{array}{l}1.1 \\
1.4 \\
2.3\end{array}$ & \\
\hline
\end{tabular}




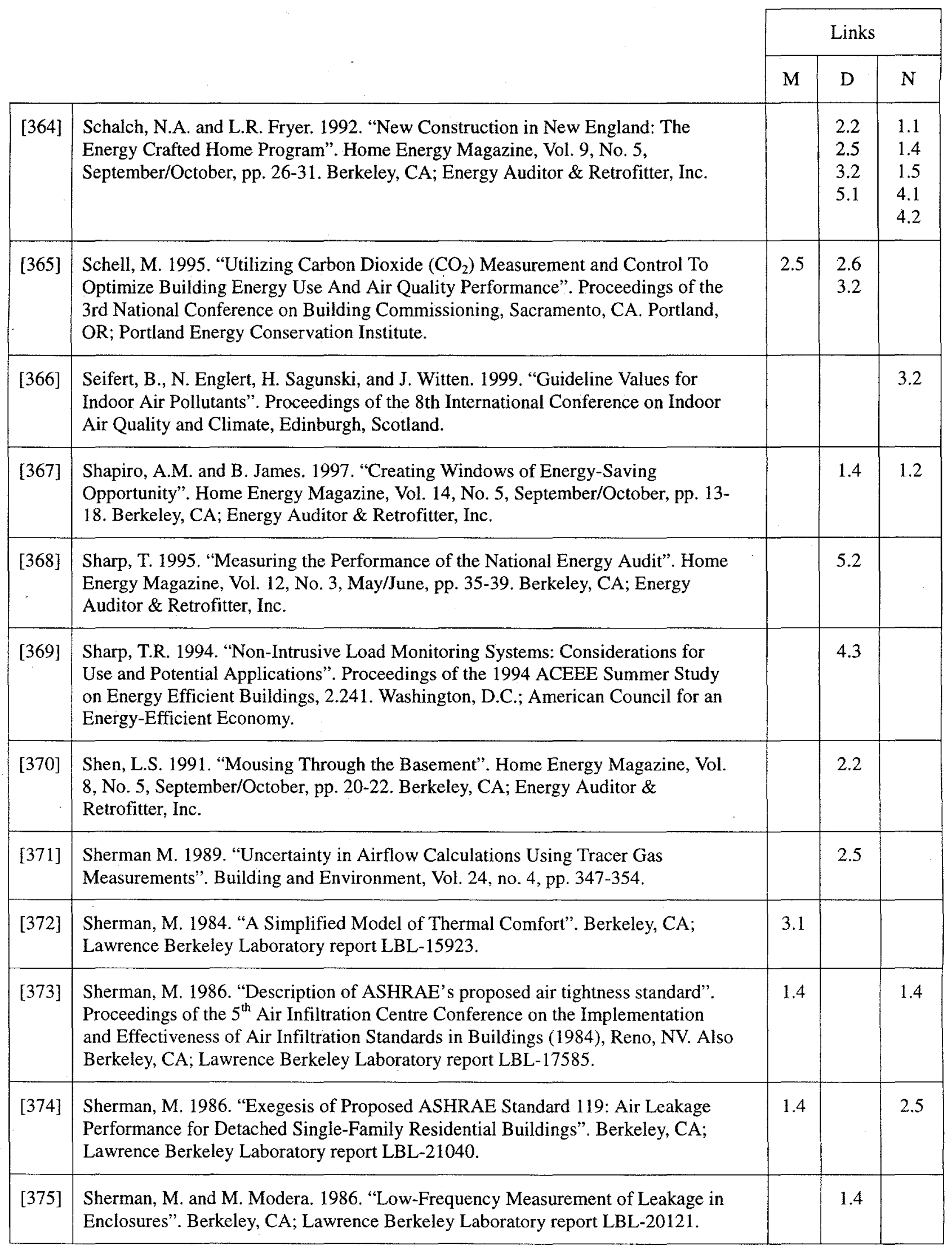




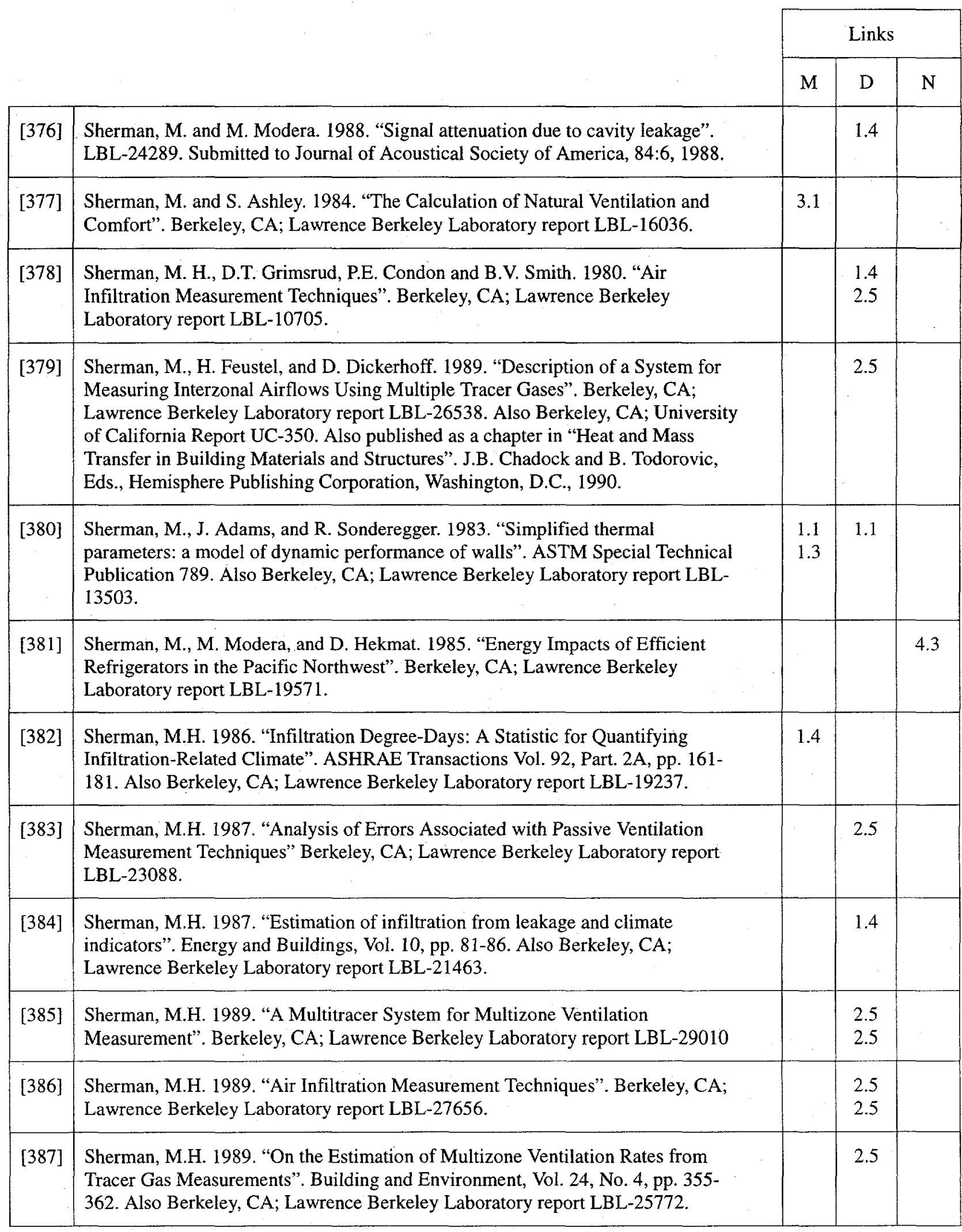




\begin{tabular}{|c|c|c|c|c|}
\hline & & \multicolumn{3}{|c|}{ Links } \\
\hline & & $\mathrm{M}$ & $\mathrm{D}$ & $\mathrm{N}$ \\
\hline [388] & $\begin{array}{l}\text { Sherman, M.H. 1990. "Tracer-Gas Techniques for Measuring Ventilation in a } \\
\text { Single Zone". Building and Environment, 25(4), pp. 365-374. Also Berkeley, CA; } \\
\text { Lawrence Berkeley Laboratory report LBL-29328. }\end{array}$ & & 2.5 & \\
\hline [389] & $\begin{array}{l}\text { Sherman, M.H. 1994. "The Use of Blower Door Data". Berkeley, CA; Lawrence } \\
\text { Berkeley Laboratory report LBL-35173. }\end{array}$ & & 2.5 & \\
\hline [390] & $\begin{array}{l}\text { Sherman, M.H. and D. T. Grimsrud. 1980. "Measurement of Infiltration Using Fan } \\
\text { Pressurization and Weather Data". Berkeley, CA; Lawrence Berkeley Laboratory } \\
\text { report LBL-10852. }\end{array}$ & 1.4 & $\begin{array}{l}1.4 \\
2.5\end{array}$ & \\
\hline [391] & $\begin{array}{l}\text { Sherman, M.H. and D.J. Dickerhoff. 1989. "A multi-gas tracer system for multi- } \\
\text { zone airflow measurements". Proceedings of the Thermal Performance of the } \\
\text { Exterior Envelopes of Buildings IV, Orlando, FL, pp. } 417-432 \text {. Atlanta, GA; } \\
\text { American Society of Heating, Refrigerating, and Air-Conditioning Engineers, Inc. } \\
\text { Also Berkeley, CA; Lawrence Berkeley Laboratory Report LBL-26087. }\end{array}$ & & $\begin{array}{l}2.5 \\
4.7\end{array}$ & \\
\hline [392] & $\begin{array}{l}\text { Sherman, M.H. and D.J. Wilson. 1986. "Relating Actual and Effective Ventilation } \\
\text { in Determining Indoor Air Quality". Berkeley, CA; Lawrence Berkeley Laboratory } \\
\text { report LBL-20424. }\end{array}$ & 2.5 & & \\
\hline [393] & $\begin{array}{l}\text { Sherman, M.H. and D.T. Grimsrud. 1982. "Wind and Infiltration for Small } \\
\text { Buildings". Berkeley, CA; Lawrence Berkeley Laboratory report LBL-13949. }\end{array}$ & 2.5 & & \\
\hline [394] & $\begin{array}{l}\text { Sherman, M.H. and L. Palmiter. 1994. "Uncertainties in Fan Pressurization } \\
\text { Measurements". In Airflow Performance of Envelopes, Components and Systems, } \\
\text { Philadelphia, American Society for Testing and Materials (STP 1255), Modera \& } \\
\text { Persily Eds., pp. 262-283, 1994. Also Berkeley, CA; Lawrence Berkeley } \\
\text { Laboratory report LBL- 32115. }\end{array}$ & & 1.4 & \\
\hline [395] & $\begin{array}{l}\text { Sherman, M.H., D. J. Wilson, and D. E. Kiel. } 1984 \text { "Variability in Residential Air } \\
\text { Leakage". Berkeley, CA; Lawrence Berkeley Laboratory report LBL-17587 }\end{array}$ & & & 1.4 \\
\hline [396] & $\begin{array}{l}\text { Sherman, M.H., D.T. Grimsrud, and R.C. Diamond. 1979. "Infiltration- } \\
\text { Pressurization Correlations: Surface Pressures and Terrain Effects". ASHRAE } \\
\text { Transactions Vol. 85, Part 2, pp. 458-479. Also Berkeley, CA; Lawrence Berkeley } \\
\text { Laboratory report LBL-8785. }\end{array}$ & & 2.5 & \\
\hline [397] & $\begin{array}{l}\text { Sherman, M.H., D.T. Grimsrud, and R.C. Sonderegger. 1989. "The Low Pressure } \\
\text { Leakage Function of a Building". Berkeley, CA; Lawrence Berkeley Laboratory } \\
\text { report LBL-9162. }\end{array}$ & & 1.4 & \\
\hline [398] & $\begin{array}{l}\text { Sherman, M.H., H. Feustel, and D. Dickerhoff. 1989. "Description of a System for } \\
\text { Measuring Interzonal Airflows Using Multiple Tracer Gases". Berkeley, CA; } \\
\text { Lawrence Berkeley Laboratory report LBL-26538 }\end{array}$ & & $\begin{array}{l}2.5 \\
2.5\end{array}$ & \\
\hline [399] & $\begin{array}{l}\text { Sherman, M.H., M.P. Modera, and D.T. Grimsrud. 1981. "A Predictive Air } \\
\text { Infiltration Model-Field Validation and Sensitivity Analysis". Berkeley, CA; } \\
\text { Lawrence Berkeley Laboratory report LBL-13520. }\end{array}$ & 2.5 & & \\
\hline
\end{tabular}




\begin{tabular}{|c|c|c|c|c|}
\hline \multirow{2}{*}{ 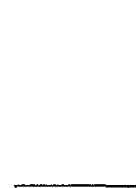 } & & \multicolumn{3}{|c|}{ Links } \\
\hline & & \multirow[t]{2}{*}{$M$} & $D$ & $\mathrm{~N}$ \\
\hline [400] & $\begin{array}{l}\text { Sherman, M.H., R.C. Sonderegger, and J.W. Adams. 1982. "The Determination of } \\
\text { the Dynamic Performance of Walls". ASHRAE Transactions Vol. 88, Part. 1, pp. } \\
\text { 689-712. Also Berkeley, CA; Lawrence Berkeley Laboratory report LBL-13510. }\end{array}$ & & 1.1 & \\
\hline [401] & $\begin{array}{l}\text { Sherman, M.H., R.F. Szydlowski, P.G. Cleary, M.P. Modera, and M.D. Levine. } \\
\text { 1987. "Development and Implementation of Survey Techniques for Assessing In- } \\
\text { Situ Appliance Efficiencies". Berkeley, CA; Lawrence Berkeley Laboratory report } \\
\text { LBL-23455. }\end{array}$ & $\begin{array}{l}2.1 \\
2.2 \\
4.1 \\
4.3\end{array}$ & $\begin{array}{l}1.1 \\
2.1 \\
2.2 \\
4.1 \\
4.3\end{array}$ & \\
\hline [402] & $\begin{array}{l}\text { Sherman. M and N. Matson. 1997. "Residential ventilation and energy } \\
\text { characteristics". ASHRAE Transactions, Vol. 103, Part 1, pp. 717-730. Also } \\
\text { Berkeley, CA; Lawrence Berkeley National Laboratory report LBNL-39036. }\end{array}$ & 1.4 & & \\
\hline [403] & $\begin{array}{l}\text { Siegel, J. and B. Davis. 1998. "Measured Heating System Efficiency Retrofits in } \\
\text { Eight Manufactured (HUD-Code) Homes". Proceedings of the 1998 ACEEE } \\
\text { Summer Study on Energy Efficient Buildings, 2.189. Washington, D.C.; American } \\
\text { Council for an Energy-Efficient Economy. }\end{array}$ & 2.3 & $\begin{array}{l}1.4 \\
2.3\end{array}$ & \\
\hline [404] & $\begin{array}{l}\text { Siegel, J. and B. Manclark. 1998. "Pressure Pans: New Uses and Old } \\
\text { Fundamentals". Home Energy Magazine, Vol. 15, No. 1, January/February } 1998 \\
\text { pp. 37-42. Berkeley, CA; Energy Auditor \& Retrofitter, Inc. }\end{array}$ & 2.3 & 2.3 & \\
\hline [405] & $\begin{array}{l}\text { Simonson, C.J., D.L. Ciepliski, and R.W. Besant. 1999. "Determining the } \\
\text { performance of energy wheels: part I - experimental and numerical methods". } \\
\text { ASHRAE Transactions, Vol. 105, Part 1, pp. 174-187. }\end{array}$ & 2.5 & 2.5 & \\
\hline [406] & $\begin{array}{l}\text { Skopek, J. 1999. "BREEAM Strategy for Reducing Buildings' Environmental } \\
\text { Impact". ASHRAE Transactions, Vol. 105, Part 2, SE-99-10-3. }\end{array}$ & & & 2.1 \\
\hline [407] & $\begin{array}{l}\text { SMACNA. 1993. "HVAC Systems-Testing, Adjusting, and Balancing, } 2^{\text {nd }} \\
\text { Edition". Washington, D.C.; Sheet Metal and Air Conditioning Contractors } \\
\text { National Association. }\end{array}$ & & $\begin{array}{l}2.3 \\
2.6 \\
4.7\end{array}$ & \\
\hline [408] & $\begin{array}{l}\text { Snell, J. 1993. "Selecting an Infrared Imaging System". Home Energy Magazine, } \\
\text { Vol. 10, No. 4, July/August, pp. 37-42. Berkeley, CA; Energy Auditor \& } \\
\text { Retrofitter, Inc. }\end{array}$ & & 1.1 & 4.7 \\
\hline [409] & $\begin{array}{l}\text { Sonderegger, R. C., M. H. Sherman, and J. W. Adams. 1981. "The Envelope } \\
\text { Thermal Test Unit (ETTU): Field Measurement of Wall Performance". Berkeley, } \\
\text { CA; Lawrence Berkeley Laboratory report LBL-13436. }\end{array}$ & $\begin{array}{l}1.1 \\
1.3\end{array}$ & 1.1 & \\
\hline [410] & $\begin{array}{l}\text { Sonderegger, R.C. 1998. "A Baseline Model for Utility Bill Analysis Using Both } \\
\text { Weather and Non-Weather-Related Variables". ASHRAE Transactions, Vol. 104, } \\
\text { Part 2, pp. 859-870. }\end{array}$ & & 5.1 & \\
\hline [411] & $\begin{array}{l}\text { Sonderegger, R.C., P.E. Condon, and M.P. Modera. 1980. "In-situ measurements of } \\
\text { residential energy performance using electric coheating". ASHRAE Transactions, } \\
\text { Vol. 86, Part 1, pp. 394-407. }\end{array}$ & & $\begin{array}{l}2.1 \\
2.5\end{array}$ & \\
\hline
\end{tabular}




\begin{tabular}{|c|c|c|c|c|}
\hline & & \multirow{2}{*}{\multicolumn{3}{|c|}{ Links }} \\
\hline & & & & \\
\hline & & M & $\mathrm{D}$ & $\mathrm{N}$ \\
\hline [412] & $\begin{array}{l}\text { Stein, J.R. 1997. "Home Energy Rating Systems: Actual Usage May Vary". Home } \\
\text { Energy Magazine, Vol. 14, No. 5, pp. 21-27. Berkeley, CA; Energy Auditor \& } \\
\text { Retrofitter, Inc. }\end{array}$ & & 5.2 & \\
\hline [413] & $\begin{array}{l}\text { Sterling, E. and C. Collett. 1994. "The Building Commissioning/Quality Assurance } \\
\text { Process in North America". ASHRAE Journal, Vol. 36, Number 10, pp. 32-36, } \\
\text { October. }\end{array}$ & & 5.1 & 5.1 \\
\hline [414] & $\begin{array}{l}\text { Sterling, E.M., C.W. Collett, S. Turner, and C.C. Downing. 1992. "Commissioning } \\
\text { to Avoid Indoor Air Quality Problems". ASHRAE Journal, October 1992, pp. 28- } \\
32 \text {. }\end{array}$ & & 5.1 & \\
\hline [415] & $\begin{array}{l}\text { Stewart, W.E., C.K. Saunders, and C.L.G. Dona. 1999. "Evaluation of service hot } \\
\text { water distribution systems losses in residential and commercial installations: part } 1 \\
\text { - field/laboratory experiments and simulation model". ASHRAE Transactions, Vol. } \\
\text { 105, Part 1, pp. 237-246. }\end{array}$ & & 4.1 & \\
\hline [416] & $\begin{array}{l}\text { Stock, T.H., M.T. Morandi, G.C. Pratt, D. Bock, and J.H. Cross. } 1999 . \\
\text { "Comparison of the Results of VOC Monitoring with Diffusive Samplers and } \\
\text { Canisters". Proceedings of the 8th International Conference on Indoor Air Quality } \\
\text { and Climate, Edinburgh, Scotland. }\end{array}$ & & 3.2 & \\
\hline [417] & $\begin{array}{l}\text { Su, H.J., C.Y. Huang, C.M. Chiang, C.C. Lee, and Y.Y. Li. 1999. "Design of a } \\
\text { Comprehensive Indoor Air Quality (IAQ) Investigation and Its Implications for } \\
\text { Proposing IAQ Regulation". Proceedings of the 8th International Conference on } \\
\text { Indoor Air Quality and Climate, Edinburgh, Scotland. }\end{array}$ & $\begin{array}{l}3.2 \\
3.4\end{array}$ & 3.2 & \\
\hline [418] & $\begin{array}{l}\text { Subbarao, K., D. Mort, and J. Burch. 1985. "Short term measurements for the } \\
\text { determination of envelope retrofit performance". ASHRAE Transactions, Vol. } 91 \text {, } \\
\text { Part 2B, pp. 1516-1524. }\end{array}$ & 1.1 & & \\
\hline [419] & $\begin{array}{l}\text { Subbarao, K., J. Burch, E. Hancock, and H. Jeon. 1985. "Measurement of effective } \\
\text { thermal capacitance in buildings". Proceedings of Thermal Performance of the } \\
\text { Exterior Envelopes of Buildings III, Clearwater Beach, FL, pp. 351-363. Atlanta, } \\
\text { GA; American Society of Heating, Refrigerating, and Air-Conditioning Engineers, } \\
\text { Inc. }\end{array}$ & 1.3 & 1.3 & \\
\hline [420] & $\begin{array}{l}\text { Ternes, M.P. 1987. “A data specification guideline for DOE's single-family } \\
\text { building energy retrofit research program”. ASHRAE Transactions, Vol. 93, Part 1, } \\
\text { pp. 1607-1618 }\end{array}$ & & $\begin{array}{l}1.4 \\
2.1 \\
2.3 \\
4.7 \\
5.1\end{array}$ & 2.2 \\
\hline [421] & $\begin{array}{l}\text { The Energy Conservatory. 1998. "APT System Used to Automate Home } \\
\text { Inspections in Minneapolis Sound Abatement Program". TEC Update, Fall } 1998 \\
\text { and www.energyconservatory.com. }\end{array}$ & & 1.4 & \\
\hline [422] & The Energy Conservatory. 1999. www.energyconservatory.com. & & $\begin{array}{l}1.4 \\
2.3 \\
4.7\end{array}$ & \\
\hline
\end{tabular}




\begin{tabular}{|c|c|c|c|c|}
\hline & & \multirow{2}{*}{\multicolumn{3}{|c|}{ Links }} \\
\hline & & & & \\
\hline & & \multirow[t]{2}{*}{$\mathrm{M}$} & \multirow{2}{*}{$\mathrm{D}$} & \multirow[t]{2}{*}{$\mathrm{N}$} \\
\hline [423] & $\begin{array}{l}\text { Thomas, G. 1992. "Performance Contracting: An ESCo Perspective". Home } \\
\text { Energy Magazine, Vol. 9, No. 6, November/December, pp. 23-25. Berkeley, CA; } \\
\text { Energy Auditor \& Retrofitter, Inc. }\end{array}$ & & & \\
\hline [424] & $\begin{array}{l}\text { Thomas, G.. 1999. "Home Ratings Sweep the Nation - Almost". Home Energy } \\
\text { Magazine, Vol. 16, No. 5, September/October, pp. 12-16. Berkeley, CA; Energy } \\
\text { Auditor \& Retrofitter, Inc. }\end{array}$ & & 5.1 & \\
\hline [425] & $\begin{array}{l}\text { Tinker, J.A. and K. Al-Buijan. 1998. "Thermal Performance of Fenestration } \\
\text { Systems in the Hot Climate of Saudi Arabia". Proceedings of the Thermal } \\
\text { Performance of the Exterior Envelopes of Buildings VII, Clearwater Beach, FL, } \\
\text { pp. 311. Atlanta, GA; American Society of Heating, Refrigerating, and Air- } \\
\text { Conditioning Engineers, Inc. }\end{array}$ & & 1.2 & \\
\hline [426] & $\begin{array}{l}\text { Tooley, J. 1999. "Handling Framing Details in High-Performance Homes". Home } \\
\text { Energy Magazine, Vol. 16, No. 3, May/June, pp. 22-27. Berkeley, CA; Energy } \\
\text { Auditor \& Retrofitter, Inc. }\end{array}$ & & $\begin{array}{l}1.4 \\
1.4\end{array}$ & \\
\hline$[427]$ & $\begin{array}{l}\text { Tooley, J. 1999. "The High-Performance House - What Does It Take?". Home } \\
\text { Energy Magazine, Vol. 16, No. 2, March/April, pp. 16-23. Berkeley, CA; Energy } \\
\text { Auditor \& Retrofitter, Inc. }\end{array}$ & & $\begin{array}{l}1.4 \\
1.4\end{array}$ & \\
\hline$[428]$ & $\begin{array}{l}\text { Tooley, J.L. and B.E. Davis. 1994. "Powered Attic Ventilators, Another Applied } \\
\text { Building Science Nightmare and Treasure Trove". Proceedings of the } 1994 \\
\text { ACEEE Summer Study on Energy Efficiency in Buildings. Washington, D.C.; } \\
\text { American Council for an Energy-Efficient Economy. }\end{array}$ & & $\begin{array}{l}1.4 \\
1.5 \\
2.5 \\
3.3\end{array}$ & \\
\hline [429] & $\begin{array}{l}\text { Torry, B. 1994. "Blower Door Cruise Control". Home Energy Magazine, Vol. 11, } \\
\text { No. 2. Berkeley, CA; Energy Auditor \& Retrofitter, Inc. }\end{array}$ & & 1.4 & \\
\hline$[430]$ & $\begin{array}{l}\text { Treado, S.J. and D.M. Burch. 1983. "Applications of aerial thermophotography for } \\
\text { residential energy analysis". ASHRAE Transactions, Vol. 89, Part 2B, pp. 95-101. }\end{array}$ & & 1.1 & \\
\hline [431] & $\begin{array}{l}\text { Treidler, B. and M. Modera. 1994. "Peak Demand Impacts of Residential Air- } \\
\text { Conditioning Conservation Measures." Proceedings of the ACEEE 1994 Summer } \\
\text { Study on Energy Efficiency in Buildings, pp. 7.249-7.258. Washington, D.C.; } \\
\text { American Council for an Energy-Efficient Economy. }\end{array}$ & & & 2.1 \\
\hline [432] & $\begin{array}{l}\text { Treidler, B., M.P. Modera, R.G. Lucas, and J.D. Miller. 1996. "Impact of } \\
\text { Residential Duct Insulation on HVAC Energy Use and Life-Cycle Costs to } \\
\text { Consumers". ASHRAE Transactions, Vol. 102, Part 1, pp. 881-891. }\end{array}$ & & & $\begin{array}{l}2.3 \\
2.3\end{array}$ \\
\hline [433] & $\begin{array}{l}\text { Trombly, J. 1991. "Strike That Match: Low-E Detection Made Easy". Home } \\
\text { Energy Magazine, Vol. 8, No. 6, November/December 1991, p. 10. Berkeley, CA; } \\
\text { Energy Auditor \& Retrofitter, Inc. }\end{array}$ & & 4.7 & \\
\hline [434] & $\begin{array}{l}\text { Tseng, P.C., D.R. Stanton-Hoyle, and W.M. Withers. 1994. "Commissioning } \\
\text { Through Digital Controls and an Advanced Monitoring System--A Project } \\
\text { Perspective". ASHRAE Transactions, Vol. 100, Part 1, pp. 1382-1392. }\end{array}$ & & $\begin{array}{l}2.5 \\
2.6\end{array}$ & \\
\hline
\end{tabular}




\begin{tabular}{|c|c|c|c|c|}
\hline & & \multicolumn{3}{|c|}{ Links } \\
\hline & & $\mathrm{M}$ & $\mathrm{D}$ & $\mathrm{N}$ \\
\hline [435] & $\begin{array}{l}\text { Tseng, P.C., S.E. Batterden, and W.A. Appenzellar. 1994. "Assessment criteria for } \\
\text { commissioning and construction quality control—assessing the effectiveness of } \\
\text { total building commissioning". ASHRAE Transactions, Vol. 100, Part 2, pp. 1149- } \\
1154 \text {. }\end{array}$ & 5.1 & & \\
\hline [436] & $\begin{array}{l}\text { Tsongas, G. 1995. "Carbon Monoxide From Ovens:" Home Energy Magazine } \\
\text { Online, http://hem.dis.anl.gov/eehem/95/950907.html. }\end{array}$ & & 3.2 & \\
\hline [437] & $\begin{array}{l}\text { Tsongas, G. 1995. "Moisture and Mobile Home Weatherization". Home Energy } \\
\text { Magazine, Vol. 12, No. 4, July/August, pp. 29-31. Berkeley, CA; Energy Auditor \& } \\
\text { Retrofitter, Inc. }\end{array}$ & & & 1.5 \\
\hline [438] & $\begin{array}{l}\text { Tsongas, G. and W.D. Hager. 1994. "Field Monitoring of Elevated Carbon } \\
\text { Monoxide Production from Residential Gas Ovens". Proceedings of the ASHRAE } \\
\text { Indoor Air Quality Conference ' } 94 \text {, St. Louis, MO, pp. 185-195. Atlanta, GA; } \\
\text { American Society of Heating, Refrigerating, and Air-Conditioning Engineers, Inc. }\end{array}$ & & 3.2 & 3.2 \\
\hline [439] & $\begin{array}{l}\text { Tsongas, G.A. and G.D. Nelson. 1991. "A field test for correlation of air leakage } \\
\text { and high moisture content sites in tightly built walls". ASHRAE Transactions, Vol. } \\
\text { 97, Part 1, pp. 1-8. }\end{array}$ & & $\begin{array}{l}1.4 \\
1.5\end{array}$ & \\
\hline [440] & $\begin{array}{l}\text { Turner, W.A. and D.W. Bearg. 1989. "Determining Delivered Quantities of Outside } \\
\text { Air: } \mathrm{CO}_{2} \text {, Tracer Gas, or Both?" Proceedings of the ASHRAE Indoor Air Quality } \\
\text { Conference ' } 89 \text {, San Diego, CA, pp.117-121. Atlanta, GA; American Society of } \\
\text { Heating, Refrigerating, and Air-Conditioning Engineers, Inc. }\end{array}$ & & 2.5 & \\
\hline [441] & $\begin{array}{l}\text { Turner, W.A., F. McKnight, D.W. Bearg, and R.Shaughnessy. 1996. "Indoor PM- } \\
\text { 10, PM-2.5, and Laser Optics Particle Sampling: How the Building Operator can } \\
\text { Benefit From This Type of Information". Proceedings of the ASHRAE Indoor Air } \\
\text { Quality Conference ' } 96, \text { Baltimore, MD, pp. 210-218. Atlanta, GA; American } \\
\text { Society of Heating, Refrigerating, and Air-Conditioning Engineers, Inc. }\end{array}$ & 3.5 & 3.5 & \\
\hline [442] & $\begin{array}{l}\text { UL. 1999. "Test standards for household and commercial products". Underwriters } \\
\text { Laboratories, http://www.ul.com/energy/tet.html. }\end{array}$ & & $\begin{array}{l}2.1 \\
4.2\end{array}$ & \\
\hline [443] & $\begin{array}{l}\text { Uniacke, M. 1992. "A Perspective from the Field: The House as a System". } \\
\text { Proceedings of the Thermal Performance of the Exterior Envelopes of Buildings V, } \\
\text { Clearwater Beach, FL, p. } 60 \text {. Atlanta, GA; American Society of Heating, } \\
\text { Refrigerating, and Air-Conditioning Engineers, Inc. }\end{array}$ & & 5.1 & \\
\hline [444] & $\begin{array}{l}\text { Uniacke, M. 1996. "Creating Quality in New Construction: A Practitioner's } \\
\text { Perspective". Home Energy Magazine, Vol. 13, No. 1, January/February, pp. 33-37. } \\
\text { Berkeley, CA; Energy Auditor \& Retrofitter, Inc. }\end{array}$ & & 1.4 & $\begin{array}{l}1.1 \\
1.4\end{array}$ \\
\hline [445] & $\begin{array}{l}\text { Vieira, R.K., J.E. Cummings, P.W. Fairey, and K. Hannani. 1998. "How to } \\
\text { Calculate Financial Information for Home Energy Raters, Lenders and Savvy } \\
\text { Home Buyers". Proceedings of the } 1998 \text { ACEEE Summer Study on Energy } \\
\text { Efficient Buildings, 7.335. Washington, D.C.; American Council for an Energy- } \\
\text { Efficient Economy. }\end{array}$ & 5.2 & 5.2 & \\
\hline
\end{tabular}




\begin{tabular}{|c|c|c|c|c|}
\hline & & & Link & \\
\hline & & $\mathbf{M}$ & $\mathrm{D}$ & $\mathrm{N}$ \\
\hline [446] & $\begin{array}{l}\text { Walker, I., M. Modera, A. Tuluca, and I. Graham. 1996. "Energy-effectiveness of } \\
\text { duct sealing and insulation in two multifamily buildings". Proceedings of } 1996 \\
\text { ACEEE Summer Study, Asilomar, CA. Washington, D.C.; American Council for } \\
\text { an Energy-Efficient Economy. }\end{array}$ & 2.3 & $\begin{array}{l}2.3 \\
2.3\end{array}$ & \\
\hline [447] & $\begin{array}{l}\text { Walker, I., M. Sherman, and J. Siegel. 1999. "Distribution Effectiveness and } \\
\text { Impacts on Equipment Sizing: Residential Thermal Distribution Systems } \\
\text { Transition Phase Final Report (DRAFT)". CIEE-sponsored report through DOE. }\end{array}$ & $\begin{array}{l}2.1 \\
2.3\end{array}$ & $\begin{array}{l}2.3 \\
2.3\end{array}$ & \\
\hline [448] & $\begin{array}{l}\text { Walker, I., M. Sherman, M. Modera, and J. Siegel. 1998. "Leakage Diagnostics, } \\
\text { Sealant Longevity, Sizing and Technology Transfer in Residential Thermal } \\
\text { Distribution Systems". CIEE-sponsored report through DOE. }\end{array}$ & 1.4 & $\begin{array}{l}1.4 \\
2.3\end{array}$ & \\
\hline [449] & $\begin{array}{l}\text { Walker, I., M. Sherman, M. Modera, and J. Siegel. 1998. "Leakage Diagnostics, } \\
\text { Sealant Longevity, Sizing and Technology Transfer in Residential Thermal } \\
\text { Distribution Systems: Part II". Residential Thermal Distribution Systems Phase VI } \\
\text { Final Report. CIEE-sponsored report through DOE. }\end{array}$ & $\begin{array}{l}2.1 \\
2.3\end{array}$ & $\begin{array}{l}2.3 \\
2.3\end{array}$ & \\
\hline$[450]$ & $\begin{array}{l}\text { Walker, I.S. 1993. "Prediction of ventilation, heat transfer and moisture transport in } \\
\text { attics". Ph.D. thesis, Department of Mechanical Engineering, University of } \\
\text { Alberta, Edmonton, AB, Canada. }\end{array}$ & & $\begin{array}{l}1.5 \\
3.3\end{array}$ & \\
\hline [451] & $\begin{array}{l}\text { Walker, I.S. and M.P. Modera. 1998. "Field Measurements of Interactions Between } \\
\text { Furnaces and Forced-Air Distribution Systems". ASHRAE Transactions, Vol. 104, } \\
\text { Part 1B, pp. 1805-1816. }\end{array}$ & 2.2 & & \\
\hline [452] & $\begin{array}{l}\text { Walker, I.S. and T.W. Forest. 1995. "Field Measurements of Ventilation Rates in } \\
\text { Attics". Building and Environment, Vol. 30, No. 3, pp. 333-347. }\end{array}$ & $\begin{array}{l}1.5 \\
2.5 \\
3.3\end{array}$ & $\begin{array}{l}1.5 \\
2.5 \\
3.3\end{array}$ & \\
\hline [453] & $\begin{array}{l}\text { Walker, I.S., J. Siegel, K. Brown, and M.H. Sherman. 1998. "Saving Tons at the } \\
\text { Register". Proceedings of } 1998 \text { ACEEE Summer Study, Pacific Grove, CA. } \\
\text { Washington, D.C.; American Council for an Energy-Efficient Economy. Also } \\
\text { Lawrence Berkeley National Laboratory report LBNL-41957. }\end{array}$ & $\begin{array}{l}2.1 \\
2.3 \\
2.3 \\
3.1\end{array}$ & $\begin{array}{l}2.1 \\
2.2 \\
2.3 \\
3.1\end{array}$ & $\begin{array}{l}2.1 \\
2.3\end{array}$ \\
\hline [454] & $\begin{array}{l}\text { Walker, I.S., T.W. Forest, and D.J. Wilson. 1995. "A Simple Calculation Method } \\
\text { for Attic Ventilation Rates". Proceedings of the 16th AIVC Conference, Palm } \\
\text { Springs, CA, Vol. 1, pp. 221-232. Coventry, Great Britain; Air Infiltration and } \\
\text { Ventilation Centre. }\end{array}$ & & $\begin{array}{l}1.5 \\
2.5\end{array}$ & \\
\hline [455] & $\begin{array}{l}\text { Walker, K. and R. Lewis. 1996. "Contracting for Comfort". Home Energy } \\
\text { Magazine, Vol. 13, No. 6. Berkeley, CA; Energy Auditor \& Retrofitter, Inc. }\end{array}$ & & 5.2 & \\
\hline$[456]$ & $\begin{array}{l}\text { Warner, J. 1991. "How to Avoid Window Condensation". Home Energy Magazine, } \\
\text { Vol. 8, No. 5, September/October, pp. 27-29. Berkeley, CA; Energy Auditor \& } \\
\text { Retrofitter, Inc. }\end{array}$ & & $\begin{array}{l}1.5 \\
3.2\end{array}$ & \\
\hline$[457]$ & $\begin{array}{l}\text { Weingarten, L. and S. Weingarten. 1996. "Water Heaters and Energy Conservation } \\
\text { - Choices, Choices!" Home Energy Magazine, Vol. 13, No. 3, May/June, pp. 15- } \\
\text { 21. Berkeley, CA; Energy Auditor \& Retrofitter, Inc. }\end{array}$ & & & 4.1 \\
\hline
\end{tabular}




\begin{tabular}{|c|c|c|c|c|}
\hline & & \multirow{2}{*}{\multicolumn{3}{|c|}{ Links }} \\
\hline & & & & \\
\hline & & $\mathrm{M}$ & D & $\mathrm{N}$ \\
\hline$[458]$ & $\begin{array}{l}\text { Weingarten, L. and S. Weingarten. 1996. Response to Reader Letter. Home Energy } \\
\text { Magazine, Vol. 13, No. 5, September/October 1996, p. 4. Berkeley, CA; Energy } \\
\text { Auditor \& Retrofitter, Inc. }\end{array}$ & & & 4.1 \\
\hline [459] & $\begin{array}{l}\text { Weir, B. 1996. "Report on the CSA Questionnaire on Building Commissioning". } \\
\text { Ottawa, ON, Canada; Canadian Mortgage and Housing Corporation Technical } \\
\text { Series 96-235 98-116. }\end{array}$ & & 5.1 & \\
\hline$[460]$ & $\begin{array}{l}\text { Werling, E., J.D. Hall, and D. Meisegeier. 1998. "Lessons Learned in the } \\
\text { ENERGY STAR Homes Program". Proceedings of the } 1998 \text { ACEEE Summer } \\
\text { Study on Energy Efficient Buildings, 2.243. Washington, D.C.; American Council } \\
\text { for an Energy-Efficient Economy. }\end{array}$ & & & $\begin{array}{l}1.1 \\
1.4 \\
2.1 \\
2.6\end{array}$ \\
\hline [461] & $\begin{array}{l}\text { West, A.M., D. Robinson, H. Reichmuth, and T. West. 1998. "Savings from an } \\
\text { Expedited Duct Sealing Program for Mobile Homes". Proceedings of the } 1998 \\
\text { ACEEE Summer Study on Energy Efficient Buildings, 2.259. Washington, D.C.; } \\
\text { American Council for an Energy-Efficient Economy. }\end{array}$ & & 2.3 & \\
\hline [462] & $\begin{array}{l}\text { Wilson, A.G., E. Scheuneman, and M. Tremayne. 1986. "House Depressurization } \\
\text { and Flue Gas Spillage". Proceedings IAQ 86: Managing Indoor Air for Health and } \\
\text { Energy Conservation. American Society of Heating, Refrigerating, and Air } \\
\text { Conditioning Engineers. Atlanta, Georgia, 20-23 April, pp. 417-429. }\end{array}$ & 2.4 & 2.4 & 2.4 \\
\hline [463] & $\begin{array}{l}\text { Wishner, N. 1996. "A Plan to Stop Fluffing and Cheating in Attic Insulation". } \\
\text { Home Energy Magazine, Vol. 13, No. 3, May/June, pp. 10-11. Berkeley, CA; } \\
\text { Energy Auditor \& Retrofitter, Inc. }\end{array}$ & & 1.1 & \\
\hline [464] & $\begin{array}{l}\text { Womble, S.E., L.E. Burton, L. Kolb, J.R. Girman, G.E. Hadwen, M. Carpenter, and } \\
\text { J.F. McCarthy. 1999. "Prevalence and Concentrations of Culturable Airborne } \\
\text { Fungal Spores in } 86 \text { Office Buildings from the Building Assessment Survey and } \\
\text { Evaluation (BASE) Study". Proceedings of the } 8^{\text {th }} \text { International Conference on } \\
\text { Indoor Air Quality and Climate, Edinburgh, Scotland. }\end{array}$ & 3.4 & 3.4 & \\
\hline [465] & $\begin{array}{l}\text { Yoder, R. and M. Kaplan. 1992. "Building Commissioning for Demand-Side } \\
\text { Resource Acquisition Programs". Proceedings of the ACEEE } 1992 \text { Summer Study } \\
\text { on Energy Efficiency in Buildings, Vol. 5, August. Washington, D.C.; American } \\
\text { Council for an Energy-Efficient Economy. }\end{array}$ & & $\begin{array}{l}5.1 \\
5.2\end{array}$ & \\
\hline [466] & $\begin{array}{l}\text { Yuill, G.K. and D.P. Yuill. 1998. "Development of a Field Procedure to Measure } \\
\text { the Airtightness of Wall Construction Elements of Houses". Proceedings of the } \\
1998 \text { Thermal Performance of the Exterior Envelopes of Buildings VIl, Clearwater } \\
\text { Beach, FL pp. 753. Atlanta, GA; American Society of Heating, Refrigerating, and } \\
\text { Air-Conditioning Engineers, Inc. }\end{array}$ & & 1.4 & \\
\hline [467] & $\begin{array}{l}\text { Yuill, G.K. and J.E. Lovatt. 1986. "Prediction of Pollutant Concentration in } \\
\text { Houses". Proceedings of the ASHRAE Indoor Air Quality Conference ' } 86 \text {, } \\
\text { Atlanta, GA, pp. 383-391. Atlanta, GA; American Society of Heating, } \\
\text { Refrigerating, and Air-Conditioning Engineers, Inc. }\end{array}$ & 2.5 & & \\
\hline
\end{tabular}




\begin{tabular}{|c|c|c|c|c|}
\hline & & \multicolumn{3}{|c|}{ Links } \\
\hline & & $\mathrm{M}$ & $\mathrm{D}$ & $\mathrm{N}$ \\
\hline [468] & $\begin{array}{l}\text { Zhivov, A.M., J.K. McLaughlin, J.B. Priest, L.L. Christianson, R.N. Kulp, and L.E. } \\
\text { Sparks. 1994. "International Differences in Indoor Environmental Quality } \\
\text { Standards and Guidelines". Proceedings of the ASHRAE Indoor Air Quality } \\
\text { Conference ' } 94 \text {, St. Louis, MO, pp. 67-78. Atlanta, GA; American Society of } \\
\text { Heating, Refrigerating, and Air-Conditioning Engineers, Inc. }\end{array}$ & & & 3.1 \\
\hline [469] & $\begin{array}{l}\text { Zmeureanu, R.G., M.L. Marceau, J. Payer, and D. Derome. 1998. "Evaluation of } \\
\text { Energy Performance of Nine Identical Row Houses in Montreal". Proceedings of } \\
\text { the } 1998 \text { Thermal Performance of the Exterior Envelopes of Buildings VII, } \\
\text { Clearwater Beach, FL, pp. } 81 \text {. Atlanta, GA; American Society of Heating, } \\
\text { Refrigerating, and Air-Conditioning Engineers, Inc. }\end{array}$ & & $\begin{array}{l}1.1 \\
1.4 \\
3.1\end{array}$ & \\
\hline
\end{tabular}




\section{APPENDIX C: LITERATURE CATEGORIZATION GUIDELINE}

\section{Building Envelope}

1.1 opaque building assemblies

1.1.1 assembly thermal conductance

1.1.2 insulation level and location

1.1.3 design-condition interior surface temperature (comfort)

1.2 windows and skylights

1.2.1 assembly thermal conductance

1.2 .2 radiative behavior

1.2.3 design-condition interior surface temperature (comfort)

1.3 thermal mass

1.2.4 design-condition condensation potential

1.3.1 amount and location

1.3.2 time constant

1.4 airtightness

1.4.1 envelope and interzone leakage

1.4.2 air barrier type and location

1.5 moisture-damage susceptibility

1.5.1 vapor barrier type and location

1.5.2 design-condition dew-point temperature location

2. HVAC

1.5.3 assembly moisture content (plus permeability and drying potential)

2.1 cooling equipment - air conditioners and heat pumps

2.1.1 room cooling loads (sensible and latent)

2.1.2 equipment selection and sizing

2.1.3 refrigerant charge

2.1.4 coil total airflow

2.1.5 supply air temperature drop

2.1.6 steady-state capacity and efficiency

2.2 heating equipment - furnaces, boilers, and heat pumps

2.2.1 room heating loads (sensible)

2.2.2 equipment selection and sizing

2.2.3 refrigerant charge

2.2.4 coil total airflow

2.2.5 supply air and/or water temperature rise

2.2.6 steady-state capacity and efficiency

2.3 thermal distribution systems - air and/or water flow

2.3.1 system selection and sizing

2.3.2 air handler total flow

2.3.3 pump total flow

2.3.4 water supply line location and insulation

2.3.5 zone coil water flow, temperature, and air fraction

2.3.6 duct location, support, and insulation

2.3.7 duct leakage

2.3.8 register flow and outlet temperature

2.3.9 register location and jet distribution

2.3.10 distribution system efficiency

2.3.11 system operating external static pressure 
2.4 combustion safety

2.4.1 combustion air supply sizing and location

2.4 .2 vent sizing and location

2.4.3 house depressurization level

2.4.4 backdrafting and spillage (combustion gas flow and concentration)

2.5 ventilation

2.4.5 heat exchanger leakage

2.5.1 requirements

2.5.2 equipment selection and sizing

2.5.3 device airflows and room air exchange rates

2.5.4 device operating external static pressures

2.5.5 indoor-outdoor and interzonal pressures

2.5.6 ventilation spatial and temporal effectiveness

2.6 controls

2.6.1 room thermostats

2.6.1.1 calibration

2.6.1.2 setup/setback strategy

2.6.2 burner

2.6.1.3 anticipator

2.6.2.1 fuel pressure

2.6.2.2 orifice sizing

2.6.2.3 primary air supply

2.6.3 thermal expansion devices

2.6.2.1 orifice sizing

2.6.2.2 TXV sizing and adjustment

2.6.2.3 superheat sensing bulb location and line connection

2.6.4 heat pump outdoor thermostat and defrost timer

2.6.5 hydronic air vents, check valves, and balance valves

2.6.6 blower and burner thermal limit switches

2.6.7 blower motor speed and duct dampers

2.6 .8 ventilation switches (e.g. humidistats) and timers (fan cycling and defrost)

2.6.9 EMCS

2.7 HVAC installation process

3. Indoor Air Quality

3.1 comfort (e.g. room air temperature and velocity)

3.2 non-biological gaseous generation, transportation, concentration, and absorption

3.3 moisture generation, transport, concentration, and absorption

3.4 bioaerosol (fungi/mold/mites) generation, transport, and concentration

3.5 particulate generation, transport, and concentration

4. Other

4.1 water heaters

4.2 lighting controls

4.3 plug loads

4.4 air filters and cleaners

4.5 noise (from equipment or attenuation by envelope)

4.6 maintenance ease and necessity

4.7 instrumentation (e.g. sensors and data loggers)

5. Non-technical

5.1 Commissioning process

5.2 Economics

6. Irrelevant 